\title{
Unintended pregnancy and abortion in India: Country profile report
}

\author{
Mary Philip Sebastian \\ Population Council \\ M.E. Khan \\ Population Council \\ Daliya Sebastian
}

Follow this and additional works at: https://knowledgecommons.popcouncil.org/departments_sbsr-rh

Part of the Demography, Population, and Ecology Commons, Family, Life Course, and Society Commons, International Public Health Commons, Maternal and Child Health Commons, Obstetrics and Gynecology Commons, and the Women's Health Commons How does access to this work benefit you? Let us know!

\section{Recommended Citation}

Sebastian, Mary Philip, M.E. Khan, and Daliya Sebastian. 2014. "Unintended pregnancy and abortion in India: Country profile report," STEP UP Research Report. New Delhi: Population Council. 


\section{STEP}

STRENGTHENING EVIDENCE FOR PROGRAMMING ON UNINTENDED PREGNANCY
INDIA

RESEARCH REPORT

MARCH 2014

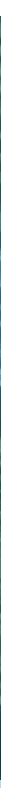

\section{Unintended Pregnancy \\ and Abortion in India: \\ Country Profile Report}

MARY PHILIP SEBASTIAN

M.E. KHAN

DALIYA SEBASTIAN
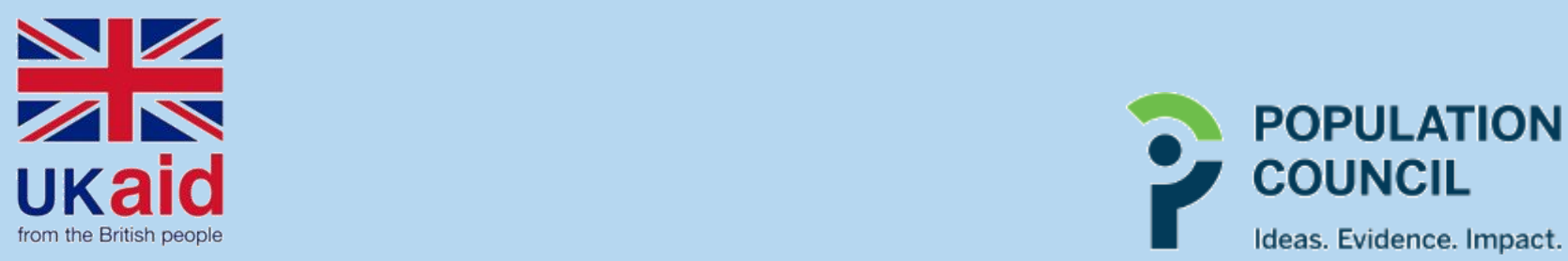


\section{UNINTENDED PREGNANCY AND ABORTION IN INDIA: COUNTRY PROFILE REPORT}

WITH FOCUS ON BIHAR, MADHYA PRADESH AND ODISHA

MARY PHILIP SEBASTIAN, M.E. KHAN, DALIYA SEBASTIAN

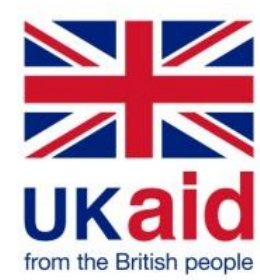


The STEP UP (Strengthening Evidence for Programming on Unintended Pregnancy) Research Programme Consortium generates policy-relevant research to promote an evidence-based approach for improving access to family planning and safe abortion. STEP UP focuses its activities in five countries: Bangladesh, Ghana, India, Kenya, and Senegal. STEP UP is coordinated by the Population Council in partnership with the African Population and Health Research Center; The International Center for Diarrhoeal Disease Research -Bangladesh (icddr-b), the London School of Hygiene and Tropical Medicine; Marie Stopes International; and Partners in Population and Development. STEP UP is funded by UK aid from the UK Government.

www.stepup.popcouncil.org

\section{POPULATION COUNCIL \\ Ideas, Evidence. Impact.}

The Population Council confronts critical health and development issues-from stopping the spread of HIV to improving reproductive health and ensuring that young people lead full and productive lives. Through biomedical, social science, and public health research in 50 countries, we work with our partners to deliver solutions that lead to more effective policies, programs, and technologies that improve lives around the world. Established in 1952 and headquartered in New York, the Council is a non-governmental, non-profit organization governed by an international board of trustees. www.popcouncil.org

Suggested citation: Mary Philip Sebastian, M.E. Khan and Daliya Sebastian, 2013. "Unintended Pregnency and Aboration in India with Focus on Bihar, Madhya Pradesh and Odisha." New Delhi, India: Population Council.

(C) 2014 Population Council, Inc.

Please address any inquiries about STEP UP to the RPC co-directors:

Dr. Harriet Birungi, hbirungi@popcouncil.org

Dr. lan Askew, iaskew@popcouncil.org

Funded by

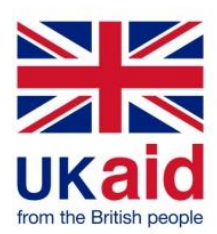




\section{TABLE OF CONTENTS}

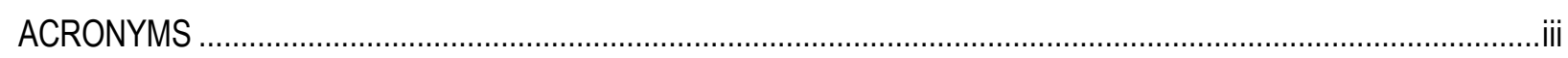

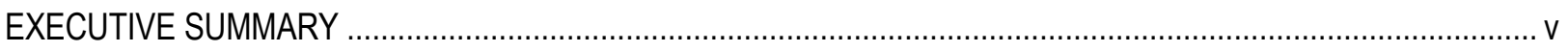

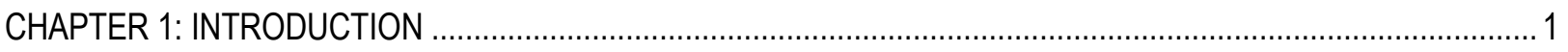

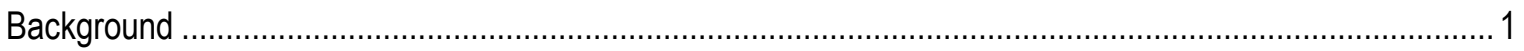

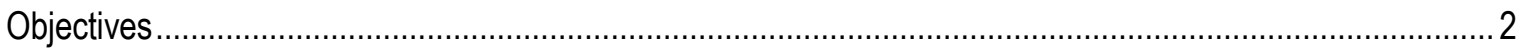

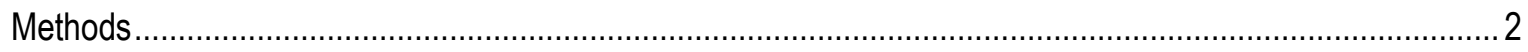

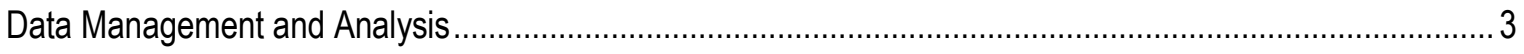

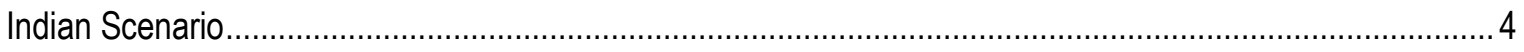

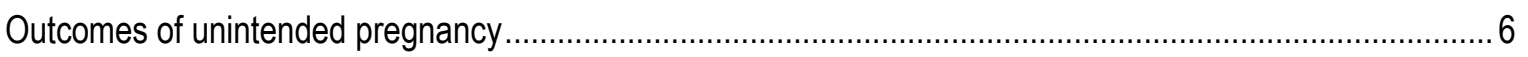

CHAPTER 2: THE LEGAL, POLICY AND SOCIO-CULTURAL CONTEXT OF SEXUAL AND REPRODUCTIVE

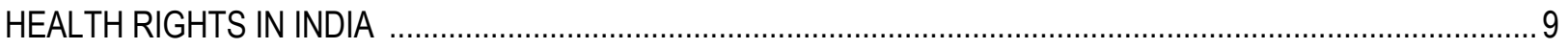

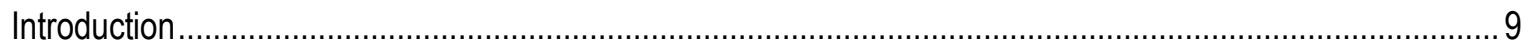

International Covenants / Conventions / Treaties Ratified / Acceded / Signed by India ................................. 9

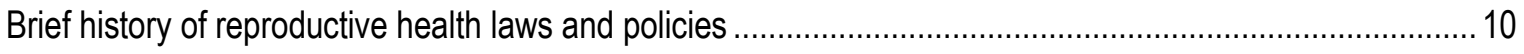

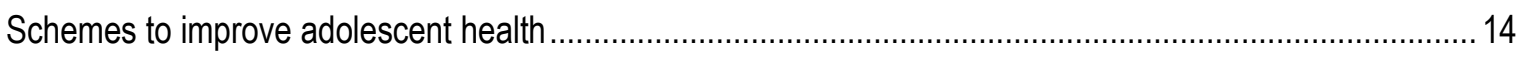

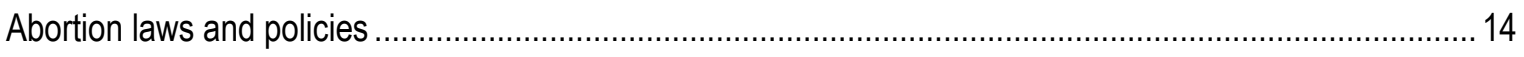

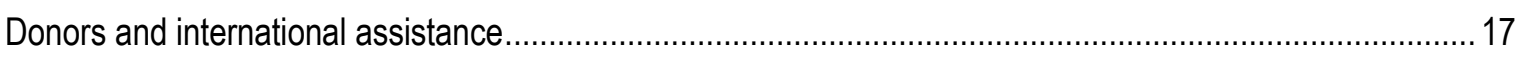

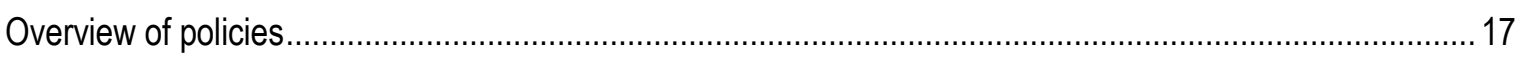

CHAPTER 3: FAMILY PLANNING AND REPRODUCTIVE HEALTH INDICATORS: TRENDS AND EQUITY

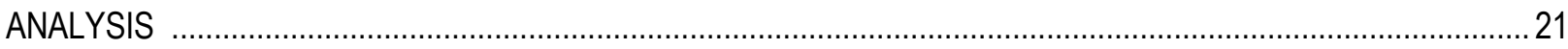

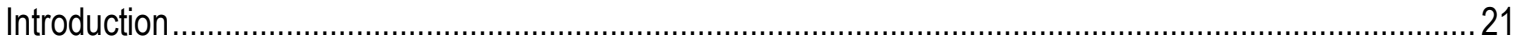

History and trends of India's national family planning program .............................................................. 21

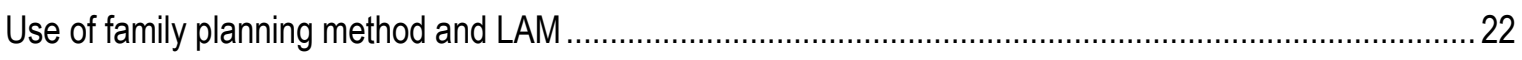

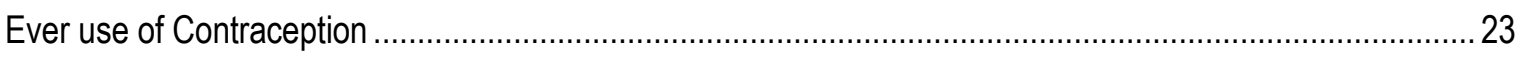

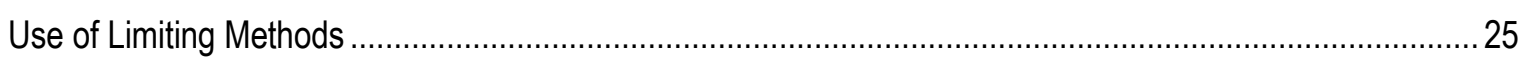

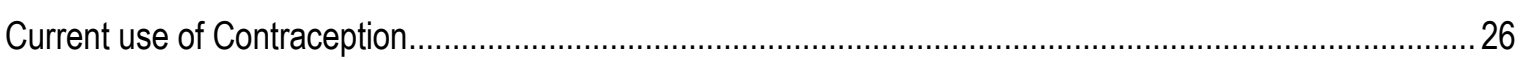

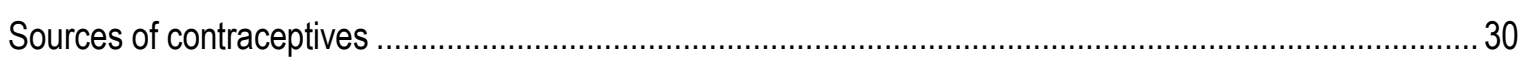

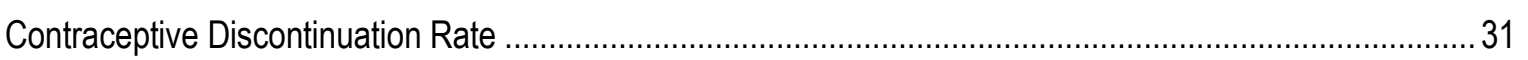

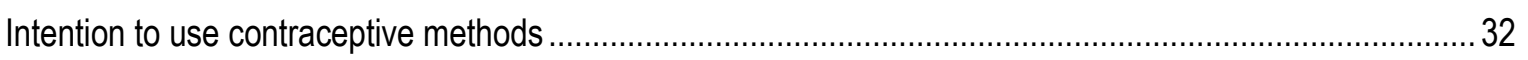

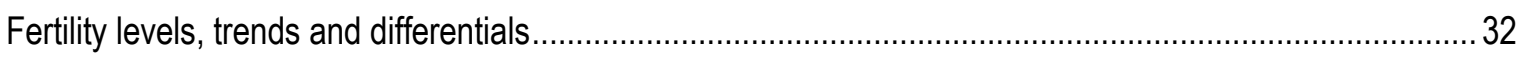

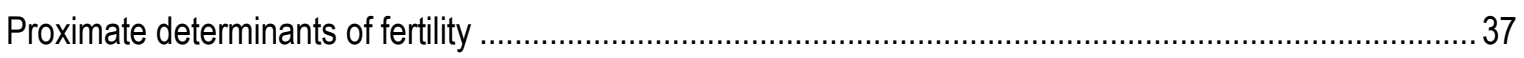

CHAPTER 4: TRENDS IN UNMET NEED FOR CONTRACEPTION AND SAFE ABORTION SERVICES ..............42

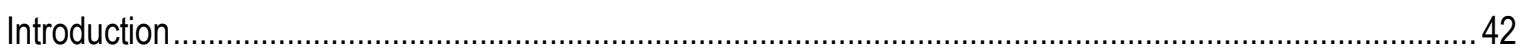


Trends in unmet need for contraception

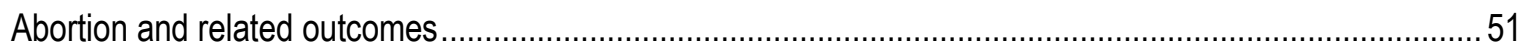

CHAPTER 5: ACCESS TO AND QUALITY OF FAMILY PLANING AND ABORTION AND POST ABORTION SERVICES

Introduction

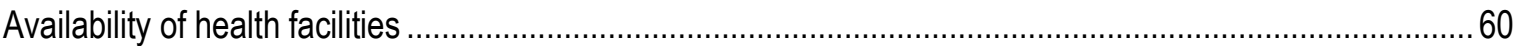

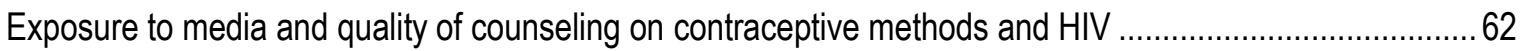

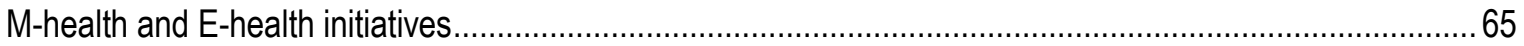

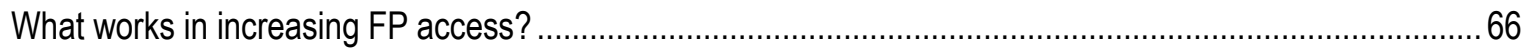

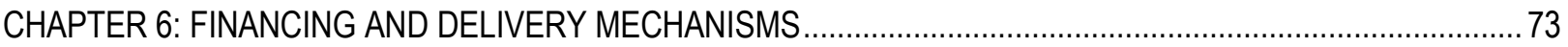

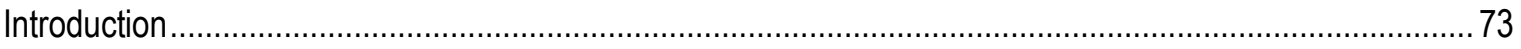

Conditional Cash Transfer Mechanisms ........................................................................................ 73

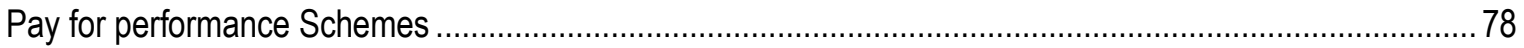

CHAPTER 7: GAPS \& BARRIERS IN SERVICE PROVISION; RECOMMENDATIONS FOR A WAY FORWARD .. 81

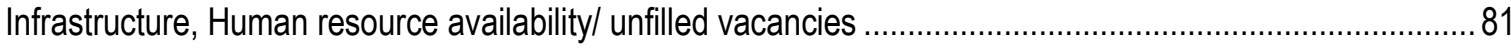

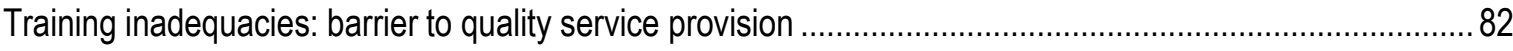

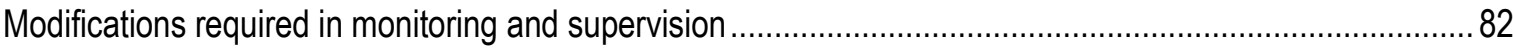

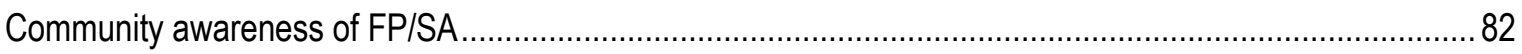

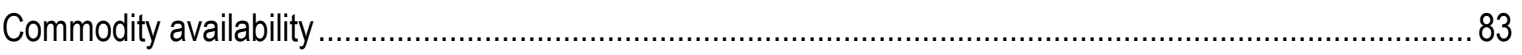

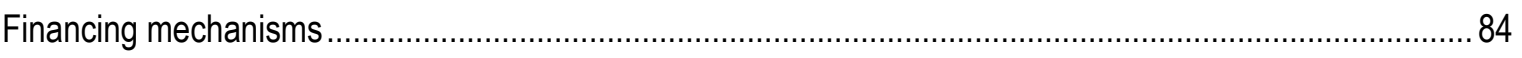

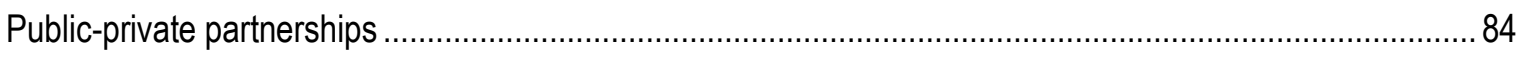

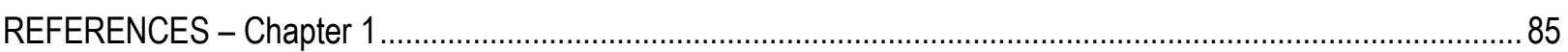

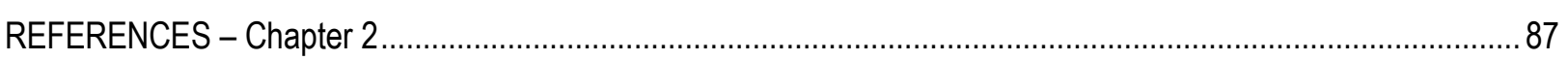

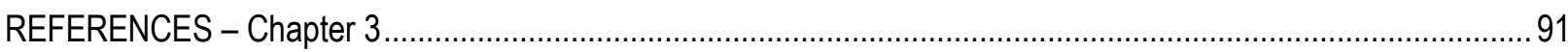

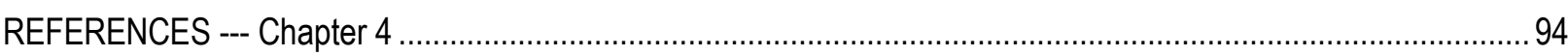

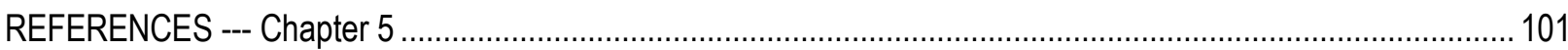

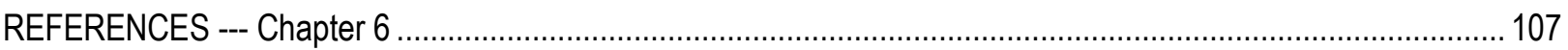




\section{ACRONYMS}

AIDS $\quad$ Acquired Immunodeficiency Syndrome

ANC Antenatal Care

ANM Auxiliary Nurse Mid-wife

ASHA Accredited Social Health Activists

BCC Behavior Change Communication

BEE Block Extension Educator

CBD community Based Distribution

CEDAW Committee on the Elimination of the Discrimination against Women

CHW Community Health Worker

D\&C Digital Curettage

DLHS District level Household and Facility Survey

ECG Electro CardioGram

EmOC Emergency Obstetric Care

FP Family Planning

FRONTIERS Frontiers in Reproductive Health

GIS

Geographic Information System

GSM

Global System for Mobile Communications

HIV $\quad$ Human Immunodeficiency Virus

ICDC Integrated Child Development Centers

ICPD International Conference on Population and Development

ICT Information and Communications Technology

IEC Information, Education, and Communication

IUD Intra-Uterine Device

IVR Interactive Voice Response

LHV Lady Health Visitor

MDG Millennium Development Goals

MMR Maternal Mortality Rate

MMS Multimedia Messaging Service

$\mathrm{MNCH} \quad$ Maternal and Child Health

MR Menstrual Regulation

MSH Management Sciences for Health

MSI Marie Stopes International 


\begin{tabular}{ll} 
MTP & Medical Termination of Pregnancy \\
MVA & Manual Vacuum Aspiration \\
NFHS & National Family Health Survey \\
NGO & Non-Governmental Organization \\
NRHM & National Rural Health Mission \\
ORS & Oral Rehydration SaltSolutions \\
PAC & Post-abortion Care \\
PHC & Primary Health Care \\
PIP & Program Implementation Plan \\
PCPNDT & Preconception and Prenatal Diagnostic Techniques Act \\
PNDT & Pre-Natal Diagnostic Techniques \\
PPTCT & Prevention of Parent to Child Transmission \\
PWC & Princewater Coopers \\
RCH & Reproductive and Child Health \\
RH & Reproductive Health \\
RMNCHN & Reproductive, maternal, neonatal, child health and nutrition. \\
SA & Safe Abortion \\
SMS & Short Messaging Service \\
SRS & Sample registration system \\
STEP-UP & Strengthening Evidence for Programming on Unintended Pregnancy \\
STI & Sexually Transmitted Infection \\
TFR & Total Fertility Rate \\
UN & United Nations \\
UNFPA & United Nations Population Fund \\
UNICEF & United Nations Children's Fund \\
UP & Uttar Pradesh \\
USAID & US Agency for International Development \\
WHO & World Health Organization \\
\hline
\end{tabular}




\section{EXECUTIVE SUMMARY}

\section{Background}

The ability of couples to plan the number, spacing and timing of births is an important fundamental human reproductive right. In the 1970s and 1980s governments of Asian countries focused on promotion of modern contraceptives as population growth threatened food production and availability. These efforts led to decline in Total Fertility Rate (TFR) and other pressing new areas got the attention of donors ${ }^{1}$. According to 2008 global estimates nearly half (48 percent) of the unintended pregnancies will end in abortion and most of them will be unsafe ${ }^{2}$. Unsafe abortion and unmet need for Family Planning (FP) are preventable; but remains the cause of maternal mortality and morbidities and even child health problems and mortality.

In India, nationwide FP program was introduced in 1952. Currently, oral contraceptive pills (OCP), condoms, Intra Uterine Device (IUD), male and female sterilization are provided through the public sector and injectable contraceptives are available in the private sector. Despite six decades of family planning promotion, contraceptive prevalence rate (CPR) in India remains poor, particularly in North Indian states of Bihar, Madhya Pradesh and Odisha. Population of these three focused states accounts for nearly 18 percent of the national population. Female sterilization still continues to be the major and most of the times the only contraceptive method adopted. A review of literature and analysis of large surveys were carried out with funding from the STEP-UP consortium led by Population Council to build a coherent body of robust research based evidence on the situation in India in the context of unmet need for FP and safe abortion services.

Methodology: Focused states for the study were 3 backward states: Bihar, Odisha, Madhya Pradesh (MP). Review of published literature and reanalysis of existing large scale survey data were employed. The review of literature is confined to peer-reviewed articles and reports published in the last ten years (2002-2012). Since published articles referring to the study states were limited, few articles referring to other states were also included for analysis. Relevant state level data of women 15-34 years were extracted from District level household and facility survey (DLHS), 2007-08, and National Family Health survey 2005-06. Furthermore, the results from various large surveys like the landscaping study in Uttar Pradesh (UP) and Bihar during 2009-11, Youth in India: Situation and Needs Study (2007-08) (Youth Study) carried out in six states of the country and fact sheets of Annual Health Survey (AHS) 2010-11 for the 3 states were also used. Youth study was done among unmarried and married women and men age 15 to 24 years and married men age 15 to 29 years (since there were very few married men in the -age group 15-24 years).

\section{Key Findings:}

\section{The legal, policy and socio-cultural context of the sexual and reproductive health rights}

Sexual and reproductive health (SRH) and rights are recognized by the country and various laws and policies have been implemented to make it happen. India is signatory to various international covenants/conventions/treaties like the universal deceleration of human rights and convention on the rights of the child.

\footnotetext{
${ }^{1}$ Bongaarts J, Cleland J, Townsend JW et al. Family planning programs for the 21 st century: Rationale and design. New York: the Population council; 2012.

2 World Health Organisation (WHO). Unsafe abortion: Global and regional estimates of the incidence of unsafe abortion and associated mortality in 2008, sixth ed., Geneva: WHO, 2011.
} 
India is the first country in the world to initiate a nationwide family planning program in 1952. India promotes freedom of choice and also includes many methods in its FP basket. India has a system for the testing and approval of medicines. All medicines are approved by the drug controller of India. After this, other approvals are required before it can become part of the national family planning program.

As early as 1971, the Medical Termination or Pregnancy (MTP) act, was passed with a rights perspective making abortion legal. The term "Medical Termination of Pregnancy" (MTP) was used to reduce opposition from socioreligious groups. Abortion can be sought in India on all grounds-physical and mental health and environmental considerations. Since 1991, 80 percent of districts in India have recorded a declining sex ratio. Prenatal Diagnostic Techniques (prohibition of sex selection) (PCPNDT) act, 1994 was passed to curb this. However, implementation is not satisfactory and confusion among law enforcement about the two acts is proving to be damaging to service availability. Awareness of the acts or its difference is lacking in the community too. Only a handful of women in the focused states considered abortion as legal.

A number of conditional cash transfer schemes both centrally sponsored as well as state sponsored schemes (e.g. Dhan laxmi scheme, Ladli lakshmi yojana) exist with the aim of promoting value for girl child as a strategy to end the increasing female feticides.

There is health policy, population policy, maternity benefits act, minimum legal age of marriage and other acts to ensure SRH rights and services to women. Madhya Pradesh has formulated its own population policy and health policy. Odisha had its own health policy. The state policies are in line with the national population policy and health policy. However, girls are married before age 18, children are born to women before age 18 and often maternal health care services do not reach these young women. Since Odisha's spending of allocated health funds are below optimum level state is taking steps to assist the very poor with financial aid.

\section{Unmet need for Family Planning services}

In all the 3 states, unmet need for spacing has gone up indicating an increase in demand or decrease in supply (Figure 1). The share of sterilization in CPR in the focused states reduced from 91 percent in 1992-93 to 74 percent in 2005-06. The unmet need for Family Planning (FP) in India reduced from 19.5 percent in 1992-93 to 14.4 percent in 2007-08; only 5 point decline in nearly 15 years. Rural women reported continuously higher unmet need for family planning than urban women.

Figure 1: Trend in unmet need for spacing and limiting methods in focused states, 1992-2011

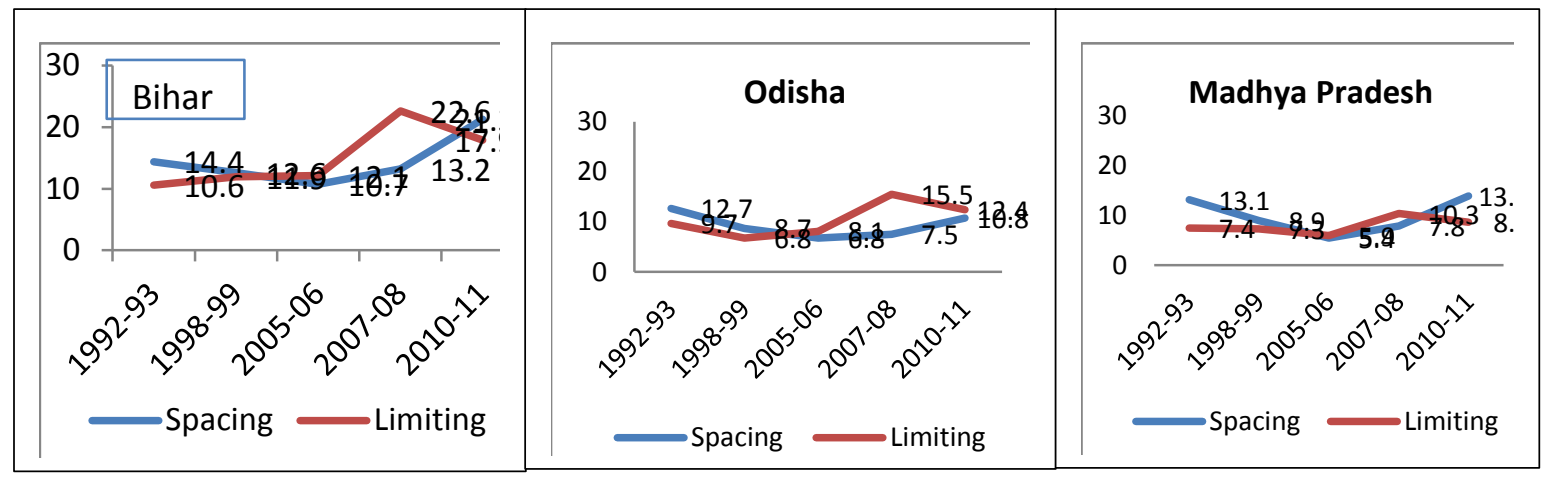

Source: NFHS 1992-93, NFHS 1998-99, NFHS 2005-06, DLHS 2007-08, AHS 2010-11

District Level Household and Facility Survey (DLHS)-3 data indicate that Bihar has the highest unmet need for family planning (22.8\%). Madhya Pradesh and Odisha also show fairly high unmet need for family planning in 2007$08,11.3$ percent and 14.9 percentrespectively among young women aged 15-34 years. Majority of the young rural 
women in the study states were not using any family planning method at the time of interview, it varies from 75 percent in Bihar to 54 percent in Madhya Pradesh. Women who were less than 25 years of age, non-literate, and those belonging to poorer/poor wealth quintile reported comparatively higher percentage of non-use of family planning methods than their counter parts. Large distances to be travelled to reach a health facility, low purchasing power of the people, lack of correct and full information of the different FP methods and community acceptance of spacing methods all contribute to the low CPR.

\section{Unmet need for safe abortion services}

Table 1 is indicative of the non-existence of reliable data on induced and spontaneous abortions. The questions asked to gather information about abortions and reporting of abortion varied across the NFHS, DLHS and AHS surveys.

\begin{tabular}{|l|l|l|l|l|l|}
\hline & NFHS 3, 2005-06 & DLHS 3, 2007-08 & AHS, 2010-11 \\
\hline State & $\begin{array}{l}\text { Ever terminated } \\
\text { pregnancy }\end{array}$ & $\begin{array}{l}\text { Had induced } \\
\text { abortion }\end{array}$ & $\begin{array}{l}\text { Had spontaneous } \\
\text { abortion }\end{array}$ & $\begin{array}{l}\text { Any form of } \\
\text { abortion }\end{array}$ & $\begin{array}{l}\text { Pregnancy resulting in } \\
\text { abortion }\end{array}$ \\
\hline Bihar & 20.1 & 3.9 & 13.6 & 15.1 & 5.3 \\
\hline Odisha & 17.2 & 4.5 & 10.1 & 14.1 & 5.6 \\
\hline $\begin{array}{l}\text { Madhya } \\
\text { Pradesh }\end{array}$ & 12.1 & 2.3 & $8-7$ & 9.8 & 6.0 \\
\hline India & 13.3 & 3.4 & 10.8 & 13.4 & -- \\
\hline
\end{tabular}

Unsafe abortion is estimated to account for 9 to 20 percent of all maternal deaths in India ${ }^{3}$. Several factors contribute to women opting for abortion outside the accredited abortion centers ${ }^{45}$. They include absence of competent health professionals in rural areas, high abortion cost at hospitals in the cities, limited understanding of the legality of abortion, reluctance to obtain services from known neighborhood clinics, lack of awareness about the need to seek abortion early in pregnancy, poor perceived quality of care in government facilities, lack of confidentiality and insistence on adopting FP method. Private sector charges are huge and unaffordable for the poor 6 .

Sex ratios (number of females per 1000 males) at birth in the 3 states in 2010-11 were; Bihar: 919, Odisha: 905, Madhya Pradesh: 904. If all ages were considered, sex-ratios were; Bihar: 950, Odisha:994, Madhya Pradesh:912. This indicates that sex-selective abortions might be increasing in Odisha and the state has to initiate programs to address this issue.

Medical abortion pills introduced in 2002 have increased the availability of safe abortion services not only because of its ease of use, but also because any trained medical practitioner can provide it. Recognizing the need to increase access to safe abortion, particularly in rural areas, the Health Policy recommended expanding the provision of abortion services to the PHC level. The MTP Act was amended in May 2003 to specify that medical abortion

\footnotetext{
3 Ganatra B and Elul B. Legal but not always safe: Three decades of a legal abortion policy in India. Gaceta Medica de Mexico 2003; 139: S103-S108

${ }^{4}$ Hirve SS. Abortion law, policy and services in India: A critical review. Reproductive Health Matters, 2004; 12: 114-121

5 Ganatra B. Maintaining access to safe abortion and reducing sex ratio imbalances in Asia. Reprod Health Matters 2008; 16: 90-98.

6 ibid
} 
could be provided by certified providers in unregistered facilities, as long as they had access to a registered facility for back-up. A South Asia consultation held in 2011 on the feasibility of expanding the provider base for improving access to safe abortion brought together studies from different South Asian countries on the feasibility, safety and effectiveness of expanding provider base and found that trained providers like nurses, midwives and non-allopathic providers can provide abortion till 8-9 weeks gestation safely and effectively?

\section{Shortfalls in staff, infrastructure and supply of FP}

Infrastructural and staff shortfalls are huge in the study states. The shortfall in sub centers in Bihar is 8,837 , in Madhya Pradesh it is around 3,445 and in Odisha it is 1,448. There are significant shortfalls in PHCs also in the focused states. The DLHS 2007-08 facility survey reports indicate that nearly 59 percent of the villages in Bihar, 68 percent villages in Madhya Pradesh and 27 percent villages in Odisha were not having any health facility in the surveyed year.

An assessment of the health care in India published in Lancet (2011) noted that India has more than 1 million rural practitioners, many of whom are not formally trained or licensed 8 . ASHA program, with pay for performance model was introduced to reach services to women and be of assistance to ANMs as part of NRHM initiative. ANMs and ASHAs are filling the gap in rural areas for FP counselling and provision. When community workers make home visits, travel time is eliminated for clients, and uptake and continued contraceptive use is facilitated. However, supply of contraceptives at all times with the community workers has to be ensured. As per the contraceptives to the door steps program, ASHAs are expected to stock and distribute condoms and contraceptive pills, along with pregnancy kits, ORS packets, and other items; data from the UP and Bihar studies (by Population Council in 2011) show that on the day of the interview, few ASHAs had any contraceptive methods in stock; Payments to ASHAs are often delayed; due to procedural issues. An evaluation of the door steps program by FHI 360, in 2012 found among others that confusion prevailed with procurement and supply chain in this program as well as charging of contraceptives by ASHAs leading to villagers feeling that they are charging for free supply 9 .

\section{Recommendations}

Insufficient training on abortion provision, post-abortion care, FP counseling of young couples, on emergency contraception and IUD insertion/ removal of different cadre of health staff is prevalent in the public health system. The training adequacy of health care providers in the private sector is difficult to assess. Despite service delivery guidelines in India expecting providers to provide FP counseling during antenatal visits, only a fraction of women receive counseling. In all most all the states, the monitoring format prepared during target approach (prior to 1980s) is still used for monitoring.

$>$ To improve the reach and quality of FP counselling, the following are suggested:

- Competency based training of community workers' counselling skills and basic primary health care technical silks be put in place.

- Re-training of ANMs on IUD counselling, insertion and removal, and follow-up of acceptors.

\footnotetext{
${ }^{7}$ Population Council. Expanding access to safe abortion and post-abortion care: Recommendations of a South Asia regional consultation. New Delhi: Population council, 2011.

8 Balarajan Y, Selvaraj S, Subramanian SV. Health care and equity in India. The Lancet 2011; 377:505-15

$9 \mathrm{FHI} 360$. Contraceptive to doorsteps in Inda: Rapid evaluation provides recommnendations for national scale-up. Research Brief, New Delhi: FHI360, 2012.
} 
- Provision of counselling aids and supportive supervision that is required for skill improvement and better quality services be made available.

- Public-private partnership models can assist the public health system in many ways. In reality few good examples exist, which needs attention particularly keeping in mind the profitability of the private sector as an important component of the program.

Sex selective abortion becoming a booming business is making the provision of safe abortion services a nightmare. It is important to have awareness raising programs in the community about the legality of abortion and availability of safe abortion services and what is unsafe abortion and its consequences on health. Pregnancies resulting from unprotected sex and forced sex are mostly aborted by untrained abortion providers. It is important that community understand the difference between MTP and PCPNDT act and know where legal abortion services are available.

$>$ To increase adherence of MTP and PCPNDT acts, and post-abortion contraception the following are suggested:

- Simplify reporting and monitoring formats and registers that has to be maintained under the different acts.

- Raise the awareness in the community that MTP is legal although sex determination and female feticide is illegal

- Standardize abortion service fee of private providers

- Reporting forms of abortion services to include a column to provide information on whether FP counselling was provided and services accepted. 


\section{Background}

The ability of couples to plan the number, spacing and timing of births is an important fundamental human reproductive right. Women living in every country, irrespective of its development status, have been facing the problem of unintended pregnancy. Unintended pregnancy is an important public health issue in both developing and developed countries because of its negative association with the social, economic and health outcomes for both women and families [1]. Even though, globally, there is a decline in the number of unintended pregnancies, the proportion of pregnancies that are unintended remains high among the developing countries. It is estimated that nearly 40 per cent of the pregnancies in developing countries are unintended--either not wanted at all or mistimed [2]. According to 2008 global estimates nearly half (48 percent) of the unintended pregnancies will end up in abortion and most of them will be unsafe. Many of these cases end in death adding to the existing high maternal mortality ratio [3]. Unsafe abortion and unmet need for Family Planning (FP) are preventable; but remains the cause of maternal mortality and morbidities.

"Despite this longstanding and widely accepted rationale for voluntary family planning programs, interest in and funding for these programs declined after the mid-1990s. A number of reasons can be cited, including the claim that such programs are ineffective; new priorities among donors; persistent opposition from conservative governments and institutions; and the need for resources to address other pressing problems, such as the AIDS epidemic. This neglect is now being reconsidered in the face of mounting evidence that continuing high levels of fertility in sub-Saharan Africa and South Asia contribute to poor health, pose constraints on social and economic development, and harm the natural environment (p.1)"[4].

"The world community recommitted itself to the attainment of the Millennium Development Goals (MDGs) in September 2010. At that time the United Nations' Secretary General also launched his Global Strategy for Women and Children's Health to advance progress on attainment of MDG4 (reduce child mortality) and MDG5 (improve women's health). MDG5 targets reduction of maternal mortality and achievement of universal access to reproductive health [5]." For these goals to get translated and for the developing countries to reap benefits from it; lot of attention has to be paid to the existing policy and programs in these countries and recommend improvements in policies and programs per se or strategic actions that are necessary in its implementation.

Deliberations at different forums on the ground level realities and actions or support necessary to bring about a change in the existing health scenario led to the formation of "Strengthening Evidence for Programming on Unintended Pregnancy" (STEP UP) Research Programme Consortium (RPC) with funding from the United Kingdom's Department for International Development (DFID). "The goal of the STEP UP project, is to improve the health of the poorest and most vulnerable, particularly women, in the developing world. The RPC supports an evidence-based approach to scaling up access to quality FP and safe abortion services. Ensuring greater accessibility to family planning and safe abortion services (where available within the context of national laws) is critical not only to achieving the health-related MDGs, but to enabling countries to reduce poverty, advance women's empowerment, slow their population growth and safeguard the environment [5]." To achieve this goal, it is important to generate a coherent body of robust research based evidence. From evidence then follows scaling up access to quality family planning and safe abortion services. With this objective, STEP UP undertook preparation of country profile on the situation of FP and safe abortion for certain countries, India being one of them. India being a large country, the study focused on three states of India with poor health and economic indicators. The DFID focus states of Bihar, Madhya Pradesh and Odisha were chosen for this exercise. Since young women are at most risk of unintended pregnancy and abortion, where possible data analysis focused on women below age 35 years than all women of reproductive age. 


\section{Objectives}

The objectives of the country profile are to provide detailed information on the situation of reproductive health needs, access to safe abortion services and unmet need for family planning and their trends during the last decade in the study states of Bihar, Madhya Pradesh and Odisha.

The specific objectives are:

- To provide detailed information on the status, determinants and consequences of unintended pregnancy and their trends during the last 10 years among the young women below 35 years of age.

- Based on the evidence generated from review of literature, to assist decision makers and programmers to implement evidence based strategies to reduce unintended pregnancies and increase access to safe abortion services.

\section{Methods}

The current report is based on the analysis of available secondary data from national and state-level surveys, the evaluation surveys of existing Reproductive and Child Health (RCH) and Family planning (FP) programs in the country and other published research studies and reviews between 2002 and 2012. For the purpose of analysis family welfare statistics from various rounds of National Family Health Surveys (NFHS) and District Level Household and Facility Survey (DLHS) were used. Since the three study states were covered under the Annual Health Survey, we have included findings from this survey where ever we were discussing NFHS and DLHS data as a way of understanding the progress made on the vraibles under discussion. Mid- term reviews of flagship programs like National Rural Health Mission (NRHM), and RCH programs were also used. We expect that since DLHS was carried out soon after the introduction of NRHM, many indicators may not have shown the expected outcome in DLHS, 2007-08; but it could get reflected in the Annual Health Survey, 201011. Furthermore the results from various large surveys like the landscaping study in Uttar Pradesh (UP) and Bihar during 2009-11 and Youth in India: Situation and Needs Study (2007-08) (Youth Study) carried out in six states of the country were also included. Youth study was done among unmarried and married women and men age 15 to 24 years and married men age 15 to 29 years (since there were very few married men in the age group 15-24 years).

More specifically, the review and data analysis addresses the following issues: (1) Fertility and fertility intentions; (2) Demand for and practice of family planning; (3) Supply of family planning methods; (4) Financing and pricing of services; (5) Abortion incidence; (6) Existing abortion services and use of the same; (7) Unintended pregnancy among adolescents and youth (unmarried and married) and (8) FP and Safe Abortion (SA) information and services for adolescents/youth.

Different search engines like Google, Google Scholar, JSTOR, PubMed, Medline and SCOPUS were used to gather published articles. Key words such as safe abortion, unmet need, India, Bihar, Odisha, Madhya Pradesh, schemes, quality of abortion, sex selective abortion, adolescents, youth and unmarried pregnancy were used for the search. From the retrieved journal articles, cross references was followed through to other associated sources. Special efforts were made to identify studies conducted in Bihar, Odisha and Madhya Pradesh. The framework used by a WHO study "Engaging men and boys in changing gender based inequity in health" was of assistance in successfully carrying out this exercise [6]. This framework helps in deciding whether chosen journal articles or reports provides reliable findings and are of good quality. It also distinguishes journal articles as descriptive analysis or intervention studies with scientific rigor. 


\section{Data Management and Analysis}

Three rounds of NFHS and DLHS data was used for the purpose of reanalysis of data for young women. Relevant state level data has been extracted from the NFHS and DLHS data. The newly generated datasets included all currently married women aged 15-49, who had given birth to at least one child during the last three years preceding the survey dates. Age-specific analysis has been done to assess the pattern of unintended pregnancy, abortion, use of family planning methods and unmet need among adolescents, young women and older women. Relevant information from the analysis of landscaping surveys in UP and Bihar and the Youth study were used to substantiate the findings with more recent data.

The operational definitions for unintended pregnancy, unsafe abortion and unmet need, which are the main dependent variables in the analysis, are defined as:

- Unwanted pregnancy is a pregnancy that was unwanted by woman at the time of conception. These include both undesired and mistimed pregnancies.

- Unsafe abortion is defined as "a procedure for terminating an unintended pregnancy carried out either by persons lacking the necessary skills or in an environment that does not conform to minimal medical standards, or both" [7].

- Unmet need for family planning is defined as the percentage of currently married women who either want to space their next birth or stop child bearing entirely but are not using contraception (7).

- Unmet need for spacing includes pregnant women whose pregnancy was mistimed; amenorrhoeic women who are not using family planning and whose last birth was mistimed, or whose last birth was unwanted but now say that they want more children; and fecund women who are neither pregnant nor amenorrhoeic, who are not using any method of family planning and say that they want to wait 2 or more years for their next birth. Also included in unmet need for spacing are fecund women who are not using any methods of family planning and say that they are unsure whether they want another child or who want another child but are unsure when to have the birth [8].

- Unmet need for limiting refers to pregnant women whose pregnancy was unwanted; amenorrhoeic women who are not using any family planning, whose last child was unwanted and who do not want any more children; and fecund women who are neither pregnant nor amenorrhoeic, who are not using any method of family planning and do not want any more children [8].

Some of the independent variables included for analysis are age of women, number of children ever born or number of surviving children, desire for more children, place of residence, religion, caste, economic condition of the household, education, exposure to mass media, contact with health workers, knowledge of services and family planning methods and place to get the services among others.

In order to understand the levels of unmet need for family planning and abortion univariate analysis were carried out and bivariate analysis with appropriate statistical test was used to understand the degree of association between dependent and independent variables. Since the variable: unmet need for family planning was dichotomous and categorical in nature, logistic regression was used to understand the effect of each independent variables on the dependent variable by using SPSS software. The minimal data on abortion and induced abortion in particular was also included for data analysis.

The report has also attempted a review of the population parameters, policies and various financial mechanisms and special schemes for vulnerable groups like adolescents and girls. The report is divided into 7 chapters. The current chapter covers background, rationale, methodology and certain demographics of the study states. Chapter 2 gives a critical review of the various policies in the country and focused states. 
Chapter 3 discusses the context and trends of contraceptive use, discontinuation of FP and the use of LAM. Chapter 4 reports the trends and current situation of unmet need for family planning and abortion services. Chapter 5 discusses access to and quality of FP and abortion services. Chapter 6 reports the various financial schemes in the focused states including schemes introduced to delay marriage till legal age of marriage and improve sex ratio. The final chapter discusses the barriers and gaps in existing programs and policies and recommends a way forward to reduce the gaps.

\section{Indian Scenario}

After the inception of the Family Welfare Program in India in 1951, the country experienced a significant growth in the service delivery of reproductive and child health services and quality of care. Nevertheless there are some areas which daunt the success of the program - the significant number of unintended pregnancies and the unmet need for contraception. Studies show that though there is a decline in the total fertility rate in India, the prevalence of unintended pregnancy has not shown much variation or to a certain extent has been stagnant during last one decade $[8,9]$. About one-fourth of the women in India reported that their pregnancy was unintended in all three rounds of National Family Health Surveys (NFHS) $[8,11,12]$. The existing literature shows that there is regional variation observed in the extent of unintended pregnancy within India. A state specific analysis in India shows that within country variation in unwanted fertility is much higher than variation in wanted fertility. The analysis shows that the unwanted fertility is high among the states like Uttar Pradesh, Bihar, Madhya Pradesh and Rajasthan compared to more socially advanced states like Kerala, Maharashtra, Himachal Pradesh and Punjab [13]. India being a large country with diversities in access and use of family planning as well as maternal and child health outcomes; three states belonging to the Economic Action Group (EAG) group was chosen for special study. The southern and western states of India have historically fared better than the northern and eastern states in socio-economic status. These socioeconomically backward states were termed as EAG states (Assam, Bihar, Jharkhand, Madhya Pradesh, Chhattisgarh, Odisha, Rajasthan, Uttar Pradesh, and Uttarakhand). The three states of focus in the report are Bihar, Madhya Pradesh (MP) and Odisha.

\section{Overview of Socio-Demographic and Health Indicators of India and Focused States}

Table 1.1 provides the existing socio-demographic and health indicators of focused states and India. The latest census data of 2011 reveals that the population of India is 1210 million and the percentage decadal growth rate during the year 2001-11 was registering the sharpest decline since independence [14]. However, projection for 2026 places India's population at 1581 million. More than 50 percent of this additional 371 million will come from eight states viz. Uttar Pradesh (UP), Uttarakhand, Bihar, Jharkhand, Madhya Pradesh, Chhattisgarh, Rajasthan and Orissa [15].

The median age at first marriage in all the three focused states is below the legal minimum age for marriage of girls, v.z. 18 years. Median age at marriage is as low as 15 years and 15.9 years in Bihar and Madhya Pradesh respectively. These two states also report a higher Total Fertility Rate (TFR) than the national average. 60 percent and 55 percent women respectively from Bihar and Madhya Pradesh had a child by age 20 years. Maternal and child mortality are also high and births attended by skilled personnel low in the three states (Table 1.1). 
Table 1.1: Socio-demographic and health indicators of India and focused states

\begin{tabular}{|l|l|l|l|l|}
\hline Indicators & India & Bihar & Odisha & $\begin{array}{l}\text { Madhya } \\
\text { Pradesh }\end{array}$ \\
\hline Population in millions (2011 census) & 1210.19 & 103.80 & 41.94 & 72.59 \\
\hline Median age at first marriage (women age 20-49 years) & 17.2 & 15.1 & 17.9 & 15.9 \\
\hline Median age at first intercourse (women age 20-49 years) & 17.8 & 16.5 & 18.3 & 16.9 \\
\hline $\begin{array}{l}\text { TFR (average number of children born to a woman during her lifetime), } \\
\text { 2011 SRS }\end{array}$ & 2.4 & 3.6 & 2.2 & 3.1 \\
\hline Women giving birth by age 20 years (\%) & 45.2 & 59.6 & 46.2 & 54.9 \\
\hline Current use of modern FP among married women age 15-49 years (\%) & 55.8 & 41.3 & 50.1 & 56.3 \\
\hline Unmet need for contraception among currently married women (2007-08) & 21.3 & 37.2 & 24.0 & 19.3 \\
\hline $\begin{array}{l}\text { Maternal Mortality Ratio= Maternal Deaths per 100,000 live births (2007- } \\
\text { 09) (SRS special bulletin) }\end{array}$ & 212 & 261 & 258 & 269 \\
\hline $\begin{array}{l}\text { Level (\%) of unintended pregnancy (including mistimed and } \\
\text { unwanted)(2005-06) }\end{array}$ & 24.3 & 25.4 & 18.3 & 21.6 \\
\hline Births attended by skilled personnel (2005-06) (\%) & 46.6 & 29.3 & 44.0 & 32.7 \\
\hline $\begin{array}{l}\text { Infant mortality rate= infant deaths per 1,000 live births (SRS bulletin, } \\
\text { 2011) }\end{array}$ & 44 & 44 & 57 & 59 \\
\hline
\end{tabular}

Note: 2011 data is based on the provisional population figures published by census of India.

The 2011 census provisional figures also shows that population of these three focused states-Bihar, Madhya Pradesh, Odisha- accounts for nearly 18 percent of the national population. The two focused states other than Odisha show higher growth rate than the national average, [14-18]. The trend of growth rate in the focused states and India after independence shows that the growth rate of Madhya Pradesh was higher than the national average throughout the reference period. Until reference period 1981-91, Bihar had shown lower growth rate than India, but during the last two decades, the growth rate of the state is considerably higher than the national average and it shows the highest growth rate among the focused states in 1991-01 and 2001-11 period (Figure 1.1).

Figure 1.1: Trends in the growth rate of focused states and India, 1951-61 to 2001-11

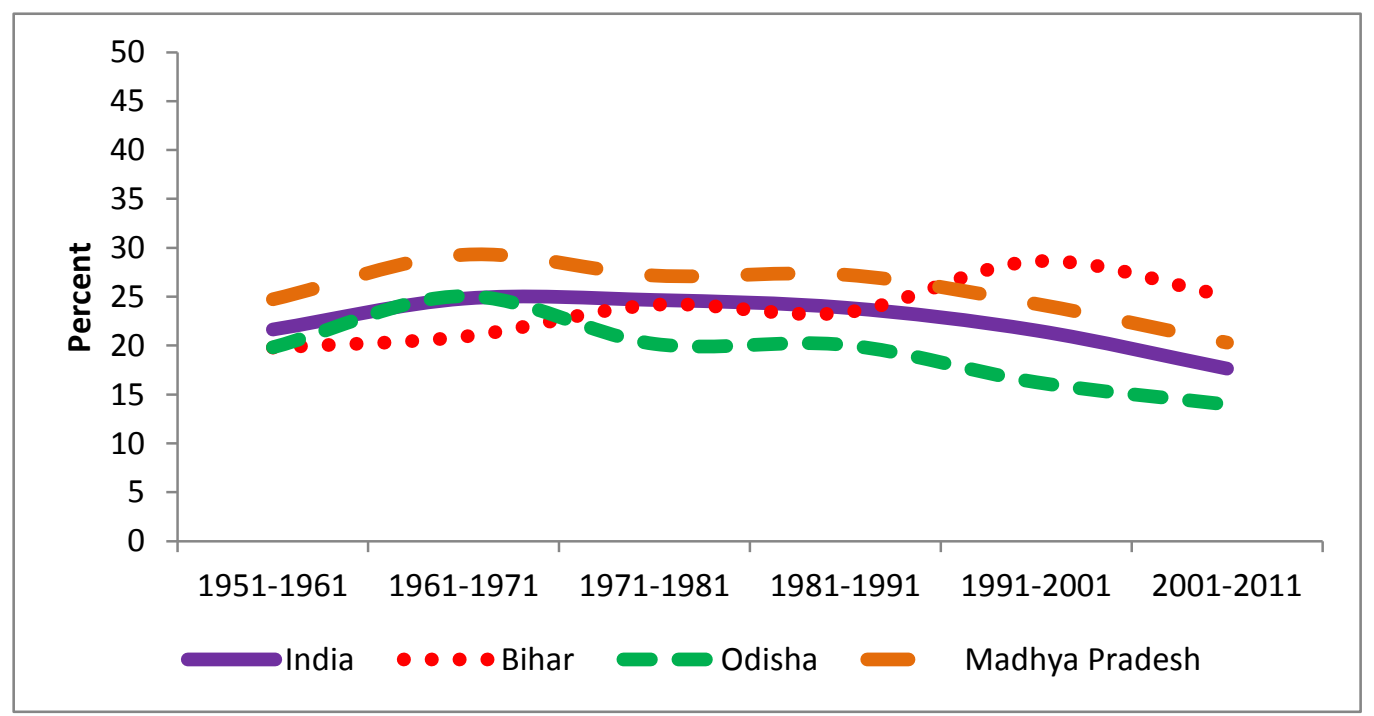


Figure 1.2: Projected percentage of women of reproductive age, focused states and India

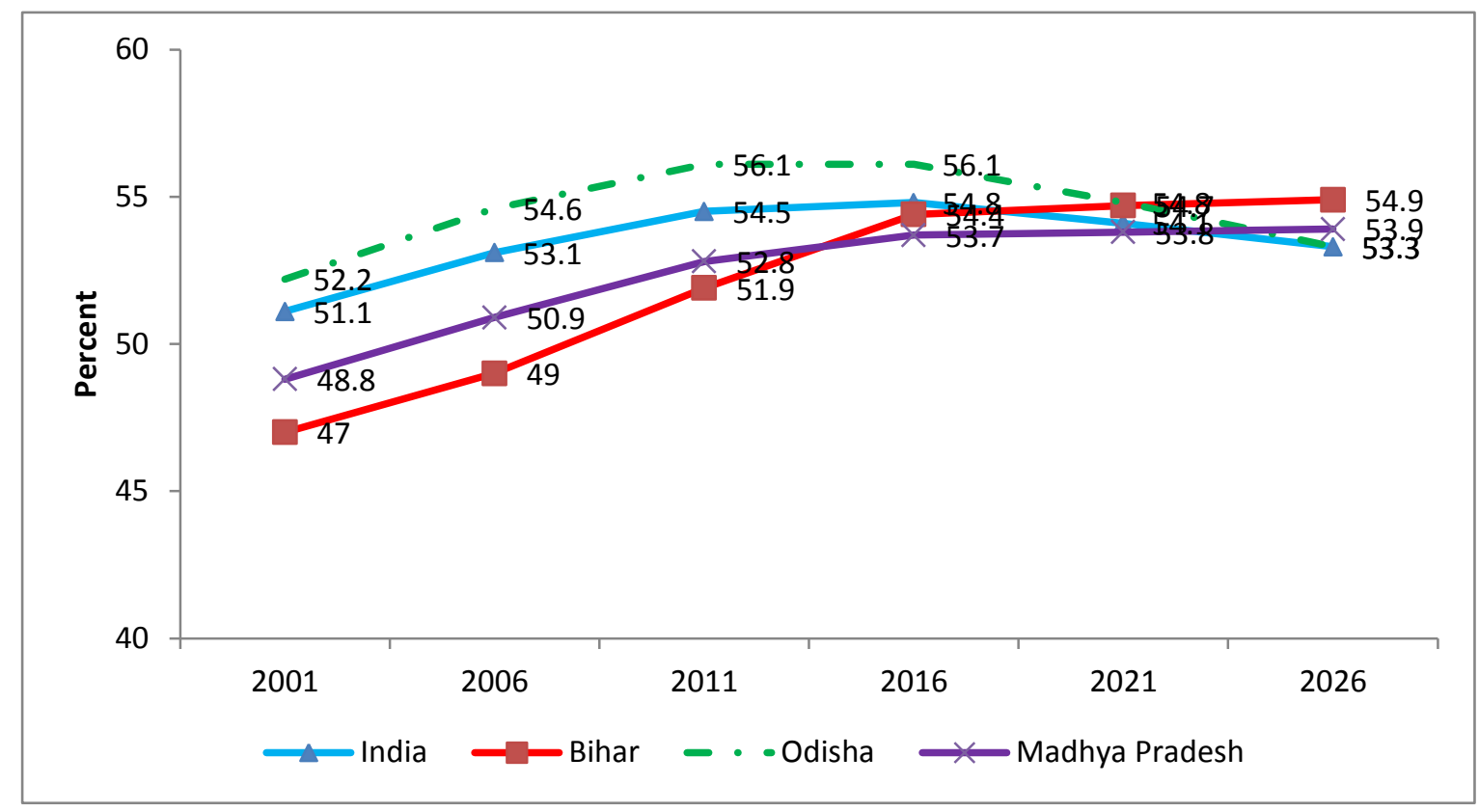

Source: Population projection for India and States, 2006; Office of the Registrar General.

The women in reproductive age group determine the fertility behavior and need for family planning in future. With the current fertility levels, women in the reproductive age will be 53 percent, 54 percent, 55 percent in Odisha, Madhya Pradesh and Bihar respectively in the year 2026. The change in percentage of women in reproductive age is only marginal for Bihar and Madhya Pradesh. In the case of Odisha, substantial decrease is projected from 2016 to 2026 (Figure 1.2).

\section{Outcomes of unintended pregnancy}

\section{Maternal mortality and morbidity in the focused states}

A recent estimation found that 183,400 fewer women died in 2008 than in the year 1980 [19]. However, India alone accounted for 19 percent of all maternal deaths in 2008. India country overview of World Bank mentions that there were 68,000 maternal deaths in the country in 2008 [2]. About a quarter or more of maternal and child mortality in the world takes place in India [20,21]. There are variations in the country level in the risk for maternal and infant mortality. Despite a declining Maternal Mortality Ratio (MMR), huge disparities are visible between different states, and between districts in the same state. This disparity is due to differential levels of socioeconomic development. Various factors like access to skilled birth attendance, emergency obstetric care, overall status of women, female literacy, maternal health, and anemia are factors that were seen to be attenuating it [22]. 
Figure 1.3: Trends in MMR in the focused states and India, 2001-2009

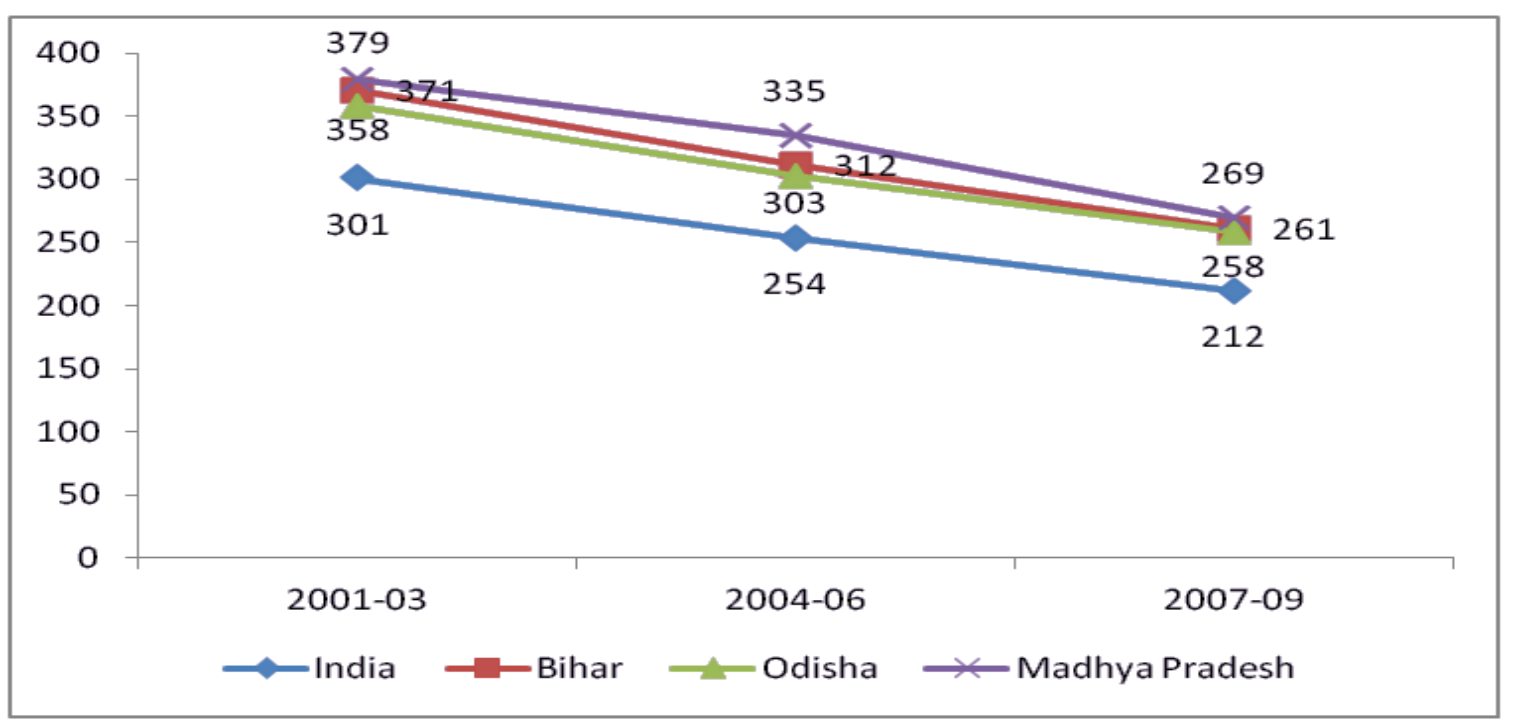

Source: SRS Special bulletins on Maternal Mortality

While looking at the trends of maternal mortality ratio in the focused states, it was found that even though there is a decline in MMR in the focused states the ratio is comparatively higher than the national average. Among the three focused states, Madhya Pradesh showed highest maternal mortality ratio throughout the period and Bihar is not far behind. Another analysis of the maternal deaths in the country found that Odisha is accounting for most of the maternal deaths in the country. The other states with high MMR are Bihar, Jharkhand, Madhya Pradesh, Chhattisgarh, Rajasthan, Uttar Pradesh, Uttaranchal, and Assam. These states had weak infrastructure which in some way is correlated to poor development indicators and poor health outcomes [22].

A hypothetical exercise using data from Sweden for years 1911 and 2005 (because maternal deaths were rare in 2005) highlighted the role of fertility decline in reducing maternal deaths. Estimations revealed that more than 30,000 maternal deaths would occur if the TFR and MMR were both at 1911 levels. Changing both measures to their 2005 values reduced the number of deaths to 104 . Fertility decline alone halved the number of maternal deaths, to fewer than 15,000 . For example, the maternal mortality rate for the youngest women (15-19 years), who face a higher risk for adverse outcomes, fell by two-thirds (69\%) [23].

In 2010, there were 52.8 million deaths globally. At the most aggregate level, communicable, maternal, neonatal, and nutritional causes were $24.9 \%$ of deaths worldwide in 2010 , down from 15.9 million $(34 \cdot 1 \%)$ of 46.5 million in 1990. This decrease was largely due to decreases in mortality from diarrhoeal disease (from 2.5 to 1.4 million), lower respiratory infections (from 3.4 to 2.8 million), neonatal disorders (from 3.1 to 2.2 million), measles (from 0.63 to 0.13 million), and tetanus (from 0.27 to 0.06 million) [24]. For every woman who succumbs to maternal death, many more suffer injuries, infections, and disabilities brought about by pregnancy or childbirth complications. Globally, it is estimated that for every maternal death, about thirty women suffer disability or injury due to pregnancy complications, childbirth or abortion. In $2010,35 \%$ of global disability adjusted life years was from communicable, maternal, neonatal and maternal disorders. About half of all deaths from unsafe abortion are in Asia, with most of the remainder $(44 \%)$ in Africa $[25,26]$. 


\section{Infant and child health}

Of the approximate 10 million child deaths across the world, 1 in 5 children die in India (1-3). The recent Indian DHS data further show that 12 percent of children ever born to currently married women have died [8]. Available studies demonstrate that birth intervals of three to five years could increase chances of infant and maternal survival by 2.5 times more than children born at interval of 2 years or less [27-29]. Not using a contraceptive method for spacing births can lead to unintended pregnancies and subsequently increase the odds of neonatal mortality.

Figure 1.4: Trends in neonatal and post-neonatal mortality, India and focused states 1992-2011

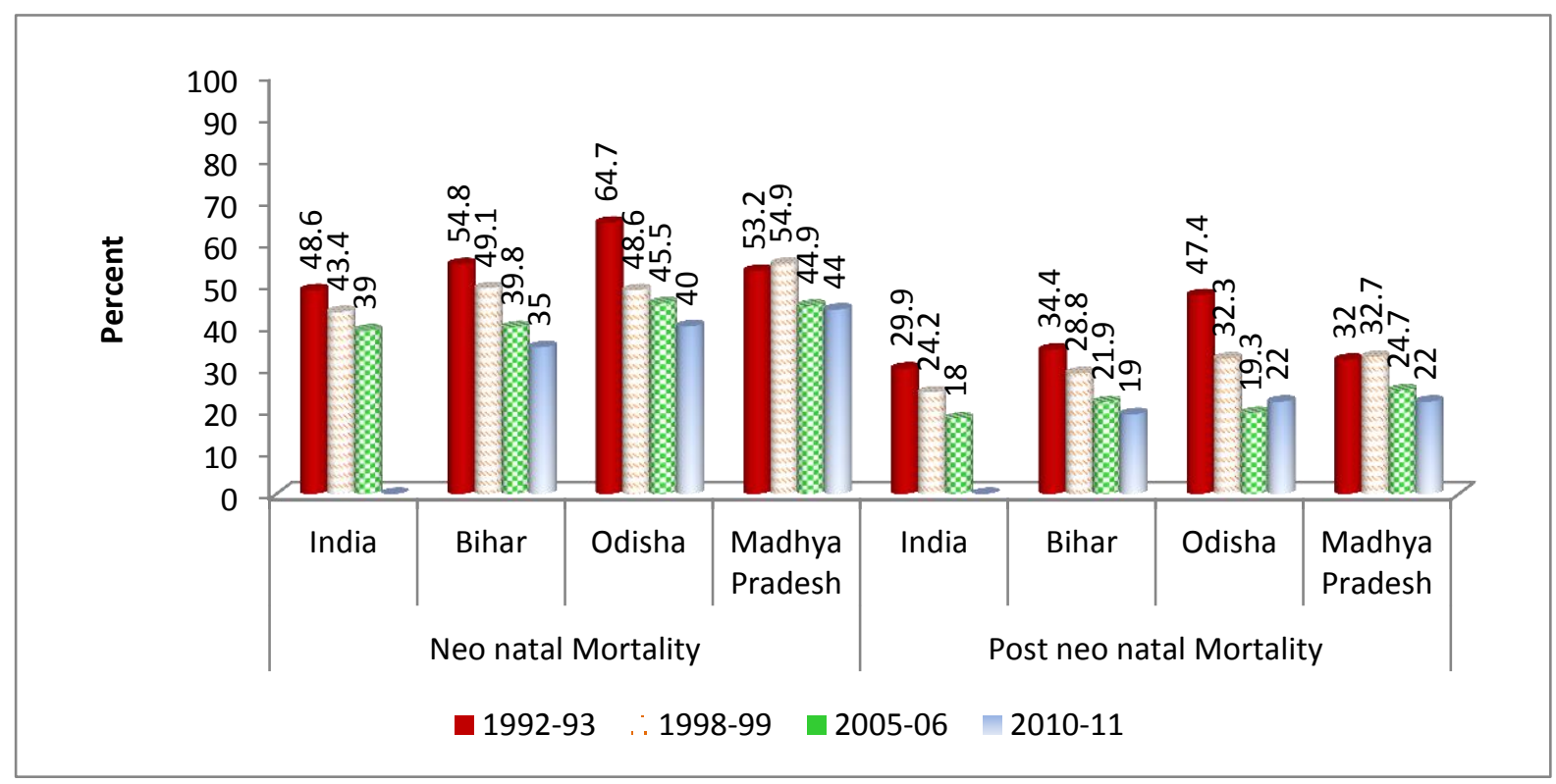

Source: Three rounds of NFHS, AHS, 2010-11. No India average in AHS since not done in all states.

Trends in neonatal and post neonatal mortality reported by women age 15-49 years is presented in Figure 1.4. Decline in neonatal mortality is visible in the recent national survey. However, the decline is only minimal in Madhya Pradesh: from 53.2 \% in 1992-93 to 44.9 percent in 2005-06. Substantial declines in neonatal and post neonatal mortality was reported by Odisha: 45.5 percent neonatal mortality in 2005-06 down from 64.7percent in 1992-93; and 19.3percent post neonatal mortality in 2005-06 down from 47.4percent in 199293. However, the recent annual health survey data indicate that there had not been perceptible decline in neonatal mortality in the 2010-11 survey despite the efforts to reach the set goals of MDG 4. Slight decline in post neonatal mortality was observed for Bihar and Madhya Pradesh whichh had shown an increase in Odisha five years after the last NFHS. 


\section{CHAPTER 2: THE LEGAL, POLICY AND SOCIO-CULTURAL CONTEXT OF SEXUAL AND REPRODUCTIVE HEALTH RIGHTS IN INDIA}

\section{Introduction}

There is amble evidence on how promoting family planning can help any country's economies and development. "Family planning is one of the most successful development interventions of the past 50 years. It is unique in its range of potential benefits, encompassing economic development, maternal and child health, educational advances, and women's empowerment. Research shows that with high-quality voluntary family planning programs, governments hold the power to reduce fertility and generate substantial improvements in health, wealth, human rights, and education. The costs of family planning services are modest, and the benefits large, relative to other public health interventions [1]."

The public health impact of unsafe abortion was recognized as early as 1967 (the world health assembly) and WHO in their second policy guidelines on safe abortion has taken a human rights approach [2]. Elimination and reduction of unsafe abortion is the key in WHO global reproductive health strategy. India had made abortion legal through the passing of the Medical Termination of Pregnancy (MTP) act, 1971. In the area of reproductive health of women too, a rights approach was adopted. India is committed to the ICPD program of action. At the Millennium submit in 2000, India had set targets for all the millennium development goals. However, the progress is slower than anticipated that India is currently far behind the set targets [2-3].

Globally, various committees were formed to discuss discrimination against women, human rights and the like. A number of declarations and resolutions were passed resulting from these committees/commissions and conferences and India is signatory to most of them [4-5]. Given below is the list of international covenants/conventions/treaties ratified/signed by India.

\section{International Covenants / Conventions / Treaties Ratified / Acceded / Signed by India}

- The Universal Declaration of Human Rights (UDHR)

- The International Covenant on Economic, Social and Cultural Rights (ICESCR) - Ratified on 10th April, 1979

- The International Covenant on Civil and Political Rights (ICCPR) - Acceded on 10th April, 1979.

- The International Convention on Elimination of all forms of Racial Discrimination - Ratified on 3rd December, 1968.

- The Convention on Rights of the Child.

- The Convention on Elimination of all Forms of Discrimination Against Women - Signed on 30th July, 1981.

- Convention against Torture and other Cruel, Inhuman or Degrading Treatment or Punishment - Signed on 8th October, 1997.

- International Covenant on Suppression and Punishment of the Crime of Apartheid - Acceded to on 22nd September, 1977.

- The Convention on the Prevention and Punishment on the Crime on Genocide - Ratified on 27th August, 1959. 
- Convention on the Non-Applicability of Statutory Limitations to War Crimes and Crimes against Humanity - Signed on 12th January, 1971.

- Slavery Convention ratified 18th June, 1927.

- Protocol amending the Slavery Convention signed at Geneva on 25th September, 1926.

- Supplementary Convention on the Evolution of Slavery, Slave Trade and Institutions and Practice similar to Slavery - Ratified on 23rd June, 1960.

- Convention for the Suppression of the Traffic in Persons and of the Exploitation of the Prostitution of others - Ratified on 9th January, 1953.

- Convention on the Nationality of the Married Women - Signed on 15th May, 1957.

- Convention on the Political Rights of the Women - Ratified on 1st November, 1961.

Source: Ministry of Home Affairs, GOI. http://mha.nic.in/uniquepage.asp?ld_Pk=235.

According to article 2(1) International Convention on Economic, Social and Cultural Rights (ICESCR), states are required to take immediate and progressive steps to achieve rights enshrined in the Covenant which includes right to the highest attainable standard of health.

\section{Brief history of reproductive health laws and policies}

Women's health as a separate subject was always recognized through various provisions in the Factories Act, laws concerning abortion and the Maternity Benefit Act. But the special importance of women's reproductive rights emerged in the 1980s after women's groups revolted saying women were being used as guinea pigs for testing contraceptives [6]. A case in point is the ban on injectable contraceptive DMPA. Currently DMPA is provided by the private sector, but is not part of the contraceptive methods available through the national family planning program. Supreme Court observed while responding to a case in their courts, that providing adequate medical facilities was an essential part of the obligation undertaken by the State in a welfare state. And failure on the part of a government hospital to provide timely medical treatment to a person in need of such treatment results in the violation of his right to life guaranteed under Article 21 [7].

Various strategies were introduced by the government during the various five year plan periods to improve maternal and child health. In 1992, India launched the Child Survival and Safe Motherhood programme followed in 1997 by a five-year programme called Reproductive and Child Health (RCH) program [3,8, 9]. Although $\mathrm{EmOC}$ was one of the strategies, the programme was not implemented. Unavailability of qualified health workers is a major constraint for providing locally accessible skilled delivery care for rural women $[3,9]$. $\mathrm{RCH}$ program went through two phases. When it ended in 2005, government introduced the National Rural Health Mission (NRHM) 2005-2015 [9]. The lessons learnt during the implementation of the RCH program as well as consultations with the NGOs working in the field assisted in the strategy formulation of the NRHM. Integrating the various HIV prevention work into the NRHM is one of the new efforts that is ongoing. The National AIDS Control Organization (NACO) was set up in 1992 to implement the first national AIDS control programme (1992-1999) [10].

Various policies were introduced in India at various years and many states then formed their own policies [1123]. The different policies that were reviewed for this chapter are: The National Youth Policy 2003, The National Health Policy 2002, The National AIDS Prevention and Control Policy 2002, The National Policy for the Empowerment of Women 2001, The National Population Policy 2000 and state level population policies of the study states. Madhya Pradesh formulated its own population policy and health policy. Odisha also has a state health policy and public private partnership policy in health sector. Through the public private partnership 
policy, few of the primary health centers of the state are contracted out for running its services. Mother NGOs (MNGOs)-service NGOs program is also a way of reaching out to the community with programs and using the resources available in the community. MNGOs also run the capacity building of ASHAs in the state. Urban health centers in the lines of primary health centers are currently operational in slum communities [24]. Available reports of these various activities were also included for review.

Often the reproductive and sexual health knowledge is inadequate and incorrect among young people. They are also unaware of their reproductive rights and services available. The health policy 2002 hence focuses on school and college children so that awareness about various reproductive and sexual health topics and services can be increased among them and as a result there could also be increase in their health seeking behavior [13]. The policy envisages giving priority to school health programs through preventive health education, regular health checkups and promoting health seeking behavior. The National Youth Policy 2003 was formulated keeping in mind the special attention that the youth needs. Acknowledging the vulnerability in reproductive and sexual health of young people, policy mentions establishment and provision of counseling services, adolescent clinics and youth health associations as source of reproductive health and contraceptive information [13-15].

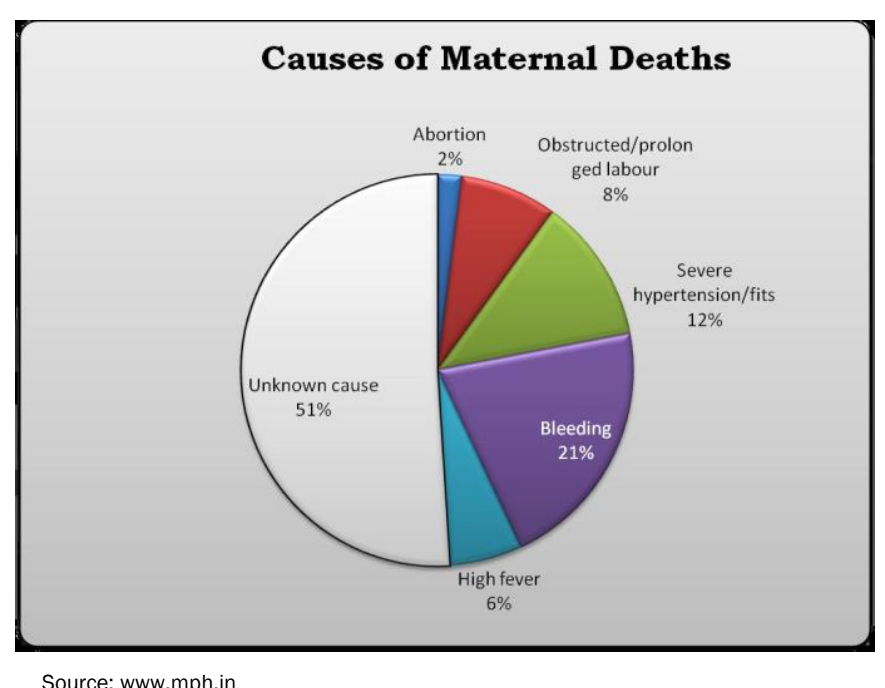

Source: www.mph.in

Madhya Pradesh (MP) has formulated its own population policy and health policy [25,26]. A critical analysis of the MP population policy mentions that the state has adopted the national policy in its entirety [27]. The main strategy adopted by the state policy is population stabilization: adoption of family planning and other government initiatives with focus on birth limitation than birth planning. Another reason for its limited success is its dependence on center for planning and delivery of family welfare services. So the capacity of the state and districts not getting built for implementation of the policy and state has not factored in capacity building for the same. Using decomposition of the desired and undesired fertility in the state, the author found that undesired excess fertility (difference of observed total fertility rate and the wanted total fertility rate) has increased and desired excess fertility has decreased. Based on the analyses carried out, the author concluded that increasing proportion of couples in the state desire to keep their family small but is unable to do so. The goal set by the state in year 2000 was 220 maternal mortality per lakh live births. However, in the year 2011, it stands at 310 per 1 lakh births, Gawlior division was having the lowest maternal mortality of 262 deaths per lakh live births. The age group 20-24 recorded the highest maternal mortality of 149 per lakh live births. As seen from the figure above, 2 percent mortality resulted from abortion [28]. A human rights-based approach to maternal mortality requires effective, accessible and transparent monitoring and accountability mechanisms. UNFPA's review of policies mentions that although India has three main systems for measuring mortality, the reporting of maternal deaths are unreliable $[8,29,30]$.

Odisha has its own health policy and expects that this will help it in achieving health goals better. Pro-poor approach and inter-sectoral coordination are highlighted in the policy. Since the existing health facilities are used by comparatively well-off population, the state is taking steps to assist the very poor with financial aid. The states' spending of allocated health funds is below optimum level. To meet demand with supply, state plans to start more medical colleges. The policy components of women's health are in sync with the women's policy [31-33]. 
The National Policy for Empowerment of Women (2001) had announced formation of National and State Councils to oversee the operationalization of the Policy on an ongoing basis [19]. Within this policy, promotion of self-help groups for the empowerment of women is highly encouraged. Various schemes are in place to enhance their financial capability and independence using the platform of self-help groups. This policy covers compensation for rape victims and implementation of protection from domestic violence act and other acts of the ministry. Short stay homes, crèche for children of working mothers are some of the schemes aiming to assist women that are mentioned in the policy. Protection of women from domestic violence act (2005) came into force in 2006 [20]. The major problem that comes in the implementation is the coverage of various schemes as the various law falling under different ministries. Government is looking at more ways to integrate the schemes and services under different ministries. For example, the health policy comes under the ministry of health and family welfare; the youth policy comes under the ministry of sports and youth affairs and so on. Given the wide array of services or programs that each policy deliberates many of which has inter-linkages proper monitoring becomes difficult. It can also lead to duplication of services. For example, the accredited social health activists (ASHAs) under the department of health and family welfare as well as anganwadi workers under the department or women and child development are working with pregnant women and children with different objectives. While ananwadi worker's focus is nutrition, ASHAs advice on ANC, immunization among others. Anaganwadi worker also is involved with ANC and immunization and ASHAs also has to teach about nutrition. It is difficult to work dissociated on different topics with the same target group. The attempt made here was to make a point about optimum use of existing resources and the need for intersectoral linkages.

Adolescent health and development issues are mentioned in various policies and programs that the government of India has introduced. The Children's Code Bill, 2000; National Health Policy, 1983; National Nutrition Policy, 1993; National Plan of Action for Children (Planning Commission of India), 1992; National Plan of Action for the South Asian Association for Regional Cooperation (SAARC); Decade of the Girl Child, 1991-2000; National Policy for Children, 1974; National Policy in Education 1986 (Modified 1992); National Policy on Child Labor, 1987; National Population Policy, 1997; National Population Policy, 2000; National Youth Policy, 1986 and National Youth Policy, 2000 all has special reference to adolescents. Under the NRHM, there is separate adolescent reproductive and sexual health strategy and guidelines for its implementation [34].

UNICF, UNFPA and WHO proposed a joint strategy for adolescent reproductive health in 1989 and also supported country level programs to make this a reality. International Conference on Population and Development (ICDP) convened in Cairo in 1994 and the program of action formulated at this conference gave an impetus to reproductive health programs worldwide. It also increased the focus on adolescent health and action by countries in formulating strategies towards improving access to focused health services and counseling for adolescents [35].

The Convention on the Elimination of All Forms of Discrimination Against Women (CEDAW), is an international bill attempting to end discrimination against women. Article 16, states that all women, as well as men, have the right to choose their spouse, to have the same responsibilities, and to decide on how many children and the spacing between them. The article bans child marriage and wants that all marriages are registered. India signed the convention on 30 July 1980 but made the declaration that, because of the nation's size and amount of people, it's impractical to have a registration of marriages [5, 34].

The Government of India has adopted the Prohibition of Child Marriage Act in 2006, replacing the Child Marriage Restraint Act, 1929. The Compulsory Registration of Marriages Act, 2006, The Dowry Prohibition Act, 1961 and Right to Free and Compulsory Education Act, 2009 reinforces India's stand against child 
marriage and efforts in that direction. India does not promote polygamy. However, in the national survey, one percent women reported that their husbands have another wife.

Marriage has a strong effect on fertility, and is considered one of the most important proximate determinants of fertility. Age at first union is important because of the strong link between marriage and child bearing [36]. The age when men and women form unions is influenced by social norms and expectations of their roles as spouses and parents. Early marriage or child marriage is a human rights concern because the child is robbed of childhood and is forced to attain adult roles. By ages 25-29 sizable number of men in developing countries are married. Women aged 20-24, 30-34 and 40-44 reporting being married by age 18 years in the developing countries were 41.5 percent, 54.2 percent, and 57.6 percent respectively. West/central Africa had reported higher percentage of child marriage than south Asia [36]. In addition to being in vulnerable position because of young age marriage, these women are disadvantaged by lack of schooling or minimal schooling.

55.7percent of 20-24 year old women from South Asia who were married by age 18 had only $0-3$ years of schooling. Not surprisingly, nearly half of the $20-24$ year old women who were married by age 18 belonged to rural area. Despite compulsory and free elementary education being part of the law in India, children are not attending school and are married off early since it is less expensive than older age marriage of girls who are educated [36].

The legal minimum age of marriage for women in India is 18 years and for men it is 21 years. The highest rates of child marriages are in rural areas of Andhra Pradesh, Bihar, Madhya Pradesh, Rajasthan and Uttar Pradesh $[37,38]$. Pregnancy-related deaths are known to be the leading cause of mortality among married girls between 15 and 19 years of age. Adolescents are twice more likely to die in childbirth than women age 20- 24 years. Girls younger than 15 years of age are 5 times more likely to die in childbirth $[39,40]$.

Table 2.1A: Currently married women age 20-24 years married before legal minimum age of 18 years, 2007-08 and 2010-11

\begin{tabular}{|l|l|l|}
\hline & $2007-08$ & $2010-11$ \\
\hline Bihar & 68.2 & 54.6 \\
\hline Odisha & 37.5 & 30.9 \\
\hline Madhya Pradesh & 53.7 & 48.1 \\
\hline
\end{tabular}

Source:DLHS, 2007-08; AHS, 2010-11 [41-46]

Table 2.1B: Women 15-34 years in focused states married by age 15 and pregnant or with child by age 18 years, 2007-08

\begin{tabular}{|l|l|l|}
\hline & Women age 15-34 Married by age 15 & $\begin{array}{l}\text { Women age 15-34 pregnant or with } \\
\text { child before age 18 }\end{array}$ \\
\hline Bihar & 52.4 & 39.1 \\
\hline Odisha & 15.4 & 27.9 \\
\hline Madhya Pradesh & 37.7 & 33.9 \\
\hline
\end{tabular}

Source:DLHS, 2007-08

As can be seen from Table 2.1A, marriages before age 18 years are still rampant In the three focused states. Table $2.1 \mathrm{~B}$ is indicative of early marriage and pregnancy soon after before age 18 years. Bihar has reported more than half the women being married by age 15 years and more than quarter women in all three states were either pregnant or were mothers by age 18 years. To thwart this trend of early marriage and young age pregnancy various cash incentive schemes were introduced by the government [47]. These conditional cash transfer schemes are described in detail in chapter 6 on "financing and delivery mechanisms". No studies are 
available to measure the effectiveness of these schemes in decreasing child marriages. The increase of age at marriage that is reported in more recent surveys could be because of other factors than the various schemes that the state and centre have introduced. In the absence of research, a causal relationship is difficult to be established. Madhya Pradesh launched Bitiya campaign in the state to promote acceptance of girl child and reduce sex determination and subsequent female feticides. Awareness generation campaigns were the main means used by the state to change this existing trend in the state. The state also formed "parents with one and only daughter" club. The issue of sex determination and female feticide that the state has been struggling with and the increasing trend seen in Bihar recently is discussed in the latter part of this chapter.

\section{Schemes to improve adolescent health}

Adolescent reproductive health strategy and the establishment of adolescent friendly clinics is a move taken by the ministry to improve the reproductive and sexual health of adolescents and also to promote the use of contraceptives [22, 23]. Under the Department of Social Welfare, the Directorate of Integrated Child Development Services (ICDS) was set up for developing policies, legislations, budget, training requirements, monitoring, evaluation and supervision of programs concerning early childhood care including immunization, nutrition and management of diarrhea as well as nutrition of pregnant women and lactating mothers. The Directorate is responsible to implement three flagship programs which have direct linkages with family health, which include: the Integrated Child Development Scheme (ICDS), the Rajiv Gandhi Scheme for Empowerment of Adolescent Girls (RGSEAG) - called Sabla introduced in April1, 2011 and the Indira Gandhi Matritva Sahyog Yojana (IGMSY).

The highlighted scheme here is the sable program. An integrated package of services is to be provided to adolescent girls: (1)Nutrition provision, (2) Iron and Folic Acid (IFA) supplementation, (3) Health check-up and Referral services, (4) Nutrition \& Health Education (NHE), (6) Counseling/Guidance on family welfare, ARSH, child care practices and home management, (7) Life Skill Education and accessing public services, (8) Vocational training for girls aged 16 and above under NSDP (21). At the village level, the program envisions to have groups of 15 to 25 adolescent girls, each called Kishori Samoohs which are led by peer educators-a Sakhi and two Sahelis nominated by each group. These peer educators are expected to facilitate discussions on topics such as health, hygiene, nutrition, adolescent reproductive health and life skills, motivate adolescent girls to form more Kishori Samoohs and encourage to take home ration of supplementary nutrition and iron and folic acid(IFA) tablets. Kishori Diwas is planned to be held once in three months and the adolescents are expected to participate in this and gain reproductive health information. Another key responsibility of the Sakhi and a Saheli is to motivate and assist all adolescent girls to fill up and maintain their Kishori cards. These cards contain information such as weight, height, body mass index, IFA supplementation, de-worming, referrals and services taken under Sabla for each girl [22, 23]. Nutrition is provided to adolescent girls, the eligibility for the same is determined by their weight. The nutrition provision is sponsored by the ministry of women and child development. This is a centrally sponsored program.

\section{Abortion laws and policies}

Voluntarily causing miscarriage to a woman with child other than in good faith for the purpose of saving her life is a crime under section 312 of the Indian Penal Code (IPC) punishable by simple rigorous imprisonment and/or fine. Induced abortion was legalized in India in 1971 to curb maternal mortality and morbidity stemming from illegal abortions. Medical Termination of Pregnancy Act 1971 was hailed as a progressive act when it was passed, which was expected to decrease existing high mortality and morbidity of women by reducing illegal abortions. The term "Medical Termination of Pregnancy" (MTP) was used to reduce opposition from socio-religious groups [48]. Unlike many developed countries which permitted abortion if there was fetal 
malformations, danger to mother's health or it was resulting from rape; abortion can be sought in India on all grounds-physical and mental health and environmental considerations. No spousal consent was required and only if women were under age 18 years, parental consent was mentioned. Indian Penal Code 1862 found women seeking abortion as well as abortionist guilty and were imprisoned. The new act was seen as pro women and pro life with its base on human rights. Despite this, women continued to seek unsafe abortions $[48,49]$. Three decades after the introduction of the MTP act, only $9 \%$ of the 2400 women surveyed in Madhya Pradesh knew that abortion was legal. Nearly half considered induced abortion to be illegal [50]. Likewise, poor knowledge of the rights under the MTP act was reported from other states too [51-56]. MTP act has recognized the implications of second trimester abortions (thanks to the involvement of the medical community in pushing for the act) and while allowing the same within the act, infrastructural requirements are very well elaborated [48].

In the year 2008, India saw 6.41 lakh abortions across 12, 510 institutions approved to carry out medical termination of pregnancy (MTP) [57]. The number will be much higher if unreported abortions are also counted. This statistics is disquieting because unreported abortions tend to be unsafe abortions. A study in Gujarat showed that majority of women coming for 2nd trimester abortion had tried to abort the fetus unsuccessfully in the first trimester. Even married women go for clandestine abortions when the pregnancy is from contraceptive failure and they fear their husband will suspect them of infidelity or they are worried about the increasing number of children and lack of care to them while husbands are least bothered about the issue [49]. In a study, of the 549 unmarried women age 15-24 years surveyed from Bihar and Jharkhand; one in six women mentioned that non-consensual sex had resulted in pregnancy. Eighty-four percent decided before the end of the first trimester to have an abortion, but only $75 \%$ obtained one in this period. Women who were older or who had more schooling had a decreased likelihood of having a second-trimester abortion whereas those who lived in rural areas, those who did not receive full support from their partners and those who reported a forced encounter had an increased likelihood of having a late abortion[56]. For every identified case coming to hospital with post abortion complications; there will be many who did not suffer worrying complications and so had not sought treatment. Despite a well-defined law, there is a lack of regulation of abortion services or providers, and the cost to women is determined by supply side economics [58].

Since 1991, 80 percent of districts in India have recorded a declining sex ratio with the state of Punjab being the worst. Preconception and Prenatal Diagnostic Techniques (prohibition of sex selection) Act (PCPNDT) 1994 was passed to curb the increasing sex selective abortion leading to the skewed sex ratio [59]. Sex selective abortions are mostly second trimester abortions. Dealing with fetal sex determination and sex selective abortion as business and money making opportunity by unethical medical professionals led to the modification of the PCPNDT act in 2003 to target the medical profession - the 'supply side' of the practice of sex selection. However, the envisaged effect could not be achieved since the implementers and the judges did not know the act and its requirements in detail. Despite many complaints and cases, number of convictions is few, making the act ineffective in achieving its objective [60-64]. This situation is discussed in detail while discussing the two acts together.

One of the abortion service providers in India is of the opinion that women are not seeking abortion in second trimester for sex selection [65]. "Girls are often seen as a burden by their families, particularly in poor rural areas" [66]. However, sex selective abortion especially if the first born is a girl is higher in urban areas and in educated and wealthier families. The conditional sex ratio for second-order births when the firstborn was a girl fell from 906 per 1000 boys (99\% Cl 798-1013) in 1990 to 836 (733-939) in 2005; an annual decline of 0.52\% ( $p$ for trend $=0.002$ ). No significant declines were noticed if first born was a boy[77]. Trend in reported abortions increased after MTP act in 1971. The number of approved institutions providing MTP has increased every year. Despite this trend, safe abortion services are still negligible in rural areas. 
The recent census data highlighted the increase in sexual disparity at birth and the disap pearing girl children. The news papers and other media focused on this issue with numerous articles. This has had its negative effects on the provisions in the MTP act $[67,68]$. FOGSI narrated that despite having committed persons and NGOs working for promotion of safe abortion; fear is ruling the provision of services in Maharashtra.

Pharmacists do not stock medical abortion pills, doctors do not apply for registering their clinics as an abortion service provider. Tabling the amendment to the CAC guidelines in the parliament was delayed since the focus soon after the census 2011 data was released was its highlight of the disappearing girls in many states. There was an increasing consensus at the one day meeting held in Delhi by FOGSI and PSI that the clini cians who are not well versed with the law and the maintenance of the forms and registers get easily caught and punished by the inspectors who themselves are not sure of their roles and powers [68]. Thus despite the presence of MTP act that allows induced abortion for all reasons, women are unable to access safe abortion $[59,60]$.

To understand this dichotomy, the two laws in India-MTP and PCPNDT—need to be discussed here to highlight how the laws tend to help as well as restrict safe abortion. MTP act had made abortion legal. Technology; ultrasound made it possible for couples to find out the sex of the fetus. Son preference of the Indian society thus gave an easy way to abort the female fetuses and also promoted a business by some medical professionals. To thwart this trend, PCPNDT act was passed in 1994. This has made disclosure of the sex of the child a punishable offence.

The existence of MTP and PCPNDT acts one focusing on the right of the women and the other looking at punishable things have led to confusion among the common people on what is allowed by law and what is restricted. MTP is based on the right of the woman and so there is a tendency of health professionals to feel that sex-selective abortion is a right of the woman. Communities are also not able to differentiate between the restriction in PCPNDT act and the allowances in the MTP act [56]. Many feel that integrating MTP and PCPNDT into a single act is necessary for its successful implementation. The difficulty of one act covering the components of the two acts is difficult because of the differing focus and basic theme in the two acts. The safe abortion lobby in the country is against merging the two acts because the protection of women's health with the MTP act will get compromised. Hence the lobby's efforts are in the direction of rejuvenating the lack of interest among providers in providing abortion services.

The study carried out by CYDA and UNFPA further found that appropriate authority (AA) who are responsible to monitor the implementation of the PCPNDT act are dysfunctional in most districts of the selected states. Even where it was operational, clarity is lacking among the officials about their roles and actions they should implement. Sometimes political interference prevents the officials from implementation of the provisions in the act. The lack of proper knowledge on the maintenance of forms by the doctors and by the AA on what procedures they need to document and poor knowledge of the act among the judges have all come in the way of convictions as well as unjust jailing of the medical officers. CMO is the chair of the AA, which is cited by few as a conflict of interest (doctors checking on doctors) [62]. Situation analysis of MTP services in Bihar and Jharkhand carried out by IPAS found that district level committee (DLC) with chief medical officer (CMO) as the chairperson required to be formed within the MTP act was not formed in many districts. The nine districts that reported ever having a DLC In Bihar at the time of the survey were Bhojpur, Patna, Muzaffarpur,Darbhanga, Madhepur, Vaishali, Supaul,Bhagalpur, and Kishanganj. Of these, DLC in 7 districts were active and had periodic meetings. A total of 334 health facilities were reported providing MTP services at the time of the survey. An overwhelming majority of these health facilities $(79 \%, 265$ of 334$)$ were from the private sector [63].

The Bihar state government launched 'Yukti', scheme in 2011 to provide comprehensive abortion care 
services to women across the state. The scheme has been launched in association with Ipas, a Nongovernment Organization. Additionally, 2011 was declared as safe motherhood year and high focus was given to safe delivery and abortion. To bring down the MMR, the government has taken measures like increasing institutional deliveries (IDs), appointment of women health workers such as Mamta in government hospitals across the state for better care of mother and child, and launching of 'Yukti Yojana' for providing accreditation to private institutions to provide proper facilities for monitoring of pregnancy and ensuring safe delivery $[70,71]$. The dialogue around the changes needed to MTP act is ongoing. Ministry had requested Ipas to review the act and they have submitted their recommendations to the government.

\section{Donors and international assistance}

International donors and their involvement and special strategies focusing rural (NRHM) and urban (urban health initiative) population launched by the government are contributing to development of the health sector as well as reduction in poverty. DFID's sector approach in Bihar, Odisha and Madhya Pradesh; USAID's investment in Uttar Pradesh and other EAG states for behavior change communication, Bill and Melinda Gates Foundation (BMGF)'s substantial investment in Bihar and their growing interest in UP, besides huge investment by the Central Government in the form of NRHM are indicative. Bilateral cooperation between the Indian government other countries are also assisting the EAG states. The Norway-India Partnership Initiative (NIPI) provides strategic support to NRHM (NIPI 2008) focusing on five States-Uttar Pradesh, Bihar, Madhya Pradesh, Rajasthan, and Odisha. Many development partners and NGOs like Marie Stopes International (MSI), Ipas, Population Services International (PSI), Jhpiego, Janani etc. are helping the State Governments through training and capacity building, outreach camps, social marketing as well as by providing knowledge and contraceptive and abortion services to vulnerable and difficult to reach population [72]

\section{Overview of policies}

Conclusions drawn by Khan and Hazra [73] on the policies and programs give a critical overview of the policies in India, which is given below:

Our review of the program and policy documents show keen desire on the part of MoHFW, Government of India to address reproductive health needs of people including unmet need and unwanted pregnancy of all but particularly adolescents and youth and poor and marginalized families. However, there are gaps between desire and action and may require some time when these initiative start showing results. The points that emerged are given below:

Health system and quality: The Eleventh Five Year Plan (2007-12) underlined that "the country has to deal with rising costs of health care and growing expectations of the people. The challenge of quality health services in remote rural regions has to be urgently met. Given the magnitude of the problem, we need to transform public health care into an accountable, accessible, and affordable system of quality services during the Eleventh Five Year Plan" (Planning Commission, 2008).

Contraceptive use and addressing unmet need: The Plan document underlined that even meeting half of the unmet need could lead to an appreciable decline in the birth rate. It was emphasized that ANMs and ASHAs will identify the couples with unmet need in their area, and addresses their concerns. During the Eleventh Five Year Plan, all existing strategies will be continued with a greater focus in areas of high unmet need (Planning Commission, 2008). 
Strategies adopted and increased resources allocated: The Indian government has identified certain strategies under the Eleventh Five Year Plan. The first one is the high focus approach, as part of the core strategies under NRHM, the whole country was grouped into high focus states ${ }^{10}$ (HFS) and the rest. The high focus states are those states which have weak public health indicators and / or weak infrastructure. All north-eastern states are included in HFS. This was done to reduce regional imbalance in health infrastructure. 264 high focus districts were also identified which require focused attention. The fund released to districts was Rs. 24111.3 million in 2009-10 and the proposed allocation to the districts by States is Rs. 35675.2 million in 2010-11, accounting for 47.96 percent increase (Planning Commission, 2008).

Initiatives taken to strengthen service delivery: The government has taken several steps to strengthen the service delivery (Ambwani, 2011). These include

- Fixed Day Static Services till PHC Level (priority as per delivery load): one NSV/one Minilap provider at each PHC and one trained IUCD provider at Sub Centre

- Availability of Postpartum Family Planning at all facilities, where deliveries are conducted (Counselor / Trained Minilap and PPIUCD Service Provider)

- Training and rational placement of service providers

- Increasing male participation in accepting NSV

- Demand generation (IEC/BCC) activities: communication strategy focusing on specific issues like delaying age at marriage, spacing, male participation

- Accreditation of private providers to increase the pool of service providers

- Involving ASHAs/CHWs for demand generation, follow ups, and distribution of contraceptives.

D The other strategies are operationalization of the first delivery points and expansion to other facilities, strengthening human resource structures from national to district level, roll out of IUD 375 as a short term spacing method and delivery of contraceptives by ASHA (Sikdar, 2012).

In order to reduce the unmet need for spacing methods by increasing access of contraceptives in rural areas and uplift the motivation of health workers in family planning related issues, new initiatives have been taken on pilot basis. The concept of ASHA as agents of social marketing is being introduced for condoms, oral pills and sanitary napkins. In this regard on $4^{\text {th }}$ August 2011, Govt. of India issued letter to the Secretaries, Health and Family Welfare, of 17 high focus states on the provision of home delivery of contraceptives (condoms, oral contraceptive pills: OCPs and emergency contraceptive pills: ECPs) by ASHA at the doorstep of beneficiaries (MoHFW, 2011). As per the letter, "the Government of India supplies contraceptives such as condoms, OCP and ECP to the states as part of free supply and social marketing schemes. However, access to these contraceptives is reported to be low because of several causes including delay in making supplies to sub district level downwards. As such, use of contraceptives in the country has become largely static. On the other hand, unmet need for spacing methods continues to be substantial. To improve access to contraceptives by the eligible couples, it has been decided to utilize the services of ASHA to deliver contraceptives at the doorstep of households and incentivize her for the effort. To begin with, the initiative is being implemented on a pilot basis in 233 districts in 17 States. In the districts

10 The high focus states are Bihar, Chhattisgarh, Himachal Pradesh, Jammu \& Kashmir, Jharkhand, Madhya Pradesh, Orissa, Rajasthan, Uttar Pradesh, Uttarakhand, Assam, Meghalaya, Mizoram, Sikkim, Tripura, Arunachal Pradesh, Manipur and Nagaland. 
where distribution of contraceptives by ASHA is being introduced, the free supply of contraceptives at PHC and Sub-Centre level would stand withdrawn in the light of the new provision of home delivery of contraceptives by ASHA. However, free supply of contraceptives at CHCs, Sub-Divisional and District level hospitals shall continue as before". ASHA would charge Re. 1 for a pack of 3 condoms, Rs. 1 for a cycle of OCP and Rs. 2 for a pack of one tablet of ECP, from the beneficiaries as an incentive for her efforts (MoHFW, 2011).

- As per the latest available information, among the 233 pilot districts, in 191 districts the program is already running and 158 districts of them have already started reporting (Sikdar, 2012).

$>$ As per this order, ASHA would make a list of all the eligible couples of her village mentioning the preferred type of contraception and share the data of users with the sub centre as well as the PHC. This listing will also help in identifying couples with unmet need and wherever possible she could provide required spacing methods otherwise refer cases of sterilization and IUD to appropriate facilities. The ASHA has to collect the consignment/replenish her stock every month from the Block $\mathrm{PHC} / \mathrm{CHC} / \mathrm{PHC}$ as per the system put in place by the state. However, these programs are at too early stage to gauge any impact but definitely have potential to increase access to spacing methods at the door steps of couples. The fifth common review mission report (2011) noted that on the ground the program was seen only in Uttar Pradesh and Uttarakhand and the interesting observation from this state was that ASHA was not accepting the payment for contraceptives as she did not want to alter the social image that she had built up. It would be interesting to see how the ASHA herself would respond to efforts to shape her role in this direction (NHSRC, 2012).

$>$ The fifth common review mission report (2011) observed that progress in the provision of family planning services is varied, with a majority of states reflecting positive achievements over the NRHM period, for both limiting and spacing methods. But states such as Haryana show a decline in female sterilization and Sikkim shows a decline in IUD insertions. Likely reasons appear to be the shortage of doctors, slow progress in training for multi-skilling, and the lack of attention to providing fixed day services (NHSRC, 2012).

$>$ There is significant improvement in the availability of outreach services in all states as measured by the rise in immunization, antenatal care and access to contraceptives. This is attributable to increasing the number of ANMs, provision of untied funds to the sub-centre, and to the ASHA. 95 percent of the sub-centers are functional with at least one ANM, and 35 percent of sub-centers have a second ANM (NHSRC, 2012).

$>$ The report pointed out that skill up-gradation trainings especially for family planning (IUCD insertion, Minilap, PPIUCD, NSV) need to be improved to increase the contraceptive acceptance.

> In 2011, outreach services across states have improved in terms of achievements in deliverables immunization rates and antenatal care and promotion of small family norm and access to contraceptives. This is due to (a) filling up of ANM vacancies in all sub-centers, (b) the untied funds provision to sub-centers that has helped close gaps in minor equipments and amenities; (c) due to the ASHA who has proven an effective approach to increasing demand. Of the total of 145,920 sub-centers, 95 percent are functional with at least one ANM whereas in 2005, one fourth of sub-centers were non- functional. Further, 35 percent of current sub-centers (50,728 in number) have a second ANM. In 2005, no sub-centre had a second ANM.

$>$ While the promotion of institutional delivery and immunization are the two key tasks that continue to be seen as ASHA's most important responsibilities, she is active on a range of tasks including malaria surveillance, nutrition, DOTS, home based newborn care, motivation for family planning and contraceptive counseling.

$>$ The common review mission report mentioned that in states with persistent high fertility, the gaps are mainly in the supply side and they would need to be addressed through creating a larger pool of service providers who are trained in mini-lap and NSV (NHSRC, 2012). The report also highlighted the need for much more 
attention to spacing methods, especially like long term IUCD. IUCD insertion on fixed days by ANMs (under supervision of LHV for new ANMs/Staff nurses) has to be encouraged.

$>$ The NRHM claims that with the concerted efforts of the State/UT Governments and the Ministry of Health and Family Welfare, a lot has been achieved in improving the health care delivery system in the country. Annual Program Implementation Plans (PIP) gives opportunity to reflect the achievements and shortcomings and renew NRHM efforts to achieve the Mission goals (NRHM, 2012).

$>$ Several States reported that the vision comprises of two main components: empowerment and equity. That is; empowering the people living in the State with knowledge and skills required to keep them healthy and equity in access to effective and affordable health care (Government of Madhya Pradesh, 2012). NRHM in Bihar seeks to address these issues through the strategies that provide equitable access to quality affordable health care services to all segments of population (State Health Society Bihar, 2011).

$>$ According to the NRHM PIP 2011-12, following are few important issues that States should consider while strategizing and formulating the PIP (2010-12) for family planning. These include

- Family planning management (Review meetings on Family Planning performance and initiatives at the state and district level, Monitoring and supervisory visits to districts/ facilities, Orientation workshops on technical manuals of FP viz. standards, QA, FDS approach, SOP for camps, Insurance etc.

- Terminal/limiting methods (providing sterilization services in districts)

- Spacing method (providing of IUD services by districts)

- Social marketing of contraceptives

- Family planning training

- BCC activities/campaigns/melas for family planning e.g. Funds earmarked for district and block level activities during 'World Population Day' celebration week

- Innovatory schemes for promoting FP at state or district level

- Performance based rewards to institutions and providers for FP performance at state and district level

40 years after the introduction of MTP act which is liberal in nature, unsafe abortions continue to outnumber legal ones. Expert committee formed three years back to review the MTP act had recommended among others the following:

- Increase the limit of abortion from 20 weeks to 24 weeks

- Increasing the base of legal MTP providers by including medical practitioners with a Bachelor's degree in Unani, Ayurveda or Homeopathy. Nurses with a three and half year's degree and registered with the Nursing Council of India, could also be included in the base of legal providers.

- Since the training required to provide only medical methods of abortion is significantly less than surgical abortions, recommended to distinguish between the two trainings [74-75].

The government efforts to increase the access to safe abortion services at the village level has made the central ministry to ascertain in definite terms that if PIP s of the states do not reflect provision of abortion services at the PHC level and if abortion provision at the PHC level has not improved, funding to the state will be stopped. 


\section{CHAPTER 3: FAMILY PLANNING AND REPRODUCTIVE HEALTH INDICATORS: TRENDS AND EQUITY ANALYSIS}

\section{Introduction}

An analysis of contraceptive prevalence between 1950 and 2011 from 194 countries found that worldwide, contraceptive prevalence increased from 54.8 percent in 1990, to 63.3 percent in 2010 , and unmet need for family planning decreased from 15.4 percent in 1990 , to 12.3 percent in 2010 . According to the authors, the absolute number of married women who either use contraception or who have an unmet need for family planning is projected to grow from 900 million in 2010 to 962 million in 2015, and will increase in most developing countries [1]. Various factors like limited human and financial resources lead to low contraceptive prevalence in less developed regions of the world and hence these regions report relatively high maternal mortality and morbidity [2].

The less developed nations are comparatively poor and have rapid population growth while the rich developed nations face problem of another kind because of negative population growth. Moderate annual growth of 1 to 2 percent is concentrated in large countries, such as India and Indonesia, and across North Africa and western Latin America [3]. Countries with rapid growth face adverse social, economic, and environmental pressures. Hence it is important that these countries focus on the promotion of family planning methods and assist couples to plan their number of children.

\section{History and trends of India's national family planning program}

India is the first country in the world to initiate a nationwide family planning program in 1952; with the aim of population control. It underwent a paradigm shift and now the program emphasis is to improve the reproductive, maternal and child health. The total number of family planning (FP) acceptors has increased from 6.49 million in 1980-81 to 27.36 million in 1990-91 and 36.63 million in 2000-01. The total number of FP acceptors in the year 2010-11 was 34.5 million. The couple protection rate has quadrupled from 10 per cent in 1971 to 40 per cent in 2010-11 [4]. However, some of the effects of the target approach practiced earlier is still lingering and the use of spacing methods is not seeing an appreciable increase. Customs and traditions, son preference and availability of FP methods or myths around certain methods also influence contraceptive acceptance. Decades after the initiation of family planning programs in India still the family planning method acceptance in the country is heavily leaning towards limiting methods, especially female sterilization. The latest Indian DHS (2005-06) results show that 77 percent of sterilized women did not use a family planning method before sterilization [5]. The data also shows that among the focused states nearly 80 percent of the women in Bihar, 84 percent women in Odisha and 83 percent women in Madhya Pradesh have not used any family planning method before sterilization, much higher than the national average. A study conducted in rural areas of 28 districts of 14 states in India revealed that there is no concept of using any family planning method for either postponing the first conception after marriage or spacing between children. Nearly 70 percent of the women interviewed reported the use of a method for the first time after completing their desired family size [6].

Table 3.1: Had heard of contraceptive method among women age 15-34 years in focused states, 2007-08

\begin{tabular}{|l|l|l|l|}
\hline Method & Bihar & Odisha & Madhya Pradesh \\
\hline Any Method & 99.4 & 98.4 & 98.4 \\
\hline Any modern Method & 99.3 & 98.2 & 98.3 \\
\hline Traditional Method & 99.8 & 99.6 & 99.7 \\
\hline
\end{tabular}

Source: DLHS, 2007-08 
Table 3.1 gives the impression that young women know about modern contraceptive methods and traditional methods in the focused states as evident from the data from the district level household and facility survey (DLHS) [7]. Universal knowledge of contraceptives in India is reflecting only the knowledge of the names of contraceptive methods. The question that is asked in the national family health surveys or the district level household and facility surveys is if the woman has heard of the method and name of the methods. If women are not able to answer the earlier question, then the description of the method is read to her. The answer to the earlier question is marked as "spontaneously" and the latter as "on probing". No other questions are asked on the knowledge of these methods. The persons mentioning the name of a method will know nothing more than the name as evident from small scale surveys [8, 9]. Knowledge has to be all encompassing for It to translate to contraceptive use. Women must be aware of contraceptive methods, they must know where supplies of these methods can be obtained and how to properly and correctly use it to avoid pregnancy.

\section{Use of family planning method and LAM}

\section{Practice of breastfeeding and LAM}

Breastfeeding is one of the most important determinants of child survival, birth spacing, and prevention of childhood infections. Even though breastfeeding in India is a universal phenomenon, initiation of breastfeeding after birth is considerably delayed in many parts of the country as part of certain customs and traditions. A study conducted among women in rural villages of West Bengal found that initiation of breast feeding was delayed in most of the cases and the reason cited for the delay is the belief that mother's milk is 'not ready' until two-three days of postpartum and colostrum was considered as not good for child's health. Generally colostrum was discarded before putting the child into the breast in majority of the cases in study villages. [10].

There are studies that indicate that the place of delivery and presence of professionals positively affects the early initiation of breastfeeding. In Nigeria, 40 percent of the women who delivered at a health care facility where professional were available initiated breastfeeding within an hour compared to less than 30 percent of women delivered in other places [11] and is also evident in the landscaping study of Bihar and Uttar Pradesh $[12,13]$. Exclusive breastfeeding is not common. For example, a study in Haryana showed that only 30 percent of the women interviewed reported they exclusively breastfed their child till four months and 10 percent of women reported 6 months exclusive breastfeeding. The study also reveals that lack of breastfeeding counseling was significantly associated with low rate of exclusive breastfeeding [14]. Insufficient breast milk is the main reason given by women for weaning the child early and for not practicing LAM $[15,16]$. However, a study from Gujarat reported that more than half the women interviewed had initiated breast feeding within an hour of delivery and similar percent practiced exclusive breastfeeding for 6 months [17]. Studies in other states had found low percentages initiating breast feeding within one hour and few who practiced exclusive breast feeding for 6 months [18-20].

The analysis of DLHS-3 [7] data indicates that the percentage of young women (15-34 years) who initiated breastfeeding within an hour is only 16 percent in Bihar compared to 63 percent in Odisha and 42 percent in Madhya Pradesh (Table 3.2). In Bihar nearly 40 percent of the children were breastfed within 24 hrs of birth and 32 percent breastfed within 2-3 days. It was encouraging to note that nearly 90 percent of the children in Odisha and 70 percent of the children in Madhya Pradesh were breastfed within 24 hours of birth.

If used correctly and consistently LAM provides 98-99 percent effectiveness in protecting from pregnancy. Studies also indicate that women are afraid of using any hormonal contraceptives during breastfeeding due to the fear it might affect the quality of milk and baby's health [21]. LAM being an effective natural method can be used by women for 6 months in the absence of other viable modern methods availability in the national family planning program now. However, even providers lack correct knowledge of the three conditions of LAM- 
exclusively or nearly exclusively breastfeeding of the baby, menstruation has not resumed and the infant should be less than 6 months. Most of the time women are not aware about these three criteria's and LAM is not practiced as a contraceptive method [22-24].

Table 3.2: Percentage of currently married women reporting time of breastfeeding initiation and exclusive breastfeeding

\begin{tabular}{|c|c|c|c|}
\hline Breastfeeding Initiation & Bihar & Odisha & Madhya Pradesh \\
\hline \multicolumn{4}{|c|}{ Women 15-34 years } \\
\hline Immediately/within one hour & 15.9 & 63.2 & 42.3 \\
\hline Within 24 hrs & 40.1 & 24.7 & 29.1 \\
\hline 2-3 days & 32.2 & 7.9 & 16.7 \\
\hline After 3 days & 11.1 & 3.2 & 10.8 \\
\hline Never & 0.8 & 1.0 & 1.1 \\
\hline $\mathrm{N}$ & 18621 & 6932 & 14613 \\
\hline \multicolumn{4}{|c|}{ Women $15-49$ years } \\
\hline $\begin{array}{l}\text { Children breastfed within one hour of birth } \\
\text { DLHS, 2007-08 } \\
\text { AHS, 2010-11 }\end{array}$ & $\begin{array}{l}16.0 \\
30.3\end{array}$ & $\begin{array}{l}63.2 \\
71.5\end{array}$ & $\begin{array}{l}42.7 \\
61.5\end{array}$ \\
\hline $\begin{array}{l}\text { Children 0-5 months who were exclusively breastfed } \\
\text { (DLHS, 2007-08) }\end{array}$ & 38.3 & 54.3 & 51.3 \\
\hline $\begin{array}{l}\text { Children 6-35 months who exclusively breastfed for } 6 \\
\text { months (AHS, 2010-11) }\end{array}$ & 28.5 & 24.9 & 36.8 \\
\hline
\end{tabular}

Source: DLHS, 2007-08; AHS, 2010-11

Even provider's lack correct knowledge of LAM and few women report being counseled about LAM. The surveys have asked women if they were exclusively breastfeeding for 6 months. However, DLHS and AHS have compiled information for different set of children. From AHS, 2010-11, we get a rough Idea of the percentage of women who might fall within the purview of LAM. Only one third of the women in the focused states had reported that they exlusively breastfed their children for 6 months after delivery.

The intervention study conducted in Meerut district of Uttar Pradesh by Population council, found that none of the community workers were able to mention the three criteria for LAM before training and 95 percent were able to mention all the three conditions of LAM after training. Since the women in the intervention area were explained about LAM and the three conditions necessary for preventing pregnancy, 79 percent women had correct knowledge of LAM and 30 percent practiced LAM for postpartum contraception [16].

\section{Ever use of Contraception}

Ever use of contraception provides the measure of a cumulative experience of a population with family planning [2]. Percentage of young women aged 15-34 years from the focused states who reported ever using a contraceptive method in the survey of 2007-08 were 31 percent from Bihar, 48 percent from Odisha and 52 percent from Madhya Pradesh. 
Figure 3.1: Percentage of women age 15-34 years who have ever used any contraceptive method, 2007-08

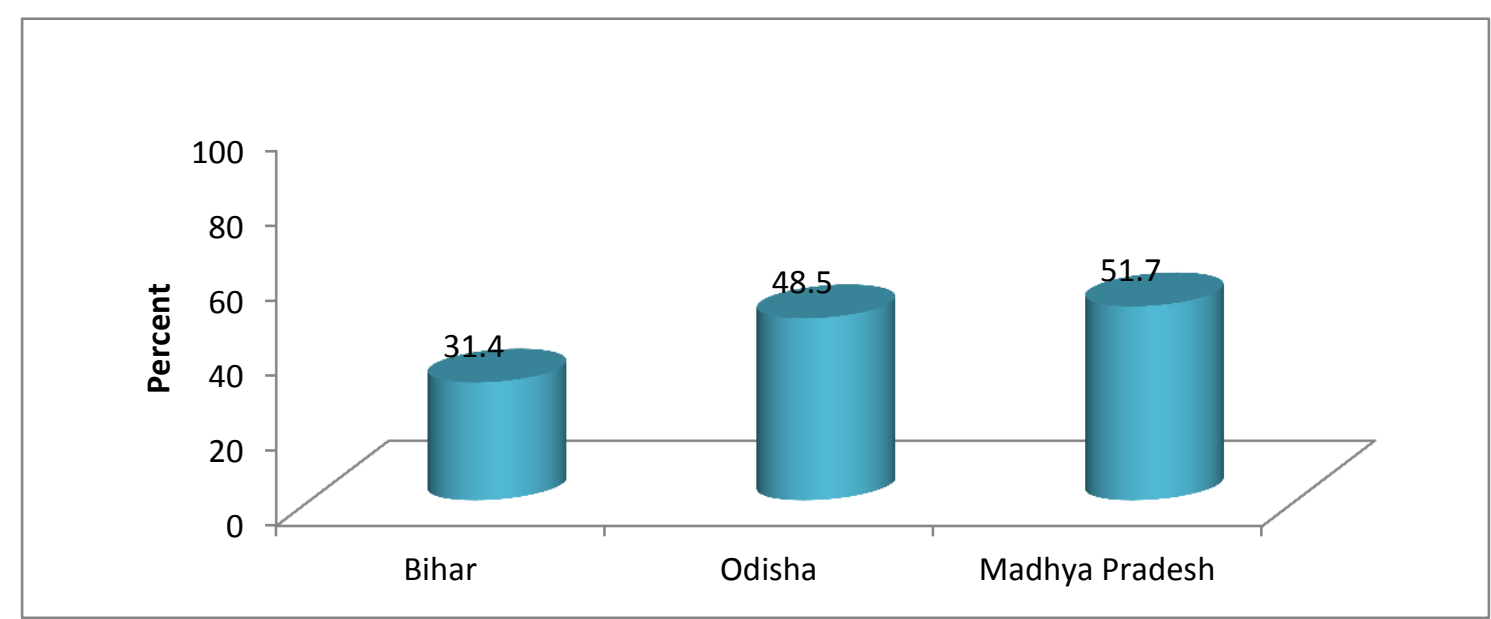

Source: DLHS, 2007-08

Percentage of currently married young women who ever used any reversible method of contraception was however only 16 percent in Bihar, 36 percent in Odisha and 24 percent in Madhya Pradesh. If this was restricted to modern methods, the percentage again fall down and the data clearly indicate that a sizable proportion of young women who reported ever use of spacing method was depending on the traditional methods which are the least effective among the available spacing methods.

Table 3.3: Percentage of currently married women age 15-34 years reporting ever use of family planning (reversible) method

\begin{tabular}{|l|l|l|}
\hline State & Ever used any method & Ever used modern method \\
\hline Bihar & 16.6 & 8.8 \\
\hline Odisha & 35.9 & 24.5 \\
\hline Madhya Pradesh & 23.8 & 16.3 \\
\hline
\end{tabular}

Source: DLHS, 2007-08

Table 3.4: Percent distribution of currently married women age 15-34 years who have ever used any method of contraception by age of respondent, 2007-08

\begin{tabular}{|l|l|l|l|}
\hline Age & Bihar & Odisha & Madhya Pradesh \\
\hline $15-19$ & 7.3 & 15.0 & 12.5 \\
\hline $20-24$ & 21.0 & 33.8 & 33.4 \\
\hline $25-29$ & 40.5 & 53.2 & 61.5 \\
\hline $30-34$ & 51.5 & 64.3 & 75.7 \\
\hline
\end{tabular}

Source: DLHS, 2007-08 
Although 50-76 percent of women in the age 30-34 years are reporting ever use of contraception, it is minimal in the 15-19 years age group (Table 3.4). The adolescents (15-19 years age group) have high risk of pregnancy related complications and mortality, but this group has not used any contraceptives to prevent pregnancy.

Table 3.5 shows the current use of contraception among those young currently married women who reported ever use of modern spacing method in the focused states. It was found that more than half of the women are currently using any family planning methods in Bihar and the corresponding figure for Odisha and Madhya Pradesh is more than 70 percent.

Table 3.5: Percentage of currently married women age 15-34 years who reported ever use of modern spacing method by current use of contraception and pregnancy status

\begin{tabular}{|l|l|l|}
\hline State & Currently Pregnant & Currently using contraception \\
\hline Bihar & 11.6 & 57.9 \\
\hline Odisha & 6.7 & 72.2 \\
\hline Madhya Pradesh & 10.5 & 74.9 \\
\hline
\end{tabular}

Source: DLHS, 2007-08

Though about 10 percent of the women in Bihar who had reported ever using FP method was pregnant at the time of the survey; another 58 perecnt were only using a FP method at the time. The situation was better in Madhya Pradesh and Odisha. Clearly, about 15-20 percent currently married young women in Madhya Pradesh and Odisha who ever used any modern spacing method has not been using any method of contraception nor was pregnant at the time of interview and the corresponding figure for Bihar is nearly 30 percent.

Knowledge of emergency contraceptive pills and its use is close to nil. Only 0.1 percent women from Bihar, 0.5 percent from Odisha and 0.4 percent from Madhya Pradesh reports ever using emergency contraceptive method. Condoms are the prominent method of spacing in Madhya Pradesh and Bihar whereas, in Odisha majority of those who reported use of spacing methods depended on pills followed by condoms.

\section{Use of Limiting Methods}

Female sterilization is widely accepted and widely used method in India. Nationally, the share of sterilization in the Contraceptive Prevalence Rae (CPR) (modern methods) decreased from 85 percent in NFHS-1 to 80 percent in NFHS-3(Table 3.6) [5, 25, 26]. Among the focused states, Odisha shows a substantial decline in the share of sterilization in CPR (modern methods) during the last 13 years from 91 percent in 1992-93 to 74 percent in 2005-06. On the other hand Madhya Pradesh shows the lowest decline among the focused states with only 2 percent decline over 13 years and Bihar shows 4 percent decline in the share of sterilization in CPR (Table 3.6). There is a strong preference for sterilization among couples once the desired family size is achieved and also they do not feel it is necessary to use FP method before that. 
Table 3.6: Share of sterilization on contraceptive prevalence rate (modern methods) in three rounds of NFHS

\begin{tabular}{|l|l|l|l|l|l|l|}
\hline \multirow{2}{*}{} & \multicolumn{2}{|l|}{ NFHS-1 (1992-93) } & \multicolumn{2}{l|}{ NFHS-2 (1998-99) } & \multicolumn{2}{l|}{ NFHS-3 (2005-06) } \\
\cline { 2 - 7 } & Sterilization & Spacing & Sterilization & Spacing & Sterilization & Spacing \\
\hline Bihar & 86 & 14 & 90 & 10 & 82 & 18 \\
\hline Odisha & 91 & 9 & 88 & 12 & 74 & 26 \\
\hline Madhya Pradesh & 88 & 11 & 89 & 11 & 86 & 14 \\
\hline India & 85 & 15 & 84 & 16 & 80 & 20 \\
\hline
\end{tabular}

Source: NFHS-1, NFHS-2 and NFHS-3 data

\section{Current use of Contraception}

In India, Women are encouraged to marry early and complete childbearing soon thereafter. Typically, women are sterilized once they have achieved their desired family size. Thus, sterilization tends to occur relatively early, and age at sterilization is declining significantly in some states. According to the latest DHS data median age of sterilization in India is 25.3 years compared to 26.7 years in 1992-93 [25]. Among the focused states, in Bihar the median age of sterilization is 27.4 years, Odisha it is 26.1 years and Madhya Pradesh it is 26.4 years. Considering the median age of sterilization an analysis was carried out among young women (15-34 years) on their contraceptive behavior.

Table 3.7: Percentage of currently married women 15-49 years reporting current use of contraception

\begin{tabular}{|l|l|l|l|}
\hline State & Any method & Any Modern method & Female Sterilisation \\
\hline Bihar & & & \\
NFHS, 2005-06 & 50.6 & 41.3 & 31.2 \\
DLHS, 2007-08 & 33.3 & 29.4 & 26.1 \\
AHS, 2010-11 & 37.6 & 33.9 & 29.4 \\
\hline Odisha & & & \\
NFHS, 2005-06 & 59.4 & 50.1 & 30.3 \\
DLHS, 2007-08 & 48.2 & 39.6 & 27.9 \\
AHS, 2010-11 & 56.2 & 44.0 & 30.1 \\
\hline Madhya Pradesh & & & \\
NFHS, 2005-06 & 61.1 & 56.3 & 36.8 \\
DLHS, 2007-08 & 57.8 & 54.8 & 47.1 \\
AHS, 2010-11 & 61.2 & 57.0 & 47.6 \\
\hline
\end{tabular}

Source: NFHS 2005-06, DLHS 2007-08, AHS 2010-11 [27-35]

In the recent years, the use of traditional methods has declined and so can not be attributed to contraceptive failure and subsequent unwanted pregnancies from the use of traditional methods. There are only few women who are depending on traditional methods. However, majority reporting use of a modern contraceptive method is reporting female sterilization as their current contraceptive method. The low adoption of a spacing method is thus a great cause of unwanted pregnancies. Only in Odisha, there is comparable percentage difference between the women using modern method and using female sterilization.

Current use of contraception among the young women in the focused states indicate that majority of the women are not using any family planning method and it varies from 82 percent of women in the age group 15- 
34 in Bihar to 70 percent in Madhya Pradesh (not shown in Table). A sizable proportion of young women currently using contraception has reported a limiting method as their current method. About 19 percent young women in Madhya Pradesh have reported use of contraceptive method for limiting births. Among the focused states, young women in Odisha reported comparatively higher use of spacing methods followed by Madhya Pradesh and Bihar. NFHS-3 data indicate that among the currently married women in the age group of 15-19, only 4 percent in Bihar 12 percent in Odisha and 6 percent in Madhya Pradesh are currently using any family panning method.

Table 3.8: Percentage of currently married women 15-34 years reported 'currently using family planning' by type of method, 2007-08

\begin{tabular}{|l|l|l|l|l|}
\hline State & Age group & $\begin{array}{l}\text { Spacing-Modern } \\
\text { method }\end{array}$ & Traditional method & Limiting method \\
\hline \multirow{4}{*}{ Bihar } & $15-19$ & 45.5 & 50.7 & 3.7 \\
\cline { 2 - 5 } & $20-24$ & 28.8 & 19.1 & 52.1 \\
\cline { 2 - 5 } & $25-29$ & 19.4 & 18.9 & 61.7 \\
\cline { 2 - 5 } & $30-34$ & 14.4 & 31.1 & 54.6 \\
\hline \multirow{5}{*}{ Odisha } & $15-19$ & 51.9 & 48.1 & 0 \\
\cline { 2 - 5 } & $20-24$ & 57.3 & 20.1 & 22.6 \\
\cline { 2 - 5 } & $25-29$ & 43.8 & 18.1 & 38.1 \\
\cline { 2 - 5 } & $30-34$ & 39.5 & 23.1 & 37.4 \\
\hline \multirow{5}{*}{ Madhya Pradesh } & $15-19$ & 58 & 28 & 14 \\
\cline { 2 - 5 } & $20-24$ & 34.7 & 7.8 & 61.8 \\
\cline { 2 - 5 } & $25-29$ & 25.8 & 5 & 79.2 \\
\cline { 2 - 5 } & $30-34$ & 15.9 & & \\
\hline
\end{tabular}

Source: DLHS, 2007-08

Table 3.8 indicates that the contraceptive use among the women who are more than 30 years is much higher than those who are less than 25 years in Odisha and Madhya Pradesh. It may be due to the fact that by the age of 30-35years, majority of the women might have achieved their desired family size and have opted for a limiting method. Studies indicate that the use of contraceptive methods varies by the age of women [36, 37]. Married adolescents are less likely to use any kind of contraception than adult women. Analysis of type of family planning method used among current users by age group found that nearly half of the women in 20-24 age group reported current use of contraception as a limiting method in Bihar and Madhya Pradesh, whereas in Odisha the corresponding figure is only 22 percent. It is important to note that in Madhya Pradesh nearly 14 percent of the current users in the age group15-19 years also reported they are using a limiting method. 
Table 3.9: Current use of contraceptive methods of women $15-34$ years by selected background characteristics, 2007-08

\begin{tabular}{|l|l|l|l|l|l|l|l|l|l|}
\hline \multirow{2}{*}{$\begin{array}{l}\text { Background } \\
\text { Characteristics }\end{array}$} & \multicolumn{3}{|l|}{ Any Method } & \multicolumn{3}{l|}{ Any Modern method } & \multicolumn{3}{l|}{ Any Modern Spacing Method } \\
\cline { 2 - 11 } & Bihar & Odisha & $\begin{array}{l}\text { Madhya } \\
\text { Pradesh }\end{array}$ & Bihar & Odisha & $\begin{array}{l}\text { Madhya } \\
\text { Pradesh }\end{array}$ & Bihar & Odisha & $\begin{array}{l}\text { Madhya } \\
\text { Pradesh }\end{array}$ \\
\hline Education & & & & & & & & & \\
\hline Non Literate & 20.9 & 30.3 & 46.1 & 18.4 & 25.0 & 43.7 & 1.2 & 5.7 & 3.4 \\
\hline Primary Education & 25.4 & 40.3 & 48.2 & 20.9 & 31.4 & 45.6 & 2.9 & 10.8 & 5.3 \\
\hline Middle+ & 32.9 & 45.0 & 44.0 & 27.8 & 32.8 & 40.0 & 7.6 & 19.7 & 14.0 \\
\hline Wealth & & & & & & & & & \\
\hline Low & 20.6 & 30.9 & 41.3 & 17.8 & 24.2 & 38.9 & 1.5 & 7.0 & 2.8 \\
\hline Medium & 27.8 & 45.4 & 46.3 & 24.1 & 35.7 & 43.5 & 3.5 & 16.6 & 6.6 \\
\hline High & 40.6 & 54.0 & 52.0 & 34.5 & 39.5 & 47.5 & 10.9 & 26.4 & 18.9 \\
\hline Residence & & & & & & & & & \\
\hline Urban & 38.6 & 53.7 & 50.1 & 32.7 & 40.5 & 45.6 & 10.1 & 23.2 & 19.9 \\
\hline Rural & 23.7 & 36.2 & 44.1 & 20.4 & 27.9 & 41.3 & 2.7 & 11.4 & 5.0 \\
\hline Total & 24.8 & 38.3 & 45.3 & 21.4 & 29.4 & 42.2 & 3.2 & 12.8 & 8.1 \\
\hline
\end{tabular}

Source: DLHS, 2007-08

Although 21 percent illiterate women in Bihar reported using a contraceptive method currently, only 1.2 percent were using a modern spacing method. The situation is better in the other two focused states with 30 percent and 46 percent illiterate women from Odisha and Madhya Pradesh respectively reporting current use of FP and 6 percent and 3 percent respectively reporting use of modern spacing methods. Higher the education higher the chances of reporting current FP use and use of spacing method (Table 3.9). Similarly women in the higher wealth quartile and women from urban areas reported higher FP use as well as spacing method use.

Figure 3.2: Husband/Partner's knowledge of woman's (15-34 years) use of family planning

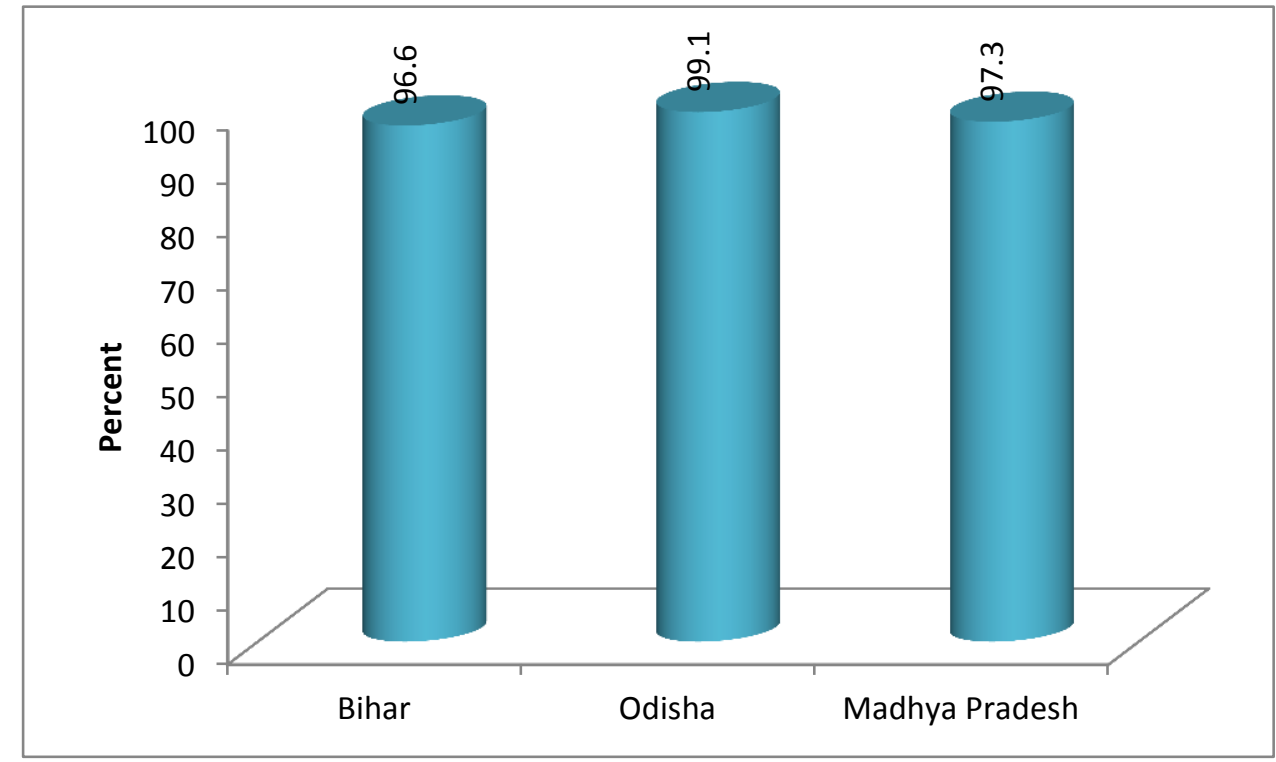

Source: DLHS, 2007-08 
Above 90 percent women said that their husbands are aware of their FP use, which was 99 percent in Odisha (Figure 3.2). Figure 3.3 gives a method wise break-up of the methods that the women are currently using.

Figure 3.3: The contraceptive method used, 2007-08

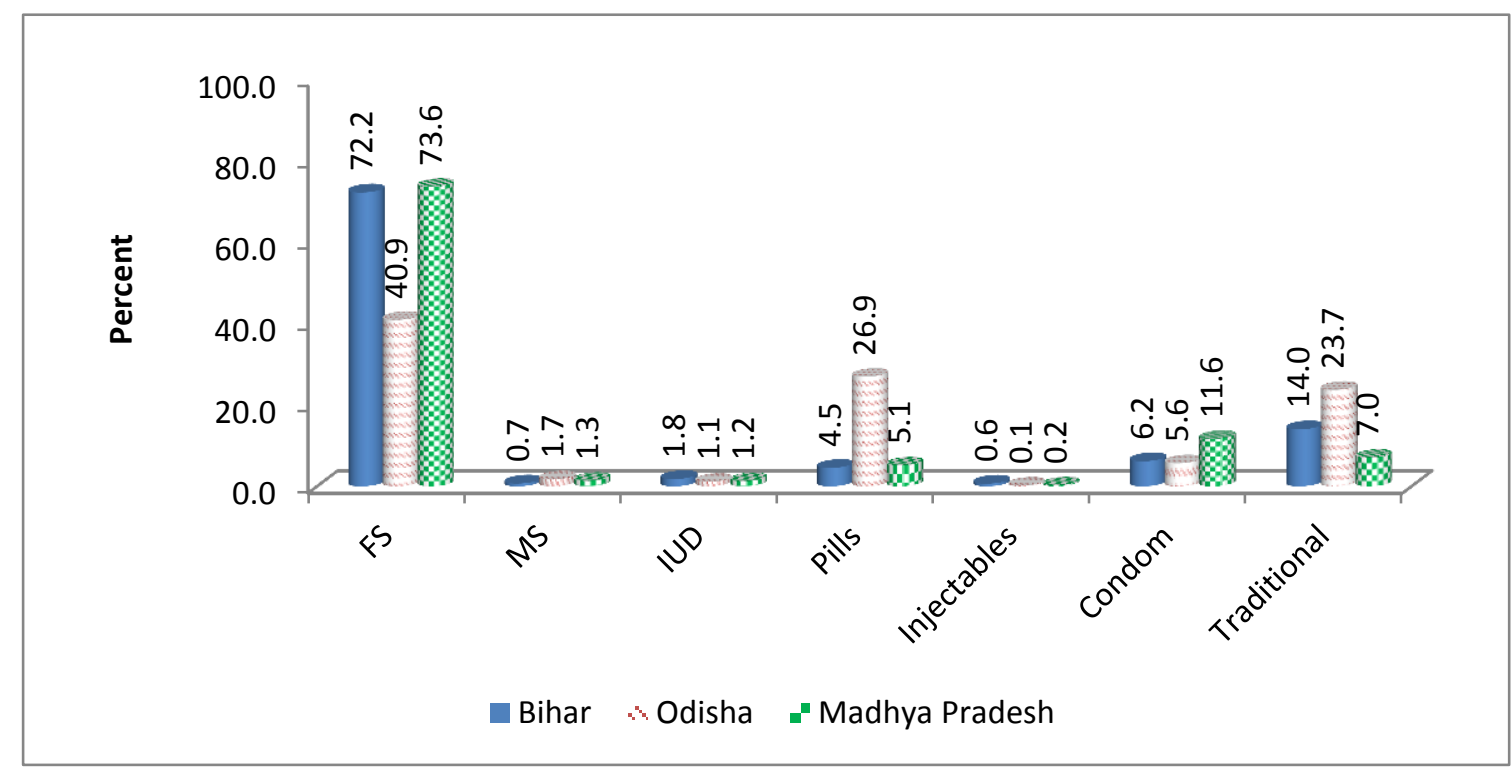

Source: DLHS, 2007-08

An attempt was made to see if women with higher involvement in decisions and who did not justify wife beating were more probable to use contraceptive method, modern contraceptive method and contraceptive method for spacing. No significant pattern was visible in the three focused states. Women in Bihar who did not justify wife beating had a higher probability of using modern contraceptive method than the others.

Table 3.10: Current use of contraception by women's (15-34 years) empowerment status

\begin{tabular}{|l|c|c|c|c|c|c|c|c|c|c|c|c|c|c|c|}
\hline & \multicolumn{3}{|c|}{ Bihar } & \multicolumn{4}{c|}{ Odisha } & \multicolumn{3}{c|}{ Madhya Pradesh } \\
\cline { 2 - 7 } & & & & MSM & & & & & MSM & & & & & MSM & \\
$\begin{array}{l}\text { Empower } \\
\text { ment } \\
\text { Indicators }\end{array}$ & AM & MM & FS & (F) & TM & AM & MM & FS & (F) & TM & AM & MM & FS & (F) & TM \\
\hline
\end{tabular}

Number of Decisions in Which women Participate

\begin{tabular}{|l|l|l|l|l|l|l|l|l|l|l|l|l|l|l|l|}
\hline 0 & 14.5 & 10.4 & 7.0 & 1.2 & 4.1 & 21.5 & 15.8 & 5.4 & 5.1 & 5.7 & 21.8 & 18.8 & 14.1 & 1.2 & 3.0 \\
\hline $1-2$ & 18.0 & 13.3 & 9.2 & 2.7 & 4.7 & 27.8 & 21.3 & 9.1 & 8.3 & 6.4 & 33.0 & 29.7 & 19.9 & 2.6 & 3.4 \\
\hline $3-4$ & 21.6 & 18.8 & 14.0 & 2.6 & 2.8 & 32.3 & 25.6 & 9.5 & 11.3 & 6.7 & 34.2 & 32.0 & 21.8 & 3.3 & 2.2 \\
\hline 5 & 15.7 & 11.1 & 6.5 & 0.8 & 4.6 & 30.2 & 24.8 & 9.2 & 11.2 & 5.4 & 30.5 & 27.9 & 18.8 & 3.3 & 2.6 \\
\hline
\end{tabular}

Number of Reasons for Which Wife Beating is Justified

\begin{tabular}{|l|l|l|l|l|l|l|l|l|l|l|l|l|l|l|l|}
\hline 0 & 19.2 & 15.4 & 9.6 & 2.2 & 3.8 & 30.5 & 24.2 & 9.9 & 8.5 & 6.3 & 31.6 & 28.9 & 17.3 & 3.6 & 2.7 \\
\hline $1-2$ & 17.0 & 12.5 & 10.0 & 1.1 & 4.5 & 32.9 & 26.5 & 10.0 & 12.6 & 6.4 & 30.0 & 27.6 & 22.7 & 1.5 & 2.3 \\
\hline $3-4$ & 13.1 & 9.1 & 5.1 & 2.9 & 4.0 & 20.4 & 15.1 & 3.6 & 7.8 & 5.3 & 26.3 & 21.0 & 18.7 & 0.8 & 5.2 \\
\hline 5 & 13.2 & 10.7 & 10.0 & 0.7 & 2.5 & 25.5 & 20.1 & 8.7 & 8.7 & 5.4 & 21.9 & 20.3 & 17.2 & 0.0 & 1.6 \\
\hline
\end{tabular}

AM-Any Method, MM-Modern Method, FS-Female Sterilization, MSM (F)- Modern Spacing Method(Female), TMTraditional Method 
Figure 3.4: Percent distribution of women aged 15-34 years by number of children at the time of first use of contraception, 2005-06

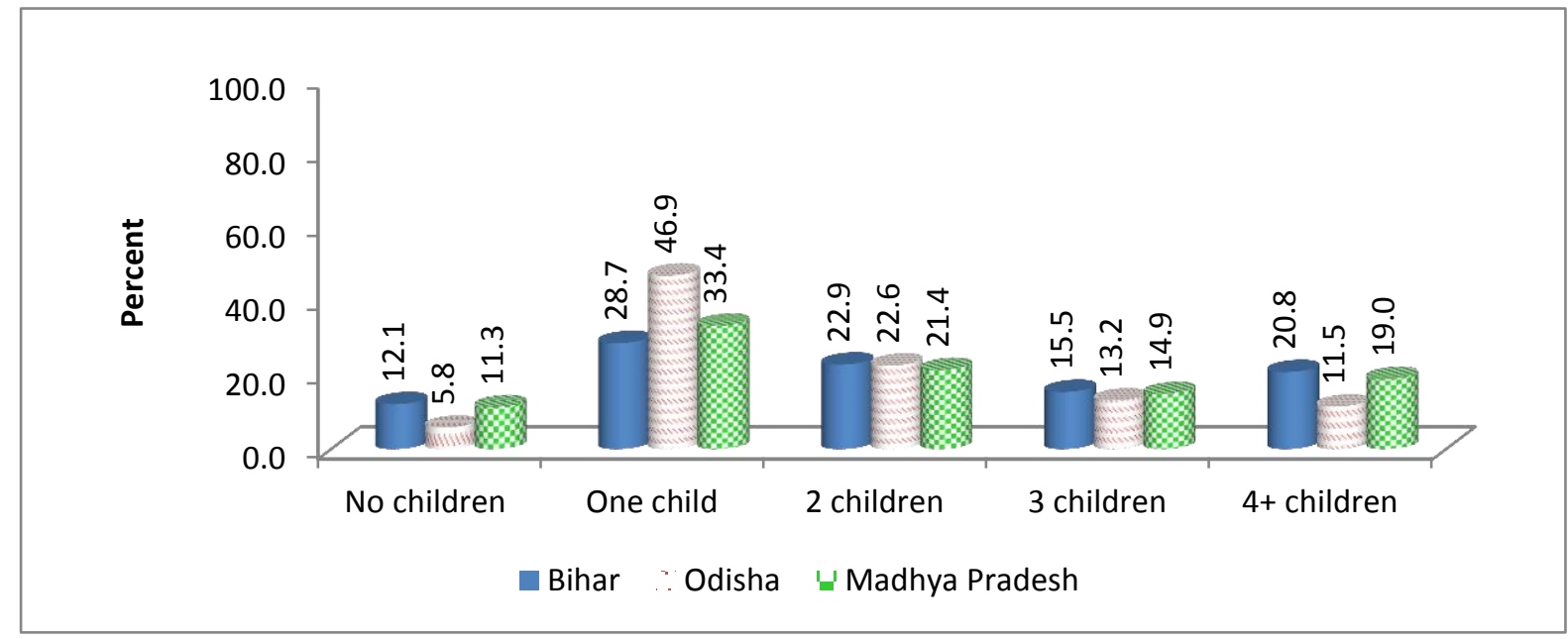

Source: NFHS, 2005-06

A small percentage in all the three focused states had used a contraceptive method before their first child, the lowest being in Odisha (5.8\%). However, Odisha reported the highest use of FP after the first child (46.9\%) which was only 28.7 percent in Bihar and 33.4 percent in Madhya Pradesh. The percentages who started FP use after their $2^{\text {nd }}$ or $3^{\text {rd }}$ child were comparable in the three states.

\section{Sources of contraceptives}

Figure 3.5: Source of current contraceptive method of women age 15-34 years, 2005-06

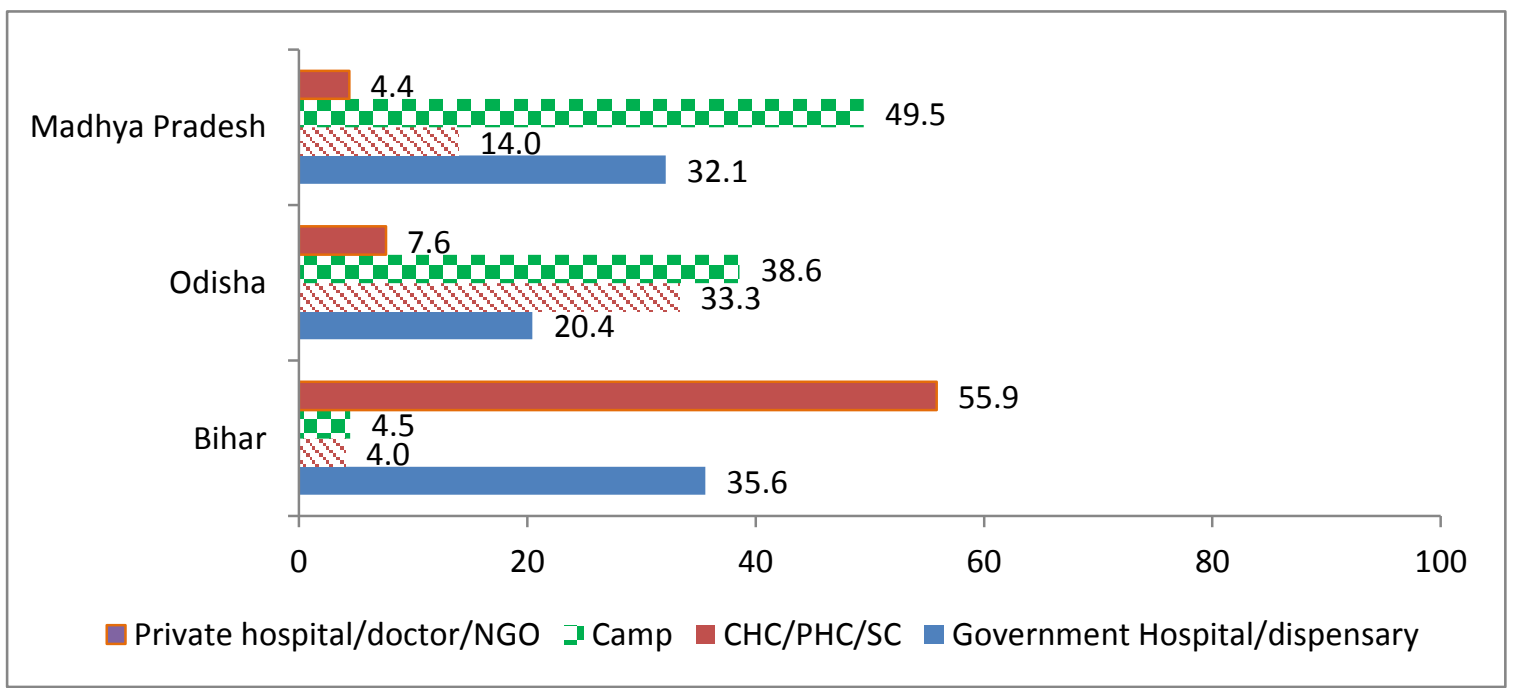

Source: NFHS, 2005-06

Source of the current contraceptive method, 2005-06 as reported by currently married young women is given in Figure 3.5. Camps seem to be popular source in Odisha and Madhya Pradesh; 38.6 percent and 49.5 percent women respectively reporting the same. In Bihar, the main source of contraceptives is the private sector followed by government hospital. Only very few women are receiving contraceptives from government services at the village level. In Odisha, village level government health facilities come next to camps and private facilities are hardly used (7.6\%). Although in Madhya Pradesh too private sector is not the popular 
source of contraceptives, village level services were accessed by only 14 percent whereas 32 percent had received current contraceptive from government hospital.

\section{Contraceptive Discontinuation Rate}

A major concern for family planning program is the discontinuation of contraceptive methods, either voluntarily or due to method failure. Unwanted pregnancies not only occur as a result of the failure to use contraceptives, they can also occur during periods when women engage in contraceptive switching. In countries with moderate to high contraceptive prevalence, the majority of unintended pregnancies are the result of contraceptive discontinuation or failure [39].

Table 3.11: Percentage of contraceptive users who discontinued use of a method within 12 months of beginning use, 2005-06

\begin{tabular}{|l|l|l|l|l|}
\hline & Any spacing method & Oral contraceptive pill & Condom & Rhythm method \\
\hline Bihar & 44.1 & 68.0 & 53.7 & 23.9 \\
\hline Odisha & 39.3 & 42.4 & 50.0 & - \\
\hline Madhya Pradesh & 48.7 & 48.8 & 49.3 & 51.5 \\
\hline India & 38.7 & 49.2 & 44.8 & 32.2 \\
\hline
\end{tabular}

Source: NFHS-3, 2005-06

NFHS-3 captures the information on contraceptive discontinuation rate by type of method among currently married women (15-49 years) [5]. At the national level, more than one third of the reversible contraceptive users discontinue the use of that method within 12 months of adoption in 2005-06. Nearly 44 percent of the contraceptive users (spacing) in Bihar, 39.3 percent in Odisha and 48 percent contraceptive users in Madhya Pradesh discontinue the method within one year.

Discontinuation rates are highest for injectables ( 53 percent), followed by pills (49 percent) and male condoms (45 percent). The one-year discontinuation rates for two traditional methods, rhythm (32 percent) and withdrawal (35 percent), are somewhat lower, but still substantial. Existing studies also reported higher discontinuation rate of injectables globally as well as in Indian context [39-42]. The United Nations report on levels and trends of contraceptive use suggests that 34 percent of oral contraceptive users compared to 46 percent of injectable contraceptive users had discontinued the method during the first 12 months of use [43].

Table 3.12: Percentage of currently married women age 15-34 years who reported ever use of any modern method and reason for discontinuing last method, 2005-06

\begin{tabular}{|l|l|l|l|}
\hline Reasons for discontinuing last method & Bihar & Odisha & Madhya Pradesh \\
\hline Want a child & 50.6 & 43.5 & 74.1 \\
\hline Method failure and become pregnant & 6.9 & 6.6 & 4.3 \\
\hline Method related problems & 14.1 & 30.1 & 10.3 \\
\hline Objection from Husband/Family & 1.6 & 1.4 & 1.4 \\
\hline Infrequent sex/Husband away & 21.8 & 14.1 & 6.4 \\
\hline Other & 5.0 & 4.2 & 3.4 \\
\hline
\end{tabular}

Source: NFHS, 2005-06 
The decision to continue or discontinue use of a contraceptive depends on a number of factors (Table 3.12). The analysis of NFHS 2005-06 data shows that nearly 50 percent of the women from Bihar, 43.5 percent women from Odisha and 74 percent in Madhya Pradesh mentioned wanting another child as the reason for discontinuation. However, nearly 30 percent of the women in Odisha and nearly 10-14 percent women in Bihar and Madhya Pradesh reported method related problems like side effects and health concern.

Management of the reasons for contraceptive discontinuation through proper counseling and follow-up of FP acceptors can help improve this situation. For example, the rate at which women discontinue use of a method due to experiencing side effects may indicate that counseling needs improvement and that information about the method needs to be communicated more effectively [16, 41-46].

Large proportion of women who discontinue one method of contraception, switch to another less effective method and some women abandon contraceptive use [40-43]. The rate of switching to no method is of particular concern because these women are at highest risk of unwanted pregnancy. Moreau et al. have found that among women who experienced an unwanted pregnancy leading to an abortion, half had discontinued their contraceptive methods due to a method-related reason in the six months preceding the abortion [47].

\section{Intention to use contraceptive methods}

Many of the non-users of contraceptive methods mentioned intention to use a method in the future as can be seen from Figure 3.6.

Figure 3.6: Percentage distribution of currently married women's (15-34 years) intention to use contraception in future, 2007-08

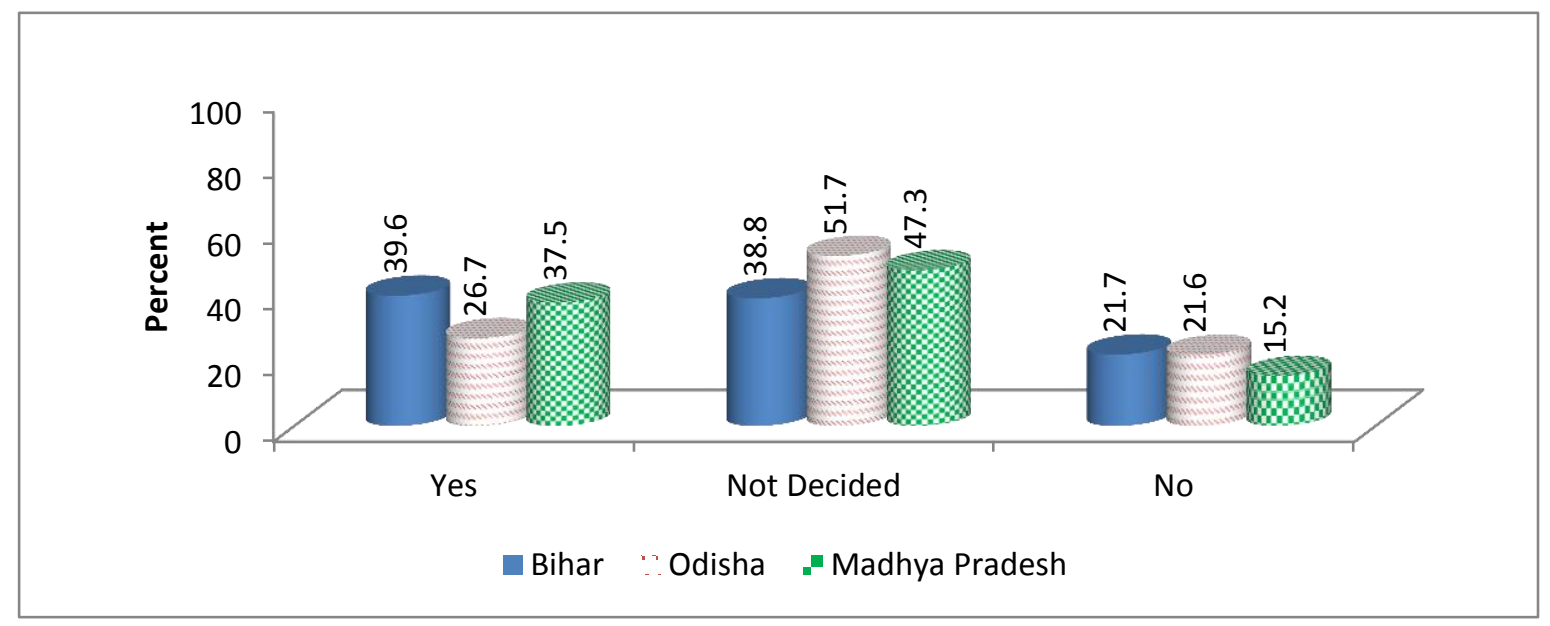

Substantial proportion of non-users falls in the undecided category in the three focused states. About 15-22 percent has no intention to use a family planning method. Percentage of non-user having future intention to use a method is substantially low in Odisha compared to the other two states; a little more than a quarter reports future intention to use. However, the undecided group is highest in this state.

\section{Fertility levels, trends and differentials}

Fertility among young people accounts for more than half of India's total fertility [39-41]. 39 percent of women aged 15-24 years either have a child or are currently pregnant. Fewer than one in five young women were currently practicing contraception in Bihar and Odisha (7). Young women who had married at age 18 or older were more likely than those who had married before age 18 to have used contraceptives to delay their first pregnancy and to have had their first birth in a health facility and less likely to have had a miscarriage or stillbirth $[49,50]$. 
Figure 3.7: Trends in Total fertility rates

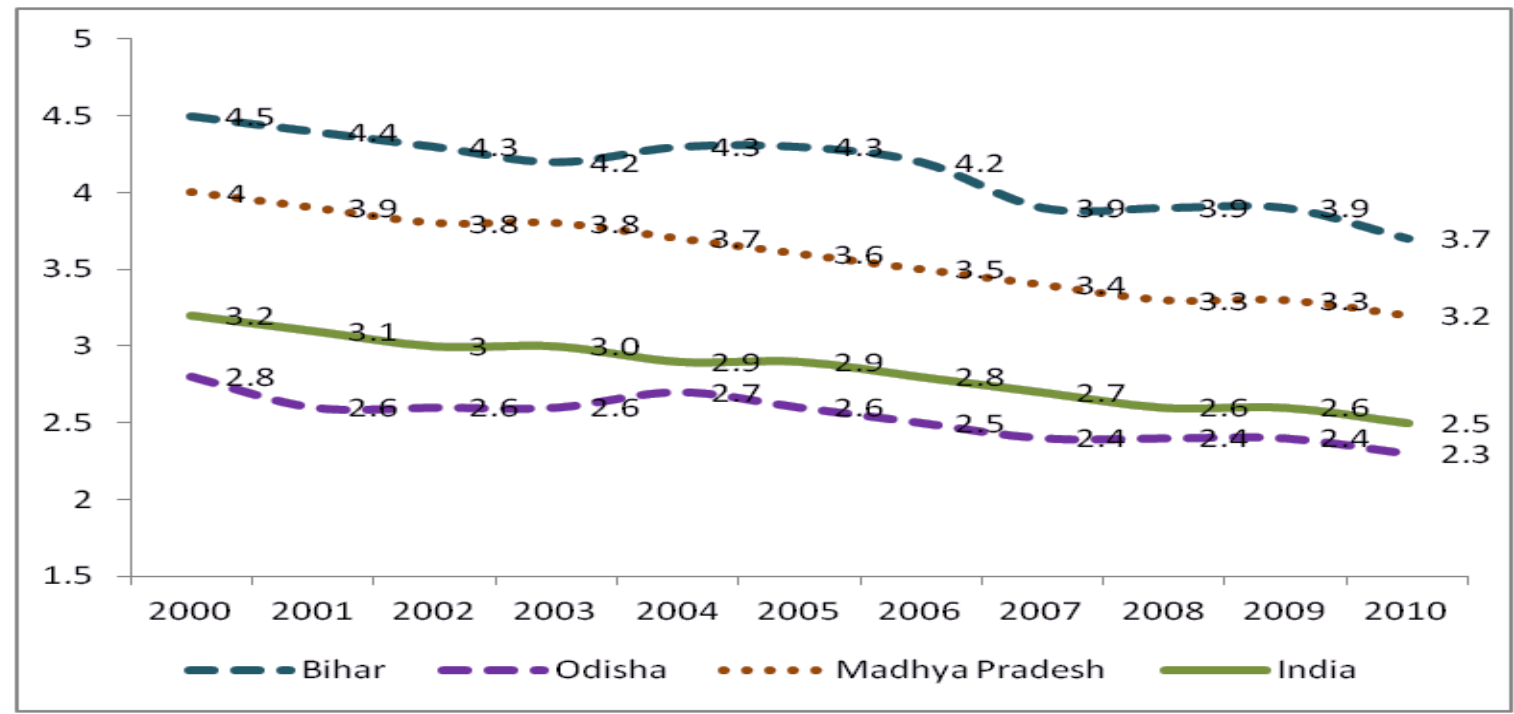

Source: SRS reports for the years 2000 to 2010

Figures 3.7 illustrate the trends in TFR in the selected states in comparison with all India figures for the last decade. It was observed that during the last decade, TFR shows a declining trend in the focused states as well as national level. The TFR in Bihar has reduced from 4.5 in 2000 to 3.6 births per woman in 2011, in Odisha from 2.8 to 2.2 and in Madhya Pradesh from 4.0 to 3.1 children respectively compared to the national average of 3.2 in 2000 and 2.4 in 2011 [51].

Figure 3.8: Wanted fertility, unwanted fertility and total fertility rates

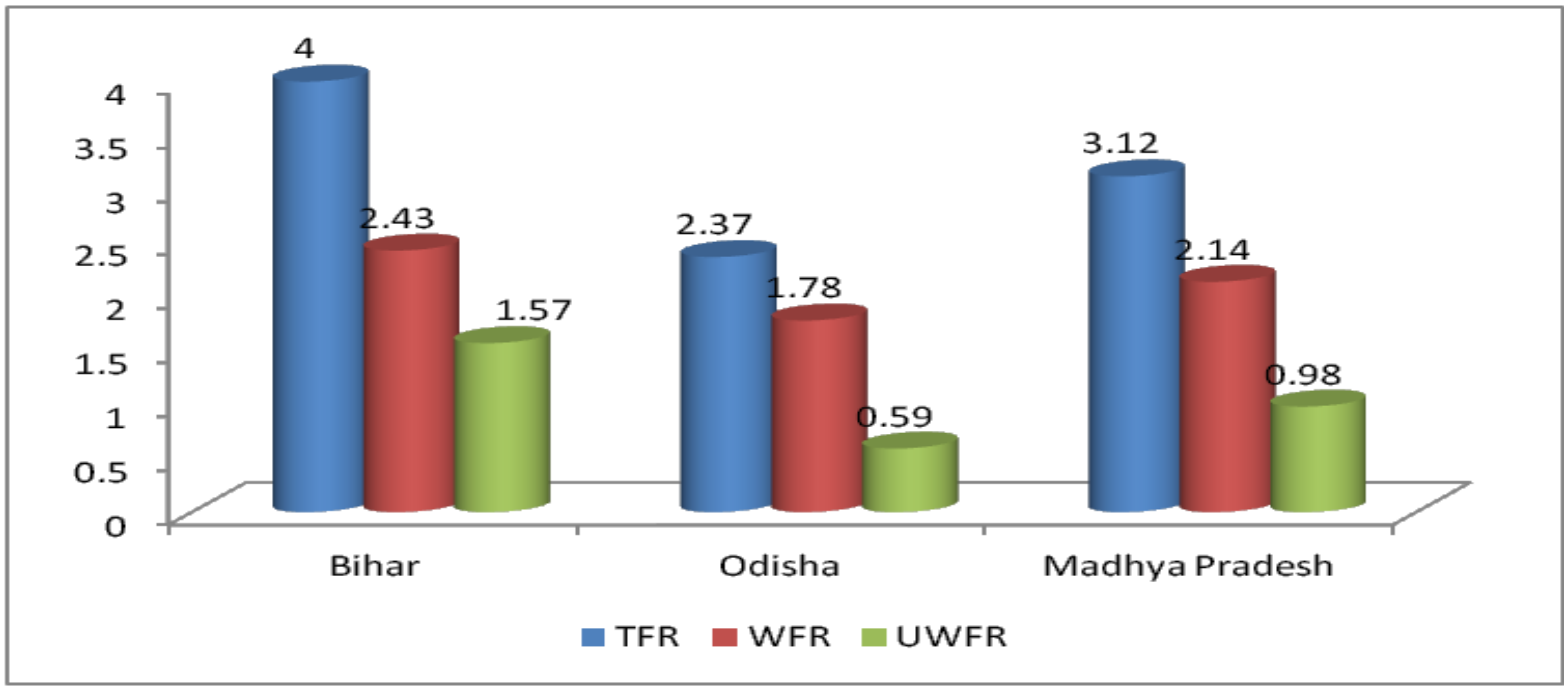

TFR: Total Fertility Rate, WFR: Wanted Fertility Rate, UWFR: Unwanted Fertility Rate

Figure 3.8 shows the wanted and unwanted fertility rates as well as the total fertility rates in the focused states. Unwanted fertility rates were highest in Bihar and lowest in Odisha. Wanted fertility rate too was highest in Bihar and lowest in Odisha. However, wanted fertility rate in Madha Pradesh was not much different from Bihar. Total fertility rate was 4 in Bihar which was only 3.12 in Madhya Pradesh. The total fertility rate in Odisha is close to replacement level fertility at 2.37. Table 3.13 shows substantial decrease in unintended pregnancy in Odisha: from 40.8 percent in 1992-93 to 22 percent in 19998-99 and to 18percent in 2005-06. 
The reported unintended pregnancy was mostly unchanged in Madhya Pradesh. Bihar showed a fluctuation with unintended pregnancy increasing from 27.6 percent in 1992-93 to 29.3 percent in 1998-99 and decreasing to 25 percent in 2005-06.

Table 3.13: Trends in unintended pregnancy, women age 15-34 years

\begin{tabular}{|l|r|r|r|r|r|r|r|r|r|}
\hline & \multicolumn{3}{|c|}{ NFHS-1 (1992-93) } & \multicolumn{3}{c|}{ NFHS-2 (1998-99) } & \multicolumn{3}{c|}{ NFHS-3 (2005-06) } \\
\cline { 2 - 10 } & Unintended & Mistimed & Unwanted & Unintended & Mistimed & Unwanted & Unintended & $\begin{array}{l}\text { Mistime } \\
\text { d }\end{array}$ & $\begin{array}{l}\text { Unwante } \\
\text { d }\end{array}$ \\
\hline Bihar & 27.6 & 17.6 & 10.2 & 29.3 & 12.7 & 16.6 & 25.0 & 12.8 & 12.2 \\
\hline Odisha & 40.8 & 27.5 & 13.3 & 22 & 14.3 & 7.7 & 18.1 & 11.2 & 6.9 \\
\hline $\begin{array}{l}\text { Madhya } \\
\text { Pradesh }\end{array}$ & 22.1 & 14.4 & 7.7 & 22.9 & 12.1 & 10.8 & & 13.8 & 7.4 \\
\hline
\end{tabular}

Source: NFHS-1, NFHS-2 and NFHS-3 data

\section{Last pregnancy/ last child: whether unintended/ mistimed/ unwanted}

Women who want to avoid pregnancy but discontinue contraceptive use without switching to a new method are at risk of unplanned pregnancies and unwanted or mistimed births. NFHS-3 data was used to analyse the level of unintended pregnancies among currently married young women in the focused states. Table 3.14 gives data of women reporting current pregnancy was unintended/ unwanted and Table 3.15 gives data about whether last child was unwanted/ unintended.

Table 3.14: Percentage of women age 15-34 years who reported current pregnancy was unintended

\begin{tabular}{|l|l|l|l|}
\hline State & Unintended & Mistimed & Unwanted \\
\hline Bihar & 25.0 & 12.8 & 12.2 \\
\hline Odisha & 18.1 & 11.2 & 6.9 \\
\hline Madhya Pradesh & 21.2 & 13.8 & 7.4 \\
\hline
\end{tabular}

Source:NFHS, 2005-06

Table 3.15: Percentage of women age15-34years who reported last child was unintended

\begin{tabular}{|l|l|l|l|}
\hline State & Unintended & Mistimed & Unwanted \\
\hline Bihar & 18.1 & 5.2 & 12.9 \\
\hline Odisha & 16.9 & 10.9 & 6.0 \\
\hline Madhya Pradesh & 15.1 & 8.2 & 6.9 \\
\hline
\end{tabular}

Source: NFHS, 2005-06

Nearly one-fourth of the young women from Bihar reported that their current pregnancy was unintended in 2005-06 (Table 3.14). 18 percent and 21 percent women from Odisha and Madhya Pradesh respectively reported that their current pregnancy was unintended. In Odisha and Bihar comparatively higher number of mistimed pregnancies was reported than unwanted pregnancies, where as in Bihar the percentage of mistimed and unwanted pregnancies are almost same. Table 3.15 shows that 18 percent of the women in Bihar, 17 percent women in Odisha and 15 percent women in Madhya Pradesh reported that their last child was unintended and in Bihar majority of the births was unwanted whereas in Odisha it was reported as mistimed. 
Table 3.16: Percentage of women age 15-34 years who reported current pregnancy was unintended by background characteristics, 2005-06

\begin{tabular}{|c|c|c|c|c|c|c|}
\hline \multirow{2}{*}{ Background Characteristics } & \multicolumn{2}{|c|}{ Bihar } & \multicolumn{2}{|c|}{ Odisha } & \multicolumn{2}{|c|}{ Madhya Pradesh } \\
\hline & Mistimed & Unwanted & Mistimed & Unwanted & Mistimed & Unwanted \\
\hline \multicolumn{7}{|l|}{ Age (years) } \\
\hline $15-19$ & 10.8 & 1.5 & 11.2 & 2.8 & 15.0 & 4.9 \\
\hline $20-24$ & 16.8 & 9.3 & 9.1 & 4.1 & 11.4 & 4.0 \\
\hline $25-29$ & 11.8 & 19.1 & 21.1 & 7.0 & 17.6 & 8.8 \\
\hline $30-34$ & 4.8 & 35.1 & 0 & 28.7 & 15.9 & 31.0 \\
\hline \multicolumn{7}{|l|}{ Place of Residence } \\
\hline Rural & 12.8 & 11.4 & 10.0 & 6.7 & 13.9 & 6.7 \\
\hline Urban & 13.2 & 17.9 & 18.9 & 8.1 & 13.6 & 9.4 \\
\hline \multicolumn{7}{|l|}{ Education } \\
\hline No Education & 12.0 & 11.5 & 6.3 & 7.0 & 12.3 & 9.0 \\
\hline Less than 5 years & 18.2 & 9.1 & 9.1 & 6.1 & 15.5 & 2.2 \\
\hline $5-9$ years & 13.9 & 17.3 & 18.9 & 8.4 & 14.8 & 8.5 \\
\hline 10 or more years & - & - & 9.4 & 0.0 & 21.8 & 0.0 \\
\hline \multicolumn{7}{|l|}{ Religion } \\
\hline Hindu & 11.1 & 12.1 & 11.1 & 6.3 & 13.3 & 7.6 \\
\hline Muslim & 20.3 & 12.8 & 32.8 & 0.0 & 11.2 & 5.5 \\
\hline Others & & & 0 & 50.0 & 81.7 & 0 \\
\hline \multicolumn{7}{|l|}{ Caste/Ethnicity } \\
\hline SC & 7.3 & 16.0 & 6.6 & 13.4 & 6.6 & 13.4 \\
\hline ST & - & - & 8.9 & 6.9 & 8.9 & 6.9 \\
\hline $\mathrm{OBC}$ & 12.8 & 12.3 & 11.7 & 5.0 & 11.7 & 5.0 \\
\hline Other & 19.4 & 9.0 & 15.6 & 3.1 & 15.6 & 3.1 \\
\hline \multicolumn{7}{|l|}{ Wealth Index } \\
\hline Lowest & 10.0 & 7.4 & 4.8 & 7.9 & 15.4 & 7.7 \\
\hline Low & 15.8 & 16.5 & 9.3 & 0 & 14.2 & 7.1 \\
\hline Middle & 10.1 & 15.5 & 15.6 & 7.9 & 5.4 & 2.6 \\
\hline High & 13.5 & 8.2 & 20.0 & 6.6 & 18.0 & 9.9 \\
\hline Highest & 13.2 & 11.1 & 21.8 & 8.8 & 14.7 & 13.2 \\
\hline
\end{tabular}


Table 3.17: Percentage of women age 15-34 years who reported last child was unintended by background characteristics, 2005-06

\begin{tabular}{|c|c|c|c|c|c|c|}
\hline \multirow{2}{*}{$\begin{array}{l}\text { Background } \\
\text { Characteristics }\end{array}$} & \multicolumn{2}{|c|}{ Bihar } & \multicolumn{2}{|c|}{ Odisha } & \multicolumn{2}{|c|}{ Madhya Pradesh } \\
\hline & Mistimed & Unwanted & Mistimed & Unwanted & Mistimed & Unwanted \\
\hline \multicolumn{7}{|l|}{ Age (years) } \\
\hline $15-19$ & 4.8 & 3.0 & 10.0 & 0.0 & 8.0 & 0.0 \\
\hline $20-24$ & 7.7 & 8.5 & 13.9 & 2.1 & 9.0 & 3.5 \\
\hline $25-29$ & 4.2 & 17.4 & 10.7 & 7.8 & 9.0 & 8.0 \\
\hline $30-34$ & 1.0 & 24.4 & 4.3 & 15.8 & 4.2 & 18.0 \\
\hline \multicolumn{7}{|c|}{ Place of Residence } \\
\hline Rural & 5.2 & 12.3 & 10.8 & 5.8 & 7.7 & 7.0 \\
\hline Urban & 7.8 & 17.5 & 11.6 & 7.1 & 9.9 & 6.5 \\
\hline \multicolumn{7}{|l|}{ Education } \\
\hline No Education & 3.3 & 14.4 & 8.1 & 6.8 & 5.8 & 7.9 \\
\hline Less than 5 years & 9.3 & 13.3 & 11.0 & 8.0 & 5.6 & 7.6 \\
\hline $5-9$ years & 9.3 & 7.8 & 14.4 & 4.6 & 13.4 & 4.7 \\
\hline 10 or more years & 6.0 & 8.7 & 11.2 & 0.0 & 20.4 & 3.2 \\
\hline \multicolumn{7}{|l|}{ Religion } \\
\hline Hindu & 4.8 & 12.0 & 11.1 & 5.9 & 8.4 & 6.8 \\
\hline Muslim & 6.7 & 17.2 & 19.7 & 0.0 & 6.2 & 9.1 \\
\hline Others & - & - & 2.2 & 13.6 & 8.4 & 0.0 \\
\hline \multicolumn{7}{|l|}{ Caste/Ethnicity } \\
\hline SC & 4.6 & 8.8 & 11.8 & 5.9 & 11.0 & 6.9 \\
\hline ST & - & - & 8.3 & 8.8 & 4.5 & 10.3 \\
\hline $\mathrm{OBC}$ & 4.5 & 13.6 & 11.6 & 3.6 & 8.9 & 6.9 \\
\hline Other & 8.0 & 13.4 & 12.6 & 6.2 & 8.6 & 2.3 \\
\hline \multicolumn{7}{|l|}{ Wealth Index } \\
\hline Lowest & 2.9 & 15.5 & 8.1 & 8.5 & 5.8 & 8.1 \\
\hline Low & 6.0 & 10.2 & 10.7 & 5.3 & 9.5 & 6.4 \\
\hline Middle & 4.2 & 18.2 & 14.2 & 2.9 & 8.3 & 9.3 \\
\hline High & 5.9 & 9.5 & 15.6 & 4.5 & 6.9 & 4.1 \\
\hline Highest & 13.7 & 6.9 & 12.8 & 3.0 & 17.5 & 2.7 \\
\hline
\end{tabular}

Source: NFHS-3 data

Table 3.16 and 3.17 are bivariate tables with background variables by young women who reported current pregnancy and last child as unwanted/mistimed respectively. Nearly 40 percent women in 30-34 age groups in Bihar, 45 percent women in Madhya Pradesh and 29 percent women in Odisha reported that their current pregnancy was unintended (Table 3.16). Nearly 24 percent women in age group 30-34 years from Bihar reported that their last child was unintended which was 18 percent and 15.8 percent in Madhya Pradesh and Odisha respectively. This age group reported the highest wanted last child in all the focused states. In the case of mistimed pregnancy, only Odisha had many women reporting last child was mistimed. Reporting last child as mistimed by women aged 15-19 years, 20-24 years and 25-29 years were 10 percent, 13.9 percent and 10.7 percent respectively in Odisha. The other states reported lower mistimed last child than Odisha. Bihar tended to report more unwanted than mistimed last child. Comparatively, women from urban than rural areas have reported higher mistimed current pregnancy and last child. With regard to the education the percentage of women reporting the last child was born mistimed is high among women who have more than 5 
years of education whereas, a higher proportion of non-literate women reported their last child was unwanted.

The pattern for current pregnancy and last child was different when wealth index differentials were considered. The women were divided into 5 wealth quartiles. The highest unwanted current pregnancy was reported by women in low wealth quartile in Bihar (16.5\%), highest wealth quartile in Odisha (8.8\%) and Madhya Pradesh $(13.2 \%)$. Among those reporting that current pregnancy was mistimed; highest in Bihar was among low wealth quartile again (15.8\%), highest wealth quartile in Odisha (21.8\%) and among high wealth quartile in Madhya Pradesh (18\%). The highest unwanted last child was reported by the middle wealth quartile in Bihar $(18.2 \%)$, lowest wealth quartile in Odisha (8.5\%) and middle wealth quartile in Madhya Pradesh (9.3\%).

\section{Proximate determinants of fertility}

Age at first intercourse is considered a proximate determinant of fertility because it marks the beginning of the window of possible childbearing. In India, since reported age at first intercourse coincides with the age at marriage, we have looked into age at marriage and age at which they started living with the husband. In many rural settings, girls are married off early but will continue to stay with the parents. Hence, age when they started living with the husband denotes the age at first sexual intercourse.

Table 3.18: Age at first marriage of women 15-34 years, 2007-08

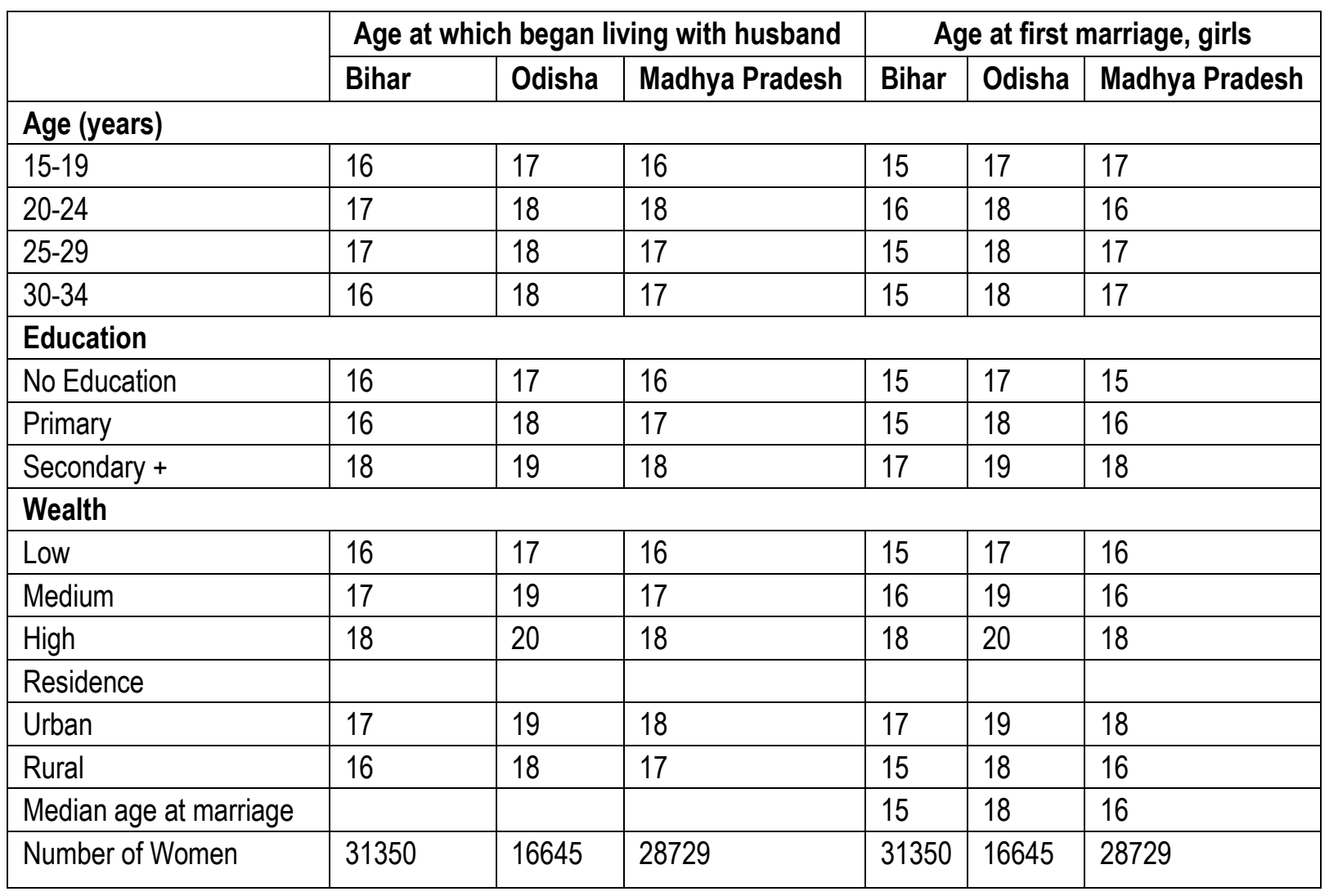

Source: DLHS, 2007-08

The state of Odisha which had reported less unwanted/mistimed pregnancies is also the state which reported median age at marriage at 18 years. The median age at marriage of young women was 15 years for Bihar and 16 years for Madhya Pradesh. Education is not seen to have a major impact on the age at marriage. Those families belonging to the low wealth quartile are more prone to get their daughters married off young 
since it is less expensive than when the girl is older. There are one or two studies which have looked into the economics of early marriage. In their analysis of marriage change in South India in the early 1980s, Caldwell and his colleagues (1983) argued that parents are unwilling to postpone marriage beyond the teenage years because of the increased cost of dowry for older brides [52], an issue that was also seen in Bangladesh [53]. When too few men of marriageable age are available, families compete for the eligible men by paying higher dowries [54]. Available articles from 1990s that the authors reviewed had shown that because of reductions in infant and maternal mortality more women of marriageable age are available. They contend that given the low levels of schooling in India, the increase in educational attainment has not led to a rise in age at marriage, at least not in a mechanical sense [54].

Table 3.19: Age at first birth, women 15-34 years, 2007-08

\begin{tabular}{|l|l|l|l|}
\hline \multirow{2}{*}{ Background characteristics } & \multicolumn{3}{l}{ Median Age at First Birth } \\
\cline { 2 - 4 } & Bihar & Odisha & Madhya Pradesh \\
\hline Education & 18 & 19 & 19 \\
\hline No Education & 18 & 20 & 19 \\
\hline Primary & 19 & 21 & 20 \\
\hline Secondary + & \multicolumn{4}{l}{} \\
\hline Residence & 19 & 20 & 20 \\
\hline Urban & 19 & 20 & 19 \\
\hline Rural & 19 & 20 & 19 \\
\hline Total & \multicolumn{2}{|l|}{} \\
\hline
\end{tabular}

Source: DLHS, 2007-08

Table 3.20: Percentage of women aged 15-19 years who were mothers or pregnant with their first child by selected background characteristics, 2007-08

\begin{tabular}{|l|l|l|l|}
\hline Background Characteristic & Bihar & Odisha & Madhya Pradesh \\
\hline Education & & & \\
\hline No education & 57.4 & 59.1 & 40.9 \\
\hline Primary & 54.5 & 60.2 & 38.9 \\
\hline Secondary + & 53.9 & 67.8 & 49.0 \\
\hline Wealth & & & \\
\hline Low & 56.7 & 60.4 & 41.8 \\
\hline Medium & 54.1 & 62.8 & 40.7 \\
\hline High & 55.9 & 71.6 & 51.2 \\
\hline Residence & & & \\
\hline Urban & 56.7 & 66.3 & 53.8 \\
\hline Rural & 56.1 & 62.9 & 41.8 \\
\hline
\end{tabular}

Source: DLHS, 2007-08

Table 3.19 and 3.20 give break up of different background characteristics of women age 25-34 years and adolescent girls respectively who gave birth to their first child or are currently pregnant. Median age at first birth of women age 25-34 years is not much different across the different background characteristics. However, Bihar with the lowest median age at marriage also had the lowest median age at first birth (Table 3.19). Table 3.20 gives the details of adolescent mothers. There is no significant difference in the adolescent mothers by educational, wealth or residence categories. Belonging to low income quartile was one factor 
contributing to reported higher number of early marriages. So among the adolescent sub-group no noticeable difference was seen in the background characteristics for first birth.

\section{Fertility preferences and desire to limit childbearing}

Some young women have adopted a limiting method after they had the desired number of children. Table 3.21 gives the percentage of women with two or more children who has said that they do not desire more children. The analysis included also women who had adopted female sterilization.

Table 3.21: Percentage of currently married women age 15-34 years with two or more children who do not want any more children (including those sterilized), by selected background characteristics, 2007-08

\begin{tabular}{|l|l|l|l|}
\hline Background Characteristics & Bihar & Odisha & Madhya Pradesh \\
\hline Age & & & \\
\hline $15-24$ & 51.3 & 53.3 & 64.0 \\
\hline $25-34$ & 78.0 & 77.6 & 84.4 \\
\hline Education & & & \\
\hline No Education & 68.4 & 66.3 & 78.1 \\
\hline Primary & 69.7 & 77.5 & 81.8 \\
\hline Secondary+ & 79.0 & 82.0 & 83.2 \\
\hline Wealth & & & \\
\hline Low & 68.6 & 68.3 & 77.2 \\
\hline Medium & 73.7 & 83.5 & 83.2 \\
\hline High & 81.1 & 86.4 & 84.5 \\
\hline Residence & & & \\
\hline Urban & 78.7 & 82.9 & 83.1 \\
\hline Rural & 70.7 & 72.7 & 79.5 \\
\hline Total & 71.3 & 73.9 & 80.2 \\
\hline
\end{tabular}

Source: DLHS, 2007-08

More than half the women age 15-24 years in all the three states expressed that they do not want more children which was over 77 percent among women age 25-34 years. Educational level did not significantly influence the desire for more children. Illiterate as well as those with education equally expressed that they do not want more children. State specific variation was however noticed. While in Madhya Pradesh the percentage of women with two or more children reporting not wanting more children varied between 78-83 percent among educational levels, it was lower in Odisha and lowest in Bihar. In Bihar, about 68 percent of women with no education expressed not wanting more children. The variation in the wealth quartile and educational level were similar. 
Table 3.22: Mean ideal number of children among women (age 15-34 years) by selected background characteristics, 2005-06

\begin{tabular}{|l|l|l|l|}
\hline \multirow{2}{*}{ Background Characteristics } & \multicolumn{3}{|c|}{ Mean Ideal Number of Children } \\
\cline { 2 - 4 } & Bihar & Odisha & Madhya Pradesh \\
\hline Age & & & \\
\hline $15-24$ & 2.6 & 2.3 & 2.3 \\
\hline $25-34$ & 2.9 & 2.4 & 2.6 \\
\hline Education & & & \\
\hline No Education & 2.9 & 2.8 & 2.7 \\
\hline Primary Education & 2.6 & 2.2 & 2.3 \\
\hline Secondary+ & 2.2 & 1.9 & 2.1 \\
\hline Wealth & & & \\
\hline Low & 2.9 & 2.6 & 2.6 \\
\hline Medium & 2.6 & 2.0 & 2.3 \\
\hline High & 2.3 & 1.8 & 2.1 \\
\hline Residence & & & \\
\hline Urban & 2.5 & 2.0 & 2.3 \\
\hline Rural & 2.8 & 2.4 & 2.5 \\
\hline Total & 2.7 & 2.3 & 2.4 \\
\hline
\end{tabular}

Source: NFHS, 2005-06

Although there is variation across states, the mean ideal number of children was lowest among women with secondary or higher education and among the high wealth quartile (Table 3.22). Those with secondary or higher education mentioned mean ideal number of children as 2.2 in Bihar, 1.9 in Odisha and 2.1 in Madhya Pradesh. It was quite similar among the high income quartile. There was no perceptible variation in the other back ground characteristics except for urban residence: Odisha showed 2 children in urban against 2.4 in rural.

Despite the introduction of medical abortion in the country in the year 2002; even in the year 2006 about 90 percent of the estimated abortions were taking place in uncertified settings despite the fact that 7 pharmaceutical companies were producing the drug in the country in 2003 [55]. 
Table 3.22: Mean ideal number of children for women 15-34 years by indicators of women's empowerment, 2005-06

\begin{tabular}{|c|c|c|c|}
\hline & \multicolumn{3}{|c|}{ Mean Ideal Number of Children } \\
\hline Empowerment Indicators & Bihar & Odisha & Madhya Pradesh \\
\hline \multicolumn{4}{|c|}{ Number of Decisions in Which women Participate } \\
\hline 0 & 2.5 & 2.4 & 2.5 \\
\hline $1-2$ & 2.7 & 2.3 & 2.4 \\
\hline $3-4$ & 2.8 & 2.3 & 2.4 \\
\hline 5 & 2.9 & 2.4 & 2.4 \\
\hline \multicolumn{4}{|c|}{ Number of Reasons for Which Wife Beating is Justified } \\
\hline 0 & 2.6 & 2.2 & 2.3 \\
\hline $1-2$ & 2.8 & 2.3 & 2.5 \\
\hline 3-4 & 3.0 & 2.5 & 2.5 \\
\hline 5 & 3.0 & 2.6 & 2.7 \\
\hline Total & 2.7 & 2.3 & 2.4 \\
\hline
\end{tabular}

Source: NFHS, 2005-06

Table 3.22 shows that there is no relationship between the number of children desired and woman's level of participation in household decisions or her level of feeling wife beating is not justified. Thus to increase contraceptive use, imparting correct knowledge is more important than working on women's empowerment. Poverty is a great leveler since it leads to more women with no education and no money to take health seeking seriously. Poverty alleviation programs can thus play a great role in increasing education and women's desire for improving quality of life and thus taking the steps for it. 


\section{CHAPTER 4: TRENDS IN UNMET NEED FOR CONTRACEPTION AND SAFE ABORTION SERVICES}

\section{Introduction}

The concept of "unmet need for contraception", which refers to the proportion of women who do not want to become pregnant but are not using contraception, has been used in the international population field since the 1960s. In 1994 the ICPD international conference held in Cairo recognized reproductive health and family planning as fundamental human right and committed to achieve universal access to family planning services by 2015. During the last two or more decades, unmet need for family planning has been receiving much attention worldwide. In 2006 unmet need for family planning was added as the fifth Millennium Development Goal (MDG) an indicator for tracking progress on improving maternal health [1]. A report from the Guttmacher Institute and the United Nations Population Fund (UNFPA) mentioned that there were 137 million women in the developing world with an unmet need for contraception, and another 64 million with an unmet need for a modern contraceptive method in 2003 [2] . Another analysis found that about 17 percent of the married women in developing countries prefer to avoid a pregnancy but are not using any contraceptive method [3]. A review of existing evidence on the promotion of postpartum contraception found the same intent, throughout the developing world, most women do not want to become pregnant again in the first year or longer after they have given birth [4]. According to a study on worldwide trends in pregnancy; the proportions of pregnancies that are unintended remains high in the developing world [5]. This discrepancy between intent and actual behavior has cost many women's lives and many more with morbidities. Approximately half of the unintended pregnancies ended in induced abortions, only 12 percent in Asia resulted in a birth [6].

Countries vary in the type of support they need to develop, implement, and monitor transformational national family planning strategies. Despite improvements in availability and access to contraceptive services, a considerable proportion of pregnancies in India are unplanned (mistimed or unwanted). There was not much variation observed in the percentage of women reporting unwanted pregnancies between the three rounds of NFHS [7-9]. There are a number of studies conducted in India on unmet need [3, 10-13], yet to get a holistic picture we are dependent on the various rounds of NFHS and District Level Household and Facility Surveys (DLHS) [14] and Annual Health Surveys.

\section{Trends in unmet need for contraception}

The NFHS and DLHS data show a decline in the unmet need for family planning in India. According to NFHS1 the total unmet need for family planning in India was 19.5 percent in 1992-93 which has reduced to 15.8 in 1998-99 (NFHS-2) and further declined to 12.8 during 2005-06 (NFHS-3). Figure 4.1 gives the trend in unmet need for contraception in the three focused states in the three rounds of NFHS. To the trendline we have added the data from DLHS, 2007-08 and AHS, 2010-11. However the DLHS-3 survey conducted during 200708 shows that nearly 14 percent of the women reported unmet need for family planning in India a little higher than the NFHS figure in 2005-06. Even after decades of initiation of family planning programs in India still the family planning (FP) method acceptance in the country is heavily leaning towards limiting methods, especially female sterilization.

Figure 4.1 gives the trend in unmet need for spacing and limiting methods in the focused states-Bihar, Odisha, Madhya Pradesh. While the unmet need for spacing has been steradily incresing in the three states across the survey rounds, there was fluctution in unmet need for limiting methods. All three states showed a spurt in unmet need for limiting in 2007-08, which is now getting reduced. Whether the efforts through NRHM may have increased demand for contraceptive methods are not certain. 
Figure 4.1: Trend in unmet need for spacing and limiting methods in focused states, 1992-2011

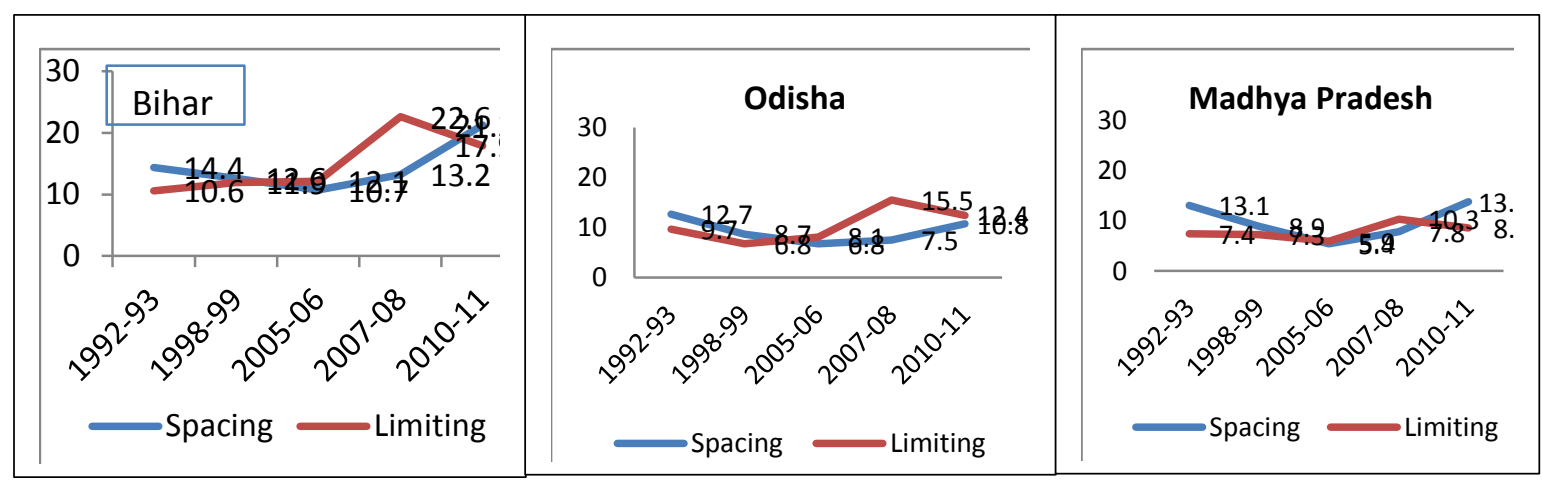

Source: NFHS 1992-93, NFHS 1998-99, NFHS 2005-06, DLHS 2007-08, AHS 2010-11 [7-9, 15-20]

Figure 4.2: Comparison of trend in CPR (modern methods) and unmet need for contraceptive methods in focused states, 1992-2011
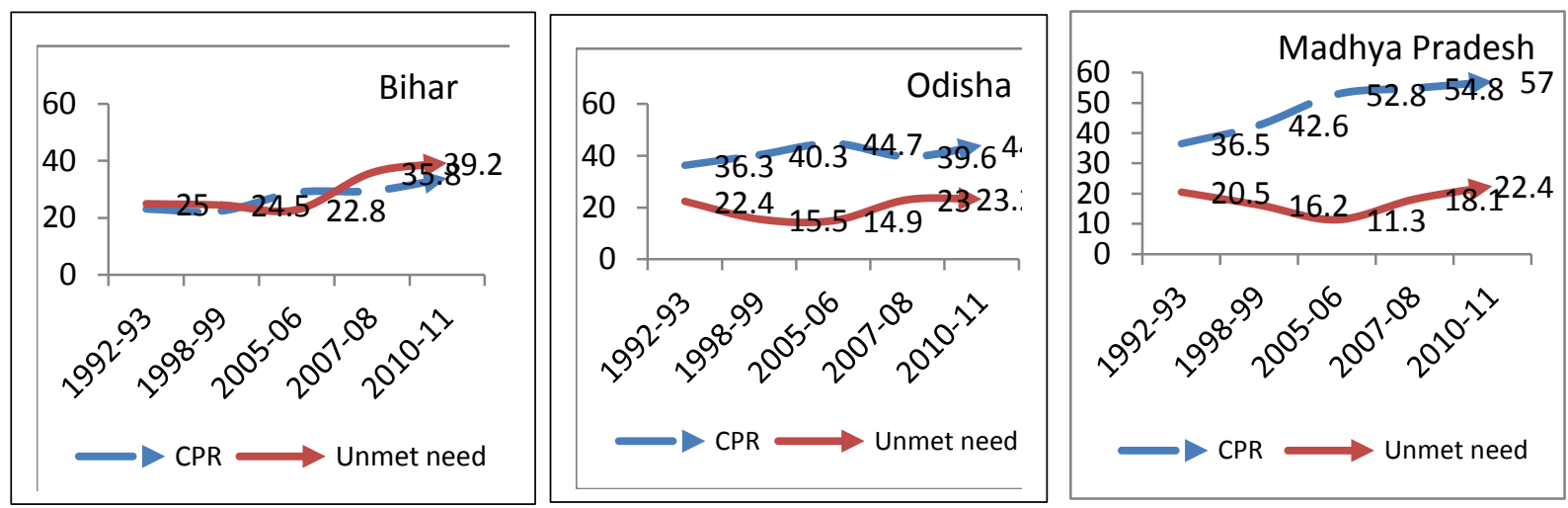

Source: NFHS 1992-93, NFHS 1998-99, NFHS 2005-06, DLHS 2007-08, AHS 2010-11 [7-9, 15-20]

Figure 4.2 indicates that the unmet need for family planning in Bihar remains unchanged in the last two decades with nearly one fourth of the currently married women reporting a need for family planning. In Odisha and Madhya Pradesh the unmet need had slightly decreased over time, with an increase in unmet need in the recent annual health survey. Despite the decline in unmet need for contraception and increase in CPR from round 1 to round 3 of NFHS; after the introduction of NRHM in 2005, there is a higher reporting of unmet need and only in Madhya Pradesh the line did not show any dip in 2007-08 survey for CPR (modern methods). Some authors have argued that unmet need is not an accurate indicator of the demand for family planning or the met need since fertility intentions can change with time [21]. Results from a longitudinal data from Nepal showed that about half the women who had mentioned two children as their ideal family size had continued child bearing after their second child. The findings indicated the impact of the neighbour's family size preferences in influencing their behaviour [22]. In the case of Bihar, CPR and unmet need were alsmost same until 1999, with unmet need and CPR showing a dramatic increase there after. However, in 2005-06, CPR was quite high and unmet need substantially low. In the other two states the CPR trendline is always above the unmet need trendline.

In 2009, expert observers in 81 developing countries completed a questionnaire that assessed 31 features of family planning program effort, as well as other program measures. Similar surveys were fielded in 1999 and 
2004. Results indicate that on average, national family planning programs improved their effort levels slightly from 1999 to 2004, and again from 2004 to 2009. However, the average effort in 2009 was only about half of maximum; component scores for service measures and for measures of access to contraception did not reach 50 percent of maximum in 2009 [23].

An estimation to check the role of safe motherhood programs and declining fertility in reducing maternal deaths showed that the proportion of fifth and higher order deaths in India declined from 19 percent in 1992 93 to 15 percent in 2005-06. The estimation highlighted that 121,000 fewer women died in 2008 in the South Asian countries (India, Pakistan, Bangladesh) because of pregnancy related complications than was the case in 1990 and about 35 percent maternal lives that were saved can be attributed to fertility decline and 65 percent to safe motherhood programs. Given this scenario, while concentrating on safe motherhood programs, it is also important to focus on decreasing unmet need and unwanted pregnancies [24]. Another analysis based on the data of 172 countries shows that the number of maternal deaths would have been 1.8 times higher that of 2008 if there was no contraceptive use. The study also concluded that if we can satisfy the unmet need for contraception; that can prevent 104,000 maternal deaths per year- a reduction of 29 percent [25]. Unmet need for family planning is responsible for 7.4 million disability-adjusted life years [26] and 30 percent of the maternity-related disease burden [27]. By reducing high-risk pregnancies; those unwanted in women above 40 or below 20 years of age, high parity (above 5), short birth intervals [28, 29], family planning [30], it is estimated that the risk of maternal deaths can be reduced to 58 percent.

Table 4.1: Comparison of women age 15-34 years and women age 35-49 yeas reporting unmet need for family planning in focused states, 2007-08

\begin{tabular}{|c|c|c|c|c|c|c|}
\hline $\begin{array}{c}\text { Unmet } \\
\text { need for- }\end{array}$ & \multicolumn{2}{|c|}{ Bihar } & \multicolumn{2}{c|}{ Odisha } & \multicolumn{2}{c|}{ Madhya Pradesh } \\
\hline & $\begin{array}{c}\text { Women, 15-34 } \\
\text { years }\end{array}$ & $\begin{array}{c}\text { Women, 35- } \\
49 \text { years }\end{array}$ & $\begin{array}{c}\text { Women, 15- } \\
34 \text { years }\end{array}$ & $\begin{array}{c}\text { Women, 35- } \\
49 \text { years }\end{array}$ & $\begin{array}{c}\text { Women, 15- } \\
34 \text { years }\end{array}$ & $\begin{array}{c}\text { Women, 35-49 } \\
\text { years }\end{array}$ \\
\hline Spacing & 15.8 & 3.6 & 9.0 & 5.7 & 11.0 & 4.5 \\
\hline Limiting & 16.0 & 12.0 & 10.5 & 7.0 & 8.6 & 3.7 \\
\hline Total & 31.8 & 15.6 & 19.5 & 12.7 & 19.6 & 8.2 \\
\hline
\end{tabular}

Source: DLHS-3, 2007-08

Currently married young women and older women who reported unmet need for family planning shows that older women in Bihar reported the lowest unmet need for spacing among the focused states but the highest unmet need for limiting in this age group. Lowest unmet need was reported by the women in Madhya Pradesh. It is evident from Table 4.1 that the unmet need for limiting was more prevalent than the unmet need for spacing among young women in all the focused states. Current use of contraceptives discussed in last chapter shows that if traditional methods are included to modern contraceptive method, there is substantial increase in current contraceptive use-- Bihar: 33 percent, Odisha: 48 percent, Madhya Pradesh: 58 percent. India is known for its high acceptance of and high unmet need for limiting than spacing. Despite short birth intervals, couples are not feeling the need for using spacing methods [31, 32].

A comparative analysis of population fertility (measured in terms of birth rate) and individual fertility (measured in terms of total marital fertility rate or unweighted average marital fertility rate) in India found that while population fertility is decreasing in India and states; decline in the individual fertility is stalled in the country and increased in many states in the five years following the introduction of the target free or community needs 
assessment approach. This analysis highlighted that the family welfare program could not objectively assess the family planning needs of young couples. Author feels that not meeting the family planning needs of young couples resulted in an increase in their fertility. The trend in the age specific marital fertility rates indicates that the family planning needs of couples 15-19 years of age largely remain unmet [33]. Greatest pitfall in the implementation of the family welfare program is the lack of proper monitoring. In all most all the states, the monitoring format prepared during target approach is still used for monitoring [34].

"The new State of World Population 2012report, entitled By Choice, Not By Chance and published by the United Nations Population Fund on Nov 14, estimates that making voluntary family planning available to everyone in developing countries would reduce costs of health care for women and newborn babies by $\$ 11.3$ billion annually. So, there would be a substantial net saving regarding costs alone. The more pertinent and humane argument is ----women must be allowed to take part in society beyond reproduction. Adolescent girls' lives should not be restricted by early childbirth, lack of education, and poverty. Deaths and disability from childbirth and unsafe abortions should become a scourge of the past [35, pg.1791]."

Disparities in access to FP exist in all regions of the developing countries. Married women aged 15-19 have greater difficulty than older women in meeting their need for contraceptive services [36]. Equity analysis of family planning services is of vital importance because the same women who are least able to protect themselves from an unwanted pregnancy also lack the appropriate resources to deal with such a pregnancy. Research shows that the poorest, the least educated, those living in rural or remote areas, and adolescents encounter greater barriers to accessing skilled birth attendance [36-38] and are more likely to undergo unsafe abortion when they opt to terminate a pregnancy [39]. 
Table 4.2: Percentage of women age 15-34 years from focused states with unmet and met need for family planning, 2007-08

\begin{tabular}{|c|c|c|c|c|c|c|c|c|c|c|c|}
\hline \multirow[t]{2}{*}{ State } & & \multicolumn{2}{|c|}{ Unmet Need ${ }^{*}$} & \multicolumn{3}{|c|}{ Met Need } & \multicolumn{4}{|c|}{ Total Demand for FP } & \multirow[b]{2}{*}{$\%$ DS } \\
\hline & & Spacing & Limiting & Total & Spacing & Limiting & Total & Spacing & Limiting & Total & \\
\hline \multirow[t]{15}{*}{ Bihar } & Age & & & & & & & & & & \\
\hline & $15-24$ & 25.3 & 8.9 & 34.2 & 2.4 & 4.4 & 6.8 & 27.7 & 13.3 & 41 & 16.6 \\
\hline & $25-34$ & 7.1 & 22.4 & 29.5 & 4.0 & 30.5 & 34.5 & 11.1 & 52.9 & 64 & 53.9 \\
\hline & Education & & & & & & & & & & \\
\hline & No Education & 14.8 & 17.8 & 32.6 & 1.2 & 17.1 & 18.3 & 16 & 34.9 & 50.9 & 36.0 \\
\hline & Primary & 16.9 & 13.2 & 30.1 & 2.9 & 18.0 & 20.9 & 19.8 & 31.2 & 51 & 41.0 \\
\hline & Secondary + & 17.4 & 13.1 & 30.5 & 7.6 & 20.2 & 27.8 & 25 & 33.3 & 58.3 & 47.7 \\
\hline & Wealth & & & & & & & & & & \\
\hline & Low & 16.1 & 17.0 & 33.1 & 1.5 & 16.2 & 17.7 & 17.6 & 33.2 & 50.8 & 34.8 \\
\hline & Medium & 16.6 & 14.9 & 31.5 & 3.5 & 20.6 & 24.1 & 20.1 & 35.5 & 55.6 & 43.3 \\
\hline & High & 13.4 & 12.8 & 26.2 & 10.9 & 23.5 & 34.4 & 24.3 & 36.3 & 60.6 & 56.8 \\
\hline & Residence & & & & & & & & & & \\
\hline & Urban & 6.5 & 11.3 & 17.8 & 10.1 & 22.6 & 32.7 & 16.6 & 33.9 & 50.5 & 64.8 \\
\hline & Rural & 8.2 & 15.9 & 24.1 & 2.7 & 17.7 & 20.4 & 10.9 & 33.6 & 44.5 & 45.8 \\
\hline & Total & 15.8 & 16.0 & 31.8 & 3.2 & 18.1 & 21.3 & 19 & 34.1 & 53.1 & 40.1 \\
\hline \multirow[t]{15}{*}{ Odisha } & Age & & & & & & & & & & \\
\hline & $15-24$ & 13.5 & 6.4 & 19.9 & 9.7 & 3.7 & 13.4 & 23.2 & 10.1 & 33.3 & 40.2 \\
\hline & $25-34$ & 6.6 & 12.7 & 19.3 & 14.4 & 23.2 & 37.6 & 21 & 35.9 & 56.9 & 66.1 \\
\hline & Education & & & & & & & & & & \\
\hline & No Education & 8.7 & 11.1 & 19.8 & 5.7 & 19.0 & 24.7 & 14.4 & 30.1 & 44.5 & 55.5 \\
\hline & Primary & 8.7 & 10.7 & 19.4 & 10.8 & 20.5 & 31.3 & 19.5 & 31.2 & 50.7 & 61.7 \\
\hline & Secondary + & 9.2 & 10.0 & 19.2 & 19.7 & 13.2 & 32.9 & 28.9 & 23.2 & 52.1 & 63.1 \\
\hline & Wealth & & & & & & & & & & \\
\hline & Low & 9.4 & 10.9 & 20.3 & 7.0 & 17.1 & 24.1 & 16.4 & 28 & 44.4 & 54.3 \\
\hline & Medium & 7.7 & 10.3 & 18.0 & 16.6 & 19.2 & 35.8 & 24.3 & 29.5 & 53.8 & 66.5 \\
\hline & High & 9.0 & 9.7 & 18.7 & 26.4 & 13.1 & 39.5 & 35.4 & 22.8 & 58.2 & 67.9 \\
\hline & Residence & & & & & & & & & & \\
\hline & Urban & 3.2 & 8.8 & 12.0 & 23.2 & 17.2 & 40.4 & 26.4 & 26 & 52.4 & 77.1 \\
\hline & Rural & 4.7 & 9.8 & 14.5 & 11.4 & 16.4 & 27.8 & 16.1 & 26.2 & 42.3 & 65.7 \\
\hline & Total & 9.0 & 10.5 & 19.5 & 12.8 & 16.5 & 29.3 & 21.8 & 27 & 48.8 & 60.0 \\
\hline Madhya & Age & & & & & & & & & & \\
\hline \multirow[t]{14}{*}{ Pradesh } & $15-24$ & 18.8 & 7.2 & 26.0 & 6.6 & 10.3 & 16.9 & 25.4 & 17.5 & 42.9 & 39.4 \\
\hline & $25-34$ & 5.6 & 9.6 & 15.2 & 9.2 & 50.6 & 59.8 & 14.8 & 60.2 & 75 & 79.7 \\
\hline & Education & & & & & & & & & & \\
\hline & No Education & 9.3 & 9.4 & 18.7 & 3.4 & 40.2 & 43.6 & 12.7 & 49.6 & 62.3 & 70.0 \\
\hline & Primary & 12.1 & 8.4 & 20.5 & 5.4 & 40.1 & 45.5 & 17.5 & 48.5 & 66 & 68.9 \\
\hline & Secondary + & 12.8 & 7.8 & 20.6 & 14.0 & 25.9 & 39.9 & 26.8 & 33.7 & 60.5 & 66.0 \\
\hline & Wealth & & & & & & & & & & \\
\hline & Low & 11.3 & 9.4 & 20.7 & 2.8 & 36.0 & 38.8 & 14.1 & 45.4 & 59.5 & 65.2 \\
\hline & Medium & 12.0 & 7.8 & 19.8 & 6.6 & 36.8 & 43.4 & 18.6 & 44.6 & 63.2 & 68.7 \\
\hline & High & 10.0 & 7.4 & 17.4 & 18.9 & 28.6 & 47.5 & 28.9 & 36 & 64.9 & 73.2 \\
\hline & Residence & & & & & & & & & & \\
\hline & Urban & 4.3 & 6.9 & 11.2 & 19.9 & 25.7 & 45.6 & 24.2 & 32.6 & 56.8 & 80.3 \\
\hline & Rural & 5.1 & 7.2 & 12.3 & 5.0 & 36.2 & 41.2 & 10.1 & 43.4 & 53.5 & 77.0 \\
\hline & Total & 11.0 & 8.6 & 19.6 & 8.1 & 34.0 & 42.1 & 19.1 & 42.6 & 61.7 & 68.2 \\
\hline
\end{tabular}

Source: DLHS 2007-08; DS=Demand Satisfied 
Table 4.3: Percentage of women age 15-34 years with an unmet need for family planning by empowerment indicators

\begin{tabular}{|c|c|c|c|c|c|c|c|c|c|}
\hline \multirow{2}{*}{$\begin{array}{l}\text { Empowerment } \\
\text { Indicators }\end{array}$} & \multicolumn{3}{|l|}{ Bihar } & \multicolumn{3}{|l|}{ Odisha } & \multicolumn{3}{|c|}{ Madhya Pradesh } \\
\hline & $\begin{array}{l}\text { UN For } \\
\text { Spacing }\end{array}$ & $\begin{array}{l}\text { UN For } \\
\text { Limiting }\end{array}$ & Total & \begin{tabular}{|l|} 
UN For \\
Spacing
\end{tabular} & $\begin{array}{l}\text { UN For } \\
\text { Limiting }\end{array}$ & Total & $\begin{array}{l}\text { UN For } \\
\text { Spacing }\end{array}$ & $\begin{array}{l}\text { UN For } \\
\text { Limiting }\end{array}$ & Total \\
\hline \multicolumn{10}{|c|}{ Number of Decisions in Which women Participate } \\
\hline 0 & 22.5 & 8.0 & 30.6 & 22.2 & 7.6 & 29.8 & 11.6 & 10.9 & 22.5 \\
\hline $1-2$ & 18.4 & 16.7 & 35.1 & 20.6 & 12.7 & 33.3 & 14.7 & 5.9 & 20.6 \\
\hline 3-4 & 20.8 & 18.3 & 39.1 & 13.3 & 15.9 & 29.2 & 12.0 & 12.5 & 24.5 \\
\hline 5 & 13.7 & 24.2 & 37.8 & 16.5 & 13.5 & 29.9 & 8.3 & 12.4 & 20.7 \\
\hline \multicolumn{10}{|c|}{ Number of Reasons for Which Wife Beating is Justified } \\
\hline 0 & 16.3 & 14.5 & 30.8 & 18.8 & 10.9 & 29.7 & 11.9 & 10.3 & 22.2 \\
\hline $1-2$ & 18.7 & 17.5 & 36.2 & 15.9 & 11.1 & 27.0 & 12.7 & 8.6 & 21.3 \\
\hline 3-4 & 22.6 & 24.2 & 46.8 & 19.6 & 15.7 & 35.3 & 12.9 & 7.6 & 20.5 \\
\hline 5 & 39.8 & 13.2 & 53.0 & 15.8 & 19.0 & 34.8 & 7.8 & 17.2 & 25.0 \\
\hline
\end{tabular}

UN: Unmet need

Table 4.4: Percentage of women age 15-34 years with unmet need for family planning by selected background characteristics, 2007-08

\begin{tabular}{|c|c|c|c|c|c|c|c|c|c|}
\hline \multirow{2}{*}{$\begin{array}{l}\text { Background } \\
\text { Characteristics }\end{array}$} & \multicolumn{3}{|l|}{ Bihar } & \multicolumn{3}{|l|}{ Odisha } & \multicolumn{3}{|c|}{ Madhya Pradesh } \\
\hline & Spacing & Limiting & Total & Spacing & Limiting & Total & Spacing & Limiting & Total \\
\hline \multicolumn{10}{|c|}{ Age of the women } \\
\hline $15-19$ years & 23.9 & 2.5 & 26.4 & 11.4 & 2.6 & 14.0 & 20.6 & 2.3 & 22.9 \\
\hline $20-29$ years & 12.3 & 17.8 & 30.2 & 9.0 & 11.0 & 20.0 & 8.7 & 10.4 & 19.1 \\
\hline $30-34$ years & 1.2 & 16.3 & 17.5 & 1.1 & 9.3 & 10.4 & 0.6 & 5.2 & 5.8 \\
\hline \multicolumn{10}{|c|}{ Place of Residence } \\
\hline Rural & $8.2^{*}$ & $15.9^{*}$ & $24.1^{*}$ & $4.7^{*}$ & 9.8 & $14.5^{*}$ & $5.1^{\text {** }}$ & 7.2 & $12.3^{* \star}$ \\
\hline Urban & 6.5 & 11.3 & 17.8 & 3.2 & 8.8 & 12.0 & 4.3 & 6.9 & 11.2 \\
\hline \multicolumn{10}{|l|}{ Religion } \\
\hline Hindu & 7.9 & $14.4^{*}$ & $22.3^{*}$ & 4.5 & 9.7 & 14.2 & 5.0 & 7.1 & 12.1 \\
\hline Muslim & 8.8 & 23.1 & 31.9 & 6.5 & 8.7 & 15.2 & 4.6 & 8.0 & 12.6 \\
\hline Others & 11.1 & 15.7 & 26.9 & 4.9 & 9.5 & 14.5 & 3.6 & 4.9 & 8.5 \\
\hline \multicolumn{10}{|c|}{ Number of Living children* } \\
\hline Zero & 13.5 & 0.2 & 13.7 & 4.5 & 0.3 & 4.8 & 11.3 & 0.3 & 11.6 \\
\hline One child & 24.9 & 2.1 & 27.0 & 13.3 & 4.9 & 18.2 & 16.9 & 2.9 & 19.8 \\
\hline 2-3 children & 7.2 & 16.4 & 23.6 & 2.4 & 11.8 & 14.2 & 2.6 & 8.5 & 11.1 \\
\hline$>3$ children & 1.2 & 24.1 & 25.3 & 0.9 & 14.9 & 15.7 & 0.6 & 9.3 & 10.0 \\
\hline \multicolumn{10}{|l|}{ Child loss } \\
\hline Yes & $3.5^{*}$ & $19.3^{*}$ & $22.8^{*}$ & $2.3^{*}$ & 10.9 & $13.3^{*}$ & $2.2^{*}$ & 7.9 & $10.1^{*}$ \\
\hline No & 9.0 & 16.4 & 25.5 & 5.3 & 10.7 & 16.0 & 5.0 & 7.8 & 12.8 \\
\hline
\end{tabular}


Table 4.4: Percentage of women age 15-34 years with unmet need for family planning by selected background characteristics, 2007-08 Cont...

\begin{tabular}{|c|c|c|c|c|c|c|c|c|c|}
\hline \multirow{2}{*}{$\begin{array}{l}\text { Background } \\
\text { Characteristics }\end{array}$} & \multicolumn{3}{|l|}{ Bihar } & \multicolumn{3}{|l|}{ Odisha } & \multicolumn{3}{|c|}{ Madhya Pradesh } \\
\hline & Spacing & Limiting & Total & Spacing & Limiting & Total & Spacing & Limiting & Total \\
\hline \multicolumn{10}{|c|}{ Education of the women } \\
\hline Non literate & $7.3^{*}$ & $17.3^{*}$ & $24.6^{*}$ & $3.8^{*}$ & 9.8 & $13.6^{*}$ & $3.6^{*}$ & 7.2 & $10.8^{*}$ \\
\hline Primary & 8.4 & 13.0 & 21.3 & 3.7 & 9.4 & 13.0 & 5.3 & 6.7 & 12.0 \\
\hline Middle/Secondary & 9.7 & 12.2 & 22.0 & 5.5 & 9.5 & 15.0 & 7.3 & 7.0 & 14.3 \\
\hline Higher & 9.4 & 10.3 & 19.7 & 5.9 & 10.2 & 16.1 & 5.1 & 7.5 & 12.6 \\
\hline \multicolumn{10}{|l|}{ Wealth Index } \\
\hline Poorest & $7.6^{*}$ & $19.9^{*}$ & 27.5 & 4.7 & $10.6^{*}$ & $15.3^{*}$ & 5.2 & $9.2^{*}$ & $14.4^{*}$ \\
\hline Second & 8.5 & 15.4 & 23.9 & 4.7 & 8.8 & 13.6 & 4.9 & 7.2 & 12.1 \\
\hline Middle & 8.8 & 12.9 & 21.7 & 4.7 & 9.4 & 14.1 & 5.3 & 5.9 & 11.2 \\
\hline Fourth & 7.6 & 11.0 & 18.6 & 4.3 & 8.9 & 13.2 & 4.8 & 6.2 & 11.0 \\
\hline Highest & 5.7 & 9.2 & 14.8 & 3.4 & 8.6 & 12.0 & 4.1 & 5.9 & 10.1 \\
\hline
\end{tabular}

Source: DLHS 2007-08; ${ }^{*} P<.01{ }^{* *} \mathrm{P}<.05$

Table 4.2 shows that unmet need for family planning varies significantly with different population and various factors affect the unmet need for contraception. Age of the women, parity, availability of contraceptive methods, religious beliefs, education of women, and son preference among others have significant effect on the level of reporting unmet need for contraception [26, 40-45]. Table 4.2 shows that women in the younger age group reported a higher unmet need for family planning than those who are above 30 years. While looking at the unmet need for spacing and limiting by age group it was found that the unmet need for spacing decreases as age of women increases and unmet need for limiting increases with increase in age of women. The unmet need for spacing is negligible among women who are more than 30 years in the three focused states.

Place of residence, either urban or rural shows significant effect on unmet need for spacing in all three focused states; rural women reporting more unmet need for spacing than urban women (Table 4.4). However, only in Bihar, rural-urban difference had significant variation on unmet need for limiting. While looking at the association of women's education on unmet need for family planning it was seen that as education of women increase the unmet need for spacing also increases. However, no significant association was found with women's education and unmet need for limiting in Odisha and Madhya Pradesh. In Bihar, with increase in the education of women the unmet need for limiting decreased.

There existed significant relationship between number of living children and extent of unmet need. The unmet need for spacing among women with no living children in Bihar and Madhya Pradesh is 13 percent and 11 percent respectively and corresponding figure for Odisha is 4 percent. Table 4.4 shows that the unmet need for spacing was highest in women with one or two children and it reduces with increase in the number of living children. As expected, the unmet need for limiting increased with higher parity. However, the total unmet need for family planning is highest among the women with one child and reduces with higher the number of living children. Child loss has significant effect on unmet need, because child loss reduces the need for family planning to space births but increases desire to get pregnant soon. The analysis also indicates that women who experienced a child loss reported less unmet need for spacing than those who did not have a child loss. On the other hand, child loss did not have any effect on unmet need for limiting except in Bihar. Studies on unmet need for family planning show that in developing countries the women are bearing more offspring than they intend [43-47]. Half the young women preferred to delay their first pregnancy. However, just 5 percent of all women and 8 percent of those who desired to delay first pregnancy had practiced contraception [46]. A study based on 
2, 444 currently married women aged 15-39 years conducted in the year 2002 in Madhya Pradesh by using different models to assess the life course experience of abortion and contraceptive use found strong association between women's previous abortion attempt and temporary contraceptive method use in the future [47]. While looking at the unmet need for spacing by poverty quintile it was observed that the women in the wealthiest quintile have higher unmet need for spacing than the women in lower quintiles, whereas in case of unmet need for limiting women in the poorest quintile reported higher unmet need and unmet need reduces as we move from lowest strata to highest income strata.

The youth study succeeded to identify key factors underlying their sexual and reproductive health, knowledge, attitudes and life choices. There was lack of knowledge on key information like fertile period, contraceptive methods, and availability of reproductive health services. Sizeable proportions of young men and few young women had engaged in premarital sex; moreover, where premarital sex was undertaken, it was largely unsafe $[48,49]$. Coerced and forced sex was reported not only by women but also by young men. Of the first premarital sexual encounter; 15 percent young women reported that it was forced, and another 14 percent said that it was persuaded. Unmarried young men acknowledged their perpetuator role. Among unmarried young men, 21 percent reported that they had ever deliberately touched or brushed past a woman in a sexual way, and 4 percent reported that they had ever experienced such an unwanted touch. Forced sex was also evident within marriage. One-third of married young women reported forced sex within marriage and 17 percent of young husbands admitted to forcing sex on their wife [49]. A study in Delhi and Lucknow found that about 21.9 percent young men in Delhi and 31 percent young men from Lucknow reported sexual debut before age 15 years. Among the males reporting sexual relationships, about 45 percent reported never using a condom; more than half the females from Delhi reported not using a condom [50]. Contraceptive use does not fare well among married women too. Higher the chances that young married girls are uninformed and have unprotected sexual relations with a husband who is likely to be considerably older; and have higher risk for sexually transmitted infections and HIV compared to unmarried sexually active girls [51-53].

Table 4.5 shows that various background variables significantly affect the presence of unmet need for family planning. Age of woman, place of residence, parity and wealth quartile have significant impact on reporting an unmet need for family planning. The causes of unmet need are complex. Surveys and other in-depth research from the 1990s reveal a range of obstacles and constraints that can undermine a woman's ability to act on her childbearing preferences. Family and gender-based constraints are also important determinants of women's reproductive behavior in India, influencing the use of contraceptives and abortion attempts. A large literature documents the ways in which social and domestic constraints, such as early marriage, social pressure on women to bear children soon after marriage, women's lack of decision making power within the household and their relationships, the frequency and acceptance of violence and coercion in sexual and family relations, and women's limited physical mobility, poor access to services increase unmet need in India [46-49]. Interventions in the community have managed to change community attitudes in favor of spacing methods as well as increased postpartum contraception and use of spacing methods [13, 54, 57]. 
Table 4.5: Results of logistic regression on unmet need for family planning among young women (15-34 years) in focused states, 2007-08

\begin{tabular}{|c|c|c|c|c|c|c|c|}
\hline \multirow{3}{*}{$\begin{array}{l}\text { Characterist } \\
\text { ics }\end{array}$} & \multirow[t]{3}{*}{ Category } & \multicolumn{6}{|c|}{ Odds Ratio } \\
\hline & & \multicolumn{2}{|l|}{ Bihar } & \multicolumn{2}{|l|}{ Odisha } & \multicolumn{2}{|c|}{ Madhya Pradesh } \\
\hline & & Spacing & Limiting & Spacing & Limiting & Spacing & Limiting \\
\hline \multirow{2}{*}{$\begin{array}{l}\text { Age of } \\
\text { Women }\end{array}$} & $15-24 \circledast$ & & & & & & \\
\hline & $25+$ & $0.26^{*}$ & $1.38^{*}$ & $0.30^{*}$ & $1.33^{*}$ & $0.28^{*}$ & $0.72^{*}$ \\
\hline \multirow{2}{*}{$\begin{array}{l}\text { Place of } \\
\text { Residence }\end{array}$} & Rura|ß & & & & & & \\
\hline & Urban & 0.94 & 0.85 & $0.72^{\star *}$ & $0.76^{* *}$ & .95 & $1.23^{*}$ \\
\hline \multirow[t]{3}{*}{ Parity } & Zero® & & & & & & \\
\hline & One & $4.67^{*}$ & $9.69^{*}$ & $14.53^{*}$ & $17.68^{*}$ & $4.83^{*}$ & $11.79^{*}$ \\
\hline & Two and more & $2.04^{*}$ & $90.32^{*}$ & $4.95^{*}$ & $64.91^{*}$ & $1.42^{*}$ & $63.26^{*}$ \\
\hline \multirow{3}{*}{$\begin{array}{l}\text { Educational } \\
\text { Status of } \\
\text { Women }\end{array}$} & Non literate $®$ & & & & & & \\
\hline & Primary & 0.99 & $0.81^{*}$ & 0.81 & 0.95 & 1.1 & 0.87 \\
\hline & Secondary \& Above & 0.97 & 0.89 & 0.86 & 0.98 & 1.1 & 1.04 \\
\hline \multirow[t]{3}{*}{ Wealth Index } & Poorest/Poor@ & & & & & & \\
\hline & Middle & 0.89 & 0.93 & 0.81 & 0.95 & $0.85^{\star *}$ & $0.85^{\star *}$ \\
\hline & Rich/Richest & $0.76^{*}$ & $0.84^{*}$ & $0.55^{\star}$ & 0.95 & $0.72^{*}$ & $0.83^{* *}$ \\
\hline
\end{tabular}

Source: DLHS 2007-08

A review of unmet need for contraception in India by Khan and Hazra (2012) brought out some key observations [58]:

- Lack of informed choice about available contraceptive methods, especially to women living in rural areas and who are neither exposed to mass media nor contacted by community health workers, is a major barrier to contraceptive use. Several small scale studies mention that most providers have a distinct bias towards sterilization and only a minority of clients was informed of reversible methods.

- Analysis of DLHS-3 data by source of availing the contraceptive methods reveal that majority (65 percent) of women obtained modern spacing methods from private sources while 85 percent relied on public sector for permanent methods.

- Methods that are perceived as less effective including spermicides, diaphragms, or are controversial including injectables and implants are dropped from the national family planning programme, not introduced or given low priority by health workers. Little or no information is available on the quality of recent initiatives taken by the Government for postpartum IUD insertion.

For each additional contraceptive method made widely available in a country, the percentage of married women using contraception increases by an average of 3.3 percentage points, according to analysis of data from demographic and health surveys in 44 countries. The current basket of choices is still limited, and there are many contraceptive methods that have not found a place in the national FP programme. At present the $\mathrm{GOI}$ emphasises the role of postpartum intrauterine contraceptive device (PPIUCD) services to expand choice beyond sterilisation. FOGSI is considered to be a neutral body of medical practitioners by the government. With 219 member societies and more than 27,000 individual members spread across the country, FOGSI strongly recommends that medical practitioners offer postpartum FP services, giving special attention to spacing needs for women. 


\section{Abortion and related outcomes}

"Over the past 15 years, human rights such as the rights to life, to health, to equality and non discrimination, to liberty, security of person and privacy, the right to be free from cruel, inhuman and degrading treatment, and the right to information and education, have been increasingly recognized in the context of different aspects of abortion" [59, pg.49]. This draft WHO document mentions restrictive legal environment, lack of adequate family planning service and violence among others as reasons for women resorting to unsafe abortion. As per the latest global abortion figures released by the WHO along with Guttmacher Institute, for every one lakh abortions, 200 women died of it in the southeast Asia region [60]. The introduction and expansion of medical abortion (using mifepristone and misoprostol pills) have improved access to safe abortions and reduced post abortion complications [59]. This can be provided without the necessity of a large infrastructure and equipments and staff trained in the use of specific manual techniques. Sufficient evidence is available and it is proven beyond doubt that medical abortion is safe and effective [61-68]. Since medical abortion is done through use of pills, it helps in demedicalising abortion and thus enables the reach of abortion services to PHCs [69]. However, factors like safety, efficacy, number of visits, how the method works, how long it takes for the abortion to be completed and cost all affect acceptability [70].

Various reasons like the legality of abortion in the country, availability of services and cause of the unwanted pregnancy will determine whether and where the women will access abortion. As a result, availability of unsafe abortion estimates in countries varies $[52,63,64]$. Data available on estimates of unsafe abortions are mostly speculative since only safe abortions are reported [65]. If women are seeking safe abortions, lot of the complications arising from unsafe abortions as well as mortality could be averted. The WHO estimated that 21.6 million unsafe abortions took place worldwide in 2008, almost all in developing countries [75]. While nearly all abortions in developed countries are safe, more than half in developing countries are unsafe [76]. Estimated deaths in developing countries resulting from unsafe abortions are 400 deaths per 100,000 abortions [77]. Forty-one per cent of unsafe abortions in developing regions are among young women aged 15-24 years, 15 percent among those aged 15-19 years and 26 percent among those aged 20-24 years. Among the 3.2 million unsafe abortions in young women $15-19$ years old, almost 50 percent are in the Africa region. 22 percent of all unsafe abortions in Africa compared to 11 percent of those in Asia (excluding Eastern Asia) and 16 percent of those in Latin America and the Caribbean are among adolescents aged 15-19 years [78].

The vast majority of abortions in India is believed to be performed outside of registered abortion centers and is not reported in government records. Considerable under-reporting of induced abortions exist: just 3percent women reported ever undergoing an induced abortion during the recent National Family Health Survey [7]. Majority or almost the entire abortion service provider is the private sector [71]. However, studies conducted in the last decade, have shed light on the prevalence of abortion and the experiences of women who underwent abortion. To cite two studies: 13 percent women aged 15-44years in Alwar district, Rajasthan, had experienced one or more abortions over the course of their life [70]; almost one-fourth of those aged 15-39 years in six districts of Madhya Pradesh had experienced an abortion [72]. Overall, 9 percent of all pregnancies among women age 15-19 years are aborted in India. Given the social taboo, under reporting is expected and also it is likely that induced abortions are reported as spontaneous abortions [73].

\section{Trends in pregnancy termination}

Data from DLHS-3 indicate that the percentage of ever married women who experienced any type of abortion is higher in Bihar (15\%) and Odisha (14\%) than the national average (13\%) and lower in Madhya Pradesh with 9.8 percent women reporting that they had undergone an abortion [14]. The NFHS-3 also captured the information about the medical termination of pregnancy among ever married women [7]. NFHS-3 data also 
indicate that the percentage of women reporting medical termination of pregnancy is higher in Bihar and Odisha than the all India average. The percentage of women reporting a terminated pregnancy in NFHS3 data is higher than that is reported in DLHS-3 data. The percentage of women reporting induced abortion is lower than the prevalence of spontaneous abortion in all three states as well as in India.

Table 4.6: Percentage of women who reported induced and spontaneous abortion in India and focused states

\begin{tabular}{|l|l|l|l|l|l|}
\hline & NFHS-3 (2005-06) & DLHS-3 (2007-08) & AHS (2010-11) \\
\hline $\begin{array}{l}\text { Name of the } \\
\text { state }\end{array}$ & $\begin{array}{l}\text { Ever Terminated } \\
\text { Pregnancy }\end{array}$ & Induced & Spontaneous & $\begin{array}{l}\text { Any form of } \\
\text { Abortion }\end{array}$ & $\begin{array}{l}\text { Pregnancy resulting } \\
\text { in abortion }\end{array}$ \\
\hline Bihar & 20.1 & 3.9 & 13.6 & 15.1 & 5.3 \\
\hline Odisha & 17.2 & 4.5 & 10.1 & 14.1 & 5.6 \\
\hline Madhya Pradesh & 12.1 & 2.3 & 8.7 & 9.8 & 6.0 \\
\hline India & 13.3 & 3.4 & 10.8 & 13.4 & --- \\
\hline
\end{tabular}

Note: DLHS-3 collected information about the number of spontaneous and induced abortions separately whereas, NFHS -3 provides the total number of terminated pregnancies a women ever had.

The abortion that was reported in the AHS, 2010-11 was only a minimiscule percentage. The sex-ratios in these states were indicative of the prevalence of sex-selective abortion (Table 4.7). Hence, it may be assumed that induced abortions are under reported or could be reported as spontaneous abortions. There is also a possibility that even spontaneous abortions are not reported.

Table 4.7: Sex-ratios in the focused states, females per 1000 males

\begin{tabular}{|l|l|l|l|l|}
\hline & \multicolumn{2}{|l|}{ AHS, 2010-11 } & Census, 2011 \\
\hline Name of the state & At birth & $\mathbf{0 - 4}$ years & All ages & All ages \\
\hline Bihar & 919 & 931 & 950 & 916 \\
\hline Odisha & 905 & 933 & 994 & 978 \\
\hline Madhya Pradesh & 904 & 911 & 912 & 930 \\
\hline
\end{tabular}

The sex ratios obtained in AHS, 2010-11 was lower than census 2011 in Madhya Pradesh. The sex ratio in odisha was 994 females per 1000 males as per AHS, 2010-11 but only 978 females per 1000 males in census 2011.

A review of the levels and trends of legal abortion worldwide, found that many countries in Asia are not having accurate statistics on abortions [74-82]. For example, declines in abortion rates found from surveys in countries like Armenia and Georgia are not borne out by changes in contraceptive use and fertility. The official report from India indicates that only two legal abortions per 1,000 women were performed in 2008 (down from 3 in 2003), a facility-based survey in 2002 estimated an overall rate of 26 abortions per 1,000 women, of which more than one-third were considered safe, even if they did not conform with all of the regulatory conditions imposed by law. Mifepristone and misoprostol manufacturing and sales data suggest that the use of medication abortion has increased substantially in recent years [74].

Sexual activity starts young in both men and women, more in rural than urban areas. Survey conducted among youth (unmarried youth and married females aged 15-24 and married males aged 15-29, (because there are few married males who are 15-24 years old) in six states of India shows that 11 percent of young men and 5 percent of young women aged 15-24 had engaged in pre-marital sex before age 20; 6 percent rural women vs. 3 percent urban women reported experience of pre-marital sex. Of these, 21 percent had 
multiple sexual partners and only 3 percent reported consistent condom use. Moreover, 18 percent young women reported forced sex [83-86]. Whether sex was forced or otherwise, resultant pregnancies were aborted almost always $[87,88]$.

Table 4.8: Percentage of women reporting experience of abortion by age in India and focused states, 2007-08

\begin{tabular}{|l|l|l|l|l|l|l|l|l|}
\hline \multirow{2}{*}{$\begin{array}{l}\text { Age } \\
\text { Group }\end{array}$} & \multicolumn{3}{|l|}{ Bihar } & \multicolumn{2}{l|}{ Odisha } & \multicolumn{2}{l|}{ Madhya Pradesh } & \multicolumn{2}{l|}{ India } \\
\hline & Induced & Spontaneous & Induced & Spontaneous & Induced & Spontaneous & Induced & Spontaneous \\
\hline $15-19$ & 16.9 & 20.6 & 0.6 & 3.7 & 14.0 & 17.0 & 11.3 & 15.1 \\
\hline $20-24$ & 1.8 & 10.1 & 2.0 & 7.6 & 1.4 & 7.0 & 2.4 & 8.7 \\
\hline $25-29$ & 2.1 & 12.5 & 3.9 & 9.9 & 1.4 & 8.3 & 3.1 & 10.3 \\
\hline $30-34$ & 2.6 & 14.0 & 6.2 & 10.7 & 1.3 & 8.4 & 4.0 & 11.4 \\
\hline $35-39$ & 2.6 & 13.9 & 6.3 & 11.9 & 1.6 & 8.6 & 4.0 & 11.2 \\
\hline $40-44$ & 2.0 & 13.8 & 4.9 & 11.0 & 1.7 & 8.7 & 3.4 & 11.1 \\
\hline $45-49$ & 1.9 & 13.4 & 4.5 & 11.8 & 1.2 & 8.1 & 2.7 & 10.5 \\
\hline
\end{tabular}

Source: DLHS, 2007-08

Table 4.8 presents the percentage of women who had reported an experience of abortion, either spontaneous of induced by age group in India and focused states. The percentage of pregnancies ending in abortion is quite high in 15-19 years age group nationally as well as Bihar and Madhya Pradesh. However, in Odisha reported induced and spontaneous abortions are very low among adolescents but increased with age. Adolescents and women in the age group of 20-29 years are the main abortion seekers in India [89]. 59 percent of abortions in Asia are among women below age 30 years; 30 percent in women under 25 years [89]. Many women in India have attempted to have induced abortion to end an unwanted pregnancy and 23-48 percent who attempted abortion did not succeed [80].

Abortion service providers are increasingly found in the private sector [64, 72]. A recent situation analysis of MTP services in Bihar found that in the year 2011 found that there were 334 health facilities that reported providing MTP services and 79 percent were in the private sector [72]. Unmarried women mostly and even married women prefer private sector for privacy and confidentiality indirectly increasing demand.

Table 4.9: Percentage of women undergoing induced abortion by place of abortion conducted, among women reporting induced abortion, 2007-08

\begin{tabular}{|l|l|l|l|}
\hline Name of the State & Govt. Facility & Pvt./NGO/Trust Facility & Home/Others \\
\hline Bihar & 16.2 & 70.4 & 13.4 \\
\hline Odisha & 67.8 & 24.3 & 7.9 \\
\hline Madhya Pradesh & 38.4 & 53.3 & 8.3 \\
\hline India & 38.3 & 54.7 & 7.0 \\
\hline
\end{tabular}

Source: DLHS 2007-08

Majority of abortions take place in private facilities. Table 4.9 indicates that majorly women used private facilities for an induced abortion than government facilities, except in the state of Odisha. Among women who reported an induced abortion, 70 percent women from Bihar and 53 percent from Madhya Pradesh availed the service at a private facility whereas in Odisha more than two-thirds of the women utilized government facility for induced abortion services. It is also important to note that about 13 percent women in Bihar and 8 percent from Odisha and Madhya Pradesh did not go to either a government facility or private facility for induced 
abortion. A community-based study in Madhya Pradesh found that more than half of abortions among urban women took place in a private facility compared to one fourth of abortions in a public sector facility and the remaining resorting to folk methods or self-induction [80].

Several factors contribute to women opting for abortion outside the accredited abortion centers. They include absence of competent health professionals in rural areas and high abortion cost at big hospitals in the cities $[90,91]$. A number of individual- and community-level factors inhibit women from seeking abortion in public sector facilities like limited understanding of the legality of abortion, reluctance to obtain services from known neighborhood clinics, lack of awareness about the need to seek abortion early in pregnancy, poor perceived quality of care, lack of confidentiality and insistence on adopting family planning method [71, 80, 93, 94]. Indeed, significant numbers of women-one-fifth in a study in Rajasthan-used a home remedy or obtained services from an informal provider in an attempt to terminate their pregnancy; most of these were unsuccessful, leading women to seek services eventually - often in the second trimester-from the formal sector [79]. Despite the introduction of medical abortion in the country in the year 2002; even in the year 2006 about 90 percent of the estimated abortions were taking place in uncertified settings despite the fact that 7 pharmaceutical companies were producing the drug in the country in $2003[7,95,96]$.

Illegal abortions in India are estimated to outnumber legal ones [97-99]. Unsafe abortion is estimated to account for 9 to 20 percent of all maternal deaths in India [100]. A study in Mexico showed that more deaths than that was reported as abortion related deaths were linked to induced abortion and/or its complications. It was highly probable that women coming for 2nd trimester abortion would have tried to abort the fetus unsuccessfully in the first trimester and also it was seen that they would say that pregnancy resulted from forced or coerced sex [84, 101-104]. The risk of abortion complications are much higher in the second and third trimester compared to the first trimester since the uterus has evolved to expel its contents early and late in pregnancy, not in the middle. A study in India shows that abortion complications are 12 times higher for second trimester abortions than the first trimester ones [105]. Because of the potential for heavy vaginal bleeding and serious complications, it is advisable that second trimester terminations take place in a health care facility where blood transfusion and emergency surgery (including laparotomy) are available [106]. Table 4.10 gives the gestational age at the time of abortion and also place of residence.

Table 4.10: Percentage of women undergoing induced abortion by gestational age and place of residence, 2007-08

\begin{tabular}{|l|l|l|l|l|}
\hline \multirow{2}{*}{ Name of the State } & \multirow{2}{*}{ Place of Residence } & \multicolumn{3}{|c|}{ Gestation Age } \\
\cline { 3 - 5 } & & First trimester & Second Trimester & Third Trimester \\
\hline \multirow{3}{*}{ Bihar } & Total & 88.5 & 10.2 & 1.3 \\
\cline { 2 - 5 } & Rural & 88.6 & 10.0 & 1.4 \\
\cline { 2 - 5 } & Urban & 88.4 & 10.9 & 0.7 \\
\hline \multirow{3}{*}{ Orissa } & Total & 87.7 & 11.1 & 1.3 \\
\cline { 2 - 5 } & Rural & 86.5 & 12.0 & 1.5 \\
\cline { 2 - 5 } & Urban & 92.2 & 7.4 & 0.4 \\
\hline Madhya Pradesh & Total & 87.3 & 12.2 & 0.5 \\
\cline { 2 - 5 } & Rural & 83.1 & 16.5 & 0.4 \\
\cline { 2 - 5 } & Urban & 90.1 & 9.3 & 2.6 \\
\hline \multirow{3}{*}{ India } & Total & 84.3 & 13.0 & 2.8 \\
\cline { 2 - 5 } & Rural & 82.8 & 14.5 & 2.4 \\
\cline { 2 - 5 } & Urban & 87.2 & 10.4 & \multicolumn{2}{|c|}{} \\
\hline
\end{tabular}

Source: DLHS 2007-08 
Table 4.10 shows that nearly 85 percent of the induced abortions are conducted in the first trimester in India and the focused states. However, about 10 percent of the abortions took place in the second trimester and nearly 2 percent in the third trimester. Data indicated that the percentage of women undergoing abortion in second and third trimester in rural areas were higher than in the urban area. Many women in the rural areas in the focused state reported that they have undergone induced abortion even in the third trimester. Given the fact that this is the reported induced abortions, the results in Table 4.10 is a matter of concern.

A study in Madhya Pradesh by surveying about 2444 women in the year 2002 showed that mean number of children at the time of trying to abort index pregnancy was 2.9. In 86 percent of the abortion attempts, the gestational age was 1-3 months. Forty-two percent of attempts were made by the woman herself; 38 percent and 13 percent, respectively, were made by private or government providers and 7 percent were made by others. 58 percent of abortion attempts in rural areas resulted in at least some symptom-defined morbidity, whereas 46 percent of attempts in urban areas led to such morbidity [80, 107].

Table 4.11 is looking at the various characteristics taking into account all abortions whereas the tables above discussed results pertaining to induced abortions only.

Table 4.11: Abortion service seeking in urban and rural areas of focused states

\begin{tabular}{|c|c|c|c|c|c|c|c|c|c|}
\hline \multirow{2}{*}{$\begin{array}{l}\text { Background } \\
\text { Characteristics }\end{array}$} & \multicolumn{3}{|c|}{ Bihar } & \multicolumn{3}{|c|}{ Odisha } & \multicolumn{3}{|c|}{ Madhya Pradesh } \\
\hline & Total & Rural & Urban & Total & Rural & Urban & Total & Rural & Urban \\
\hline \multicolumn{10}{|l|}{ Type of Abortion } \\
\hline Spontaneous & 87.8 & 88.6 & 79.9 & 69.2 & 70.8 & 60.4 & 87.4 & 91.8 & 77.0 \\
\hline Induced & 10.9 & 10.1 & 17.8 & 28.4 & 26.8 & 37.1 & 11.5 & 7.4 & 21.1 \\
\hline Both & 1.4 & 1.3 & 2.3 & 2.4 & 2.4 & 2.6 & 1.1 & 0.8 & 1.9 \\
\hline Number of Women & 3611 & 3268 & 343 & 2075 & 1762 & 313 & 2322 & 1631 & 691 \\
\hline \multicolumn{10}{|c|}{ Gestation age at the time of induced abortion } \\
\hline First Trimester & 87.6 & 87.4 & 88.2 & 87.1 & 86.2 & 91.1 & 87.4 & 84.3 & 89.9 \\
\hline Second Trimester & 11.1 & 11.0 & 11.8 & 11.6 & 12.4 & 8.1 & 11.9 & 14.9 & 9.4 \\
\hline Third Trimester & 1.4 & 1.6 & 0.0 & 1.3 & 1.4 & 0.8 & 0.7 & 0.7 & 0.6 \\
\hline \multicolumn{10}{|c|}{ Place of induced abortion conducted } \\
\hline Govt. Facility & 16.5 & 15.2 & 23.2 & 65.7 & 67.5 & 58.5 & 33.1 & 42.5 & 25.6 \\
\hline Pvt./NGO/Trust & 70.4 & 70.6 & 69.6 & 25.2 & 23.2 & 33.3 & 57.0 & 44.0 & 67.5 \\
\hline Home/Other & 13.1 & 14.2 & 7.2 & 9.1 & 9.3 & 8.1 & 9.9 & 13.4 & 6.9 \\
\hline \multicolumn{10}{|c|}{ Person advised for Induced abortion } \\
\hline Doctor & 19.6 & 18.8 & 25.0 & 21.4 & 21.2 & 22.0 & 35.5 & 32.8 & 37.7 \\
\hline ANM/Nurse/LHV & 5.2 & 4.8 & 7.2 & 1.2 & 1.2 & 1.6 & 5.5 & 6.7 & 4.4 \\
\hline ASHA & - & - & - & 0.1 & 0.2 & 0.0 & 0.3 & 0.7 & 0.0 \\
\hline Trained Dai & 0.9 & 1.1 & 0.0 & 0.8 & 0.8 & 0.8 & 0.3 & 0 & 0.6 \\
\hline Family Member & 74.3 & 75.3 & 67.8 & 76.5 & 76.6 & 75.6 & 58.4 & 59.8 & 57.3 \\
\hline $\mathrm{N}$ & 441 & 373 & 68 & 640 & 516 & 124 & 293 & 134 & 159 \\
\hline
\end{tabular}

Source: DLHS 2007-08

Although majority of the abortions were reported as spontaneous and first trimester abortions, the facility where abortion took place varied across the states. Only about a quarter of the respondents mentioned that the doctor advised for the abortion which was about 35 percent in Madhya Pradesh. The main source of contraceptives in Bihar was private facility and similar is the case of abortion services. Just as public facility was the main source of contraceptive method for the current users in Odisha, abortion services were also sought from public facility in Odisha. However, in Madhya Pradesh the main provider of abortion services is 
the private sector. It was interesting to note that in Odisha, nearly 30 percent of the abortions are induced abortions.

Table 4.12: Profile of women age 15-34 years who experienced any abortion, 2007-08

\begin{tabular}{|c|c|c|c|}
\hline & Bihar & Odisha & Madhya Pradesh \\
\hline \multicolumn{4}{|l|}{ Age of women } \\
\hline $15-19$ & $6.3^{* \star}$ & $2.5^{\star *}$ & $4.7^{* *}$ \\
\hline $20-29$ & 59.8 & 56.6 & 62.6 \\
\hline $30-34$ & 34.0 & 40.9 & 32.8 \\
\hline \multicolumn{4}{|l|}{ Place of Residence } \\
\hline Rural & $90.5^{* \star}$ & $85.0^{* \star}$ & $70.2^{* *}$ \\
\hline Urban & 9.5 & 15.0 & 29.8 \\
\hline \multicolumn{4}{|l|}{ Religion } \\
\hline Hindu & 87.4 & 96.8 & 93.6 \\
\hline Muslim & 12.4 & 1.0 & 5.6 \\
\hline Others & 0.2 & 2.2 & 0.8 \\
\hline \multicolumn{4}{|l|}{ Education of women } \\
\hline Non-literate & 60.0 & 30.3 & 42.0 \\
\hline Primary & 9.3 & 13.7 & 7.4 \\
\hline Middle/Secondary & 25.9 & 46.7 & 39.4 \\
\hline Higher & 4.8 & 9.6 & 11.2 \\
\hline \multicolumn{4}{|l|}{ Age at Marriage } \\
\hline Less than 18 years & 90.1 & $56.2^{*}$ & 80.8 \\
\hline 18 years and Above & 9.9 & 43.8 & 19.2 \\
\hline \multicolumn{4}{|l|}{ Wealth Index } \\
\hline Poorest/Poor & $63.0^{* \star}$ & $63.0^{* *}$ & $41.0^{* *}$ \\
\hline Middle & 19.1 & 19.1 & 20.1 \\
\hline Rich/Richest & 17.8 & 17.8 & 39.0 \\
\hline
\end{tabular}

Source: DLHS 2007-08; ${ }^{*} p<0.05,{ }^{* *} p<0.01$

Preventing unintended pregnancy is crucial for reducing induced abortions. Unavailability or shortage of contraceptive methods, lack of knowledge and accessibility lead to unwanted pregnancies; which are all preventable by removing the causes $[59,75,77,80,97,107-110]$. Consequently, it is the young, poor, illiterate or rural women who becomes prey to unwanted pregnancy as well as seek abortion from untrained providers compared to older women or urban women; disproportionately paying by their lives and morbidities. In the developing world as a whole, an estimated five million women are admitted to hospital for treatment of complications from induced abortions each year. This equates to an average rate of 5.7 per 1000 women per year in all developing regions, excluding China [98].

Table 4.12 provides the characteristics of women who reported they had an abortion in the focused states. Age of women, place of residence and wealth quartile significantly affected abortion. Age at marriage and marriage before age 18 years significantly contributing to abortion was visible only in Odisha. More than half of the women who reported an abortion belonged to age 20-29 years in all three states. However, nearly onethird of the women in Bihar and Madhya Pradesh and nearly 40 percent of the women in Odisha who reported they had an abortion were in 30-34 age groups. While looking at the rural-urban distribution of women who reported abortion, it was found that majority of the women reported an abortion were from rural areas in all three focused states with nearly 90 percent women in Bihar and 85 percent women in Odisha and the corresponding figure for Madhya Pradesh is 70 percent. While analyzing the educational attainment of women who experienced abortion, it was found that comparatively a higher proportion of women belonged to non- 
literate and middle/secondary school than others in all three states. Wealth quintile of women and experience of abortion shows a significant relationship with nearly 60 percent of the women reported an abortion belongs to poor/poorest quintile in Bihar and Odisha. Severe complications as well as morbidities are higher in rural than urban areas $[73,79,86-88]$.

Only 25 percent of Bihari women knew that abortion is legal [81]. According to a survey, around 0.6 million induced abortions are conducted in Bihar every year, majority of which are performed outside the recognized government centers. This contributes significantly to maternal mortality rate (MMR) in the state, which currently stands at 261/10,000, much higher than the national average of 212 [110]. A study conducted to understand the gap between safe abortion availability and use of services in Bihar and Jharkhand, India examined accessibility from the perspective of rural, Indian women. Women had limited exposure to mass media. They relied on community health workers, family and friends for health information. Women who reported exposure to abortion messages were more likely to have favorable attitudes toward abortion [111].

Despite governments intention in the seventh five year plan (1985-90) period to make abortion services available at all the PHCs in the country, only about half could start the facility and many among them were not functional because of lack of trained staff or equipments $[89,91]$. Secondary infertility and reproductive tract infections are common morbidity from unsafe abortions. Post abortion care is widely available in the villages from untrained or inappropriately trained providers. Given that these providers are the first source of care for many women, abortion complications may be exacerbated rather than alleviated, appropriate care delayed and the cost of treatment increased [88]. Additionally, complications from unsafe abortion also lead to loss in income and expenses for the health system. It is estimated that burden on health care systems in the developing world is about $\$ 375-\$ 838$ million annually; women and families pay an additional $\$ 600$ million out of pocket [112]. Thus there is substantial social, economic and emotional strain from resorting to unsafe abortion.

Many studies in India carried out in medical college hospitals or others help us to get a clear picture of the unsafe abortions, methods used for the same and complications resulting from it and contraceptive behavior of abortion seekers. The findings are compiled below:

- Of 1203 MTP cases that were analyzed, the induced abortion was carried out for the first pregnancy by $6.7 \%$ of women; $8.9 \%$ women had at least one previous MTP and $6.3 \%$ a previous spontaneous abortion. The proportions of higher gestation cases were significantly higher in public hospitals $(44.1 \%)$ as compared to other centers $(28.3 \%)$ [113].

- Retrospective analysis of 28236 MTP cases from hospital records over a span of 17 years by a study noticed that there was no decline in the rate of induced abortion over the 17 year period. Only $1.1 \%$ women were in the teenage group. Most $(99.4 \%)$ of the women were married. $72.5 \%$ women were having two or more living children. $89.3 \%$ had less than 12 weeks pregnancy at the time of termination. $52.7 \%$ accepted intrauterine contraceptive device (IUD), 38.4\% underwent sterilization, $1.7 \%$ accepted barrier or hormonal methods, while $7.2 \%$ did not accept any contraception [114].

- Of the 100 women accepting MTP in the 6 months period, only $27 \%$ were using regular contraception, condom being used by three fourths of them. Only one woman out of 100, was aware of Emergency Contraception even though it was a predominantly urban and educated population [115].

- A total of 5003 obstetrical admissions for pregnancy and its related problems took place from 1st May, 2003 to 30th April, 2004 at a tertiary health care center in UP, out of which $7.0 \%$ were for abortions threatened, incomplete, inevitable, missed, and septic ones, giving an incidence of $34.7 \%$. Most women chose to terminate the pregnancy because they did not want any more children. Their mean 
age was 30.03 years and mostly from rural areas. $78 \%$ of these women were not aware that induced abortions could be labeled as legal or illegal and of the availability of voluntary abortion (MTP) services run by government. Sixty-two percent of the women had knowledge of some kind of contraceptive measure but only seven (5.7\%) had ever used some contraception. $47.5 \%$ were admitted in a state of septic shock [116].

- A matched case control study was undertaken to investigate the possible association of induced abortion (MTP) and contraceptive behavior. Data were collected from 80 married abortion seekers attending family welfare clinic attached to Medical College, 80 pregnant controls who wanted to continue pregnancy, and 80 non-pregnant controls receiving service at the study hospital. Conditional logistic regression analysis was done for predicting risk factors. Multivariate analysis showed three statistically significant risk factors $(P<0.05)$--using only natural methods of contraception, rare discussion about contraception with partners, and frequent intercourse [117].

\section{Sex-selective abortions}

Going by the 2008 figures, Uttar Pradesh recorded the highest number of MTPs at 89,194, followed by Tamil Nadu $(63,875)$, Odisha $(59,945)$, Assam $(58,409)$ and Maharashtra $(54,545)$. The other states with high abortion numbers include West Bengal $(46,753)$, Haryana $(31,126)$, Delhi $(30,846)$, Rajasthan $(29,292)$, Gujarat $(27,837)$ and Bihar $(24,149)$. The states with the lowest abortion figures are Daman and Diu (43) and the Andaman and Nicobar Islands (94) and Goa (930) [118]. Advances in technology which is able to save many lives has its flip side too. Son preference in India leads to women availing ultra sound scanning facilities to find out the sex of the fetus. India legally allows abortion up to 12 weeks of pregnancy. Gender can be determined only after 14 weeks of pregnancy and sex selective abortion is illegal. But medical practitioners have found a way of circumventing the law. In Bihar, there are more than 1,000 ultrasound clinics, many of them still unregistered. Sex selective abortion was not the focus of the Bihar government until recently. The recent census figures was a wake up call which showed the dwindling number of female children. Madhya Pradesh was always under lens for sex selective abortion. Despite this fact, the unregistered ultrasound clinics are mushrooming in the state. The more laws and raids are there, the more these clinics charge for ultra sound and abortion.

Prenatal sex detection with ultrasound followed by second trimester abortion is one of the ways sex selection manifests itself [80]. Women are at the receiving end since there is pressure from immediate family elders to seek this facility as well as to end the pregnancy if fetus is female [118-125]. The demand has made sex selective abortion a flourishing business run by medical professionals as well as untrained persons. Often if abortion seeking is for sex selective abortion, higher the chances of it being discreet and from untrained providers since sex determination is banned by law. Since 1991, 80 percent of districts in India have recorded a declining sex ratio with the state of Punjab being the worst. There have been only two convictions -- a fine of 300 rupees (\$7) and another fine of 4,000 rupees (\$98) -- from over 400 cases lodged under the Preconception and Pre-natal Diagnostic Techniques Act [126].

Many of the national efforts have led to concerted action by states in taking steps to prevent sex selective abortion at the same time promoting safe abortion. Union health ministry has asked states to conduct a massive campaign popularizing safe abortion, besides informing women that the confidentiality clause will keep their identity secret [118]. The health ministry has identified 20,000 model health facilities across the country that will now be open for abortion service round the clock. 24 hour PHCs introduced under the NRHM, is supposed to be provided with the facility of safe abortion through MVA. Effort should be made to provide routine MTP with other techniques if infrastructure and skilled staff are available. All 24 hour PHCs should also 
have the facility to provide round the clock FP counseling and provision.

The sex ratios in Madhya Pradesh are 930 females, Odhisha is 978 and Bihar is 916 females per 1000 males as per census 2011. Bihar had lower number of females per 1000 males in the 2011census compared to sex ratio in the 2001 census, while Madhya Pradesh had shown slight improvement and Odhisha negligible improvement. As rightly said in the editorial of the recent issue of the British Medical Journal, trying to punish doctors because sex ratios in the country have caught global attention; women seeking services will be at the receiving end, leading to unsafe abortions and complications. "Abortions for the purpose of sex selection in India have again caught the attention of Indian policy makers and the global press after the 2011 Indian Census showed a decline in the sex ratio. The number of girls per 1000 boys dropped from 927 in 2001 to 914 in 2011 for children aged 0-6 years. 1 Most notable was Maharashtra state, which recorded a decline in the sex ratio from 913 in 2001 to 883 in 2011. Under an intense media spotlight, the state has set out to "save the girl child" under the tenets of the Pre-Conception and Pre-Natal Diagnostic Techniques (Prohibition of Sex Selection) Act. There have been waves of suspensions of doctors for violating this act. However, a parallel stream of ill informed directives may result in the victimisation of women seeking abortion [127]." 


\section{CHAPTER 5: ACCESS TO AND QUALITY OF FAMILY PLANNING AND ABORTION /POST ABORTION SERVICES}

\section{Introduction}

With the push to achieve millennium development goals and countries far behind in its achievement; some more than others and some able to achieve the goal; underlying factors were studied. Thus came into prominence the need to strengthen health systems [1-4] and also the role of task sharing as a strategy to deal with shortage of trained health care staff. WHO (2003) alludes that if health systems are not strengthened, the health related MDG outcomes in some of the poorest countries will remain far below the target [4]. "Historically, health care systems in many developing countries suffer from serious deficiencies in financing, efficiency, equity and quality. most of the reforms introduced in the health sector of developing countries emphasize internal reorganization of the public sector, particularly through decentralization [1; pg.7,9]. Public-private partnerships are also encouraged to improve quality care and accessibility of services. More attention is given to community level workers and motivating target groups to access services.

The availability of health facilities at the village level plays an important role in shaping the fertility behavior of women [5]. The poorest has the least access to a health facility due to barriers like distance, unpaved roads, lack of transport and not having money for travel. Planning commission as well as other units in the government recognizes that weak referral system at the $\mathrm{CHC}$ and $\mathrm{PHC}$ levels and bifurcation of health and family welfare and nutrition functions at all levels are limiting the health care of the rural population. Access to health facilities is the first and most necessary step so that people can go to the next level of care for their health and family planning needs.

\section{Availability of health facilities}

Table 5.1 provides an insight into the current status of shortfall of health facilities in the focused states. The shortfall in the sub centres in Bihar is 8,837, in Madhya Pradesh it is around 3,445 and in Odisha it is 1,448[6]. The data also show that there are significant shortfalls in PHCs also in the focused states.

Table 5.1: Shortfall of health infrastructure as on March 2011

\begin{tabular}{|l|l|l|l|l|l|l|}
\hline \multirow{2}{*}{ Facility } & \multicolumn{3}{|l|}{ Bihar } & Odisha & \multicolumn{2}{l|}{ Madhya Pradesh } \\
\cline { 2 - 7 } & Required & In Position & Required & In Position & Required & In Position \\
\hline Sub Centre & 18533 & 9696 & 8136 & 6688 & 12314 & 8869 \\
\hline PHC & 3083 & 1863 & 1308 & 1228 & 1977 & 1156 \\
\hline CHC & 770 & 70 & 327 & 377 & 494 & 333 \\
\hline
\end{tabular}

Source: RHS Statistics, 2011. MoHFW

It was evident from the DLHS-3 survey (Table 5.2) that nearly one-third of the villages in Bihar, one-fourth of the villages in Madhya Pradesh and nearly half of the villages in Odisha reported there is a sub centre in the village. Nearly 5 per cent of the villages in Bihar and Madhya Pradesh reported there is a PHC in the village, but the number of villages with $\mathrm{CHC}$ were few in number. The DLHS-3 facility survey reports also indicate that nearly 59 percent of the villages in Bihar, 68 percent villages in Madhya Pradesh and 27 percent villages in Odisha were not having any health facility in 2007-08 [7]. 
Table 5.2: Percentage of villages reporting availability of various health facilities in the village, 2007-08

\begin{tabular}{|l|l|l|l|}
\hline Health Facility & Bihar & Odisha & Madhya Pradesh \\
\hline Sub Centre & 32.7 & 52.4 & 25.6 \\
\hline PHC & 5.5 & 44.5 & 5.1 \\
\hline Block PHC & 2.3 & 43.1 & 2.2 \\
\hline CHC/RH & 1.0 & 43.3 & 1.2 \\
\hline District/Government Hospital & 1.6 & 50.8 & 2.9 \\
\hline Government Dispensary & 1.4 & 46.8 & 1.9 \\
\hline Private Clinic & 9.4 & 43.8 & 8.7 \\
\hline Private Hospital/Nursing Home & 1.7 & 46.0 & 0.8 \\
\hline AYUSH & 5.2 & 53.5 & 4.1 \\
\hline Any Health Facility* & 40.6 & 72.8 & 32.2 \\
\hline No Health Facility* & 59.4 & 27.2 & 67.8 \\
\hline
\end{tabular}

Source: DLHS 2007-08; *Integrated Child Development Centers (ICDC) were not included

The DLHS-3 Facility survey also captured the distance of the nearest health facility from the village if any village reported they did not have a health facility within the village.

Table 5.3: Percentage of villages that does not have health facilities by distance to nearest health facility

\begin{tabular}{|c|c|c|c|c|c|c|c|c|c|c|c|c|c|c|c|}
\hline \multirow{2}{*}{$\begin{array}{l}\text { Health } \\
\text { Facility }\end{array}$} & \multicolumn{5}{|c|}{ Bihar } & \multicolumn{5}{|c|}{ Odisha } & \multicolumn{5}{|c|}{ Madhya Pradesh } \\
\hline & $\begin{array}{l}<1 \\
\mathrm{~km}\end{array}$ & $\begin{array}{l}1-2 \\
\mathrm{~km}\end{array}$ & $\begin{array}{l}3-5 \\
\mathrm{~km}\end{array}$ & \begin{tabular}{|l|}
$6-10$ \\
$\mathrm{~km}$
\end{tabular} & $\begin{array}{l}>10 \\
\text { km }\end{array}$ & $\begin{array}{l}<1 \\
\mathrm{~km} \\
\end{array}$ & $\begin{array}{l}1-2 \\
\mathrm{~km} \\
\end{array}$ & $\begin{array}{l}3-5 \\
\mathrm{~km}\end{array}$ & $\begin{array}{l}6-10 \\
\mathrm{~km} \\
\end{array}$ & $\begin{array}{l}>10 \\
\mathrm{~km}\end{array}$ & $\begin{array}{l}<1 \\
\mathrm{~km}\end{array}$ & $\begin{array}{l}1-2 \\
\mathrm{~km} \\
\end{array}$ & $\begin{array}{l}3-5 \\
\mathrm{~km}\end{array}$ & \begin{tabular}{|l|}
$6-10$ \\
$\mathrm{~km}$
\end{tabular} & $\begin{array}{l}>10 \\
\mathrm{~km}\end{array}$ \\
\hline Sub C & 18.1 & 24.4 & 36.7 & 10.0 & 10.9 & 17.9 & 28.5 & 35.3 & 13.3 & 5.0 & 9.8 & 13.1 & 45.4 & 24.3 & 7.3 \\
\hline $\mathrm{PHC}$ & 2.3 & 4.6 & 26.8 & 35.1 & 31.1 & 9.3 & 11.1 & 26.8 & 24.8 & 27.9 & 9.9 & 2.6 & 15.3 & 25.3 & 46.8 \\
\hline Block PHC & 2.1 & 3.1 & 22.7 & 33.4 & 38.7 & 4.2 & 7.8 & 16.1 & 26.0 & 45.9 & 18.6 & 1.1 & 6.7 & 15.1 & 58.4 \\
\hline $\mathrm{CHC} / \mathrm{RH}$ & 0.7 & 1.5 & 8.2 & 13.9 & 75.7 & 6.3 & 6.4 & 10.4 & 20.0 & 56.9 & 9.1 & 0.6 & 6.5 & 15.3 & 68.4 \\
\hline $\begin{array}{l}\text { Dist/Govt. } \\
\text { Hospital }\end{array}$ & 0.2 & 0.4 & 3.3 & 7.2 & 88.9 & 9.0 & 6.2 & 4.4 & 8.6 & 71.9 & 14.5 & 0.3 & 1.7 & 3.0 & 80.6 \\
\hline $\begin{array}{l}\text { Govt. } \\
\text { Dispensary }\end{array}$ & 0.9 & 1. & 8.8 & 12 & 76.8 & 9 & 7.6 & 14. & 14.2 & 54. & 10.4 & 1.9 & 9.4 & 14.5 & 63.7 \\
\hline Pvt. Clinic & 0.0 & 7.6 & 26.0 & 24.9 & 35.5 & 9.0 & 7.5 & 13.8 & 16.9 & 52.3 & 9.2 & 4.7 & 19.1 & 24.3 & 42.8 \\
\hline Pvt. Hospital & 2.0 & 3.2 & 14.1 & 21.6 & 59.0 & 9.0 & 5.2 & 8.6 & 12.2 & 64.9 & 7.4 & 0.7 & 5.2 & 10.8 & 75.9 \\
\hline AYUSH & 3.7 & 3.0 & 13.4 & 14.8 & 65.2 & 21.8 & 5.6 & 6.4 & 8.1 & 58.2 & 28.0 & 1.4 & 7.5 & 11.9 & 51.2 \\
\hline
\end{tabular}

Source: DLHS 2007-08

From Table 5.3 it can be seen that nearly 18 per cent of the villages in Bihar and Odisha where there is no sub centre in the village; the distance to the nearest sub centre is less than one $\mathrm{km}$ and in Madhya Pradesh, the corresponding figure is nearly 10 percent higher. It was also observed that majority of the villages in the focused states where there is no sub centre reported the nearest sub centre is within $5 \mathrm{~km}$ from the village. Nearly one third of the villages in Bihar and one-fourth of the villages in Odisha and Madhya Pradesh reported that their nearest PHC is situated around 6-10 km from the village. When we look at the distance of $\mathrm{CHC}$ or government hospitals, the distance of the nearest facility from the village gradually increases and in majority of the villages the nearest $\mathrm{CHC} /$ district hospital were more than $10 \mathrm{~km}$ away.

Presence of health facilities, its accessibility and presence of functional equipments, medicines and other supply and staff are vital for the population to receive services they are in need of. The DLHS Facility survey also captured the accessibility of the nearest health facility from the village throughout the year. 
Table 5.4: Villages that does not have health facilities' and reported accessibility to nearest health facility throughout the year

\begin{tabular}{|l|l|l|l|}
\hline Accessibility to: & Bihar & Odisha & Madhya Pradesh \\
\hline Sub Centre & 61.7 & 76.6 & 67.2 \\
\hline PHC & 66.8 & 75.0 & 68.5 \\
\hline Block PHC & 62.7 & 76.2 & 60.8 \\
\hline CHC/RH & 61.3 & 78.0 & 69.8 \\
\hline Dist/Govt. Hospital & 62.1 & 74.7 & 65.9 \\
\hline Govt. Dispensary & 52.7 & 78.5 & 70.5 \\
\hline Pvt. Clinic & 68.0 & 81.0 & 70.9 \\
\hline Pvt. Hospital/Nursing Home & 66.0 & 76.6 & 70.2 \\
\hline AYUSH & 49.2 & 72.6 & 57.4 \\
\hline
\end{tabular}

Source: DLHS 2007-08

From Table 5.4, it is evident that nearly 40 per cent of the villages in Bihar and around one third of villages in Madhya Pradesh, where they don't have a sub centre in the village cannot access the nearest facility throughout the year and the corresponding figure for Odisha is around 23 percent. In case of other health facilities nearly 70-80 percent of the villages in Odisha and Madhya Pradesh reported they can access the nearest health facility throughout the year, whereas, in Bihar nearly 60 percent of the villages reported accessibility of nearest government health facilities throughout the year.

Infrastructural and staff unavailability can affect the service seeking behavior of women for contraceptives and safe abortion. Chapter 3 described that camps was the main source of contraceptives of current FP us ers in Odisha and Madhya Pradesh (38.6\% \& 49.5\% respectively) and private sector in Bihar. Only very few women are receiving contraceptives from government services at the village level. In Odisha, village level government health facilities come next to camps and private facilities are hardly used (7.6\%). Although in Madhya Pradesh too private sector is not the popular source of contraceptives, village level services were accessed by only 14 percent whereas 32 percent had received current contraceptive from government hospital. A shift in this pattern was visible in the case of induced abortion services in Madhya Pradesh (Chapter 4). While private sector was used for abortion services in Bihar and public sector in Odisha as similar to the FP service utilization; it was different for Madhya Pradesh. It seems possible that non-availability of services/accessibility issues is the reason for contraceptive and abortion services being sought from private sector in Bihar.

\section{Exposure to media and quality of counseling on contraceptive methods and HIV}

A recent study in India concluded that the introduction of cable television lowered fertility. The authors noted in this connection that "television may affect fertility by providing information on family planning services or changing the value of women's time" or that "television exposes rural households to urban lifestyles, values and behaviors that are radically different than their own" $[8,9]$. The more television that women watch, the more likely they are to have used modern contraceptives, the fewer children they want (even among young never married women), and the fewer children they have. These findings persist in the presence of controls for education, wealth, urban residence, age, and other covariates. Studies in other countries of the region and in other regions also had similar findings [10].

The reach of mobile phones in India even in rural areas is increasing steadily. IRS data shows that reach of mobile phone use in Bihar among married men (22\%) is comparable to mass media such as television (32\%), 
but mobile phone reach among women (5\%) lag behind mass media [11-13]. A recent study on use of mobile phone reveals that out of the 10,080 households listed in rural Bihar, 42 percent owned at least one mobile phone. Reach of mobile phones at the individual level, however, is still very low, particularly among women. Furthermore the study showed that only 10 percent of women owned a mobile phone [14]. According to the IRS Round 2 data, only about 15 percent of individuals own a mobile phone in Bihar [11]. More than 90 percent of health care providers and health workers in Bihar either own or have access to a mobile phone; apart from making personal calls, they use the phone to contact their clients or contact their supervisors for guidance.

India had initiated passing on information about FP methods and other reproductive health matters through the media with the introduction of the NRHM program. Messages through media was present in earlier decade too but with NRHM it had increased in frequency and the content covered. Figure 3.2 shows that after 2 years of NRHM, 31-42.5 percent women had some exposure to media messages. Bihar had the least media exposure with 66 percent women reporting no exposure to FP messages through media. Poverty and unavailability of TV and radio could be one reason for this stark difference across states.

Figure 5.1: Percentage of women age 15-34 years who reported exposure to family planning messages through mass media, 2007-08

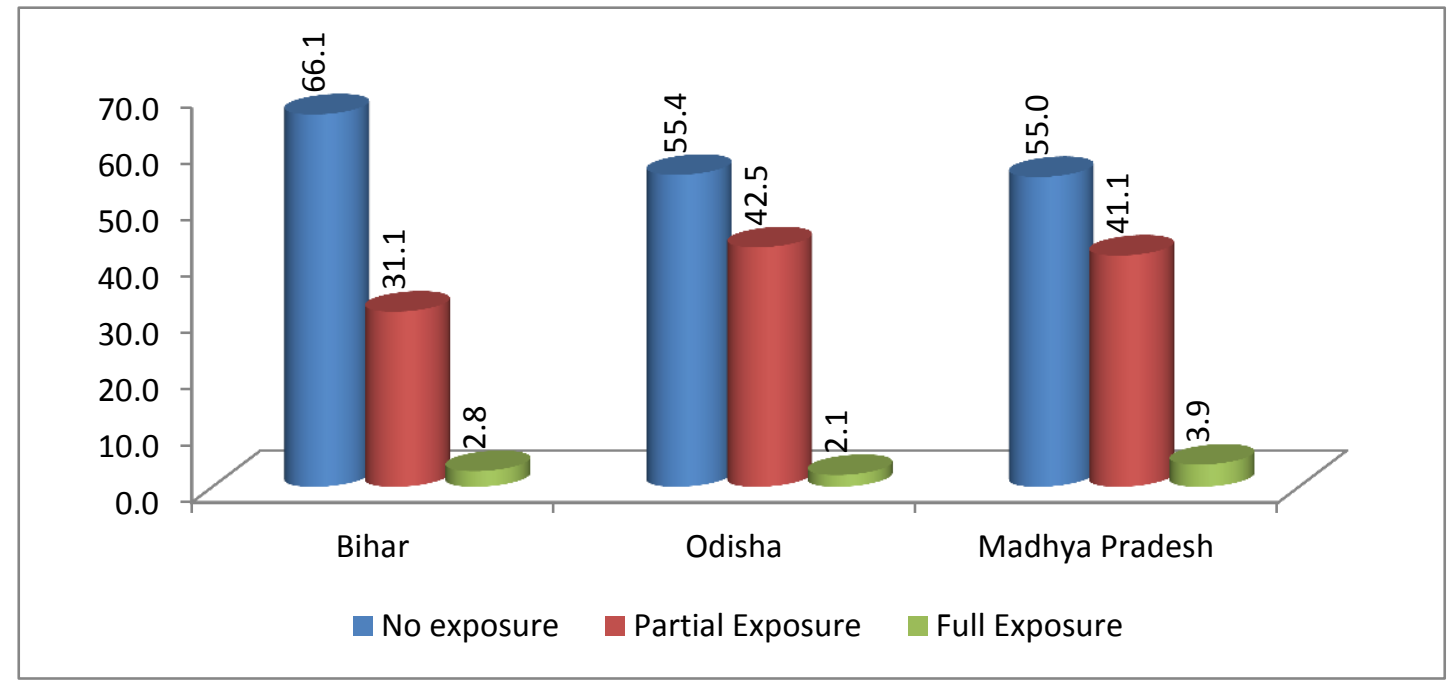

Source: DLHS 2007-08

Young unmarried rural Indian men's sexual and reproductive health (SRH) knowledge is limited, although the majority is familiar with condoms (99\%). The young men identified electronic mass media (67\%) as the prime source of reproductive health information, yet they lacked detailed knowledge of various contraceptives and felt ignored by health providers, who, they felt, would be capable of providing SRH information through interpersonal communication. Young men are more concerned about avoiding infections and securing sexual pleasure and less concerned about avoiding potential pregnancies. For example, $68 \%$ of the young men were aware of condoms and their HIVIAIDS preventive role, but only about two-fifths mentioned condom use to prevent unwanted pregnancies. Although most young men $(96 \%)$ knew where to access a condom, they felt uncomfortable or embarrassed doing so in their own villages or close by because of socio-cultural norms that prevented them from using contraceptives. Very few respondents (4\%) disclosed using condoms themselves, but $59 \%$ said they knew someone from their peer group who had used them [15]. 
As per the roles and responsibilities of the ASHAs and ANMs; they have to counsel women in the reproductive age on family planning methods and motivate them to adopt a method. The method that a woman adopts has to be after receiving information on all the methods and then she chooses a suitable method using the informed consent principles. DLHS 2007-08 data indicates that among women of reproductive age who were not using a method currently; 7.8 percent from Bihar, 18 percent from Orissa and 20 percent from Madhya Pradesh had received counseling on FP. Very few current users reported receiving information on side effects of FP: 15 percent from Bihar, 12.6 percent from Odisha and 31 percent from Madhya Pradesh. However, those who adopted IUD or sterilization reported receiving follow-up services within 48 hours: 73.5 percent in Bihar, 88 percent in Odisha and 74.9 percent in Madhya Pradesh.

Table 5.5 gives information about counseling young women received about family planning methods. The quality of counseling on contraceptive methods is very poor which is affecting the acceptance of FP methods and also discontinuation of the method by FP method acceptors.

Table 5.5: Percentage of women age 15-34 years who reported receiving counseling from community workers

\begin{tabular}{|l|r|r|r|}
\hline $\begin{array}{l}\text { FP worker informed } \\
\text { about : }\end{array}$ & Bihar & Odisha & Madhya Pradesh \\
\hline $\begin{array}{l}\text { The side effects of the } \\
\text { current method }\end{array}$ & 1.3 & 1.9 & \\
\hline $\begin{array}{l}\text { Among who were } \\
\text { counseled about side- } \\
\text { effects by CWs, \% told } \\
\text { how to deal with the side } \\
\text { effects }\end{array}$ & & & \\
\hline $\begin{array}{l}\text { Information about FP } \\
\text { methods }\end{array}$ & 67.1 & 60.9 & \\
\hline
\end{tabular}

Source: DLHS 2007-08; CW-Community workers

Very few young women reported being counseled about side-effects of FP methods or of different FP methods. Even among those who mentioned that CWs told them there would be side-effects, details regarding how to deal with the side-effects was lacking.

Awareness about the legal minimum age at marriage for girls and receiving family life education among adolescent and the unmarried women can play a role in their future behaviours. 39.3 percent, 43.6 percent, 35.2 percent umarried women from Bihar, Odisha, Madhya Pradesh respectively reported receiving family life education and 83.9 percent, 84 percent, 88 percent from Bihar, Odisha, Madhya Pradesh respectively knew the legal minimum age for marriage of girls in India. Knowledge that sex selection and sex determination tests are banned by law, how HIV is transmitted and where to get an HIV test done for free are also important determinants of access and healthy behaviors. DLHS 2007-08 had added new questions to gather this information. Women age 15-49 years who were aware that sex selection is banned by law was 38.4 percent in Bihar, 47.5 percent in Odisha and 47.3 percent in Madhya Pradesh. 29.5 percent, 47.4 percent, 33percent from Bihar, Odisha and Madhya Pradesh respectively had heard about HIVIAIDS. Among women who had heard about HIV, very few women knew where one should go to get tested for HIV; only 43 percent from Bihar, 46 percent in Odisha and 52 percent in Madhya Pradesh knew. Data for India from the District Level Household and Facility Survey (2007-08) showed that only 51-72 percent of the pregnant women who attended at least 4 ANC visits were advised on at least one of the components of maternal and child care. Inequalities were highest in the case of advice on family planning methods. Advice on breastfeeding was least 
unequal. Public health workers working in lower level health facilities were significantly less likely than their counterparts in the higher level health facilities to provide specific advice [16].

A study conducted in Bihar shows that majority of the rural population in Bihar is out of reach from any mass media- newspaper, radio or television. An analysis of NFHS-3 data (2005-06) reveals that 65 percent of women, aged $15-34$ years in Bihar were not exposed to any mass media. A recent Population Council study (2011) shows no improvement in rural women's mass media exposure [9]. Interpersonal communication with ASHAs is better: 57 percent of women have met an ASHA at least once during their last pregnancy, to discuss health-related issues; in rural Bihar, however, the PC study shows both content and quality of counseling was poor. Further, ASHAs generally do not approach poor and Below Poverty Line (BPL) families, scheduled castes, and minorities living in cluster/hamlets, the families who need information and services the most. Midmedia such as wall paintings, posters, and leaflets for clients or counseling aids for effective counseling are hardly available at PHCs or with providers [17-19].

Discussions and interviews with state, district, and block officials revealed that the health sector's Media Unit and its sub-system in districts and blocks are too weak to implement an effective BCC strategy for all target audiences. None of Bihar's 38 districts have Mass Media Officers or deputies. Within blocks, the post of Block Extension Educator (BEE), who earlier was responsible for $\mathrm{BCC}$, has been vacant for eight to 10 years. Many district and block community mobilizers' positions, responsible for monitoring and guiding ASHA in their work, are also vacant. To make the Media Unit a viable instrument for health behavior change, it needs to be revamped, with a minimum of key staff [19].

\section{M-health and E-health initiatives}

The steering committee on health said that in the 12th plan (2012-17), all district hospitals would be linked to leading tertiary care centers through telemedicine, Skype and similar audio visual media. M-health will be used to speed up transmission of data. Disease surveillance will be put on a GIS platform. This highlights the scope for m-health and e-health initiatives in India and the government's eagerness to take this forward very quickly so as to reach the rural population with services using this initiative [20]. Concern of the global health community is that despite the promise; mHealth implementations are challenged to sustain scale at a national level in low and middle-income countries [21]. The report used the recommendations of the United Nations Commission on Life-Saving Commodities for Women and Children (or the Commodities Commission) and derived five priority categories: 1) Demand \& Awareness; 2) Performance \& Accountability; 3) Quality Monitoring; 4) Supply Chain Awareness; and 5) Financial Barriers. The analysis in the report concluded that sustainable financial models are contingent on a deep understanding of ecosystem players, market dynamics, and each value chain members' incentives specific to each application area [21].

A survey conducted by PWC in 10 countries (developed and developing countries) showed that on a 10 point scale, India stood at 7.8points on awareness and openness on $\mathrm{m}$-health; 6.4 points on regulatory environment, reimbursement and business model; 3.4 points on technology (lowest among the countries studied), 8.2 points on impact. 92 percent of physicians interviewed in India expected noticeable effect of $\mathrm{mHealth}$ on patient relations in coming 3 years. 52percent physicians believe that widespread adoption of $\mathrm{mHealth}$ is inevitable. Patients interviewed believe that mHealth offers convenient access to providers as well as possibility to reduce their own health care costs. mHealth is seen to address the pressing health care needs in India. However, patients felt that costs of mHealth implementation and lack of relevant applications were major barriers to mHealth. In general, mHealth was perceived as less disruptive to health care by emerging markets because for the vast majority in these countries it is not a substitution to care but the only access. 61percent of surveyed patients in emerging markets were aware of mHealth whereas it was only 37 percent in developed countries [22]. 
There are about 400 platforms in the government for providing telemedicine. There is one each in Bihar and Madhya Pradesh and 8 in Odisha run by medical colleges. As per the national e-governance action plan launched in 2006, about one lakh internet enabled Information and Communication Technology (ICT) access points termed as common service centers providing 80 services including maternity care and family planning were to be set up in different parts of the country by 2007. However, the use of these forums for dispensing health services is not adequate. Through public private partnership, some states are able to make use of telemedical consultations and comprehensive diagnostic services. Medicines are dispensed at these centers based on the e-consultation or tele-consultation.

A recent review of controlled trials of mobile technology-based health interventions delivered to health care consumers found that text messaging interventions increased adherence to ART and smoking cessation and should be considered for inclusion in services. Although there is suggestive evidence of benefit in some other areas, high quality, adequately powered trials of optimized interventions are required to evaluate effects on objective outcomes [23]. The current body of evidence in mHealth and $\mathrm{MNCH}$ tends to focus more on maternal health interventions, particularly reminders for antenatal appointments compared to newborn and child health interventions [24-26].

Given its scope and interest by all concerned in India, especially the government system; experiments are increasingly ongoing around mHealth. A few of these are mentioned below acknowledging the paucity of effectiveness and feasibility data.Mobile based audio and video for counseling increases client involvement and is ideal for low-literate population. It also increases community workers performance, confidence and credibility.

- mSakhi is a mobile based interactive tutorial in Hindi language with 153 health messages on prenatal and delivery care, postpartum care and family planning, and newborn care among others. Testing of 30 ASHAs from two districts with mSakhi intervention showed ASHAs were able to use the application successfully and that their own knowledge on the key health messages improved [27].

- mHealth experiment is underway in the area of HIVIAIDS. Mobile phones with the PHMMS application are used by workers for tracking, counseling and mange the Prevention of Parent to Child Transmission of HIVIAIDS (PPTCT) program. This medium is also used for the transmission of client data from the field level to the office, offering a means of monitoring and supervision [28].

- Using Blackberry, experiment is underway on remote screening, remote cardiac monitoring and early detection of fetal defects. in the areas of TeleOphthalmology, TeleSonography and Remote Cardiac monitoring there is partnership with government to provide services [29].

- More experiments are under way with tie ups with blackberry in the area of tele-medicine and mobile ECG. The eUNO is a simple handheld ECG device with a built in GSM modem. The system is supported by a secured web based platform the Rhythms24X7. The ECG, once it comes to the server, is automatically forwarded to the mobile phone of the consultant for reporting.

- In 2011, Spice had launched Jiyo Healthy, an IVR and SMS based health information system that provides $24 \times 7$ information on healthcare to users for a nominal fee [30].

\section{What works for increasing FP and safe abortion access?}

Women's awareness of their entitlements is a precursor to making demands for better maternal health services. A study was carried out in Odisha focusing on how best to improve service accountability. The study found three drivers of success as the generation of demand for rights and better services, the leverage of 
intermediaries to legitimize the demands of peer and marginalized women and the sensitization of leaders and health providers to women's needs [31]. For many of the barriers to family planning use like lack of information, misinformation, financial costs, provider unavailability, status of women and community biases $[32,33]$; there are some of other evidence available on how to tackle these and reach FP to the needy. ICPD gave the much needed paradigm shift from fertility control to reproductive rights and linked Family Planning and Sexual and Reproductive Health. ICPD has made it easier for integrated programs and that the rights approach have been helpful in increasing access to FP or rather decreasing unmet need [34]. A review on integrating STI, HIV care into FP program found evidence that demonstrates that integrated services can have a positive impact on client satisfaction, improve access to component services, and reduce clinic-based HIVrelated stigma, and that they are cost-effective. However, if it was able to reach men and adolescents with FP is inconclusive [35]. The stickler seems to be missing opportunities to integrate care and ability to maintain the quality of care. A systematic review in the year 2011 [36] to assess what works in family planning interventions in developing countries found the following. Most evaluations were of small scale interventions. However, available evidence over the last 14 years suggests that demand-side and supply-side interventions have led to improvements in attitudes and knowledge, inter personal communication and intention to use family planning. Mass media interventions were seen to have positive impact on contraceptive use [36-38]. Male involvement has been suggested as a means to increase contraceptive use [39-42]. Spousal communication and male involvement in decision making can positively influence family-planning use and continuation. However, in a study in MP, it was found that in joint families it is the relationship women have with in-laws that influences care seeking [39].

Offering the full range of FP to the woman before she leaves the hospital after childbirth is seen to be very effective in increasing FP acceptance [43]. Although LAM could protect women against pregnancy for 6 months postpartum and can reduce FP costs; its use is negligible because of the lack of correct knowledge of LAM among providers and community [43-45]. Peers can be a great source of motivation to follow good $\mathrm{MNCH}$ and FP practices. Participatory women's groups were linked to reductions in neonatal mortality (mortality in intervention vs. control was 42 vs. 59 per 1000 live births) [46]. A study by the Population Council [47] demonstrated that a woman only needs to have one friend who approves of or uses family planning to significantly increase her own chances of doing so. The observed association was significant even after controlling impact of other variables. All these show that community acceptance of birth spacing will go a long way in enabling contraceptive use by young women.

Despite service delivery guidelines in India expecting providers to provide FP counseling during antenatal visits; only a fraction of women receive counseling $[33,43]$. In a review of 27 articles and reports, to understand how to promote community based postpartum care, three approaches were identified: home visits from professional health-care providers, home visits from community workers, and home visits from community workers with referral or health-facility support [48]. All three approaches were found to be effective in promoting exclusive breastfeeding, but only the first and last approaches were effective in promoting adoption of family planning methods.

\section{Shortage of health staff and social marketing}

An assessment of the health care in India published in Lancet (2011) noted that India has more than 1 million rural practitioners, many of whom are not formally trained or licensed. Also the most disadvantaged individuals are more likely to receive treatment from less qualified providers [49]. Shortage of medical personnel especially in rural areas is a situation in developing countries preventing access to quality health care. Task sharing and task shifting has taken prominence in the effort to work around this issue. Almost 40 years of evidence and expert opinion support the safety, feasibility, and effectiveness of task sharing in the provision of family planning services [50]. 
ANMs and ASHAs are filling the gap in rural areas for FP counseling and provision. When community workers make home visits, travel time is eliminated for clients, and uptake and continued contraceptive use is facilitated. This positive outcome was one of the rationales behind household distribution of contraceptives (a type of community-based distribution [CBD] model) in Asia in the 1960s and widespread adoption of this model throughout the world [51-53]. In addition to reaching the rural population with the services, task sharing also reduces the cost to health care provision, also because lower level workers are paid less. Another distribution mechanism to reach the poor with FP is social marketing. The social marketing system, first conceived and described by Peter King and his colleagues at Calcutta's Indian Institute of Management in 1964 [54], has proved to be a viable and important model for delivering family planning so as to reach the poorest community with minimal running costs. For a large country like India, if six social marketing programs were able to reach 4.5 percent of the eligible couples, it was clear indication that social marketing succeeded in expanding modern contraceptive use [54]. Realizing that public health system alone cannot take the burden of generating demand and providing supply gave the push for social marketing and favorable government policies were put in place. Advertising is an integral part of social marketing programs and are able to reach the community with relevant messages on family planning methods.

Although presence of health volunteers from the community/ASHAs has increased ANC visits, institutional deliveries, and child immunization, they have made little positive impact on FP acceptance [55]. In Bihar, postpartum contraception increased from 13 percent in 2005-06 to 20 percent in 2010-11, seven percent in five years, the same as the prior contraceptive use increase in Bihar $[56,57]$. Public health system is more and more depending on NGOs and private sector to reach health facilities to the poor in rural areas. Janani, affiliated to DKT- International, provides family planning and comprehensive abortion care services in Bihar through a number of its outlets spread all over Bihar. Janani aims to make available the entire range of clinical and non-clinical family planning methods so that people could have choice. Janani has its own brand of clinics, called Surya clinics at the district level in 28 districts in Bihar [18, 58]. ASHAs are stocking contraceptive methods and providing them to clients for a small price like Rs.1 similar to the social marketing principle. However, it is discussed in the next chapter on financial mechanisms as ASHAs are paid for performance and not paid staff of the health department.

A delay of about one year on average between starting sexual activities and first use of modern contraceptives exists [59-63]. Emergency contraceptive pill can be seen as an option available to those indulging in unprotected sex to prevent an unwanted pregnancy. Emergency contraceptive pills is an over the counter product in the country from the year 2005, which can be given to women by ANMs. Yet even today, knowledge about the method is lacking among young women whether it be urban or rural women [62-67]. Also, availability of the pill at the sub center at any given time is not guaranteed. Inadequate knowledge of emergency contraceptive pills among providers and pharmacists is also hampering the correct use of emergency contraceptive pills by the needy [68-70].

In 2008 the Govt. of India piloted ECP introduction in the public health system by making CHWs the depot holder of ECP. Even though ECP is an innovative and unique method that gives one last chance to prevent unwanted pregnancy, the awareness and use of ECP remains low. India's Essential Medicines List still does not include ECPs, nor does it include any contraceptives.

\section{Access to Medical abortion pills}

Medical abortion pills have increased the availability of safe abortion services not only because of its ease of use, but also because any trained medical practitioner can provide it. Medical abortion was seen to be as effective whether taken at home or monitored in a clinic. Among women who took misoprostol at home, the proportion who had a complete abortion ranged from 86 percent (in India) to 97 percent (in Albania); the 
average success rate was 90 percent [71]. Misoprostol is one of the thirteen priority commodities listed by U.N. commission on life saving commodities. Where abortion is legal, use of medical abortion has expanded the array of effective options available, thus improving abortion experience [72]. The infrastructural and staff requirements of vacuum aspiration and $D \& C$ does not allow small clinics to provide safe abortion services, thus decreasing access to safe abortion in rural areas. This difficulty can be handled through the provision of medical abortion pills, provided referrals to hospitals providing MVA and PAC are well established and not very far away. Women in urban areas were highly likely to use medical abortion. Different studies that tested the effectiveness of MVA found it to be an easy and effective method of induced abortion [73-75].

A study by Gantra et al in 2005 in Bihar and Jharkhand found that most sales of medical abortion pills were prescription driven, though few over- the-counter sales did occur, especially when ability to pay seemed high or the chemist knew the customer [76]. The study also noted that chemists need accurate information on the drugs they sell as abortifacients, must be trained to encourage women to undergo pregnancy tests as well as for encouraging women to see a provider prior to purchase, and availability of visual and written material that can be given as hand out to whoever comes asking for abortifacient or abortion pill should be readily available at the chemists' shops.

Federation of Obstetric and Gynecological Societies of India and Population Services International organized a consultative meeting with organizations working to promote safe abortion in November 28, 2012 in Delhi in continuation of WHO SEARO meeting on Safe Abortions held at Kathmandu earlier. A concern that echoed throughout the meeting was how despite abortion being legal for some or other reasons doctors are refusing to conduct MTP, referring them elsewhere as well as medical abortion pills being unavailable even in chemist's shops. Providers are gripped by fear of prosecution $[77,78]$.

\section{Cost to families and fees levied for abortion}

The available statistics which highlight the deaths from unsafe abortions, show that most of these abortions were sought to end an unwanted pregnancy, which was preventable with contraceptive use. An unsafe abortion also adds a non-retractable cost to families, individuals and health system treating complications from unsafe abortions. About 60 percent of the unsafe abortions in Asia are among women below age 30 years and many unmarried women are seeking 2 nd trimester abortions or have sought abortion from untrained provider before reaching the hospital [79]. The issues of rape and coerced sex is also high among unmarried young girls and even in the case of consented sex, they may not use condoms because it is not there with them or because it might be seen as lack of trust of the partner. Young people are also secretive about their sexual activities and do not want to buy contraceptives and also try to hide their pregnancy and try illegal abortions. Lack of knowledge that abortion is legal and where abortion services are available also could send abortion seekers to unsafe abortion providers.

The cost of abortion services too will change depending on the reason for the abortion. Even providers in public health facilities ask for extra money if an unmarried woman is seeking abortion services. Similarly, they demand a huge fee for sex selective abortion saying they are risking themselves by conducting sex selective abortion though the requisite forms and documents would show it was to save the mother's life [80-84]. Bulk of the abortion services are available in the private sector either because of its unavailability in public sector or women prefer the confidentiality private sector offers. Private sector charges are huge and unaffordable for the poor and even they charge an exorbitant rate to unmarried girls and for female feticide. Wanting to keep their abortion seeking secret; families do not lodge complaint about the exorbitant charges levied or complications or death from abortion done by untrained providers [81-84].

Federation of Obstetric and Gynecological Societies of India and Population Services International mentioned 
at a meeting in Delhi that one issue is the lack of knowledge of doctors of the different forms and registers that they have to maintain or the procedures mentioned in the MTP and PNDT acts [77]. One of the recommendations made at the meeting was to that make abortion services available for every 20,000 population to reduce rural population seeking unsafe abortion providers. Union health ministry is committed to enforcing the suggestions they receive from this forum and so hope is not lost despite the discouraging new developments in its provision. The union ministry is seeking ideas for ensuring that $24 \times 7 \mathrm{PHCs}$ are able to provide safe abortion services. One suggestion in this meeting was to prepare small fact sheets with the different aspects of the Comprehensive Abortion Care (CAC) guidelines so that these guidelines reach the PHCs and are followed. The need for training about the different aspects of the MTP and PNDT act, CAC guidelines so the abortion service providers are able to follow it and not get prosecuted was also discussed. A study conducted in Rajasthan found that abortion service providers had only limited knowledge of the MTP Act and were weak in maintaining records and other formalities required within the MTP act and PNDT act [82]. Discussions are ongoing for expanding the provider base for improving access to safe abortion.

Hyman et al in their commentary in the journal Contraception suggests treating misoprostol as a harm reduction strategy for unsafe abortion just like how needle exchange programs and safe injection centers have been effective in preventing HIV transmission [85].

\section{Availability of abortion services at village level}

The National Population policy 2000 mentions expansion of safe abortion services as means to reducing MMR. It recommended MTP be available at PHC level. The $\mathrm{RCH}-2$ program documents further highlights governments commitment to provide safe abortion services by stressing the importance of increasing access, training health professionals to provide safe abortion services, counseling target population and awareness raising programs. It suggests that MTP and improving access and quality of safe abortion services should form part of the state PIP. The National Rural Health Mission's (NRHM) Programme Implementation Plan (PIP) for 2012-13 of all states mentions the push required for first trimester safe abortion service. State PIPs are prepared by the state planning team with the inputs received from the districts through the district health action plans. Within NRHM, lot of autonomy is given to the states and districts in planning, budgeting and implementation. The PIPs are a step in this direction.

The opening of 24 hour PHCs and the necessity of it being equipped with equipments and trained staff to carry out MTP and provide FP counseling and services round the clock that is mentioned in NRHM policy document is a step taken by the government to reach safe abortion services to the village level. Government has identified 20,000 model facilities to promote safe abortion practices [86]. Despite the initiation of $24 \times 7$ PHCs and inclusion of expanding the abortion service base within the PIPs of the states, abortion services are not available at PHCs and many CHCs because they lack either trained staff or the required equipment and supplies [87-89]. While public health delivery system is well established and monitoring procedures are easy to implement, the largest provider of abortion services continues to be the private sector, monitoring who is a difficult task.

Recognizing the need to increase access to safe abortion, particularly in rural areas, the Health Policy recommended expanding the provision of abortion services to the PHC level. The MTP Act was amended in May 2003 to specify that Medical Abortion (MA) could be provided by certified providers in unregistered facilities, as long as they had access to a registered facility for back-up [90]. This amendment means that medical abortion can now be provided at the PHC level fulfilling the above conditions. Awareness raising on the MTP Act, PNDT Act and about safe abortion services are another action recommended by the Ministry of Health and Family Welfare to improve access [91] 
The NRHM Programme Implementation Plan (PIP) for 2012-13 of all states mentions the push required for first trimester safe abortion service. The fund allocation of states will be cut, if such service is not doled out free to all women. The Union health ministry has sent guidelines on "Comprehensive Abortion Care" to all the states, including directions on how to counsel women before and after conducting an abortion. Funds are released to the NRHM for BCC campaign on safe abortion [92-94]. Available data indicate that in Odisha there were 401 approved facilities providing medical termination of pregnancy in 2008. 59,945 abortions were reported to have been carried out in 2008 at these facilities. 24 percent of available 1690 total health facilities only were providing MTP. Mostly PHCs in the state did not have facility to provide MTP [93].

\section{Expansion of provider base for safe abortion}

A South Asia consultation held in 2011 on the feasibility of expanding the provider base for improving acces s to safe abortion brought together studies from different South Asian countries on the feasibility, safety and effectiveness of expanding provider base [95-101]. The principles of task shifting and task sharing were embodied in these trials to increase abortion service base. All studies found that trained providers like nurses, midwives and non-allopathic providers can provide abortion till 8-9 weeks gestation safely and effectively just like allopathic medical practitioners trained in providing abortion services. The Consultation made a general recommendation that guidelines for abortion, MR and PAC service provision be prepared that are applicable to all abortion providers that is, including but not limited to other competent providers [101].

A 1997 Population Reports provided recommendations for post abortion care service improvements and expansion beyond hospital facilities. Although an increasing number of tertiary facilities were offering services, only a small proportion of women who experienced complications from unsafe or incomplete abortion were finding their way to hospitals for treatment and post abortion family planning services. Operations research from several countries contributed significantly to increase momentum for decentralized post abortion services. To expand access, some ministries of health authorized midwives and other providers at primarylevel facilities to offer post abortion care services, including treatment with manual vacuum aspiration. In many cases, this occurred once services at tertiary and other hospital facilities were functional and could accept referrals for abortion complications that could not be managed by primary-level providers

Currently, there are two main models- one developed by the PAC Consortium and another developed by the United States Agency for International Development (USAID); there are significant overlaps between the two. The model advocated by the PAC Consortium includes five elements: partnerships between communities and service providers; client-centered counseling at appropriate times during service delivery; treatment with emphasis on pain management; family planning; and links to reproductive and other health services [102-105]. The USAID model has three components: emergency treatment; family planning and STI and HIV services; and community empowerment via community awareness and mobilization. Countries have been able to draw upon the two models when designing and implementing post abortion care services [103]. Post abortion family planning services are integrated into post abortion care models. This is integral for ensuring that repeat abortions are not sought to end an unwanted pregnancy.

A study in Bangladesh showed that use of use of recommended technical interventions and providing menstrual regulation facilitates in reduction of health system costs [106]. An estimated 263,688 menstrual regulation procedures were provided at public-sector facilities in 2008, with incremental costs estimated at US $\$ 2.2$ million, and 70,098 women were treated for abortion-related complications in such facilities, with incremental costs estimated at US\$1.6 million.

Provision of manual vacuum aspiration by mid- level providers has made it possible for post abortion care services to be offered at primary health care facilities that are closer to the communities and also entail 
reduction in seeking abortion services from untrained persons [99]. Not only increasing access, it can also reduce cost incurred and the needed health system resources for post abortion care. India is moving towards legalizing this, but at this time it is being provided by only trained medical doctors. Partnerships and advocacy are necessary to keep up the momentum and political will to implement lessons learned from pilots in other countries [84]. India has been advocating for allowing mid-level providers to provide abortion services. Evidence suggests that pain management may not be a well followed part of post abortion care. Variety of reasons were seen for this non-compliance including short supplies of necessary medications and resources, negative provider attitudes toward women who have had an abortion or poor adherence to clinical protocol [101].

Despite family planning counseling being part of the post abortion care; it is not universally followed. There is empirical evidence that when contraceptives are available at the site of post abortion care services and women are counseled before discharge, they are more likely to accept a method than they are when those services are not provided [101-103].

To emphasize the importance of focusing on the process rather than new programs and policies, we cite below the findings from an experiment by Pathfinder [107]. The anti-shock garment to assist in the treatment of postpartum hemorrhage, works by stabilizing the women and thus giving time to arrange for definitive treatment. Evaluation to check effectiveness of anti-shock garment in saving lives found that cases of serious hemorrhage decreased in the facilities under study both in India and Nigeria where it was carried out. This resulted because of the training and health system strengthening that accompanied the introduction of the anti-shock garment. Pathfinder's training in 'continuum of care package' clarified to the providers what to expect at each stage of labor and what they should do. Thus by focusing on the entire process rather than the intervention of anti-shock garment; the program was able to save lives by preventing severe cases of postpartum hemorrhage that would have necessitated the use of anti-shock garment.

Ipas implemented an intervention to increase awareness about legality of the abortion in Jhankand and Bihar and also checked the increase in women seeking abortion and post abortion service. Although there was increase in seeking safe abortion services and acceptance of post abortion contraception; there was also increase in going to illegal providers and seeking treatment for abortion complications. Given this experience, the messages are being modified to include messages on consequences of unsafe abortion [108] 


\section{CHAPTER 6: FINANCING AND DELIVERY MECHANISMS}

\section{Introduction}

A recent analysis has shown that the proportion of governments in less-developed countries that provide direct or indirect support for contraceptive access grew from $64 \%$ in 1976 to $87 \%$ in 2009 . Estimates of donor assistance for population activities in 2008 , total $\$ 10.6$ billion, but only $\$ 0.25$ billion $(2.4 \%)$ is directed toward supporting family planning, or approximately US $\$ 0.17$ per woman of childbearing age in developing countries [1].

Although India is the largest democracy in the world, health is rarely a decisive political issue in national or state elections. According to a new Multidimensional Poverty Index (MPI) India has more poverty (421 million people in just eight states) than all of sub-Saharan Africa [2]. As per the official government estimates, 29 percent population are below the poverty line. The World Bank definition of poverty (an income of less than US $\$ 1.25$ a day) makes $42 \%$ of India's people living below the poverty line. But the newer MPI identifies over $55 \%$ of India's citizens as poor. According to this measure, $81 \%$ of Bihar's people are poor [3].

Lancet had published series of articles in the beginning of 2011; on the health systems in India and also published a call for action. A paper in Lancet described in detail the extent of health expenditure inequity and how poor are becoming poorer as a result; many of the points being touched upon by the other focused papers in the series. Other areas indicating inequity is the insufficient government funding for health, low density of educated health workers, unfilled vacancies or shortage of qualified health care providers and other health staff [3-10]. Few of these deliberations are noted here. Per person public health expenditures in Bihar was estimated to be INR93 compared with INR630 in Himachal Pradesh in 2004-05. Large proportions of resources are in urban-based and curative services, neglecting already disadvantaged poor rural population. About 39 million additional people are falling into poverty every year as a result of health care expenditures. Private expenditures on health have remained high during the previous decade, with India having one of the highest proportions of household out-of-pocket health expenditures in the world-71-1\% in 2004-05. Expenditure on drugs has been increasing with time, and drug costs constitute a greater proportion of out-ofpocket expenditures for people who are poor than for those who are not [5].

The Call to action began by stating that to sustain the positive economic trajectory that India has had during the past decade, and to honor the fundamental right of all citizens to adequate health care, the health of all Indian people has to be given the highest priority in public policy. The authors proposed ways to strengthen the existing health system through the creation of an Integrated National Health System in India-provision of universal health insurance, establishment of autonomous organizations to enable accountable and evidencebased good-quality health-care practices and development of appropriately trained human resources, the restructuring of health governance to make it coordinated and decentralized, and legislation of health entitlement for all Indian people [10].

\section{Conditional Cash Transfer Mechanisms}

A number of conditional cash transfer schemes exist with the aim of promoting value for girl child as a strategy to end the increasing female feticides. A few of these schemes are enumerated in detail. Although a small mention was made of the schemes in "Chapter 2: The legal, policy and socio-cultural context of the sexual and reproductive rights in India", the schemes are described in this chapter as there is cash transfer involved. Table 6.1 gives a list of these schemes that are described in more detail thereafter [11-22]. 
Table 6.1: Various conditional cash transfer schemes and their objective

\begin{tabular}{|c|c|c|c|}
\hline Name of Scheme & $\begin{array}{l}\text { State/central } \\
\text { level }\end{array}$ & Coverage/aim of scheme & $\begin{array}{l}\text { Year of } \\
\text { Introduction }\end{array}$ \\
\hline Apni Beti, Apna Dhan & Haryana State & $\begin{array}{l}\text { Post-delivery needs } \\
\text { Stop child marriage } \\
\text { Improve status or women and girl }\end{array}$ & 1994 \\
\hline Dhan Laxmi Scheme: & $\begin{array}{l}\text { Central covering } 7 \\
\text { states }\end{array}$ & $\begin{array}{l}\text { Birth registration } \\
\text { Total immunization } \\
\text { School enrolment } \\
\text { Marriage after age } 18 \text { years }\end{array}$ & 2008 \\
\hline Balika Samridhi Yojana & Central & $\begin{array}{l}\text { Change status of girl } \\
\text { School enrolment and higher studies } \\
\text { Marriage after age } 18 \text { years }\end{array}$ & 1997 \\
\hline Ladli Lakshmi Yojana & Madhya Pradesh & $\begin{array}{l}\text { Change status of girl } \\
\text { School enrolment and higher studies } \\
\text { Marriage after age } 18 \text { years }\end{array}$ & 2007 \\
\hline Kanya Suraksha Yojana & Bihar & Protection girl child births & 2007 \\
\hline Free bicycle scheme & $\begin{array}{l}\text { All three focused } \\
\text { states }\end{array}$ & Girl's enrolment in higher classes & 2009 \\
\hline Free Uniform & $\begin{array}{l}\text { All three focused } \\
\text { states }\end{array}$ & Free uniform for girls & \\
\hline Kanyadhan & Bihar & $\begin{array}{l}\text { Marriage after age } 18 \\
\text { Meet marriage expenses }\end{array}$ & 2007 \\
\hline Kanya vivah & Madhya Pradesh & $\begin{array}{l}\text { Marriage after age } 18 \\
\text { Meet marriage expenses }\end{array}$ & \\
\hline Janani sureksha yojana & Central & Institutional delivery & 2005 \\
\hline $\begin{array}{l}\text { Janani Shishu Suraksha } \\
\text { Karyakram }\end{array}$ & Central & $\begin{array}{l}\text { Additional expense coverage in the above } \\
\text { scheme (JSY) }\end{array}$ & 2011 \\
\hline Mamata Scheme & Bihar & $\begin{array}{l}\text { Personal care by trained midwife during } \\
\text { hospital delivery }\end{array}$ & \\
\hline Mamata Scheme & Odisha & $\begin{array}{l}\text { Conditional electronic cash transfer to } \\
\text { pregnant women }\end{array}$ & 2011 \\
\hline $\begin{array}{l}\text { Indira Gandhi Matritva } \\
\text { Sahyog Yojana }\end{array}$ & Central & $\begin{array}{l}\text { Coverage for wage loss due to delivery } \\
\text { and child care }\end{array}$ & 2010 \\
\hline $\begin{array}{l}\text { Bhaygashree and } \\
\text { Rajajeshwari insuraces }\end{array}$ & Central & $\begin{array}{l}\text { Accidental death of one or both parents of } \\
\text { girl } \\
\text { Death or disability of insured women age } \\
10-75 \text { years } \\
\text { Covers sterilization, hysterectomy, } \\
\text { cesarean, breast removal- cancer }\end{array}$ & 1999 \\
\hline
\end{tabular}

Apni Beti, Apna Dhan (ABAD): Apni Beti, Apna Dhan, which translates to "Our Daughter, Our Wealth," is one of India's first conditional cash transfer programmes dedicated to delaying young marriages across the nation. In 1994, the Indian government implemented this programme in the state of Haryana. On the birth of a mother's first, second, or third child, they are set to receive ₹500, or US\$11 within the first 15 days to cover their postdelivery needs. Along with this, the government gives $₹ 2,500$, or US\$55, to invest in a long-term savings bond in 
the daughter's name, which can be later cashed for $₹ 25,000$, or US $\$ 550$, after her 18 th birthday. She can only receive the money if she is unmarried.

Dhan Laxmi Scheme: The experience of the ABAD scheme was used by the central government to launch the Dhan laxmi scheme in 2008. It was launched in eleven backward blocks of seven states (Andhra Pradesh, Chhattisgarh, Odisha, Bihar, Jharkhand, Uttar Pradesh, Punjab). It covers families below and above the poverty line. The family of the girl child will be provided with a substantial amount of money if the following conditions are fulfilled: (1) registration of the birth of the girl, (2) following the total immunization schedule, (3) school enrolment, (4) delaying marriage till age 18 years. The scheme is in the form of insurance and the family receives a certain amount each year which will help them to pay the insurance premium. An insurance cover Rs. One lakh will be given to the girl at birth for born after November 19, 2008 and is unmarried till age 18 years.

Balika Samridhi Yojana: This scheme was introduced by the central government in 1997 with the aim of changing the negative attitude to girl child and her mother at birth of a girl, to improve enrolment and retention of girls in schools, to raise the age at marriage of girls and to assist the girls to undertake income generating activities. Payments are made various points like birth of the girl, her admission to school and various classes as per the amendment made in 2000. Rs. 500/- at the time of birth, Rs.300/- annual scholarship for classes 1 to 3, Rs. 500/annual scholarship for class 4, Rs. 600/- annual scholarship for class 5, Rs. 700/- annual scholarship for classes 6 to 7, Rs. 800/- annual scholarship for class 8, Ra.1000/- annual scholarship for class 9 to 10. Though the amount can be withdrawn only after the bond matures, each year the amount required to pay the premium can be withdrawn for this sole purpose.

Ladli Lakshmi Yojana, MP: Ladli laxmi yojana is a scheme introduced by the government of Madhya Pradesh in 2007. Since then, six other states have emulated the scheme. The government purchases a Rs.6,000 national savings certificate every year after the girl's birth till the amount reaches Rs.30,000. When the girl attains the age of 21 and had not married before 18 years of age, she will be paid the amount in lump sum, which comes to Rs one lakh. At the time of admission to sixth standard, Rs. 2000 will be given; at the time of admission to ninth standard Rs. $4000 /$ - will be given and at the time of admission to $11^{\text {th }}$ standard Rs. 7,500/- will be given. During $11^{\text {th }}$ and $12^{\text {th }}$ class education, she will receive Rs.200/- every month. The eligible beneficiaries' families income should be below that for which income tax is levied, parents should have adopted family planning after two live children and are registered in anganwadi center.

Kanya Suraksha Yojana (Girl protection scheme): This scheme was introduced by the state of Bihar seeing the sex ratio declining. It hopes to ensure safety and security for the girl child, improve sex ratio and encourage registration at birth. The state government would invest Rs. 2,000 for the first two girls in a family living below the poverty line, born on or after November 22, 2007. On completion of 18 years by the girl, the maturity amount will be paid to her (about Rs.18,000/-). If the girl child dies in the interim period the amount will be paid back to the government.

Free bicycle scheme for girls: Under the scheme, free bicycle is given by the Madhya Pradesh government to a rural girl, who takes admission in class IX in another village. Since 2009, the benefit of this scheme is being extended to girls belonging to all the sections of society and also to girls taking admission in class 6 in another village. This scheme exists in Bihar for girls entering class IX. In Odisha, bicycle scheme covers in addition to girls, scheduled caste/tribe boys entering class X. Girls from class 6 to 8 gets Rs.700 every year for purchasing two pairs of uniform.

Other educational schemes of Madhya Pradesh: Gaon ki beti yojana provides financial assistance to rural girls for higher education. Rs. 500 per month is given for 10 months to girls who pass class 12 exam with $60 \%$ marks. Pratibha kiran yojana is for girls belonging to families below poverty level in urban areas. Girls taking admission 
for higher studies in the year of passing class 12 exam will be given Rs. 300 per month for degree courses and Rs. 750 per month for technical courses.

Kanyadan or Kanya vivah scheme: This scheme which exists under different names in the state of Bihar and Madhya Pradesh was introduced with the aim of promoting marriages after age 18 years of the girls and age 21 years of the boys. Under the scheme in Bihar, a bond of Rs.2000/- will be issued at the time of the girl's birth. The amount that matures when the girl turns 18 years will assist in meeting her marriage expenses. In Madhya Pradesh, families enrolling for mass marriage ceremony will be paid Rs. 10,000 out of which Rs.9000 is given to procure household items; provided the girl is above 18 years of age at the time of marriage.

Janani Surakhsha Yojana (JSY): Allocating special benefits to low income families is a strategy for poverty reduction. Poverty is also forcing families to forgo health seeking and hospital deliveries [22-25]. The National Rural Health Mission (NRHM) with the objective of promoting institutional deliveries of below poverty line families launched the Janai Surakhsha Yojana (JSY) in April 2005; and hoped to reduce maternal mortalities and morbidities by promotion of institutional deliveries. Its beneficiaries multiplied 11-fold, from 0.74 million in 200506 to 8.43 million in 2008-09 (thus covering nearly a third of the 26 million women who deliver in the country annually). Budgetary allocation for the JSY increased from a mere US $\$ 8.5$ million to $\$ 275$ million in the same period [22]. Analysis of the DLHS3 data showed that the implementation of JSY in 2007-08 was highly variable by state-from less than 5 percent to 44 percent of women giving birth receiving cash payments from JSY. The poorest and least educated women did not always have the highest odds of receiving JSY payments. However, there was association with reduction in neonatal and perinatal mortality [23]. Even though rates of delivery in institutions have increased with time, only 40 percent of women in India report giving birth in a health facility for their previous birth in 2005-06, with women in the richest quintile six times more likely to deliver in an institution than those in the poorest quintile[5].

Table 6.2: Institutional deliveries in rural areas, 2005-2011

\begin{tabular}{|l|l|l|l|}
\hline & Bihar (\%) & Odisha (\%) & Madhya Pradesh (\%) \\
\hline NFHS 3(2005-06) & 19 & 20 & 20 \\
\hline DLHS 3 (2007-08) & 26 & 41 & 41 \\
\hline UNFPA (2009) & 49 & 73 & 73 \\
\hline AHS (2010-11) & 46 & 70 & 72 \\
\hline $\begin{array}{l}\text { Mothers who availed financial assistance for delivery } \\
\text { under JSY (AHS 2010-11) }\end{array}$ & 31 & 63 & 69 \\
\hline $\begin{array}{l}\text { Mothers who availed financial assistance for } \\
\text { institutional delivery under JSY (AHS 2010-11) }\end{array}$ & 67 & 88 & 85 \\
\hline
\end{tabular}

Source: NFHS 2005-06, DLHS 2007-08, AHS 2010-11 [26-37]

Table 6.2 shows that JSY has succeeded in increasing institutional deliveries. Odisha and Madhya Pradesh were more successful than Bihar in this occurrence. Avialability of facility in rural areas as well as the lack of money available for transport to the facility may be mediating the use of JSY. The recent survey in these states showed that in Odisha and Madhya Pradesh over 85 percent women mentioned that they availed JSY for institutional delivery. It was only 67 percent in Bihar whereas rural population in Bihar is comparatively poorer than the other two states.

Evaluations of the JSY showed that despite the increase in hospital deliveries, the very poor are often not able to access services since public health facility is not there close to their place of residence. Hospitals are not able to take care of the load of patients reaching for services; many times patients are delivering on hospital floors. JSY 
implementation is still immature; the findings also reflect a poor quality of maternal and neonatal care in facilities, and weak linkages. Deliveries are sometimes done by unskilled support staff rather than by skilled nurses or doctors. Most mothers and babies are discharged within hours after delivery [22-25]. There is an urgent need to ensure continuing postnatal care to neonates and mothers at home, where they spend the rest of the at-risk postnatal period [22]. Payments to families and the health workers are delayed in places and there are instances of corruption [38-40].

Janani Shishu Suraksha Karyakram (JSSK): Although the JSY scheme was successful in increasing hospital deliveries but many women opted for home deliveries because of the out of pocket expenses for travel and medicines. So government has widened its scope to cover expenses for transportation, medicines and sick child also into the program and is now called Janani Shishu Suraksha Karyakram (JSSK) which was launched in June 2011. Under the scheme, pregnant women coming to government hospitals for giving birth to a child will be given free medical care, food, and travel expenses. The scheme would ensure cashless delivery services, including Caesarean section, regardless of their above or below poverty line status. The free care services would be available for the mother up to 42 days from the date of giving birth and up to 30 days for every new-born, including care if required in a neonatal ICU. Through this scheme, Government hopes to bring down MMR and IMR by half in the next five years $[41,42]$.

Mamta Scheme: Under this scheme implemented in Bihar, trained midwives would be posted at hospitals and sub-divisional health centers to take care of mother and their new born babies, the midwives will be paid Rs. 75 for taking care of a mother and her new born. The scheme is expected to attract women to undergo hospital delivery [13].

Odisha has called their conditional electronic cash transfer scheme for pregnant women implemented from 2011 as Mamta scheme [18]. The scheme has been so designed that women become eligible for their third and fourth installments only if they meet certain conditions like proper immunization of the new-born. Evaluation by the state government noticed that most women fail to avail this money as they fail to meet the conditions embedded in the program. The scheme was open only to rural women when it was started in September 2011, but was opened for urban women too in August 2012. At least 7.34 lakh pregnant women in the State, including 7.18 lakh from rural areas, have registered themselves under the scheme. The State Government had disbursed financial assistance to the tune of Rs 196.48 crore till January-end through the scheme that aims at reducing infant and maternal mortality rate in the State [18].

Bihar state is in the process of initiating electronic cash transfer for pregnant women and also to ASHAs called government to people payments (G2P). Baseline data carried out by Population Council from three districts (Patna, Sheikhpur, East Choparan) before the G2P roll-out shows that longer time is required for processing the payments of ASHAs as the administration waits for a bulk of requests before processing. While women on average waited for 40-70 days for the money to their entitlements, ASHA's average waiting time for receiving payment was 240 days [40].

Indira Gandhi Matritva Sahyog Yojana (IGMSY): The Indira Gandhi Matritva Sahyog Yojana (IGMSY) was introduced by the Ministry of Women and Child Development for pregnant and lactating women, aiming to partly compensate them for wage-loss during childbirth and childcare and also provide conditions for ensuring safe delivery and promote good nutrition and feeding practices for infants and young children. The program is implemented in 2010-11 in 53 districts of India [21].

The IGMSY is a Conditional Cash Transfer (CCT) scheme offered as maternal benefits to women for their first two live births. Under the scheme, women directly receive a total cash payment of Rs. 4,000 during childbirth and childcare provided she is above 19 years and registered at an anganwadi center. The cash incentive is offered in 
three installments, first during the third trimester, second, three months after delivery and the third at six months after delivery. Each payment is contingent to satisfying certain conditions of availing services. However, no cash incentive is provided at the time of delivery since it is already being provided under JSY. The anganwadi worker receives a cash incentive of Rs. 200.

Very often the only source of health care available to the rural population is the public health system. Government hence needs assistance from other resources at the community level to leverage the need. The door was opened to local bodies for participation and cooperation as can be seen in the Eleventh Five-year Plan document (2007-12). Partnership with Panchayati Raj institutions which enjoys financial and administrative powers, community groups like youth, mahila mandals, self-help groups (SHGs), and Gram Sabhas are necessary for sustainable solutions to local problems [41-44]. Planning commission as well as other units in the government recognizes that weak referral system at the $\mathrm{CHC}$ and $\mathrm{PHC}$ levels and bifurcation of health and family welfare and nutrition functions at all levels are limiting the health care of the rural population.

Insurance schemes covering death and disabilities were introduced by the government of India. There are schemes that cover specific situations like death and disabilities after sterilization or failure of sterilization. The Bhagyashree and Rajrajeshwari insurance schemes are women focused insurances introduced in 1999. Bhagyashree child welfare policy is insurance meant for girls ages $0-18$ years and whose parents are below age 60 years. The cover provides relief to insured girl in case of the death of one or both parents from an accident. The premium is only Rs.15/- per annum per child. Under Rajrajeshwari mahila kalyan bhima yojana women age 10-75 years get cover for disablement or loss of two limbs/both eyes/one limb/one eye, accidental death of husband, expenses incurred for legal divorce proceedings and loss/damage to household effects. This covers sterilization, hysterectomy, cesarean, breast removal.

\section{Pay for performance Schemes}

The 1978 Alma Ata declaration of highlighted the importance of Primary Health Care and the critical role played by Community health Workers (CHW) to link communities to the health system [44]. A new type of health worker--Accredited Social Health Activists (ASHAs)--who are paid to accompany women to antenatal check-ups, delivery and post-partum visits was introduced in India. ASHA program is a critical component of the National rural health mission (NRHM) which was introduced in 2005 in 18 high focus states of India. NRHM is the principal programme of the government to achieve the health related millennium development goals such as reductions in infant mortality rate (IMR), and maternal mortality rate (MMR); as well as control of specific diseases, and improvement of nutrition status of children and mothers.

ASHA program is an incentive based program. ASHAs do not receive any fixed salary or honorarium. ASHA must be primarily a woman resident of the village - 'Married/Widow/ Divorced' and preferably in the age group of 25 to $45 \mathrm{yrs}$. The Ministry of Health \& Family Welfare (MoHFW) has developed a 23-day training schedule to provide the necessary knowledge \& skills to women identified as ASHAs [41, 42]. However, no quality checks of the quality of training or the assimilation of correct knowledge is in place. The success of the ASHA initiative depends on regular and reliable supervision; however this is a weak link in the system [43]. The main reason mentioned by ASHAs for becoming this health functionary are the financial incentive and the prestige and respect that they get in the community.

Payments to ASHA are frequently delayed, often due to procedural issues (e.g. funds not transferred to subdistrict, unfamiliarity with e-banking, confusion over what incentives are available). Some districts across the country are trying to introduce electronic transfers to counter delays and extortion. Approximately 60 percent ASHAs complain about delays in receiving their incentives. Delays were reported more for activities other than institutional deliveries $[41,44]$. Though direct payments system was introduced, the problems with delays and 
expenses incurred by making multiple trips have not diminished. A recent evaluation by Population Council of this government to people health payment system found that delays in receiving the incentive by women and ASHAs were huge. Corruption and request for bribes were also more in East Champaran region of Bihar than in Patna among the 3 districts under study [40].

\section{Supervision}

ASHA most regularly interact with ANM, AWW, MOs, and PRI. The most regular forum for interaction in most states is the Village Health and Nutrition Day (VHND). States have organized different supervisory structures; in some cases, ASHA report to a third party facilitator, and in most states they will report to the ANM or AWW. Anaganwadi worker being from another department of the ministry and carrying out many of the activities that ASHA is doing now; there exists confusion of each ones roles and responsibilities. Sure start project of PATH had worked to enhance the capacity of ASHAs and to improve their monitoring. VHND activities were strengthened. The project showed the necessity of huge investments to make these established mechanisms of the government to work efficiently [44].

\section{Social Marketing and ASHAs as family planning distributors}

An assessment of the health care in India published in Lancet (2011) noted that India has more than 1 million rural practitioners, many of whom are not formally trained or licensed. Also the most disadvantaged individuals are more likely to receive treatment from less qualified providers [4]. Shortage of medical personnel especially in rural areas is a situation in developing countries preventing access to quality health care. ANMs and ASHAs are filling the gap in rural areas for FP counseling and provision. In addition to reaching the rural population with the services, social marketing through ASHAs are hoped to benefit both the ASHAs who has taken up this role for financial incentive and the community she serves.

Review carried out by Khan and Hazra (2012) discussed the introduction of ASHAs for the provision of family planning methods [45].

In order to reduce the unmet need for spacing methods by increasing access of contraceptives in rural areas and uplift the motivation of health workers in family planning related issues, new initiatives have been taken on pilot basis. The concept of ASHA as agents of social marketing is being introduced for condoms, oral pills and sanitary napkins. In this regard on 4th August 2011, Govt. of India issued letter to the Secretaries, Health and Family Welfare, of 17 high focus states on the provision of home delivery of contraceptives (condoms, OCPs, ECPs) by ASHA at the doorstep of beneficiaries (MoHFW, 2011). As per the letter, "the Government of India supplies contraceptives such as condoms, oral contraceptive pills and emergency contraceptive pills to the states as part of free supply and social marketing schemes. However, access to these contraceptives is reported to be low because of several causes including delay in making supplies to sub district level downwards. As such, use of contraceptives in the country has become largely static. On the other hand, unmet need for spacing methods continues to be substantial. To improve access to contraceptives by the eligible couples, it has been decided to utilize the services of ASHA to deliver contraceptives at the doorstep of households and incentivize her for the effort. To begin with, the initiative is being implemented on a pilot basis in 233 districts in 17 States. In the districts where distribution of contraceptives by ASHA is being introduced, the free supply of contraceptives at PHC and Sub-Centre level would stand withdrawn in the light of the new provision of home delivery of contraceptives by ASHA. However, free supply of contraceptives at CHCs, Sub-Divisional and District level hospitals shall continue as before". ASHA would charge Re. 1 for a pack of 3 condoms, Rs. 1 for a cycle of OCP and Rs. 2 for a pack of one tablet of ECP, from the beneficiaries as an incentive for her efforts (MoHFW, 2011). 
As per the latest available information, among the 233 pilot districts, in 191 districts the program is already running and 158 districts of them have already started reporting (Sikdar, 2012).

$>$ As per this order, ASHA would make a list of all the eligible couples of her village mentioning the preferred type of contraception and share the data of users with the sub centre as well as the PHC. This listing will also help in identifying couples with unmet need and wherever possible she could provide required spacing methods otherwise refer cases of sterilization and IUD to appropriate facilities. The ASHA has to collect the consignment/replenish her stock every month from the Block $\mathrm{PHC} / \mathrm{CHC} / \mathrm{PHC}$ as per the system put in place by the state. However, these programs are at too early stage to gauge any impact but definitely have potential to increase access to spacing methods at the door steps of couples. The fifth common review mission report (2011) noted that on the ground the program was seen only in Uttar Pradesh and Uttarakhand and the interesting observation from this state was that ASHA was not accepting the payment for contraceptives as she did not want to alter the social image that she had built up. It would be interesting to see how the ASHA herself would respond to efforts to shape her role in this direction (NHSRC, 2012).

Under a new initiative to reach contraceptives to the door steps, ASHAs are supplied with condoms and pills which they sell to the consumers In the village for a nominal fee. This Is being pioleted in 233 districts in 17 states. An evaluation of the program carreid out by FHI 360 showed various flaws leading to confusion in the area of procurement and also becausee of retaining free supply and allowing ASHAs to cahrge for the products. The consumers felt that they were wrongly charged. Who has to procure and maintain the supply to ASHAs were also not clear to the district procurement officer and In some cases, they were not aware of the door steps program's existence in their district [46].

Although presence of health volunteers from the community/ASHAs has increased ANC visits, institutional deliveries, and child immunization, they have made little positive impact on FP acceptance [47]. From year 2005 , when JSY was introduced, to the end of 2009, contraceptive use increased from 20 percent to 28 percent. In Bihar, postpartum contraception increased from 13 percent in 2005-06 to 20 percent in 2010-11, seven percent in five years, the same as the prior contraceptive use increase in Bihar. ASHAs are expected to stock and distribute condoms and contraceptive pills, along with pregnancy kits, ORS packets, and other items. Data from the UP and Bihar studies show that 55 to 83 percent of ASHAs were, at some point, supplied with condoms, and 37 to 76 percent were supplied with pills, at some point. On the day of the interview, however, few ASHAs had any contraceptive methods in stock; the situation was better in UP than Bihar [48]. 


\section{CHAPTER 7: GAPS AND BARRIERS IN SERVICE PROVISION AND RECOMMENDATIONS FOR A WAY FORWARD}

Public delivery system is the main source of health care and may be the only source for the rural population. Private health providers are concentrated in urban and peri-urban areas. All most all the health care providers in rural areas were untrained practitioners without any qualifying degree in any of the streams of medicine. Available studies and the national family health surveys are also assessing the quality and accessibility of public health services. So the discussion on gaps and barriers to family planning and safe abortion services is covering the public health delivery system.

\section{Infrastructure, human resource availability, and unfilled vacancies}

Infrastructural and staff shortfalls are huge in the study states. The shortfall in sub centers in Bihar is 8,837 , in Madhya Pradesh it is around 3,445 and in Odisha it is 1,448. There are significant shortfalls in PHCs also in the focused states. The DLHS-3, facility survey reports indicate that nearly 59 percent of the villages in Bihar, 68 percent villages in Madhya Pradesh and 27 percent villages in Odisha were not having any health facility in the surveyed year 2007-08. Nearly 40 per cent of the villages in Bihar and around one third of villages in Madhya Pradesh, where they don't have a sub centre in the village cannot access the nearest facility throughout the year and the corresponding figure for Odisha is around 23 percent.

As part of a communications capability assessment in Bihar, discussions and interviews were carried out with state, district, and block officials of Bihar. Findings revealed that the health sector's Media Unit and its subsystem in districts and blocks are too weak to implement an effective BCC strategy for all target audiences. None of Bihar's 38 districts have Mass Media Officers or deputies. The post of Block Extension Educator (BEE) has been vacant for eight to 10 years. Positions of district and block community mobilizers who are responsible for monitoring and guiding ASHA, are also vacant. All the 3 states have unfilled positions of doctors and ANMs.

Various policies were introduced in India at various years and many states then formed their own policies. A reason given for the limited success of state policies is its dependence on center for planning and delivery of family welfare services; thus capacity of the state and districts are not getting built for its implementation.

Despite the initiation of $24 \times 7$ PHCs and inclusion of expanding the abortion service base within the PIPs of the states, abortion services are not available at PHCs and many $\mathrm{CHCs}$ because they lack either trained staff or the required equipment and supplies. The infrastructural and staff requirements of vacuum aspiration and D\&C does not allow small clinics to provide safe abortion services, thus decreasing access to safe abortion in rural areas. This difficulty can be handled through the provision of medical abortion pills, provided referrals to hospitals providing MVA and PAC are well established and not very far away.

The main source of contraceptives in Bihar was private facility and similar is the case of abortion services. Just as public facility was the main source of contraceptive method for the current users in Odisha, abortion services were also sought from public facility in Odisha. However, in Madhya Pradesh the main provider of abortion services is the private sector whereas for contraceptives the main source was FP camps. This clearly reflects the shortage of facilities in the states. 


\section{Training inadequacies as a barrier to quality service provision}

Insufficient training on abortion provision, post abortion care, family planning counseling of young couples, emergency contraception and IUD insertion/ removal of different cadre of health staff exists in the public health system. The training adequacy of health care providers in the private sector is difficult to assess.

Not only is the correct knowledge of contraceptive methods other than their names lacking among the young couples, correct knowledge of emergency contraception too is lacking among them and the community workers. Knowledge of the three conditions of LAM exists among negligible number of community workers who provide advice on postpartum contraceptive use. Follow-up procedure of family planning method acceptors and counseling on side-effects of family planning methods has to be refreshed through training. The doubts that come to mind after IUD acceptance-postpartum or otherwise-need to be addressed through frequent follow-up visits. Otherwise women will feel that the method is harmful and discontinue its use.

There is lack of knowledge even among doctors who provide abortion services about MTP and PCPNDT act as well as the different forms and registers that they have to maintain to comply with the procedures mentioned in the MTP and PCPNDT acts. Legal knowledge of what practices of theirs falls within which law and what forms they have to submit is gravely lacking. Training of health providers at all levels on the provisions of MTP act and PCPNDT act is necessary. Within the framework of law, who can provide medical abortion and what things should be kept in mind while providing medical abortion , what could be the possible complications with medical and other forms of abortion, how to identify complications and provide services and referrals are also important area of training for providers. Abortion providers need training in MVA, EVA and post abortion care. Practitioners are slow in adopting MVA either because of lack of equipments, training or both.

\section{Modifications required in monitoring and supervision}

Despite service delivery guidelines in India expecting providers to provide FP counseling during antenatal visits; only a fraction of women receive counseling. In all most all the states, the monitoring format prepared during target approach is still used for monitoring.

The monitoring and supervision checklist needs modification to capture the areas needing mentoring and focus. Supervisors also need training to adequately mentor their supervisees. Easier ways of reporting and supervision using forms received and sent through mobiles was seen as a good forum. Contraceptive counseling and follow-up of acceptors can be done through mobiles.

The forms and registers that are required to be maintained within the MTP and PCPNDT act are cumbersome and difficult as well as too many that providers don't pay much attention to its completeness. It may be good to modify the forms and required registers so that compliance can be ensured. This may be necessary for properly carrying out the required checks on compliance of PNDT act without providers feeling targeted and then refusing services to the women who seek it.

\section{Community awareness of FP/SA}

Youth study conducted in 6 states, Bihar being one of them gave the following findings regarding the knowledge and behavior of young people. There was lack of knowledge on fertile period, contraceptive methods, and availability of reproductive health services. Sizeable proportions of young men and few young women had engaged in premarital sex; moreover, where premarital sex was undertaken, it was largely unsafe. Coerced and forced sex was reported not only by women but also by young men. Of the first pre-marital 
sexual encounter; 15 percent young women reported that it was forced, and another 14 percent said that it was persuaded. Unmarried young men acknowledged their perpetuator role. Community awareness raising programs needs to be more organized and coordinated.

Information on various reproductive health matters has to be given to the unmarried men and women. Efforts have to focus on community's views on the FP methods and erasing of the myths around FP methods. Knowledge of the need for spacing between births and LAM is lacking in the community. Small scale interventions in the community have managed to change community's attitudes in favor of spacing methods as well as has increased postpartum contraception and use of spacing methods.

Sex selective abortion becoming a booming business is making the provision of safe abortion services a nightmare. It is important to have awareness raising programs in the community about the legality of abortion and availability of safe abortion services and what is unsafe abortion and its consequences on health.

Pregnancies resulting from unprotected sex and forced sex are mostly aborted by untrained abortion providers. It is important that community understand the difference between MTP and PCPNDT act and know where legal abortion services are available.

\section{Commodity availability}

Nearly one fourth of the women surveyed (NFHS3) reported that their current pregnancy was unwanted. A comparative analysis of population fertility (measured in terms of birth rate) and individual fertility (measured in terms of Total Marital Fertility Rate or un-weighted Average Marital Fertility Rate) in India; found that while population fertility is decreasing in India and states; decline in the individual fertility is stalled in the country and increased in many states in the five years following the introduction of the target free or community needs assessment approach. This analysis highlighted that the family welfare program could not objectively assess the family planning needs of young couples and hence could not meet their unmet need. Fertility among young people accounts for more than half of India's total fertility.

Despite abortion being legal for some or other reasons doctors are refusing to conduct MTP or are referring clients elsewhere. Medical abortion pills are unavailable in many clinics and hospitals and even in chemist's shops. Providers are gripped by fear of prosecution. Despite family planning counseling being part of the post abortion care; it is not universally followed.

ASHAs are expected to stock and distribute condoms and contraceptive pills, along with pregnancy kits, ORS packets, and other items. Data from the UP and Bihar studies (2009 and 2010) show that 55 to 83 percent of ASHAs were, at some point, supplied with condoms, and 37 to 76 percent were supplied with pills, at some point. On the day of the interview, however, few ASHAs had any contraceptive methods in stock; the situation was better in UP than Bihar. Of the three focused states, women in Bihar are going to private facilities for contraceptive methods and abortion services highlighting the shortage of facilities in Bihar.

Social marketing has succeeded in reaching FP to the door steps, but it is not available in all hamlets. ASHA as depo holders are not fully functional in all villages and adequate supply is not there with them at all times. Janani, an NGO functioning in Bihar has its own brand of clinics, called Surya clinics at the district level and are able to cover 28 districts and provides FP and abortion services.

Private sector charges are huge and unaffordable for the poor and even they charge an exorbitant rate to unmarried girls for abortion. Wanting to keep their abortion seeking secret; families do not lodge complaint about the exorbitant charges levied or complications or death from abortion done by untrained providers. Fixing charges that private sector can levy for abortion and FP may be useful to curtail this. 


\section{Financing mechanisms}

World Bank definition of poverty makes 42 percent of Indian people living below poverty line. Other areas indicating inequity is the insufficient government funding for health, low density of educated health workers, unfilled vacancies or shortage of qualified health care providers and other health staff. Per person public health expenditures in Bihar was estimated to be INR93 compared with INR630 in Himachal Pradesh in 200405. Large proportions of resources are in urban-based and curative services, neglecting already disadvantaged poor rural population. About 39 million additional people are falling into poverty every year as a result of health care expenditures. Private expenditures on health have remained high with India having one of the highest proportions of household out-of-pocket health expenditures in the world-71percent in 2004-05. Expenditure on drugs has been increasing with time, and drug costs constitute a greater proportion of out-ofpocket expenditures for people who are poor than for those who are not.

Although the JSY scheme was successful in increasing hospital deliveries but many women opted for home deliveries because of the out of pocket expenses for travel and medicines. So government has widened its scope to cover expenses for transportation, medicines and sick child also into the program and is now called Janani Shishu Suraksha Karyakram (JSSK) which was launched in June 2011. Unless the barriers of meeting shortage of staff, drugs, facilities and infrastructure are dealt with, the introduction of JSSK is not going to be beneficial in meeting the objectives.

There are many schemes to increase the status of the girl child and improve sex ratio and to delay marriage of girls till age 18 years. However, sufficient promotion of these schemes are not done and so the very poor and illiterate population are unaware of it and lack the skills to avail it.

\section{Public-private partnerships}

There is shortage of qualified staff at all levels of the public health delivery system. There is also unavailability and overload of health facility affecting access and quality of services. Public-private partnership models thus can assist the public health system in many ways.

The most disadvantaged population has the least access to health services. Poor in remote areas have to travel long distances through unpaved roads and with no available transport and money to pay for transport to get the sick to a health care facility. For this reason, they have not availed of JSY scheme. The existing private providers who have joined the public-private partnership are in urban areas. Providing additional incentives like hardship allowance for working in remote rural areas may be a way to motivate private doctors to open clinics in rural areas. 


\section{REFERENCES - Chapter 1}

1. Gipson JD, Koenig MA and Hindin MJ. The effects of unintended pregnancy on infant, child and parental health: A review of the literature. Studies in Family Planning 2008; 39: 18-38.

2. Singh S, Sedgh $G$ and Hussain R. Unintended pregnancy: Worldwide levels, trends and outcome. Studies in Family Planning 2010; 41: 241-250

3. World Health Organisation (WHO). Unsafe abortion: Global and regional estimates of the incidence of unsafe abortion and associated mortality in 2008, sixth ed., Geneva: WHO, 2011.

4. Bongaarts J, Cleland J, Townsend JW, Bertrand JT, and Gupta MD. Family planning programs for the 21st centuary: Rationale and desigen. New York:Population Council, 2012.

5. Population council. Fact sheet on scaling up access to quality family planning and safe abortion services, July 2012.

6. World Health Organization (WHO). Engaging men and boys in changing gender based inequity in health: Evidence from programming interventions, Geneva: WHO, 2007.

7. World Health Organization (WHO). The prevention and management of unsafe abortion. Report of a technical working group. Geneva: WHO, 1992.

8. International Institute for Population Sciences (IIPS) and Macro international. National Family Health Survey (NFHS-3) 2005-06: India Volume 1. IIPS and Macro International, Mumbai, 2007

9. Dixit $P$, Ram F and Dwivedi LK . Determinants of unwanted pregnancies in India using matched casecontrol designs. BMC Pregnancy and Child Birth 2012 http://www.biomedcentral.com/1471-2393/12/84

10. Gulati SC et al. Demand for contraception in India. In Ranjan A (ed.) Population and Health in India 2008, pg. 69-92

11. International Institute for Population Sciences (IIPS) and ORC Macro. National Family Health Survey (NFHS-2) 1998-99. IIPS and ORC Macro, Mumbai 2000.

12. International Institute for Population Sciences (IIPS). 'National Family Health Survey--MCH and Family Planning, 1992-93. IIPS, Mumbai, 1995.

13. Kulkarni S and Choe MK. State-level variations in wanted and unwanted fertility provide a guide for India's family planning programmes. National Family Health Survey bulletin 1997.

14. Registrar General of India. Provisional population totals, paper 1 of 2011 India series 1. Office of the Registrar General and Census Commission 2011.

15. Registrar General of India (RGI). Population projection for India and States-2001-2026. Report of the technical group on population projection constituted by the national commission on population, 2006.

16. Registrar general of India. Sample Registration System-Statistical Report 2011. Ministry of Home Affairs, Government of India, New Delhi, 2013

17. Registrar General of India. SRS Bulletin-2011. Vital Statistics Division, Ministry of Home Affairs Government of India, New Delhi, 2012

18. Registrar General of India. Special Bulletin on Maternal Mortality in India 2007-09. Vital Statistics Division, Ministry of Home Affairs, Government of India, New Delhi, 2011c

19. Hogan CM et al. Maternal mortality for 181 countries, 1980-2008: A systematic analysis of progress towards Millennium Development Goal 5. Lancet 2010; 375:1609-23. 
20. UNICEF. Progress for Children- A report Card on maternal Mortality. UNICEF, 2008

21. World Health Organization (WHO). Maternal Mortality-Fact Sheet.,WHO, 2012.

22. Chatterjee P. India addresses maternal deaths in rural areas Lancet 2007;370:1023-1024

23. Smith ND and Potts M A. Woman Cannot Die from a Pregnancy She Does Not Have International Perspectives on Sexual and Reproductive Health 2011; 37:155-157

24. Lozano R et.al. Global and regional mortality from 235 causes of death for 20 age groups in 1990 and 2010: A systematic analysis for the global burden of disease study. The Lancet 2012; 380:2095-2128.

25. Murray et.al. Disability-adjusted life years (DALYs) for 291 diseases and injuries in 21 regions, 1990_ 2010: A systematic analysis for the Global Burden of Disease Study 2010. The Lancet, 2012: 380-21972223

26. Grimes et.al. Unsafe Abortion: The preventable pandemic. The Lancet sexual and reproductive health series, 2006.

27. Rutstein S. Relationship between pregnancy intervals and perinatal mortality. Proceedings of the $2^{\text {nd }}$ hampions Meeting on Birth Spacing. 2002; pg.15-22

28. Setty V and Upadhyay UD. Birth spacing: Three to five saves lives. Population report series L. No 23. Baltimore, 2002

29. Whitworth A and Stephenson R. Birth spacing, sibling rivalry and child mortality in India. Social Science and Medicine, 55(12): 2107-2119. 2002

30. Office of the Registrar General and Census commissioner. Annual Health Survey, 2010-11: Fact Sheet, Bihar, 2012.

31. Office of the Registrar General and Census commissioner. Annual Health Survey, 2010-11: Fact Sheet, Odisha, 2012.

32. Office of the Registrar General and Census commissioner. Annual Health Survey, 2010-11: Fact Sheet, Madhya Pradesh, 2012. 


\section{REFERENCES - Chapter 2}

1. Bongaarts $\mathrm{J}$ et al. Family planning programs for the $21^{\text {st }}$ century: Rationale and design. New York : The Population Council 2012.

2. Mavalankar D et al. Achieving Millennium Development Goal 5: Is India Serious? Bulletin of World Health Organization 2008; 86:243-244.

3. Srinivasan K, Health policies in India: A review. $3^{\text {rd }}$ K4Health Lecture presentation 2011.

4. Ministry of Home Affairs. International Covenants / Conventions / Treaties Ratified / Acceded / Signed by India, Ministry of Home Affairs, GOI. http://mha.nic.in/uniquepage.asp?ld_Pk=235.

5. Ipas 2013. Maternal mortality, unwanted pregnancy and abortion as addressed by international human rights bodies-part one: Statements from treaties, treaty monitoring committees, special rapporteurs, human rights commissions, and human rights courts. Chapel Hill NC: Ipas.

6. Ved RR, Dua AS. Review of women and children's health in India: focus on safe motherhood, National Commission on Macroeconomics and Health Publication, India, 2010.

7. Duggal R. Towards establishing the right to health and healthcare. In Deasi M, Mahabal KB (eds.) Health Care Case Law in India, pg.169-77.. Mumbai:CEHAT/ICHRL , 2007.

8. UNFPA. Review of maternal health policies/strategies from a reproductive rights perspective. UNFPA/Asia and the Pacific Regional Office, 2010.

9. Ministry of Health and Family Welfare. NRHM Frame work for implementation. www.mohfw.nic.in/NRHM/Documents/NRHM_Framework_Latest.pdf.

10. NACO. About National AIDS Control Organization. www.nacoonline.org. Accessed December 2012.

11. Ministry of Health and Family Welfare (MOHFW). National Population Policy 2000. New Delhi: MOHFW, Government of India, 2000.

12. Ministry of Health and Family Welfare (MOHFW). National Health Policy. New Delhi: MOHFW, Government of India, 2002.

13. Ministry of Youth Affairs and Sports (MOYAS). National Youth Policy 2003. New Delhi: MOYAS, Government of India, 2003.

14. Ministry of Youth Affairs and Sports (MOYAS). National Programme for Youth and Adolescent Development: Scheme Guidelines. New Delhi: MOYAS, Government of India, 2006.

15. Ministry of Health and Family Welfare (MOHFW). RCH Phase II: National Programme Implementation Plan. New Delhi: MOHFW, Government of India, 2005.

16. Ministry of Health and Family Welfare (MOHFW). Implementation Guide on RCH II: Adolescent Reproductive Sexual Health Strategy, for State and District Programme Managers. New Delhi: MOHFW, Government of India, 2006.

17. Ministry of Health and Family Welfare (MOHFW). Janani Suraksha Yojana: Features and Frequently Asked Questions and Answers. New Delhi: MOHFW, Government of India, 2006.

18. Ministry of Human Resource Development (MOHRD). First Joint Review Mission of Mahila Samakhya, Aide Memoire. New Delhi: MOHRD, Government of India, 2008.

19. Ministry of Law and Justice. The Prohibition of Child Marriage Act, 2006. No. 6 of 2007 Gazette of India. New Delhi: Ministry of Law and Justice, Government of India, 2007. 
20. Ministry of Women and Child Development (MOWCD). National Policy for the Empowerment of Women. New Delhi: MOWCD, Government of India, 2001.

21. Ministry of Women and Child Development (MOWCD). Protection of Women from Domestic Violence Act,2005 (43 of 2005) the Gazette of India: Extraordinary. New Delhi: MOWCD, Government of India, 2006.

22. Ministry of Women and Child Development. (MOWCD). Implementation Plan of Rajiv Gandhi Scheme for Empowerment of Adolescent Girls (RGSEAG) SABLA. New Delhi: MOWCD, Government of India, 2010.

23. Ministry of Women and Child Development (MOWCD). State-wise Funds Released/Utilized under KSY (Kishori Shakti Yojana) in 2006-07, 2007-08, 2008-09 and Funds Released. New Delhi: MOWCD, Government of India, 2010.

24. Ministry of Health and Family Welfare (MOHFW). Public-private partnership guidelines, http://203.193.146.66/hfw/Public_Private_Partnership.asp?GL=8. Accessed February 2013.

25. Department of Health and Family Welfare, Government of Madhya Pradesh. Madhya Pradesh Health Policy. www.health.mp.gov.in/healthpolicy.htm. Accessed January 2013.

26. Department of Health and Family Welfare, Government of Madhya Pradesh, Madhya Pradesh Population Policy. www.health.mp.gov.in/population-policy.htm. Accessed January 2013.

27. Ranjan A. Strategic options for population stabilization in Madhya Pradesh. Journal of Family Welfare, 2005; 51:60-75.

28. Government of Madhya Pradesh. State Program Implimentation Plan (PIP) of Madhya Pradesh. Presentation to National Program Coordination Committee on State PIP of Madhya Pradesh for 2011-12. pipnrhm-mohfw.nic.in/ .../madhyapradesh/... /NPCC_Presentation_mp... Accessed in January 2013.

29. The Civil Registration System; the Medically Certified Causes of Death System and the Routine, Demographic Sample Registration System.

30. Soman K. Trends in Maternal Mortality. Economic and Political Weekly, 1994; 29:2859.

31. Government of odisha. State Program Implimentation Plan (PIP) of Odisha. Presentation of the Orissa state PIP 2011-12. pipnrhm-mohfw.nic.in/.../Orissa/.../NPCC\%20Presentation\%20(13.4....accessed in January 2013.

32. Ministry of Health and Family Welfare (MOHFW). www.mohfw.nic.in/NRHM/Documents/High.../Orissa_Report.pdf. accessed in January 2013

33. Department of Health and Family Welfare, Government of Orissa. Health Policy 2002. www.orissa.gov.in/health portal/plans/hpolicy.html. accessed in January 2013

34. Gupta SD. Adolescent and youth reproductive health in India: Status, Issues, Policies and programs. Policy Project, IHMR, Jaipur, 2003.

35. WHO, UNFPA and UNICEF. Investing in our future: $A$ framework for accelerating action for the sexual and reproductive health of young people. Joint Publication by WHO, UNFPA and UNICEF, 2006

36. Mensch et.al. Trends in the timing of first marriage among men and women in the developing world. Policy research division working paper 202, Population council: New York, 2005.

37. Childinfo, Statistics by Area- Child Marriage, UNICEF, 2009. http://www.childinfo.org/marriage.html. accessed in January 2013 
38. UNICEF, Early marriage: A childhood interrupted http://www.unicef.org/india/child protection 1536.htm. accessed in January 2013

39. International Center for Research on Women, Child Marriage Facts and Figures http://www.icrw.org/childmarriage-facts-and-figures. accessed in January 2013

40. Hervish A and Feldman-Jacobs C. Who speaks for me? Ending Child Marriage, Population Reference Bureau, 2011, pg. 2

41. International Institute for Population Sciences (IIPS), 2010. District Level Household and Facility Survey (DLHS-3), 2007-08: India. Bihar: Mumbai: IIPS, 2010.

42. International Institute for Population Sciences (IIPS), 2010. District Level Household and Facility Survey (DLHS-3), 2007-08: India. Orissa: Mumbai: IIPS, 2010

43. International Institute for Population Sciences (IIPS), 2010.District Level Household and Facility Survey (DLHS-3), 2007-08:India. Madhya Pradesh: Mumbai: IIPS, 2010.

44. Office of the Registrar General and Census commissioner. Annual Health Survey, 2010-11: Fact Sheet, Bihar, 2012.

45. Office of the Registrar General and Census commissioner. Annual Health Survey, 2010-11: Fact Sheet, Odisha, 2012.

46. Office of the Registrar General and Census commissioner. Annual Health Survey, 2010-11: Fact Sheet, Madhya Pradesh, 2012.

47. UNFPA. Special financial incentive schemes for the girl child in India: A review of selected schemes. UNFPA, 2010

48. Hirve SS. Abortion law, policy and services in India: A critical review. Reproductive Health Matters, 2004; 12: $114-121$.

49. World Health Organisation (WHO). Unsafe Abortion: Global and Regional Estimates of the Incidence of Unsafe Abortion and Associated Mortality in 2008, sixth ed., Geneva: WHO, 2011.

50. Malhotra A et al. Realizing Reproductive Choice and Rights: Abortion and Contraception in India. Report. Washington DC: International Council for Research on Women, 2003.

51. International Institute for Population Sciences (IIPS) and Population Council. Youth in India: Situation and Needs 2006-2007. Mumbai: IIPS, 2010.

52. Santhya KG et.al. Timing of first sex before marriage and its correlates: Evidence from India. Culture, Health and Sexuality, 2011; 13:327-41.

53. International Institute for Population Sciences (IIPS) and Population Council. Romance and sex before marriage among young women and men in India, Youth in India: Situation and Needs 2006-2007, Policy Brief No. 34. Mumbai: IIPS, 2010.

54. Visaria L et al. Abortion in India: Emerging issues from qualitative studies. Economic and Political Weekly 2004; 39:5044-52. 29.

55. CORT. Unwanted pregnancy: To accept or abort? A qualitative study of decision making in rural Uttar Pradesh. CORT, 1998.

56. Kalyanwala $S$ et al. Abortion experiences of unmarried young women In India: Evidence from a facilitybased study In Bihar and Jharkhand. International Perspectives on Sexual and Reproductive Health, 2010; 36:62-71. 
57. Times News Network. 20,000 model facilities identified to promote safe abortion practices. July 7, 2012

58. Duggal R. The Political Economy of Abortion in India: Cost and Expenditure Patterns. Reproductive Health Matters, 2004; 12:130-37.

59. Government of India (GOI). Preconception and pre-natal diagnostic techniques (prohibition of sex selection) Act. New Delhi: Government of India, 1994.

60. Government of India (GOI). The Medical Termination of Pregnancy Rules (Amendment). New Delhi: Government of India 2003.

61. UNICEF. Female feticide in India. http://www.unicef.org/india/media_3285.htm

62. CYDA and UNFPA. Reflections on the campaign against sex selection and exploring ways forward: A study Report.2007

63. IPAS. Situation analysis of MTP services in Bihar. New Delhi: IPAS, 2011

64. Times News Network. Government promotes safe abortion initiatives. May 5, 2012.

65. Suchitra SD. Second trimester abortions in India. Reproductive Health Matters, 2008; 16:37-45.

66. British Boardcasting Corporation (BBC) Asia, October 22, 2011.'Unwanted' Indian girls get new start in name ceremony.

67. Sedgh GD et al. Induced abortion: incidence and trends worldwide from 1995 to 2008. The Lancet, 2012. DOI:10.1016/S0140-6736(11)61786-8.

68. FOGSI and PSI India. Safe abortion meeting report. Unpublished report, 2012.

69. Times News Network. Bitter pill: Abortion kits sale plunge by 65\% in Mumbai. July 7, 2012.

70. 'Yukti' to provide abortion care to women. April 23, 2011. http://articles.timesofindia.indiatimes.com/201104-23/patna/29466119 1 abortion-services-abortion-care-safe-abortion. accessed January 2013.

71. State Health Society, Bihar. Financing guideliens. statehealthsocietybihar.org/.../financialguidelines\%5Cpartb\%5CB.14.b.pd...

72. Aruldas $\mathrm{K}$ and Goel $\mathrm{S}$. Development partners and international NGO assistance in strengthening the health sector in Bihar: An overview, in Khan ME, Donnay F, Tarigopula UK and Ganju D (eds), Shaping Demand and Practices to Improve Family Health Outcomes: Designing a Behavior Change Communication Strategy in India, Volume 2: Bihar. New Delhi: SAGE Publications, 2012.

73. Khan ME and Hazra A. Unmet need for contraception in India: Review and recommendations, In Zaman W and Masnin $\mathrm{H}$ (eds.) Report on the workshop on Operationalising the Call for Elimination on Unmet Need for Family Planning, 2012:101-25.

74. IPAS. Improving Abortion services in India-Lessons from the WHO safe abortion guidance. New Delhi: IPAS, 2012.

75. The Hindu. Unsafe abortions killing women every two hours, May 6, 2013. http://www.thehindu.com/news/national/unsafe-abortions-killing-a-woman-every-twohours/article4686897.ece. accessed June 2013.

76. The times of India, February 3, 2013. Allow abortion upto 24 weeks, National women's panel says. http://articles.timesofindia.indiatimes.com/2013-02-03/india/36720450_1_ncw-member-niketa-mehta-mtpact. acessed June 2013. 
77. Jha $\mathrm{P}$, Kesler MA, Kumar $\mathrm{R}$ et al. Trends in selective abortions of girls in India: analysis of nationally representative birth histories from 1990 to 2005 and census data from 1991 to 2011. Lancet 2011; 377: 1921-28

\section{REFERENCES - Chapter 3}

1. Alkema $L$ et. al. National, regional and global rates and trends in contraceptive prevalence and unmet need for family planning between 1990 and 2015: A systematic and comprehensive analysis. The Lancet 2013; 381(9878):1642-52.

2. Jacobstein $\mathrm{R}$ et al. Meeting the need for modern contraception: Effective solutions to a pressing global challenge. Int J Gynecol Obstet 2013; http://dx.doi.org/10.1016/.ijgo.2013.02.00

3. Ezeh AC et al. Global population trends and policy options. The Lancet 2012; 380(9837):142-48.

4. Government of India. Family Welfare Statistics in India. Statistic Division, Ministry of Health and Family Welfare, Government of India, New Delhi, 2011.

5. International Institute for Population Sciences and Macro International. National Family Health Survey (NFHS-3), 2005-06: India. Volume1.International Institute for Population Sciences Mumbai , 2007.

6. Chandhick $\mathrm{N}$ et.al. Contraceptive knowledge, practices and utilization of services in the rural areas of India (an ICMR task force study). Indian Journal of Medical Science 2003; 57 :303-10.

7. International Institute for Population Sciences (IIPS). District Level Household and Facility Survey (DLHS3), 2007-08: India: Key Indicators: States and Districts, Mumbai:IIPS, 2010.

8. Athavale AV and Athavale SA. Factors influencing the decision to undergo tubectomy in rural areas of Maharashtra state. Regional Health Forum WHO-South East Asia Region 2003; 7(2).

9. Sikdar S.K. Overview of Family Planning in India. Presentation by Ministry of Health and Family Welfare, Government of India. Accessed February 2013.

10. Bandyopadhyay M. Impact of ritual pollution on lactation and breastfeeding practices in rural West Bengal. International Breastfeeding Journal, 2009.

11. Bello IOM, Adedokun BO and Ojengbede OA. Social support during child birth as a catalyst for early breastfeeding initiation for the first time Nigerian mother. International Breastfeeding Journal, 2009.

12. Khan ME, Donnay F, Tarigopula UK and Ganju D (Eds.). Shaping Demand and Practices to Improve Family Health Outcomes, Designing a Behavior Change Communication Strategy in India, Volume II: Bihar. New Delhi: SAGE Publications, 2012.

13. Khan ME, Darmstadt GL, Tarigopula UK and Ganju D (Eds.). Shaping Demand and Practices to Improve Family Health Outcomes, Designing a Behavior Change Communication Strategy in India, Volume I: Uttar Pradesh. New Delhi: SAGE Publications, 2012.

14. Kishore SS, Kumar P and Aggarwal AK. Breastfeeding knowledge and practices amongst mothers in a rural Population of North India: A community-based study. Journal of Tropical Pediatrics 2008;55: 183-188

15. Madhu K, Chowdary S, Masthi R. Breast feeding practices and newborn care in rural areas: A descriptive cross-sectional study. Indian Journal of Community Medicine 2009; 34: 243-246. 
16. Sebastian MP et.al. Increasing post partum contraception in rural India: Evaluation of a community-based behavior change communication intervention. International Perspectives of Sexual and Reproductive Health 2012; 38: 68-77

17. Chudasama RK, Patel PC and Kavishwar AB. Determinants of exclusive breastfeeding in South Gujarat region of India. Journal of Clinical Medicine Research, 2009.

18. Singh $\mathrm{G}$. Estimating the duration of breastfeeding with survival analysis procedure. Indian Journal of Community Medicine 2010; 1: 18-21.

19. Radhakrishnan $S$ and Balamuruga SS. Prevalence of exclusive breastfeeding practices among rural women in Tamil Nadu. International Journal for Health and Allied Sciences 2012;1:64-68.

20. Rasania SK et.al. Breastfeeding practices in a maternal and child health centre in Delhi. Health and Population-Perspectives and Issues 2003; 26: 110-115

21. Mahmood SE et.al. Infant feeding practices in the rural population of North India. Journal of Family and Community Medicine 2012; 19: 130-135.

22. Ekpenyoung CE et.al. Lactational amenorrhea method of contraception: An in-depth study of awareness, knowledge and practice by breastfeeding mothers with unintended pregnancies. International Journal of Medicine and Medical Sciences 2013;5:6-13.

23. Audu BM, Yahya S and Bassi A. Knowledge, attitude and practice of natural family planning methods in a population with poor utilization of modern contraceptives. Journal of Obstetric Gynecology 2006; 28: 555560

24. Turk R, Terzioglu F, Eroglu K. The use of lactational amenorrhea as a method of family planning in Eastern Turkey and influential factors. J Midwifery Womens Health 2010; 55(1):e1-e7.

25. International Institute for Population Sciences (IIPS) and ORC Macro. National Family Health Survey (NFHS-2) 1998-99. IIPS and ORC Macro, Mumbai 2000.

26. International Institute for Population Sciences (IIPS). 'National Family Health Survey (MCH and Family Planning), 1992-23. IIPS, Mumbai, 1995.

27. International Institute for Population Sciences (IIPS) and Macro International. National Family Health Survey (NFHS-3), India, 2005-06: Bihar. Mumbai:IIPS, 2008.

28. International Institute for Population Sciences (IIPS) and Macro International. National Family Health Survey (NFHS-3), India, 2005-06: Orissa. Mumbai:IIPS, 2008.

29. International Institute for Population Sciences (IIPS) and Macro International. National Family Health Survey (NFHS-3), India, 2005-06: Madhya Pradesh. Mumbai:IIPS, 2008.

30. International Institute for Population Sciences (IIPS), 2010. District Level Household and Facility Survey (DLHS-3), 2007-08: India. Bihar: Mumbai: IIPS, 2010.

31. International Institute for Population Sciences (IIPS), 2010. District Level Household and Facility Survey (DLHS-3), 2007-08: India. Orissa: Mumbai: IIPS, 2010

32. International Institute for Population Sciences (IIPS), 2010.District Level Household and Facility Survey (DLHS-3), 2007-08:India. Madhya Pradesh: Mumbai: IIPS, 2010.

33. Office of the Registrar General and Census commissioner. Annual Health Survey, 2010-11: Fact Sheet, Bihar, 2012. 
34. Office of the Registrar General and Census commissioner. Annual Health Survey, 2010-11: Fact Sheet, Odisha, 2012.

35. Office of the Registrar General and Census commissioner. Annual Health Survey, 2010-11: Fact Sheet, Madhya Pradesh, 2012.

36. Brogen A K et.al. Knowledge and attitude on lactational amenorrhea method as a contraceptive device among nursing students. Indian Journal of Community Medicine, 2006; 31: 90-92

37. Parasuraman S et.al. A Profile of Youth in India. National Family Health Survey (NFHS-3), India, 2005-06. Mumbai: International Institute for Population Sciences,2009; Calverton, Maryland, USA: ICF Macro.

38. Jejeebhoy SJ. Adolescent sexual and reproductive behavior: A review of evidence from India. In R Ramasubban and SJ Jejeebhoy(Eds.) Women's Reproductive Health in India. Jaipur:Rawat Publications, 2000.

39. Ghosh S, Samanta A and Mukherjee S. Knowledge and practice of family planning in married women of reproductive age group in a slum of Kolkata. Al Ameen Journal of Medical Science 2013; 6:34-39

40. Blanc A, Curtis $S$ and Croft T. Monitoring contraceptive continuation: Links to fertility outcomes and quality of care. Studies in Family Planning 2002; 33(2): 127-140

41. Ali M.M and Cleland J. Oral contraceptive discontinuation and its aftermath in 19 developing countries. Contraception 2010; 81: 22-29.

42. Leite IC and Gupta N. Assessing regional differences in contraceptive discontinuation, failure and switching in Brazil'. Reproductive Health 2007; http://www.reproductive-health-journal.com/content/4/1/6.

43. Malas NO, Rayyan ESA and Goweri AS. Why do Depo-Provera users discontinue? Journal of the Royal Medical Services, 2009; 16: 70-74

44. United Nations. Levels and trends of contraceptive use as assessed in 2002. New York: Population Division, United Nations Department of Economic and Social Affairs, 2006.

45. Khan ME, Sebastian MP and Aeron A. Promoting healthy timing and spacing of pregnancy: Barriers and possible intervention. Observation from a Qualitative Study in Uttar Pradesh. Research Update No. 13. 2007. New Delhi: Population Council/FRONTIERS

46. Koeing MA, Foo GH and Joshi K. Quality of care within the Indian Family Welfare Program: A review of recent evidence. Studies in Family Planning 2000; 31:1-18

47. Moreau $\mathrm{C}$ et.al. Frequency of discontinuation of contraceptive use: Results from a French Population based cohorts. Human Reproduction 2009; 1:1-6.

48. Parasuraman S et.al. A Profile of Youth in India. National Family Health Survey (NFHS-3), India, 2005-06. Mumbai: International Institute for population Sciences; Calverton, Maryland, USA: ICF Macro 2009.

49. Santhya KG et al. Associations between early marriage and young women's marital and reproductive health outcomes: evidence from India."International Perspectives on Sexual and Reproductive Health 2010, 36: 132-139.

50. International Institute for Population Sciences (IIPS) and Population Council. Youth in India: Situation and Needs 2006-2007. Executive Summary. Mumbai: IIPS, 2010.

51. Registrar general of India. Sample Registration System-Statistical Report 2011. Ministry of Home Affairs, Government of India, New Delhi, 2013

52. Caldwell J et al. The causes of marriage change in South India, Population Studies 1983; 37(3):343-61. 
53. Amin S et al. Baseline survey report on rural adolescents in Bangladesh: Kishori abhijan project. UNICEF and Department of women's affairs, Ministry of women and children affairs, 2002.

54. Mensch et al. Trends in the timing of first marriage among men and women in the developing world. Policy Research Division Working Paper No. 202, New York: Population Council, 2005.

55. Ganatra B, Manning V and Palimapulla S. Availability of medical abortion pills and the role of chemists: a study of Bihar and Jharkhand, India. Reproductive Health Matters 2005; 13: 65_74

\section{REFERENCES --- Chapter 4}

1. Bernstein $S$ and Edouard $\mathrm{L}$. Targeting access to reproductive health: Giving contraception more prominence and using indicators to monitor progress. Reproductive Health Matters 2007; 15:186-91

2. Sonfield A. Working to eliminate the world's unmet need for contraception". Guttmacher Policy Review 2006; Vol. 9(1)

3. Ross AJ and Winfrey WL. Contraceptive use, intention to use and unmet need during the extended postpartum period. International Family Planning Perspectives 2001; 27 :20-27

4. Vernon R. Meeting the family planning needs of postpartum women. Studies in family planning 2009; 40:235-45

5. Singh S, Sedgh $\mathrm{G}$ and Hussain R. Unintended pregnancy: Worldwide levels, trends and outcome. Studies in Family Planning 2010; 41: 241-250

6. $\quad$ Singh S and Darroch JE. Adding it up: Costs and benefits of contraceptive services-Estimates for 2012. New York: Guttmacher Institute and United Nations Population Fund (UNFPA); 2012.

7. International Institute for Population Sciences (IIPS). National Family Health Survey (MCH and Family Planning), 1992-23. IIPS, Mumbai, India,1995

8. IIPS and ORC Macro. National Family Health Survey (NFHS-2) 1998-99. IIPS and ORC Macro, Mumbai India, 2000

9. IIPS and Macro international. National Family Health Survey (NFHS-3) 2005-06: India Volume 1. IIPS and Macro International, Mumbai India, 2007.

10. Bhattacharya SK et.al. Study on Unmet Need for Family Planning among Women of Reproductive Age Group Attending Immunization Clinic in a Medical College of Kolkata. Indian Journal of Community Medicine 2006; 31:73-75.

11. Andukar SP, Yadav VB and Dalvi SD. Study of unmet need for family planning among married women of reproductive age in urban health central field practice area of Govt. Medical College, Aurangabad. Indian Journal of Public Health 2006; $50: 45-6$

12. Indu D. Unmet needs for family planning in urban slums of Trivandrum corporation area - A cross sectional study. Calicut Medical Journal 2011; 9(2).

13. Paxman JM et al. The India Local Initiatives Program: A Model for Expanding Reproductive and Child Health Services. Studies in Family Planning 2005; 36: 203-220.

14. International Institute for Population Sciences (IIPS). District Level Household and Facility Survey (DLHS3), 2007-08: India: Key Indicators: States and Districts, Mumbai: IIPS, 2010. 
15. International Institute for Population Sciences (IIPS), 2010. District Level Household and Facility Survey (DLHS-3), 2007-08: India. Bihar: Mumbai: IIPS, 2010.

16. International Institute for Population Sciences (IIPS), 2010. District Level Household and Facility Survey (DLHS-3), 2007-08: India. Orissa: Mumbai: IIPS, 2010

17. International Institute for Population Sciences (IIPS), 2010.District Level Household and Facility Survey (DLHS-3), 2007-08:India. Madhya Pradesh: Mumbai: IIPS, 2010.

18. Office of the Registrar General and Census commissioner. Annual Health Survey, 2010-11: Fact Sheet, Bihar, 2012.

19. Office of the Registrar General and Census commissioner. Annual Health Survey, 2010-11: Fact Sheet, Odisha, 2012

20. Office of the Registrar General and Census commissioner. Annual Health Survey, 2010-11: Fact Sheet, Madhya Pradesh, 2012

21. Casterline JB and Sinding WS, 2000. Unmet need for family planning in developing countries and implications for population policy. Population and Development Review 26 (4):691-723

22. Jennings EA, Barber JS, 2013. The influence of neighbor's family size preference on progression to high parity births in rural Nepal. Studies in Family Planning, 44(1):67-84

23. Ross J and Smith E. Trends in national family planning programs, 1999,2004 and 2009. International Perspectives on Sexual and Reproductive Health 2011; 37:125-33.

24. Jain A.K. Measuring the effect of fertility decline on the maternal mortality ratio. Studies in Family Planning $2011 ; 18: 247-60$

25. Ahmed $S$ et.al. Maternal deaths averted by contraceptive use: an analysis of 172 countries. Lancet 2012;380:111-125

26. Tsui AO, McDonald-Mosley R, Burke AE. Family planning and the burden of unintended pregnancies. Epidemiol Rev 2010; 32(1):152-174.

27. World Health Organization (WHO). Department of Health Statistics and Informatics, Global health risks: mortality and burden of disease attributable to selected major risks. Geneva: Switzerland, WHO, 2009.

28. Conde-Agudelo A, Rosas-Bermudez A and Kafury-Goeta A. Effects of birth spacing on maternal health: a systematic review. Am J Obstet Gynecol 2007; 196(4):297-308.

29. Marston C, Cleland J. The effects of contraception on obstetric outcomes. Geneva: Department of Reproductive Health and Research, Geneva: World Health Organization, 2004.

30. Prata N, Sreenivas A, Vahidnia Fand Potts M. Saving maternal lives in resource-poor settings: facing reality. Health Policy 2009; 89(2):131-148.

31. Choudhary $S$ et.al. A study on the extent and reasons of unmet need for family planning among women of reproductive age group in rural area of Haryana. The Internet Journal of Health. 2011; 12 (1)

32. Khan ME, Sebastian MP and Aeron A. Promoting healthy timing and spacing of pregnancy: Barriers and possible intervention - Observation from a Qualitative Study in Uttar Pradesh. Research Update No. 13. New Delhi: Population Council/FRONTIERS, 2007.

33. Chaurasia AR. Birth rate trends in India: 1985-2007-A decomposition analysis. Journal of Family Welfare 2011 
34. Ranjan A. Strategic options for population stabilization in Madhya Pradesh. Journal of Family Welfare 2005; 51: 60-75.

35. UNFPA. The new state of world population-By choice not by chance. UNFPA, 2012;

http://www.unfpa.org/webdav/site/global/shared/swp/2012/EN-SWP2012 report.pdf. accessed April 2013.

36. Ortayli $\mathrm{N}$ and Malarcher S.Equity analysis: Identifying who benefits from family planning programs.

Studies in family planning 2010; 41:101-108.

37. Wirth et.al. Setting the stage for equity-sensitive monitoring of maternal and child health Millennium Development Goals. Bulletin of the World Health Organization 2006; 84: 519-526

38. Gwatkin et.al. Socio- economic differences in health, nutrition, and population within developing countries: An overview. Country Reports on HNP and Poverty. Washington, DC: The World Bank 2007.

39. Alan Guttmacher Institute (AGI). Sharing Responsibility: Women, Society and Abortion Worldwide. New York: AGI, 2007.

40. Parasuraman S et.al. A Profile of Youth in India. National Family Health Survey (NFHS-3), India, 2005-06. Mumbai: International Institute for population Sciences; Calverton, Maryland, USA: ICF Macro 2009.

41. Santhya KG et al. Associations between early marriage and young women's marital and reproductive health outcomes: evidence from India. International Perspectives on Sexual and Reproductive Health 2010, 36: 132-139.

42. Santhya KG, Jejeebhoy SJ and Ghosh S. Early Marriage and Sexual and Reproductive Health Risks: Experiences of Young Women and Men in Andhra Pradesh and Madhya Pradesh, India. New Delhi: Population Council, 2008.

43. Kott A. Rates of unintended pregnancy remain high in developing regions. International perspectives on sexual and reproductive health 2011; 37(1):46-47.

44. Zavier F and Padmadas SS, Use of a Spacing Method before Sterilization among Couples in Kerala, India, International Family Planning Perspectives 2000; 26: 29-35.

45. Dwivedi LK, Ram F: Multilevel analysis of unwanted fertility in Utter Pradesh. Demography India 2005; $34: 241-258$.

46. Santhya KG. Delaying first pregnancy: Intentions and realities among young women in India. Paper presented at International conference on family planning, Dakar, Senegal, 2011.

47. Edmeades J, Lee-Rife MS and Malhotra A. Women and reproductive control: The nexus between abortion and contraceptive Use in Madhya Pradesh, India. Studies in Family Planning 2010; 41: 75-88.

48. International Institute for Population Sciences (IIPS) and Population Council. 2009. Youth in India: Situation and Needs 2006-2007, Bihar. Mumbai: IIPS

49. Santhya KG \& Ram F. Premarital sexual relations among youth in India: Findings from the Youth in India: Situation and Needs Study. Paper presented at XXVI IUSSP International Population Conference, 2009.

50. Tiwari V.K and Kumar A. Pre marital sexuality and unmet need of contraception among youth-Evidences from two cities of India. The Journal of Family Welfare 2004; 50:62-72

51. Mensch B, Bruce J and Green ME. The uncharted passage: Girls' adolescence in the developing world. New York: Population Council, 1998.

52. Lloyd CB. (ed). Growing Up Global: The Changing Transitions to Adulthood in Developing Countries. Washington, DC: The National Academies Press, 2005. 
53. Haberland N. Supporting married girls: Calling attention to a neglected group. Transitions to Adulthood. New York: Population Council, 2007.

54. Mwaikambo L et.al. What works in family planning interventions: A systematic review, Studies in Family Planning 2011; 42:67-82.

55. Lee-Rife et.al. A Macro-level Exploration of the Links between Fertility Decline and Gender Equality. International Center for Research on Women Fertility. Empowerment Working Paper Series 2012; 0052012-ICRW-FE. Pages 1-36.

56. Stephenson R, Koenig MA and Ahmad S. Domestic violence and contraceptive adoption in Uttar Pradesh.

57. Sebastian et al. Increasing postpartum contraception in rural India: Evaluation of a community based behavior change communication intervention. International Perspectives on Sexual and Reproductive Health 2012; 38: 68-77.

58. Khan ME and Hazra A. Unmet need for contraception in India: Review and recommendations,In Zaman W and Masnin H (eds.) Report on the workshop on Operationalising the Call for Elimination on Unmet Need for Family Planning, 2012:101-25.

59. WHO. Sexual and reproductive health and human rights: A tool for examining laws, regulations and policies. Draft document prepared for the Policy and Coordination Committee Meeting, 16 and 17 June, 2011.

60. Sedgh GD et al. Induced abortion: incidence and trends worldwide from 1995 to 2008. The Lancet, 2012. DOI:10.1016/S0140-6736(11)61786-8.

61. Winikoff B et al. Safety, efficacy and acceptability of medical abortion in China, Cuba and India: A comparative trial of mifepristone-misoprostol versus surgical abortion. American Journal of Obstetrics and Gynecology, 1997; 176:431-37.

62. Kulier R et al. Medical methods for first trimester abortion. Cochrane Database of Systematic Reviews, 2011; (1):CD002855.

63. Ashok PW et al. An effective regimen for early medical abortion: A report of 2000 consecutive cases. Human Reproduction 1998; 13:2962-2965.

64. Trussell J, Ellertson C. Estimating the efficacy of medical abortion. Contraception 1999; 60:119-135.

65. Elul $B$ et al. Side effects of mifepristone-misoprostol abortion versus surgical abortion-data from a trial in China, Cub and India. Contraception 1999; 59:107-114.

66. Ngoc NTN et al. Feasibility, efficacy and acceptability of mifepristone-misoprostol medical abortion in Vietnam. International Family Planning Perspectives 1999; 25:10-14 and 33.

67. Tran NT et al. Feasibility, efficacy and acceptability mifepristone-misoprostol medical abortion in the Democratic People's Republic of Korea. International Journal of Gynaecology and Obstetrics 2010; 109:209-212.

68. Coyaji K: Early medical abortion in India: three studies and their implications for abortion services. J Am Med Womens Assoc 2000; 53:191-194.

69. Iyengar SD. Introducing Medical Abortion within the Primary Health System: Comparison with Other Health Interventions and Commodities. Reproductive Health Matters 2005; 13: 13-19.

70. Berer M. Why medical abortion is important for women. Reproductive Health Matters 2005; 13:6-10. 
71. Aich Paramita, Sushanta K. Banerjee, Tarun K. Jha, Anisha Aggarwal and Debashis Sinha 2011. Situation Analysis of MTP services in Bihar. New Delhi

72. Barge S et al. Formal and Informal Abortion Services in Rajasthan, India: Results of a Situation Analysis. New Delhi: Population Council, 2004.

73. Duggal $R$ and Ramachandran $V$. The abortion assessment project - India. Key findings and recommendations. Reprod Health Matters 2004; 12:122-9.

74. Hirve SS. Abortion law, policy and services in India: A critical review. Reproductive Health Matters, 2004; 12: $114-121$.

75. WHO. Unsafe Abortion: Global and Regional Estimates of the Incidence of Unsafe Abortion and Associated Mortality in 2008, sixth ed., Geneva: WHO, 2011.

76. Shah I and Ahman E. Unsafe abortion: global and regional incidence, trends, consequences, and challenges. JOGC 2009; 1149-58

77. Singh S, Sedgh $G$ and Hussain R. Unintended pregnancy: worldwide levels, trends and outcomes. Studies in Family Planning 2010; 41: 241-50.

78. Shah I and Ahman E. Unsafe abortion differentials in 2008 by age and developing country region: High burden among young women. Reproductive Health Matters, 2012; 20:169-173

79. Elul B et al. Unwanted pregnancy and induced abortion: Data from Men and Women in Rajasthan, India: Report. New Delhi: Population Council, 2004.

80. Malhotra A et al. Realizing Reproductive Choice and Rights: Abortion and Contraception in India. Report. Washington DC: International Council for Research on Women, 2003.

81. Sahoo H. Fertility behaviour among adolescents in India. Journal of Family Welfare 2011; 57:22-33.

82. Sedgh $\mathrm{G}$ et.al. Legal abortion worldwide in 2008: levels and recent trends. Int Perspect Sex Reprod Health 2011; 7: 84-94.

83. International Institute for Population Sciences (IIPS) and Population Council. Youth in India: Situation and Needs 2006-2007. Mumbai: IIPS, 2010.

84. Santhya KG et.al. Ram U. Timing of first sex before marriage and its correlates: Evidence from India. Culture, Health and Sexuality, 2011; 13:327-41.

85. International Institute for Population Sciences (IIPS) and Population Council. Romance and sex before marriage among young women and men in India, Youth in India: Situation and Needs 2006-2007, Policy Brief No. 34. Mumbai: IIPS, 2010.

86. International Institute for Population Sciences (IIPS) and Population Council. Youth in India: Situation and Needs 2006-2007. Executive Summary. Mumbai: IIPS, 2010.

87. Sujay R. Premarital sexual behaviour amongst unmarried college students of Gujarat, India. Health and Population Innovation Fellowship Programme Working Paper No. 9. New Delhi: Population Council, 2009.

88. Ganatra B, Hirve S. Induced Abortions among Adolescent Women in Rural Maharashtra, India. Reproductive Health Matters 2002; 10(19):76-85

89. Ganatra, B. R. Abortion research in India: What we know and what we need to know, in Women's Reproductive Health in India, eds. R. Ramasubban and S. Jejeebhoy. Jaipur: Rawat Publications, 2000.

90. WHO. The prevention and management of unsafe abortion. Report of a technical working group. Geneva: World Health Organization, 1992 (WHO/MSM/92.5). 
91. Balarajan Y, Selvaraj S, Subramanian SV. Health care and equity in India. The Lancet 2011; 377:505-15.

92. Sinha N. Ignorance about abortion being legal adds to maternal mortality rate. Times News Network, August 21, 2012.

93. Ganatra B. Maintaining access to safe abortion and reducing sex ratio imbalances in Asia. Reprod Health Matters 2008; 16: 90-98.

94. Barua A and Apte H. Quality of abortion care: perspectives of clients and providers in Jharkhand. Economic and Political Weekly 2007; 42:71-80.

95. Elul B et.al Are obstetrician-gynecologists in India aware of and providing medical abortion? The Journal of Obstetrics and Gynecology of India 2006; 56: 340_345.

96. Ganatra B, Manning V and Palimapulla S. Availability of medical abortion pills and the role of chemists: a study of Bihar and Jharkhand, India. Reproductive Health Matters 2005; 13: 65_74.

97. Nyblade et al. Self-Reported Abortion-Related Morbidity: A Comparison of Measures in Madhya Pradesh, India. International Perspectives on Sexual and Reproductive Health 2010; 36:140-48.

98. Singh S. Hospital admissions resulting from unsafe abortion: Estimates from 13 developing countries. Lancet 2006; 368: 1887-92.

99. Johnston HB et al., Where do rural women obtain postabortion care? The case of Uttar Pradesh, India. International Family Planning Perspectives, 2003; 29: 182-87.

100. Ganatra B and Elul B. Legal but not always safe: Three decades of a legal abortion policy in India. Gaceta Medica de Mexico 2003; 139: S103-S108

101. Visaria L et.al. Abortion in India: emerging issues from qualitative studies. Economic and Political Weekly 2004; 24 November:5044-52. 29. Xinhua. Guiyang to ban

102. CORT. Unwanted pregnancy: To accept or abort? A qualitative study of decision making in rural Uttar Pradesh, CORT, 1998.

103. Jejeebhoy SJ et al. Experience seeking abortion among unmarried young women in Bihar and Jharkhand, India: delays and disadvantages. Reproductive Health Matters 2010; 18:163-174.

104. Kalyanwala $S$ et al. Abortion experiences of unmarried young women in India: Evidence from a facilitybased study in Bihar and Jharkhand. International Perspectives on Sexual and Reproductive Health, 2010; 36:62-71.

105. Grimes DA. The choice of second trimester abortion method: Evolution, evidence and ethics. Reproductive Health Matters, 2008; 16:183-188.

106. Gemzell_Danielsson K and Lalitkumar S. Second trimester medical abortion with Mifepristone-Misoprostol and Misoprostol alone: A review of methods and management. Reproductive Health Matters, 2008; 16:162-172.

107. Banerjee S K and Andersen CK. Exploring the pathways of unsafe abortion: A prospective study of abortion clients in selected hospitals of Madhya Pradesh, India. New Delhi, Ipas: India, 2009.

108. Grimes DA et al. Unsafe abortion: The preventable pandemic. Lancet, 2006; 368:1908-19.

109. Edmeades et al. Women and reproductive control: the nexus between abortion and contraceptive use in Madhya Pradesh, India. Studies in Family Planning, 2010; 41:75-88.

110. Registrar General of India (RGI). Special Bulletin on Maternal Mortality in India 2007-09, Sample Registration System. Delhi: RGI, June 2011. 
111. Banerjee et al. Women-centered research on access to safe abortion services and implications for behavioral change communication interventions: A cross-sectional study of women in Bihar and Jharkhand, India. BMC Public Health, 2012, 12:175, http://www.biomedcentral.com/1471-2458/12/175.

112. Vlassoff $M$ et al. Economic Impact of unsafe abortion-related morbidity and mortality: Evidence and estimation challenges. IDS Research Report, 2008, No. 59. Brighton, UK: Institute of Development Studies, University of Sussex.

113. Nozer $S$ et al. First trimester MTP using MVA: Report of a FOGSI multicentric Study across 27 clinics. $J$ Obstet Gynecol India 2007; 57: 162-166.

114. Patel T and Bakul L. A. 17 year review of voluntary termination of pregnancy (MTP). J Obstet Gynecol India 2006; 56: 522-28.

115. Mehra R et.al. Knowledge of emergency contraception among women coming for induced abortion. $J$ Obstet Gynecol India 2006; 56:233-35.

116. Das V et.al. Septic abortion. J Obstet Gynecol India 2006; 56: 236-239.

117. Sheelamoni A, Nair MKC and Remadevi S. Contraceptive behavior of abortion seekers- A case control study. J Obstet Gynecol India 2007; 57:431-434.

118. Times News Network. 20,000 model facilities identified to promote safe abortion practices. July 7, 2012.

119. CYDA and UNFPA. Reflections on the campaign against sex selection and exploring ways forward: $A$ study Report. CYDA and UNFPA , 2007

120. Ganatra BR, Hirve SS and Rao VN. Sex- selective abortion: evidence from a community-based study in western India. Asia-Pacific Popul J 2001; 16:109-24.

121. Oomman N and Ganatra BR Sex selection: the systematic elimination of girls. Reproductive Health Matters, 2002; 10: 184-188

122. George SM. Millions of missing girls: From fetal sexing to high technology sex selection in India. Prenat Diagn 2006; 26:604-9.

123. George SM. Sex ratio in India. The Lancet 2006; 367:1725.

124. Zilberberg J. Sex selection and restricting abortion and sex determination. Bioethics 2007; 21:517-519.

125. Abrejo FG, Shaikh BTand Rizvi N. And they kill me, only because I am a girl'...a review of sex-selective abortions in South Asia. Eur J Contracept Reprod Health Care, 2009; 14:10-16.

126. UNICEF. Female feticide in India. http://www.unicef.org/india/media_3285.htm

127. Jain A. Editorial, Sex selection and abortion in India. BMJ,2013. 


\section{REFERENCES --- Chapter 5}

1. Rob U, Talukder (eds.). Health sector reform: Lessons from developing countries. Dhaka: Population Council, 2007.

2. Beck C, Berry NS and Choijil S. Health system reform and safe abortion: A case study of Mongolia, Global Public Health. International Journal for Research, Policy and Practice, 2013; 8: 174-18

3. Janes CR et.al. Poor medicine for poor people? Assessing the impact of neoliberal reform on health care equity in a post socialist context. Global public health 2006; 1: 5_30

4. World Health Organization (WHO). Safe abortion: technical and policy guidance for health systems. Geneva: World Health Organization, 2003

5. Dwivedi LK and Ram F. Multilevel analysis of unwanted fertility in Utter Pradesh. Demography India 2005; $34: 241-258$.

6. Government of India. Rural Health Statistics-2011. Ministry of Health and Family Welfare, Government of India, New Delhi, 2011.

7. International Institute for Population Sciences. District Level Household and Facility Survey (DLHS-3) 2007-08. International Institute for Population Sciences, Mumbai, 2008.

8. Robert J and Oster E. The power of TV: Cable television and women's status in India, Quarterly Journal of Economics 2009; 124: 1057-1094.

9. Westoff CF and Bankole A. Mass media and reproductive behavior in Pakistan, India and Bangladesh. Demographic and Health Surveys Analytical Report No. 10. Calverton, MD: Macro International, 1999.

10. Westoff CF, Koffman DA. The association of television and radio with reproductive behavior. Population and Development Review, 2011; 37:749-59.

11. Media Research Users Council (MRUC). Indian Readership Survey (IRS), 2010 Round 2. New Delhi: MRUC, 2010.

12. Garai A. Information and communication technologies in Bihar's Health sector: A review of projects and future directions, Policy brief N0.10. New Delhi: Population Council, 2011.

13. Khan ME, Donnay F, Tarigopula UK and Ganju D (Eds.). Shaping Demand and Practices to Improve Family Health Outcomes, Designing a Behavior Change Communication Strategy in India, Volume II: Bihar. New Delhi: SAGE Publications, 2012.

14. Khan M E, Hazra A and Ahmad J. Reach and use pattern of mobile phones in rural Bihar: Current scenario and future prospects, in Khan M E, Donnay F, Tarigopula U K and Ganju D (eds), Shaping Demand and Practices to Improve Family Health Outcomes: Designing a Behavior Change Communication Strategy in India, Volume 2: Bihar. New Delhi: SAGE Publications, 2012.

15. Santhya KG, Jejeebhoy SJ and Ghosh S. Early Marriage and Sexual and Reproductive Health Risks: Experiences of Young Women and Men in Andhra Pradesh and Madhya Pradesh, India, New Delhi: Population Council, 2008.

16. Singh A et.al. Inequalities in advice provided by public health workers to women during antenatal sessions in rural India, 2012. http://www.plosone.org/article/info:doi/10.1371/journal.pone.0044931. Accessed on September 19, 2012.

17. Ganju D et.al. Reach of Media and Interpersonal Communication in Rural Uttar Pradesh, The Journal of Family Welfare 2010; 56: 83-91. 
18. Bhatnagar I, Khan M E and Hazra A. Reaching audiences in rural Bihar: A situation analysis of alternative modes of communication and challenges, in Khan M. E., F. Donnay, U. K. Tarigopula and D. Ganju (eds), Shaping Demand and Practices to Improve Family Health Outcomes: Designing a Behavior Change Communication Strategy in India, Volume 2: Bihar. New Delhi: SAGE Publications, 2012.

19. Khan ME et.al. Situation Analysis of Behavior Change Communication Activities in Bihar: A Step Towards Developing a Comprehensive BCC Strategy. New Delhi: Population Council.

20. Mishra SK. E-health initiatives in India, Presentation at United Nations/India Regional Workshop on Using tele-epidemiology to benefit Asia and the Pacific Region, 2008.

21. mHealth Alliance, Vital wavw consulting. Sustainable financing for mobile health (mHealth): Options and opportunities for mHealth financial models in low and middle-income countries, 2012.

http://www.mhealthalliance.org. Accessed March 2013.

22. PricewaterhouseCoopers. Emerging $m$-Health: Paths for growth. Report prepared in cooperation with the Economist Intelligence Unit, 2012. http://www.managementthinking.eiu.com/emerging-mhealth-pathsgrowth.htm|\#ixzz2PZogGGDa, Accessed November 2012.

23. Free $\mathrm{C}$ et al. The Effectiveness of Mobile-Health Technology-Based Health Behavior Change or Disease Management Interventions for Health Care Consumers: A Systematic Review, 2013. PLoS Med 10(1): e1001362. doi:10.1371/journal.pmed.1001362., Accessed March 2013.

24. Philbrick WC. mHealth and MNCH: State of the evidence: Trends, gaps, stakeholder needs and opportunities for future research on the use of mobile technology to improve maternal, newborn and child health. mHealth Alliance, UN Foundation, 2013. http://www.mhealthalliance.org. Accessed March 2013.

25. Tamrat $\mathrm{T}$ and Kachnowski S. Special delivery: an analysis of mHealth in maternal and newborn health programs and their outcomes around the world. Matern Child Health J, 2012; 16(5):1092-101.

26. Ramachandran D, Goswani $V$ and CannyJ. Research and reality: using mobile messages to promote maternal health in rural India. http://research.microsoft.com/apps/pubs/default.aspx?id=192752. Accessed September 2012.

27. Intra Health. Mobile application reinforces frontline health workers' knowledge, confidence and credibility, 2012. http://www.intrahealth.org/page/mobile-application-reinforces-frontline-health-workers-knowledgeconfidence-and-credibility, Accessed in December 2012.

28. Varma A. There is a huge potential for mHealth in India. phttp://ehealth.eletsonline.com/2012/04/\%E2\%80\%9Cthere-is-a-huge-potential-for-mhealth-inindia\%E2\%80\%9D/Acessed January 2013.

29. Apps on the Go. http://ehealth.eletsonline.com/2012/04/apps-on-the-go/ Accessed January 2013.

30. Why Spice \& Qualcomm Have Partnered For mHealth In India. http://www.medianama.com/2013/02/223spice-qualcomm-healthcare/

31. Susan A, Gogoi A and Campbell C.Improving maternal health through social accountability: A case study from Orissa, India, Global Public Health: An International Journal for Research, Policy and Practice, 2012. DOI:10.1080/17441692.2012.748085. Acessed March 2013.

32. Campbell M et al. Barriers to Fertility Regulation: A Review of the Literature. Studies in Family Planning 2006; 37: 87-98.

33. Koenig MA, Foo GH and Joshi K. Quality of care within the Indian family welfare program: a review of recent evidence, Studies in Family Planning 2000; 31: 1-18. 
34. Sen G. Integrating Family Planning with Sexual and Reproductive Health and Rights: The Past as Prologue? Studies in Family Planning 2010; 41: 143-46.

35. Church $\mathrm{K}$ and Mayhew SH. Integration of STI and HIV prevention, care and treatment into family planning services: A review of the literature. Studies in Family Planning 2009; 40:171-186

36. Mwaikambo L et.al. What works in family planning interventions: A systematic review, Studies in Family Planning 2011; 42:67-82.

37. Storey D et.al. Impact of the integrated radio communication project in Nepal, 1994-1997. Journal of Health Communication 1999; 4: 271-294

38. Management sciences for health. Health and Other Health Programs: A Review of Trends and Evidence. Cambridge: Management Sciences for Health, 2011

39. Allendorf K. The Quality of Family Relationships and Use of Maternal Health-care Services in India. Studies in Family Planning 2010; 41: 263-276).

40. Varkey L C et.al. Involving Men in Maternity Care in India. Final report/FRONTIERS Program, Population Council, New Delhi, India, 2004.

41. Link CF. Spousal Communication and Contraceptive Use in Rural Nepal: An Event History Analysis. Studies in Family Planning 2011; 43:83-92.

42. Hartmann $M$ et al. Changes in couples' communication as a result of a male-involvement family planning intervention. J Health Commun; 2012; 17:802-19

43. Vernon R. Meeting the family planning needs of postpartum women. Studies in family planning 2009; 40:235-45

44. Wickstrom J and Jacobstein R. Contraceptive Security: Incomplete Without Long-Acting and Permanent Methods of Family Planning. Studies in Family Planning 2011; 42: 291-98.

45. Population Council. Promoting optimal inter-pregnancy interval in India through integrated public delivery systems, Final report/FRONTIERS program, Population Council: New Delhi, 2008

46. Doskoch P.Participatory Women's Groups Linked to Improved Neonatal Outcomes in India, but Not Bangladesh. International Perspectives on Sexual and Reproductive Health 2010; 36: 111-112

47. Montgomery MR et.al. Social networks and contraceptive dynamics in southern Ghana. Population Council working paper no.153. New York; Population Council, 2001.

48. Koblinsky M. Community-based postpartum care: An urgent unmet need. Catalyst Consortium, 2005. http://www.pathfind. org/site/DocServer/Community-based_postpartum_care. pdf?doclD=4881. (Accessed 17 November 2012).

49. Balarajan Y, Selvaraj S and Subramanian SV. Health care and equity in India. The Lancet 2011; 377:50515.

50. Janowitz B, Stanback J and Boyer B. Task sharing in family planning. Studies in Family Planning 2012; 43:57-62.

51. Foreit J and Raifman S. Increasing access to Family Planning (FP) and Reproductive Health (RH) services through task-sharing between Community Health Workers (CHWs) and community mid-level professionals in large-scale public-sector programs: A literature review to help guide case studies. New York: Population Council, 2011. 
52. Phillips et.al. Lessons from community-based distribution of family planning in Africa. Policy Research Division Working Paper No. 121. New York: Population Council, 1999

53. Phillips et.al. The long-term demographic role of community-based family planning in rural Bangladesh, Studies in Family Planning 1996; 27: 204-219.

54. Harvey PD. Social marketing: No longer a sideshow. Studies in Family Planning 2008; 39: 69-72.

55. National Health Systems Resource Centre (NHSRC). ASHAs: Which way forward? Evaluation of ASHAs Programme. New Delhi: NHSRC, 2011.

56. Hazra A, Khan M E and Varma D S. Increasing institutional deliveries and access to emergency obstetric care services in rural Bihar, In Khan M E, Donnay F, Tarigopula U K and Aruldas K. (eds), Shaping Demand and Practices to Improve Family Health Outcomes in Bihar, Final Surveyt Report. New Delhi: Population Council, 2012.

57. Varma DS and Khan ME. Increasing Postnatal Care of Mothers and Newborns Including Cord Care and Thermal Care in Rural Bihar, In Khan M E, Donnay F, Tarigopula U K and Aruldas K (eds). Shaping Demand and Practices to Improve Family Health Outcomes in Bihar, Final Survey Report. New Delhi: Population Council: SAGE Publications, 2012.

58. Ahmad J, Bhatnagar I and Khan ME. Increasing Access to Family Planning and Reproductive Health Services through Community Health Workers: A Case Study of a Dual Cadre Model in India. Washington, DC: Population Council, 2012.

59. IIPS and Macro international. National Family Health Survey (NFHS-3) 2005-06: India Volume 1. IIPS and Macro International, Mumbai India, 2007.

60. Government of India. Family Welfare Statistics in India. Statistic Division, Ministry of Health and Family Welfare, 2012.

61. Chandhick $\mathrm{N}$ et.al. Contraceptive knowledge, practices and utilization of services in the rural areas of India (an ICMR task force study). Indian Journal of Medical Science 2003; 57:303-10.

62. Puri $S$ et al. Awareness of emergency contraception among female college students in Chandigarh. Indian Journal of Medical Sciences 2007; 61: 338-46.

63. Kumar A et al. A study of knowledge, attitudes and practice of emergency contraceptive pills among female college students in Udaipur, Rajasthan. National Journal of Community Medicine 2012; 3:576-80.

64. Duhan N. The untapped potential for emergency contraception in India. Indian Journal of Fundamental and Applied Life Sciences 2012; 2:239-43.

65. Shelat PR, Hihoriya NH, Kumbar S. Knowledge and attitude towards the use of emergency contraceptive pills among college students. International Journal of Basic and Clinical Pharmacology 2012; 1:77-84.

66. Nigam A, Maheshwari N, Prakash A. Knowledge of emergency contraception and contraceptive practices: Representative study from rural Uttar Pradesh. Indian J Community Med. 2010; 35: 449-450.

67. Urban Health Initiative. Expanding Contraceptive Use in Urban Uttar Pradesh: Emergency Contraceptive Pills (ECP), 2010 www.uhi-india.org

68. Kishore V, Misro MM. Provider's knowledge, attitudes and dispensing practices of e-pills in government dispensaries of south district in Delhi, India. Indian Journal of Community Medicine 2010; 35:46-51.

69. Nigam A, Maheshwari N and Prakash A. Knowledge of emergency contraception and contraceptive practices: Representative study from rural Uttar Pradesh. Indian Journal of Community Medicine 2010; 35:449-50. 
70. Khan ME et al. Providers and key opinion leaders' attitudes, beliefs and practices regarding emergency contraception in India. New Delhi: Population Council, 2012.

71. Ngo TD et al. Comparative effectiveness, safety and acceptability of medical abortion at home and in a clinic: a systematic review, Bulletin of the World Health Organization, 2011; 89:360-370.

72. Winikoff $B$, Sheldon W. Use of medicines changing the face of abortion. Int Persp on Sexual and Reprod Health 2012; 38:164-166.

73. Das V et al. Evaluation of newer methods of early pregnancy termination. J Obstet Gynecol India 2005; 55: 454-456.

74. Nozer S. Accessing safe abortion in India. Journal of Family Welfare 2004; 50:49-56.

75. Jejeebhoy $\mathrm{S} J$ et al. Can nurses perform manual vacuum aspiration (MVA) as safely and effectively as physicians? Evidence from India. Contraception 2011; 84: 615-621.

76. Ganatra B, Manning V and Palimapulla S. Availability of medical abortion pills and the role of chemists: a study of Bihar and Jharkhand, India. Reproductive Health Matters 2005; 13: 65_74.

77. FOGSI, PSI India. Safe abortion meeting report. 2012. Unpublished report.

78. Times News Network. Bitter pill: Abortion kits sale plunge by 65\% in Mumbai. July 7, 2012

79. Sedgh $\mathrm{G}$ et.al. Legal abortion worldwide in 2008: Levels and recent trends. Int Perspect Sex Reprod Health 2011; 7: 84-94.

80. CYDA and UNFPA. Reflections on the campaign against sex selection and exploring ways forward: $A$ study Report. CYDA and UNFPA, 2007

81. Sundar R. Abortion Costs and Financing: A Review. Mumbai: CEHAT/HEALTHWATCH, 2003

82. Jejeebhoy SJ et.al. Increasing access to safe abortion in rural Rajasthan: Outcomes of a comprehensive abortion care model. New Delhi: Population Council, 2011.

83. Duggal R and Barge S. Abortion Services in India: Report of a Multicentric Enquiry. Abortion Assessment Project - India. Mumbai: CEHAT and HealthWatch, 2004.

84. Duggal R. The Political Economy of Abortion in India: Cost and Expenditure Patterns. Reprosuctive Health Matters, 2004; 12:130-37.

85. Hyman et al. Misoprostol in women's hands: A harm reduction strategy for unsafe abortion. Contraception, 2013; 87:128-30.

86. Times News Network. 20,000 model facilities identified to promote safe abortion practices. July 7, 2012

87. Ganatra B. Maintaining access to safe abortion and reducing sex ratio imbalances in Asia. Reprod Health Matters 2008; 16: 90-98.

88. Bali M. Sex Selection:Unethical Practice, Health Action,2005; 18:11-13.

89. Jejeebhoy SJ et al. Experience seeking abortion among unmarried young women in Bihar and Jharkhand, India: delays and disadvantages, Reproductive Health Matters 2010; 18:163-174.

90. Government of India (GOI). The Medical Termination of Pregnancy Rules (Amendment). New Delhi: Government of India, 2003.

91. . Times News Network. Government promotes safe abortion initiatives. May 5, 2012.

92. Ministry of Health and Family Welfare. Approval of state programme implementation plan 2012-13, Bihar. National rural health mission, Government of India, State of Bihar, 2012 
93. Ministry of Health and Family Welfare. Approval of state programme implementation plan 2012-13, Odisha. National rural health mission, Government of India, State of Odisha, 2012.

94. Ministry of Health and Family Welfare. Approval of state programme implementation plan 2012-13, Madhya Pradesh. National rural health mission, Government of India, State of Madhya Pradesh, 2012

95. Tamang A and Tamang J. Availability and Acceptability of Medical Abortion in Nepal: Health Care Providers' Perspectives. Reproductive Health Matters 2005; 13:110-19.

96. Warriner I $\mathrm{K}$ et al. Can midlevel health care providers administer medical abortion as safely and effectively as doctors- a randomized, controlled equivalence trial in Nepal. Lancet 2011;377:(1155-1161.

97. Bhatia S, Faruque A S G and Chakraborty J. Assessment of menstrual regulation performed by paramedics in rural Bangladesh. Studies in Family Planning 1980; 11:23-27.

98. Warriner I $\mathrm{K}$ et al. Complication rates of first trimester manual vacuum aspiration abortion performed by physicians and midlevel providers (MLPs) in South Africa and Viet Nam: A randomized, controlled, equivalence trial. Lancet 2006; 368:1965-72.

99. Population Council. Consultation on midlevel provision of safe abortions and post abortion care. Islamabad: Population Council, 2011.

100. CREHPA. Country Status Report, Nepal: Midlevel provision of abortion to expand safe abortion access. Nepal: CREPHA, 2011.

101. Population Council. Expanding access to safe abortion and post-abortion care: Recommendations of a South Asia regional consultation. New Delhi: Population council, 2011.

102. Abdel-Tawas $\mathrm{N}$, Challenges and opportunities in providing postabortion family planning services. Paper presented at the XXVI IUSSP International Population Conference, Marrakech, Morocco, Sept. 27-Oct. 2, 2009., Marrakech, Morocco, Sept. 27-Oct. 2, 2009.

103. RamaRao S et.al. Postabortion Care: Going to Scale. International Perspectives on Sexual and Reproductive Health, 2011; 37:40-44.

104. IntraHealth. Voices from the field: scaling-up postabortion care services. PRIME Voices, 2004, No. 26, <http://www.intrahealth.org/page/ scaling-up-postabortion-care-services>, accessed Feb. 18, 2012

105. Population Council. Improving the Counseling and Medical Care of Post Abortion Patients in Egypt: Final Report, Cairo: Population Council, 1995, p. 215.

106. Johnston HB et.al. Health System Costs of Menstrual Regulation and Care For Abortion Complications in Bangladesh. International Perspectives on Sexual and Reproductive Health 2010; 36: 197-204.

107. Coeytaux $\mathrm{F}$ and Wells E. Anti-shock garment for postpartum hemorrhage: Technology as a catalyst for health system strengthening. Report to John D. and Catherine T. Mc Arthur foundation, Chicago, 2012

108. Banerjee S K et. al. Sharing Messages about Safe Abortion Services: Evaluating the Ipas Behavior Change Communication Intervention in Bihar and Jharkhand, India. New Delh: Ipas India , 2012 


\section{REFERENCES --- Chapter 6}

1. Tsui $A O, M c D o n a l d-M o s e l y ~ R$ and Burke AE. Family planning and the burden of unintended pregnancies. Epidemiologic reviews 2010; 32:152-74.

2. Horton R and Das P. Indian health: The path from crisis to progress. The Lancet 2011;377:181-83.

3. Rao M et al. Human resources for health in India. The Lancet 2011; 377: 532-33.

4. Balarajan Y, Selvaraj S and Subramanian SV. Health care and equity in India. Lancet 2011; 377:50515.

5. Shiva Kumar AK et al. Financing health care for all: challenges and opportunities. The Lancet 2011.; 377:883-85.

6. Narayan R. Universal health care in India: Missing core determinants. The Lancet 2011; 377:760-68.

7. Sen B. Securing the right to health for all in India. The Lancet $2011 ; 377: 668-79$.

8. Patel V et al.Universal health care in India: the time is right. The Lancet $2011 ; 377: 587-98$.

9. Reddy KS et al. Towards achievement of universal health care in India by 2020: A call to action. The Lancet 2011.

10. Paul VK. India: conditional cash transfers for in-facility deliveries. The Lancet 2010; 375:1943-44.

11. http://faridabad.nic.in/Administration/women\&.htm\#ABAD

12. http://www.unfpa.org/gender/docs/sexselection/UNFPA Publication-39772.pdf

13. http://www.biharonline.gov.in/Site/(S(gqxtrn45e2lry5uyi1ml0t55))/Content/Government/Schemes.aspx?u $=\& \ln =e n$

14. http://www.biharonline.gov.in/Site/(S(ggxtrn45e2lry5uyi1ml0t55))/Content/Government/Schemes.aspx?u $=$ MKSY

15. http://www.ladlilaxmi.com/

16. http://www.mpinfo.org/mpinfonew/english/mp_schemes/index.asp

17. http://www.indiaedunews.net/Today/Centre launches 'Dhan Laxmi' scheme for_girl child 3638/

18. Mamata: conditional electronic cash transfer scheme for pregnant women, Odisha.

Cohttp://orissa.gov.in/e-magazine/Orissareview/2011/Nov/engpdf/1-5.pdf

19. https://www.indianembassy.org/inews/April99/women insurance.html

20. http://statehealthsocietybihar.org/rch/GOI-Guideline-JSSK.pdf

21. http://wcd.nic.in/schemes/igmsyscheme.pdf

22. Lim SS et al. India's Janani Suraksha Yojana, conditional cash transfer programme to incecrease births in health facilities: An impact evaluation. The Lancet 2010; 375:2009-23.

23. Mohapatra B et.al. An assessment of the functioning and impact of Janani Suraksha Yojana. Health Pop: Perspectives Issues 2008; 31: 120-125.

24. UNFPA and Centre for Operations Research and Training (CORT). Assessment of ASHA and Janani Suraksha Yojana in Madhya Pradesh.

http://www.cortindia.com/recentpublications.html. 
25. Malini S et al. A rapid appraisal on functioning of Janani Suraksha Yojana in South Orissa. Health Pop: Perspectives Issues 2008; 31: 126-131.

26. International Institute for Population Sciences (IIPS) and ORC Macro. National Family Health Survey (NFHS-2) 1998-99. IIPS and ORC Macro, Mumbai 2000.

27. International Institute for Population Sciences (IIPS). 'National Family Health Survey (MCH and Family Planning), 1992-23. IIPS, Mumbai, 1995.

28. International Institute for Population Sciences (IIPS) and Macro International. National Family Health Survey (NFHS-3), India, 2005-06: Bihar. Mumbai:IIPS, 2008.

29. International Institute for Population Sciences (IIPS) and Macro International. National Family Health Survey (NFHS-3), India, 2005-06: Orissa. Mumbai:IIPS, 2008.

30. International Institute for Population Sciences (IIPS) and Macro International. National Family Health Survey (NFHS-3), India, 2005-06: Madhya Pradesh. Mumbai:IIPS, 2008.

31. International Institute for Population Sciences (IIPS), 2010. District Level Household and Facility Survey (DLHS-3), 2007-08: India. Bihar: Mumbai: IIPS, 2010.

32. International Institute for Population Sciences (IIPS), 2010. District Level Household and Facility Survey (DLHS-3), 2007-08: India. Orissa: Mumbai: IIPS, 2010

33. International Institute for Population Sciences (IIPS), 2010.District Level Household and Facility Survey (DLHS-3), 2007-08: India. Madhya Pradesh: Mumbai: IIPS, 2010.

34. UNFPA. Concurrent assessment of Janani Sureksha Yojana (JSY) in selected states of India, 2008. New Delhi: UNFPA , 2009

35. Office of the Registrar General and Census commissioner. Annual Health Survey, 2010-11: Fact Sheet, Bihar, 2012.

36. Office of the Registrar General and Census commissioner. Annual Health Survey, 2010-11: Fact Sheet, Odisha, 2012.

37. Office of the Registrar General and Census commissioner. Annual Health Survey, 2010-11: Fact Sheet, Madhya Pradesh, 2012.

38. Ministry of Health and Family Welfare, Government of India. Third common review mission report (November 2009). New Delhi: National Rural Health Mission, 2010. http://mohfw.nic.in/NRHM.htm

39. Planning Commission. Eleventh Five Year Plan 2007-12, Volume II, Social Sector, Planning Commission, New Delhi: Government of India, 2008.

40. Government to People (G2P) Health Payments Project in Bihar: Key Findings from Baseline Survey. Presentation at the staff meeting, Population Council, June 2013.

41. Bajpai $\mathrm{N}$ and Dholakia RH. Improving the performance of accredited social health activists in India. Working paper No.1, Mumbai: Columbia Global Centers|South Asia, 2011

42. Ministry of Health and Family Welfare, NRHM Frame work for implementation. www.mohfw.nic.in/NRHM/Documents/NRHM_Framework_Latest.pdf.

43. Ministtry of Health and Family Welfare. Update on ASHA program, January 2012. http://202.71.128.172/nihfw/nchrc/?q=content/update-asha-programme-january-2012-new

44. Shankar S. Sure start Project in Uttar Pradesh. Presentation made at consultative meeting, Janurary 2013. 
45. Khan ME and Hazra A. Unmet need for contraception in India: Review and recommendations, In Zaman W and Masnin H (eds.) Report on the workshop on Operationalising the Call for Elimination on Unmet Need for Family Planning, 2012:101-25.

46. FHI 360. Contraceptive to doorsteps in Inda: Rapid evaluation provides recommnendations for national scale-up. Research Brief, New Delhi: FHI360, 2012.

47. Khan ME, Donnay F, Tarigopula UK and Ganju D (Eds.). Shaping Demand and Practices to Improve Family Health Outcomes, Designing a Behavior Change Communication Strategy in India, Volume II: Bihar. New Delhi: SAGE Publications, 2012.

48. Ahmad J, Bhatnagar I. and Khan ME. Increasing Access to Family Planning and Reproductive Health Services through Community Health Workers: A Case Study of a Dual Cadre Model in India. Washington, DC: Population Council, 2012. 


\section{www.stepup.popcouncil.org}

The STEP UP (Strengthening Evidence for

Programming on Unintended Pregnancy) Research

Programme Consortium generates policy-relevant

research to promote an evidence-based approach for improving access to family planning and safe abortion. STEP UP focuses its activities in five countries: Bangladesh, Ghana, India, Kenya, and Senegal.

STEP UP is coordinated by the Population Council in partnership with the African Population and Health Research Center; icddr,b; the London School of Hygiene and Tropical Medicine; Marie Stopes International; and Partners in Population and Development. STEP UP is funded by UK aid from the UK Government. 